\title{
The Distribution and Flux of Fish in the Forebay of The Dalles Dam in 2003
}

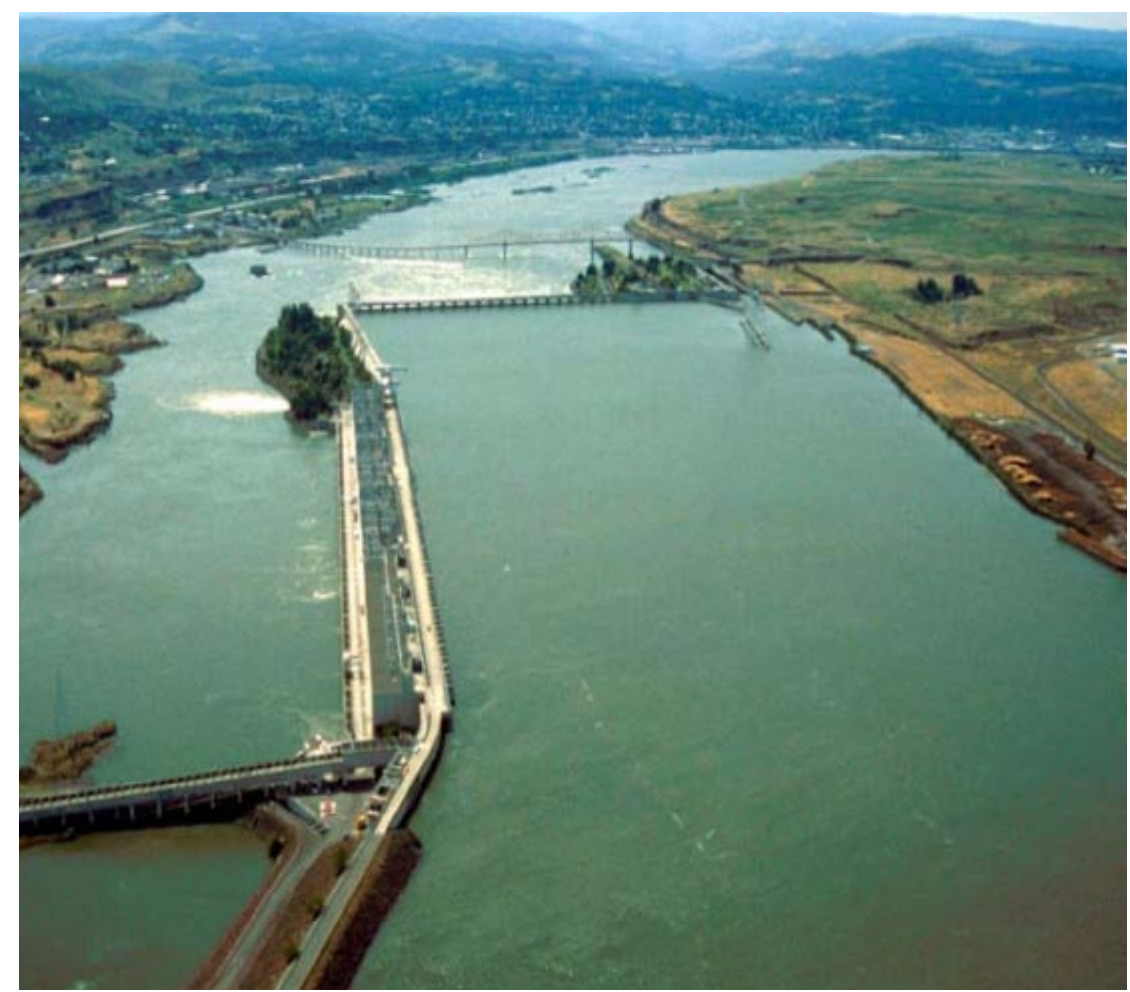

D.M. Faber

M.E. Hanks

S.A. Zimmerman

J.R. Skalski

P.W. Dillingham

FINAL REPORT

April 2005

Prepared for the U.S. Army Corps of Engineers

Portland District, Portland, Oregon

under a Related Services Agreement

with the U.S. Department of Energy

Contract DE-AC05-76RLO1830

\section{Pacific Northwest National Laboratory}

Operated by Battelle for the

U.S. Department of Energy 
This report was prepared as an account of work sponsored by an agency of the United States Government. Neither the United States Government nor any agency thereof, nor Battelle Memorial Institute, nor any of their employees, makes any warranty, express or implied, or assumes any legal liability or responsibility for the accuracy, completeness, or usefulness of any information, apparatus, product, or process disclosed, or represents that its use would not infringe privately owned rights. Reference herein to any specific commercial product, process, or service by trade name, trademark, manufacturer, or otherwise does not necessarily constitute or imply its endorsement, recommendation, or favoring by the United States Government or any agency thereof, or Battelle Memorial Institute. The views and opinions of authors expressed herein do not necessarily state or reflect those of the United States Government or any agency thereof.

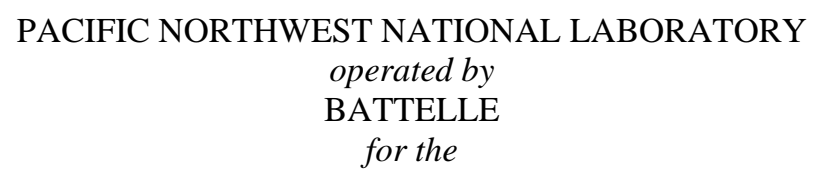

UNITED STATES DEPARTMENT OF ENERGY

under Contract DE-AC05-76RL01830

Printed in the United States of America

Available to DOE and DOE contractors from the Office of Scientific and Technical Information, P.O. Box 62, Oak Ridge, TN 37831-0062; ph: (865) 576-8401 fax: (865) 576-5728 email: reports@adonis.osti.gov

Available to the public from the National Technical Information Service, U.S. Department of Commerce, 5285 Port Royal Rd., Springfield, VA 22161 ph: (800) 553-6847

fax: (703) 605-6900

email: orders@ntis.fedworld.gov

online ordering: http://www.ntis.gov/ordering.htm 


\title{
The Distribution and Flux of Fish in the Forebay of The Dalles Dam in 2003
}

\author{
D.M. Faber \\ M.E. Hanks ${ }^{(a)}$ \\ S.A. Zimmerman ${ }^{(a)}$ \\ J.R. Skalski ${ }^{(b)}$ \\ P.W. Dillingham ${ }^{(b)}$
}

\section{FINAL REPORT}

April 2005

Prepared for the U.S. Army Corps of Engineers

Portland District, Portland, Oregon

under a Related Services Agreement

with the U.S. Department of Energy

Contract DE-AC05-76RLO1830

Pacific Northwest National Laboratory

P.O. Box 999

Richland, WA 99352

(a) BAE Systems, North Bonneville, Washington

(b) University of Washington, Seattle, Washington 



\section{Executive Summary}

In spring and summer 2003, the Pacific Northwest National Laboratory led a team that conducted mobile and fixed hydroacoustic surveys in the forebay of The Dalles Dam for the U.S. Army Corps of Engineers - Portland District. This research was part of the Corps’ Anadromous Fish Evaluation Program. The surveys provided information on the distribution and movement of smolt-sized fish relative to ambient factors such as flow, bathymetry, or diel cycle in the forebay at The Dalles Dam.

A proposal for the use of a guidance structure in the forebay at The Dalles Dam, a modified version of a similar structure located at Lower Granite Dam, has recently been suggested by the U.S. Army Corps of Engineers and regional resource managers as a potential approach to improve the passage survival of juvenile salmon at the dam. The structure would be designed to divert fish from the powerhouse to the spillway. This project provided baseline data for the development of a behavioral guidance structure and surface bypass alternatives for juvenile salmon at The Dalles Dam.

We sampled the forebay of The Dalles Dam one day and night each week for six weeks in the spring and another six weeks in the summer. Two research vessels were used. Each pushed a raft outfitted with sampling gear consisting of two split-beam transducers, four single-beam transducers, one acoustic Doppler current profiler (ADCP), a pitch-roll-heading indicator, and a differential global positioning system (GPS). The split-beam transducers provided information on the location, size, and movement of fish. The ADCP sampled the flow environment in which each fish was detected. One $12^{\circ}$ split-beam transducer was aimed downward. The other split-beam transducers and the four single-beam transducers were all forward-looking $6^{\circ}$ beams that were aimed to provide intensive sampling in the upper $9 \mathrm{~m}$ of the water column. The rafts were secured $7.5 \mathrm{~m}$ forward of the bow of the research vessels (15 $\mathrm{m}$ from the vessel's outboard motor) to minimize fish avoidance behavior.

Mobile sampling was conducted from a research vessel and raft moving in a zig-zag pattern extending from $180 \mathrm{~m}$ above the spillway to $1.8 \mathrm{~km}$ upstream of the spillway along 26 transects during each sampling period. A second research vessel sampled at 15 fixed-point locations for ten minutes at each point. From the fixed sampling we determined the rate and the direction of fish movement past those points (flux). Using the combined mobile and fixed sampling methods we were able to determine the distribution of smolt-sized fish and their movement patterns in the forebay. Smolt-sized fish were defined as those with a return signal of greater than $-56 \mathrm{~dB}$ re $\| 1 \mu \mathrm{Pa}$ and less than $-34 \mathrm{~dB}$ for spring fish (90-320 $\mathrm{mm}$ ) or less than $-45 \mathrm{~dB}$ for summer fish $(90-105 \mathrm{~mm})$. The species of smolt-sized fish that were targeted for springtime samples were juvenile steelhead trout (Oncorhynchus mykiss), juvenile yearling Chinook salmon (O. tshawytscha), juvenile coho salmon (O. kisutch), and juvenile sockeye salmon (O. nerka). Summertime samples were directed at subyearling Chinook salmon (O. tshawytscha).

In general, during the day in the spring, the greatest densities of smolt-sized fish were observed in the thalweg of the main channel from the Washington bank to the east side of the powerhouse, along the powerhouse, and in the areas adjacent to the sluiceway. The density of fish was relatively low on the Washington side of the river channel and west of the middle of the powerhouse (north spillway side). 
The spring night distribution was similar, with a few notable differences. The density of fish was higher on the east side of the powerhouse and along the face of the powerhouse, and more fish were detected on the north spillway side than during daytime. The distribution of sub-yearling-sized fish in summer followed the same general pattern as spring, except that summer fish had a greater presence on the east end of the powerhouse and on the north spillway area. Summer fish were not observed in densities comparable to those of spring fish near the sluiceway. Shad (Alosa sapidissima) populations in the summer may have also influenced the distribution maps generated during those periods.

The vertical distribution of fish was also determined. In spring, $80 \%$ of fish were above $5.6 \mathrm{~m}$ and $4.7 \mathrm{~m}$ of depth during the day and at night, respectively. The summer fish were similarly distributed in the day and night with $80 \%$ of the fish in the upper $4.5 \mathrm{~m}$ and $4.7 \mathrm{~m}$ of the water column respectively. In general smolt-sized fish were distributed deeper in the water column in the center of the channel than near the edges. Fish movement and distribution relative to physical conditions were also evaluated, but no strong associations were observed.

The net movement of smolt-sized fish in the forebay from fixed-point samples showed fish moving with the flow and channel upstream of the powerhouse but upstream at points near the powerhouse. The rate of fish movement (flux) was greatest at the east end of the powerhouse and on the upstream north side of the channel.

The sample categories of fish distribution (spring/summer, day/night) shared key findings:

- High densities of smolt-sized fish were observed on the north side of the channel.

- Shallow, high water velocity areas on the south side of the channel had relatively low densities of smolt-sized fish compared to adjacent regions. Larger than smolt-sized fish were distributed in these areas.

- The vertical distribution of fish was concentrated in the upper $5.3 \mathrm{~m}$ of the water column, regardless of time of day or season.

- Smolt-sized fish were deeper in the center of the channel than at the edges.

- The flux of fish was highest near the powerhouse and on the northeast side of the channel.

- Net movement of fish was downstream or with the channel in areas upstream of the powerhouse, but was less directed downstream in areas near the powerhouse.

Findings for the sample categories, however, diverged on several accounts:

1. In the spring, smolt-sized fish were distributed higher in the water column at night than during the day.

2. Smolt-sized fish were distributed higher in the water column during summer than during spring.

3. The density of smolt-sized fish was less during the summer than during the spring. 
If a behavioral guidance structure is deemed to be a reasonable approach to juvenile salmon passage at The Dalles Dam, we make the following recommendations:

1. Adjust powerhouse operation priorities so that the main flow encounters the guidance structure at a point nearest the spillway.

2. Create flow parallel to the guidance structure, not perpendicular to it.

3. Provide necessary attractant flow at the spillway.

4. Build a structure with at least $6 \mathrm{~m}$ of depth.

5. Consider surface flow bypass alternatives at the spillway and powerhouse.

6. Investigate further the relationship between bathymetry and fish distribution in the forebay in the shallow regions with high water velocities adjacent to the embankment at the east end of the powerhouse. 
Distribution and Flux of Fish in the Forebay of The Dalles Dam in 2003 


\section{Acknowledgments}

We thank the field scientists without whom this study could not have succeeded: Kate Deters, Abigail Capetillo-Isenberg, Fenton Khan, John Stephenson, Peter Johnson, Charlie Escher, Carl Schilt, Mark Weiland, Bill Nagy, and Rich Brown. We also thank the contracting staff at Battelle: Al Garcia, Kristi Brinkerhoff, and Kathy Lavender. We appreciate review comments from our editor Theresa Gilbride. We would also like to acknowledge Gene Ploskey for his guidance for the entirety of the study. Finally, we are grateful to the following U.S. Army Corps of Engineers staff for their assistance and guidance: Dan Feil, Rock Peters, Mike Langeslay, Dick Harrison, and Miro Zyndol. 
Distribution and Flux of Fish in the Forebay of The Dalles Dam in 2003 


\section{Acronyms and Abbreviations}

\begin{tabular}{|c|c|}
\hline ADCP & acoustic Doppler current profiler \\
\hline AFEP & Anadromous Fish Evaluation Program \\
\hline BiOp & Biological Opinion, published by NOAA Fisheries in 2000 \\
\hline BRD & Biological Resources Division of the U.S. Geological Survey \\
\hline BRZ & boat restricted zone \\
\hline CBR & Columbia Basin Research, University of Washington \\
\hline CFD & computational fluid dynamics \\
\hline CHIN0 & subyearling Chinook salmon \\
\hline CHIN1 & yearling Chinook salmon \\
\hline $\mathrm{COE}$ & Corps of Engineers \\
\hline $\mathrm{dB}$ re $\| 1 \mu \mathrm{Pa}$ & decibels referenced to 1 micro-Pascal \\
\hline FFT & fast Fourier transform \\
\hline FPE & Fish Passage Efficiency \\
\hline GPS & global positioning system \\
\hline $\mathrm{Hz}$ & Hertz or samples/second \\
\hline kcfs & thousand cubic feet of discharge/second \\
\hline $\mathrm{kHz}$ & kilo-Hertz \\
\hline $\mathrm{kph}$ & kilometers per hour \\
\hline LGR & Lower Granite Dam \\
\hline $\mathrm{m}$ & meters \\
\hline $\mathrm{m}^{3} / \mathrm{s}$ & meters cubed per second \\
\hline NAD27 & North American Datum of 1927 \\
\hline NMFS & National Marine Fisheries Service (now known as NOAA Fisheries) \\
\hline NMEA & National Marine Electronics Association \\
\hline
\end{tabular}




$\begin{array}{ll}\text { NOAA } & \text { National Oceanic and Atmospheric Administration } \\ \text { PAS } & \text { Precision Acoustic Systems } \\ \text { PNNL } & \text { Pacific Northwest National Laboratory } \\ \text { PSC } & \text { Prototype Surface Collector } \\ \text { ROV } & \text { remotely operated vehicle } \\ \text { RSW } & \text { Removable Spillway Weir } \\ \text { RTK-GPS } & \text { real time kinematics global positioning system } \\ \text { S } & \text { seconds } \\ \text { SBC } & \text { Surface Bypass Collector } \\ \text { SL } & \text { source level } \\ \text { SNR } & \text { signal to noise ratio } \\ \text { SPI } & \text { Smolt Passage Index } \\ \text { SPL } & \text { University of Washington } \\ \text { The Dalles Dam } & \text { The Dand pressure level } \\ \text { USACE } & \text { universal time clock } \\ \text { USGS } & \text { universal transverse mercator } \\ \text { UTC } & \text { The }\end{array}$




\section{Contents}

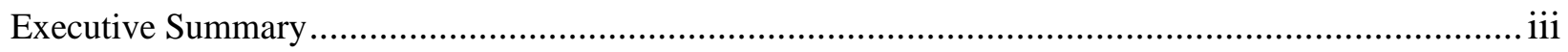

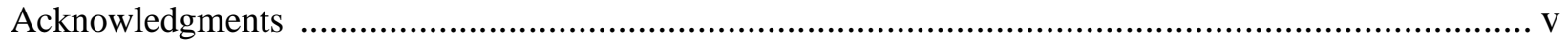

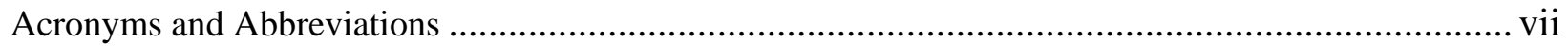

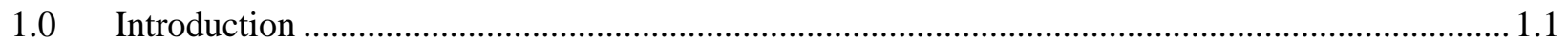

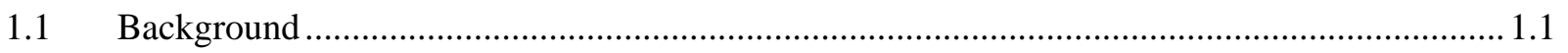

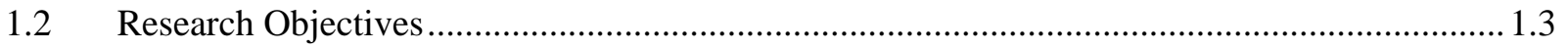

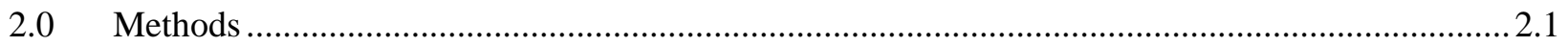

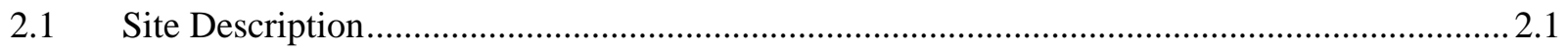

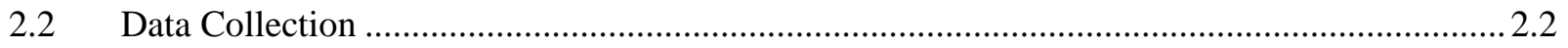

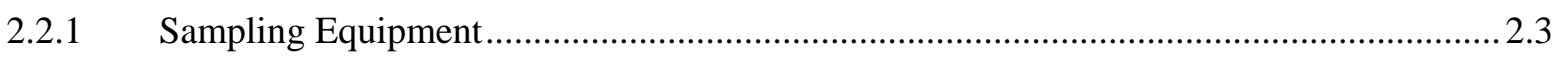

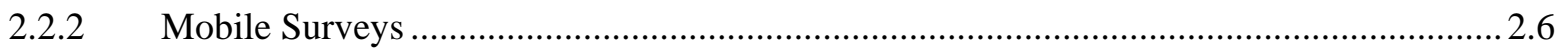

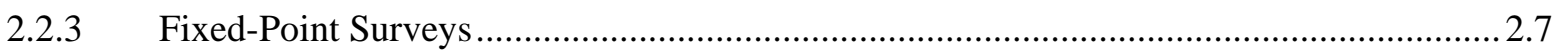

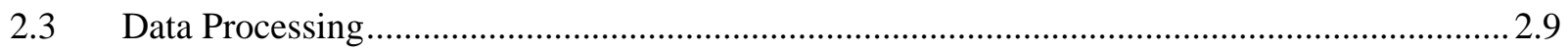

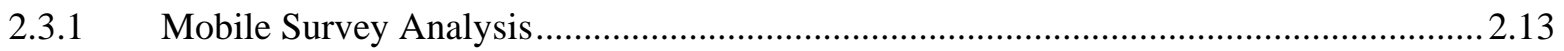

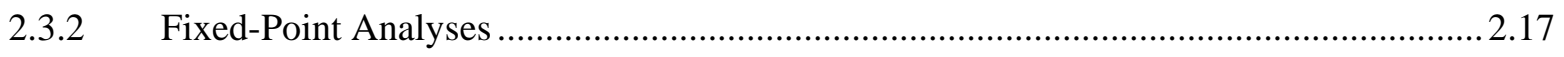

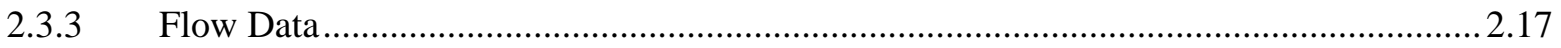

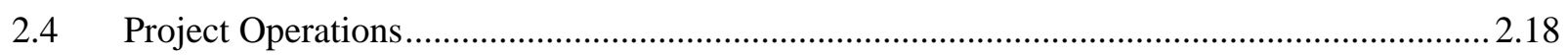

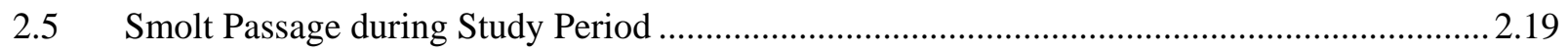

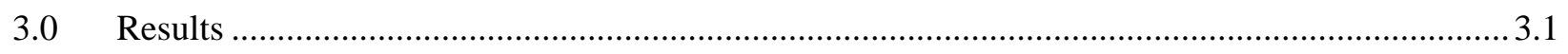

$3.1 \quad$ Flow …

3.2 Lateral Distributions Summarized by Sample Period ............................................................... 3.5

3.3 Vertical Distribution Summarized by Period ...................................................................... 3.13

3.4 Flux and Relative Movement of Smolt-Sized Fish ..............................................................17

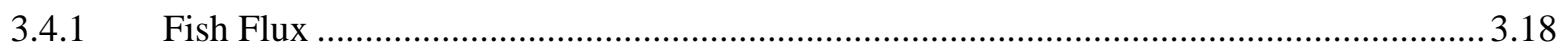

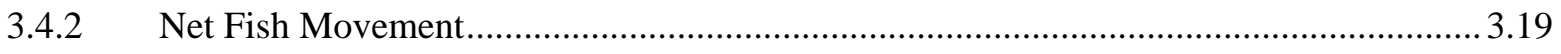

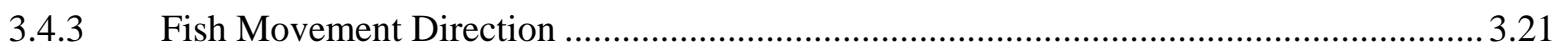

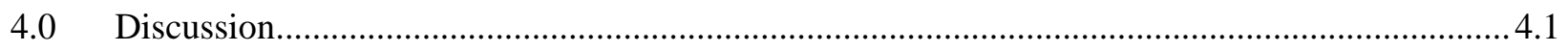

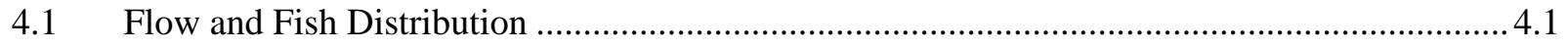

4.2 Distribution Determined by Mobile Hydroacoustics .......................................................... 4.3

4.2.1 Lateral Distribution of Smolt-Sized Fish ........................................................................ 4.3

4.2.2 Vertical Distribution of Smolt-Sized Fish................................................................. 4.4

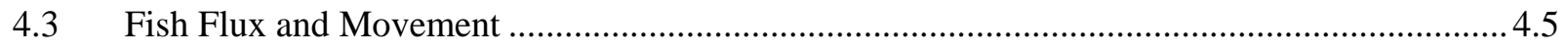

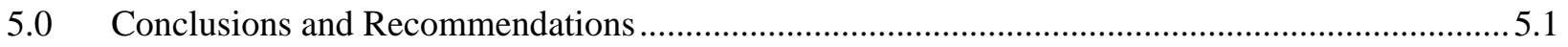

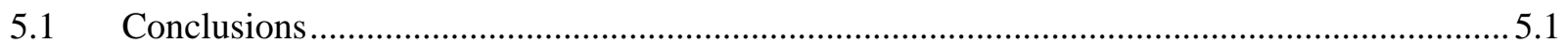

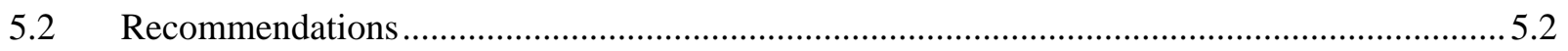


Appendix A - Predicting Smolt Densities Using Hydrologic and Bathymetric Data in the Forebay of The Dalles Dam.....

[Appendixes B-I are on the attached CD.]

Appendix B Water Velocity Magnitude in the Forebay of The Dalles Dam 2003

Appendix C - The Mean Distribution of Smolt-Sized and Larger-than-Smolt-Sized Fish Determined by Mobile Hydroacoustic Sampling in the Forebay of The Dalles Dam 2003

Appendix D - The Smolt-Sized Fish Distribution Determined by Mobile Hydroacoustic Sampling for Each Sample Day in the Forebay of The Dalles Dam Spring and Summer 2003.

Appendix E - The Larger-than-Smolt-Sized Fish Distribution Determined by Mobile Hydroacoustic Sampling for Each Sample Day in the Forebay of The Dalles Dam Spring and Summer 2003...

Appendix F - The Difference in Distribution between Large and Small Fish and between Spring and Summer Smolt-Sized Fish Determined by Mobile Hydroacoustic Sampling in the Forebay of The Dalles Dam 2003

Appendix G - The Vertical Distribution of Smolt-Sized Fish Determined by Mobile Hydroacoustic Sampling in the Forebay of The Dalles Dam 2003.

Appendix H - The Movement of Smolt-Sized Fish at Fixed Points in the Forebay of The Dalles Dam 2003

Appendix I - The Flux of Smolt-Sized Fish at Fixed Points in the Forebay of The Dalles Dam 2003....... I.1 


\section{Figures}

Figure 2.1. The Dalles Dam on the Columbia River showing the orientation of the powerhouse and spillway.

Figure 2.2. Sampling calendar for mobile and fixed hydroacoustic data collection in the forebay of The Dalles Dam.

Figure 2.3. A mobile research vessel is shown pushing a sampling raft at a distance approximately $7 \mathrm{~m}$ forward of the bow and $17 \mathrm{~m}$ forward of the outboard motor.

Figure 2.4. Mobile and fixed-point sampling raft, equipped with an attitude monitor, differential GPS, ADCP, and six hydroacoustic transducers for detecting fish.

Figure 2.5. Vertical distribution of fish density was measured in "bins" at successive 1.7-meter depths from surface.

Figure 2.6. Mobile sampling transects in the forebay of The Dalles Dam. All transects were sampled during each sample period.

Figure 2.7. Fixed points located throughout The Dalles Dam forebay that were sampled during the study.

Figure 2.8. Data collection using four computers that monitored the sampling gear attached to the rafts on each boat.

Figure 2.9. Grid used to summarize mobile hydroacoustic data

Figure 2.10. Sample volumes of the forward and down-looking transducers aboard the mobile sampling vessel.

Figure 2.11. This graph shows the relationship between the proportion of the volume of water sampled per grid unit and the calculated fish density for that grid unit.

Figure 2.12. The forebay of The Dalles Dam with grids defined by region.

Figure 2.13. Total project flow (spill and turbine) and forebay elevation shown for each of the sampling periods in 2003.

Figure 2.14. The percent of smolt passage by species, provided by the Fish-Passage Center and taken from the smolt passage index at the Juvenile Bypass Facility at John Day Dam for each day sampled.

Figure 3.1. Mean water-column direction and magnitude for ADCP-measured velocities in the forebay of The Dalles Dam during spring daytime samples

Figure 3.2. Mean water-column direction and magnitude for ADCP-measured velocities in the forebay of The Dalles Dam for spring nighttime samples

Figure 3.3. Mean water-column direction and magnitude for ADCP-measured velocities in the forebay of The Dalles Dam for summer daytime samples

Figure 3.4. Mean water-column direction and magnitude for ADCP-measured velocities in the forebay of The Dalles Dam during summer nighttime samples.

Figure 3.5. Mean smolt-sized fish density for spring daytime mobile (<-34 dB) samples. 
Figure 3.6. Mean turbine unit operations (black bars) in $1000 \mathrm{ft} / \mathrm{s}$ increments for all samples during spring day plotted against the smolt-sized fish density per $1000 \mathrm{~m}^{3}$ (gray area) within $60 \mathrm{~m}$ of each turbine unit.

Figure 3.7. Mean smolt-sized fish density for spring nighttime mobile samples (<-34 dB)

Figure 3.8. Mean turbine unit operations (black bars) in $1000 \mathrm{ft} / \mathrm{s}$ increments for all samples during spring night plotted against the smolt-sized fish density per $1000 \mathrm{~m}^{3}$ (gray area) within $60 \mathrm{~m}$ of each turbine unit.

Figure 3.9. Mean smolt-sized fish density for summer daytime mobile samples (<-45 dB)

Figure 3.10. Mean turbine unit operations (black bars) in $1000 \mathrm{ft} / \mathrm{s}$ increments for all samples during summer day plotted against the smolt-sized fish density per $1000 \mathrm{~m}^{3}$ (gray area) within $60 \mathrm{~m}$ of each turbine unit.

Figure 3.11. Mean smolt-sized fish density for spring daytime mobile samples (<-45 dB)

Figure 3.12. Mean turbine unit operations (black bars) in $1000 \mathrm{ft} / \mathrm{s}$ increments for all samples during summer night plotted against the smolt-sized fish density per $1000 \mathrm{~m}^{3}$ (gray area) within $60 \mathrm{~m}$ of each turbine unit.

Figure 3.13. Mean large fish densities (targets $>=-34 \mathrm{~dB} \|$ ref $1 \mu \mathrm{Pa}$ ) for spring daytime samples.......... 3.12

Figure 3.14. The distribution of large fish in relation to small fish for spring daytime samples

Figure 3.15. Mean vertical distribution of smolt-sized fish for spring daytime and spring nighttime samples

Figure 3.16. Mean vertical distribution of smolt-sized fish for summer daytime and summer nighttime samples.

Figure 3.17. The depth that $80 \%$ of smolt-sized fish were above in the water-column for spring daytime samples

Figure 3.18. The depth that $80 \%$ of smolt-sized fish were above in the water-column for spring nighttime samples.

Figure 3.19. The depth that $80 \%$ of smolt-sized fish were above in the water-column for summer daytime samples.

Figure 3.20. The depth that $80 \%$ of smolt-sized fish were above in the water-column for summer nighttime samples.

Figure 3.21. The number of smolt-sized fish contacted at each point per minute during spring daytime samples

Figure 3.22. The net movement of smolt-size fish contacted at each point per minute during spring daytime samples relative to flow.

Figure 3.23. The net movement of smolt-size fish contacted at each point per minute during spring daytime samples relative to channel direction

Figure 3.24. The movement distribution of smolt-sized fish contacted at each point during spring daytime samples (yellow) relative to flow (blue).

Figure 3.25. Relationship between the flux of fish sampled at fixed points and the average of the three closest smolt-sized fish density values from grid points generated from mobile surveys.

Figure 4.1. Bathymetric map of the forebay at The Dalles Dam. 4.2 


\section{Tables}

Table 3.1. Mean, minimum, and maximum water velocity magnitude for ADCP measurements taken during spring day, spring night, summer day, and summer night samples. ......

Table 3.2. Correlation values (r) of the comparison between the total smolt-passage index (SPI) at John Day Dam and the average smolt-sized fish density measured in the forebay at The Dalles Dam for each study period..... 
Distribution and Flux of Fish in the Forebay of The Dalles Dam in 2003 


\subsection{Introduction}

This study was conducted by the Pacific Northwest National Laboratory for the U.S. Army Corps of Engineers, Portland District and its Anadromous Fish Evaluation Program. The study was part of the Corps' efforts to improve conditions for juvenile salmonids at The Dalles Dam. The Dalles Dam does not have a juvenile bypass or collection facility to aid downstream migrants. Presently, spillway improvements are being pursued, and a proposal for a guidance structure in the forebay at The Dalles Dam has recently been suggested by the U.S. Army Corps of Engineers and regional resource managers as a potential approach to improve the passage survival of juvenile salmon at the dam. The guidance structure would be designed to alter the horizontal distribution of fish in the forebay and thereby to divert fish from the powerhouse to the spillway.

This study was initiated to gather baseline data on the distribution of juvenile salmon in the forebay at The Dalles Dam, and to relate that distribution to ambient factors (flow, bathymetry, etc.) and the present structures at The Dalles Dam. This information will provide baseline data for the development of a behavioral guidance structure and surface bypass alternatives for juvenile salmon at The Dalles Dam.

\subsection{Background}

The only means to protect downstream migrant salmonids at The Dalles Dam are spill and ice-trash sluiceway operations. The Dalles Dam lacks the in-turbine screens or juvenile salmonid bypass systems present in many other Columbia and Snake River dams. When $40 \%$ spill was implemented in response to a Biological Opinion on operation of the Federal Columbia River Power System for salmon listed under the Endangered Species Act (NOAA Fisheries 1995) to improve juvenile salmon survival, a fish passage efficiency (FPE) of about $80 \%$ to $90 \%$ was achieved through the spillway and sluiceway, with the remaining $10 \%$ to $20 \%$ of smolts passing via turbine routes (Ploskey et al. 2001a). However, the passage routes currently available at The Dalles Dam for smolts have among the lowest survival rates in the Columbia River Basin, with survival rates of $92 \%$ to $96 \%$ for spillway routes, $92 \%$ to $93 \%$ for sluiceway rates and $81 \%$ to $86 \%$ for turbine passage (Ploskey et al. 2001a). Therefore, the Corps is seeking alternatives to increase juvenile salmonid survival during passage at The Dalles Dam.

Substantial efforts have been made to increase the percentage of juvenile salmon passing via the routes of higher survival at the sluiceway and spillway, while reducing passage via turbine routes. For tests of FPE and survival at the spillway, Allen et al. (2000, 2001) indicated that spilling $40 \%$ of total river discharge was optimum for smolt passage and for egress from the tailrace. Spillway passage routes are currently a top priority. Other remedies for decreasing juvenile salmon turbine entrainment have been implemented near the sluiceway and at various turbine intakes, but results did not show the expected decrease in turbine entrainment. Examples of these efforts included installing vertical J-shaped occlusions on the upper half of the turbine intake trashracks and reengineering the sluiceway outfall. All of these fell short of their objective to significantly reduce the entrainment of downstream migrants (Johnson et al. 2003; Ploskey et al. 2001b). Vertical barrier screens, such as those present at John Day Dam and Bonneville Powerhouse 2, have been designed but are not planned to be installed at this time. Future development 
efforts must take advantage of the behavior that downstream migrants exhibit on their approach to The Dalles Dam and their relative vertical and horizontal distribution before and during their encounter with the dam, specifically in response to project operations.

The information base on vertical and horizontal distribution of fish and rate of movement (flux) through the forebay of The Dalles Dam is sparse (Ploskey et al. 2001a; Giorgi and Stevenson 1995). U.S. Geological Survey (USGS) studies of radio telemetry-tagged fish determined forebay approach by using boat mobile tracking although sample sizes were small. Sheer et al. (1997) mobile tracked 100 tagged yearling Chinook salmon and Holmberg et al. (1997) tracked 166 yearling Chinook salmon and 121 subyearling Chinook salmon. Most fish began moving toward the powerhouse, often toward the east end, but a small proportion moved along the north part of the forebay and spillway. Most sub-yearlings in 1995 moved down the Washington shore or at mid-channel and entered the forebay at the east end of the powerhouse (Sheer et al. 1997).

Other data on fish distribution are available in the vicinity of the dam, where detection devices such as hydroacoustic transducers and radio telemetry antennas were placed at the turbine or spillway units. For example, fixed station radio tag monitoring at the dam was used in 1997, 1999, and 2000, and sample sizes were larger than in previous mobile tracking studies. In the study year 1997, out of 168 steelhead, 152 yearling Chinook, and 76 sub-yearling Chinook salmon, Hensleigh et al. (1999) detected about 60\% of steelhead and $56 \%$ of yearling Chinook salmon entering the forebay at the east end of the powerhouse.

Recent hydroacoustic studies have shown that the distribution of fish passage at the powerhouse was uniform or skewed toward the west end in spring but skewed toward the east end in summer (Ploskey et al. 2001b; Moursund et al. 2001; Moursund et al. 2002). Unfortunately, hydroacoustic sampling of fish passage at The Dalles was not available for 2003, thus fish passage information could not be compared to the fish distribution in the forebay that year and could only be compared to the general distribution at the powerhouse for prior years. Given the scarcity of available general distribution data, mobile hydroacoustic methods were deployed to determine the overall distribution of juvenile salmonids within the forebay.

Mobile hydroacoustic techniques have been used in Columbia Basin studies to investigate the distribution of fish relative to many ambient factors and project operations (Feil and Rondorf 2000; Kofoot et al. 1996). Generally these studies were successful at describing the local distribution of juvenile outmigrants and their distribution relative to ambient factors such as temperature, dissolved gas, and water velocity. The researchers used mobile hydroacoustics in combination with trawling to determine the relationship between the sonar-identified fish tracks and the fish species composition. Measuring the near-surface distribution of juvenile salmon was often problematic and different techniques were utilized. Nearsurface distribution is an important behavioral attribute displayed by numerous salmonid species (BioSonics, Inc. 1996; Johnson 1996), and therefore it must be measured. Traditional hydroacoustic survey techniques have relied on the positioning of a solitary transducer fixed just below the water surface so that the "hydroacoustic beam" is oriented to look downward (Kofoot et al. 1994). Since the shape of the hydroacoustic beam is essentially a cone, with sample volume increasing as the depth increases, the 
upper water column is often under-sampled using this technique because of the very small volume sampled in the upper part of the cone, near the water surface. This can result in a bias for population estimates in the upper water column.

Attempts have been made to increase the volume of water sampled in the upper water column by using various methods. One technique used by Kofoot et al. 1996 involved towing a side-looking six-degree transducer that was aimed 5 degrees down from the water surface. This enabled the measurement of fish distribution in the very upper portion of the water column. Another method used by Feil in 1997 was to drive a remotely operated vehicle (ROV) at a depth of $10 \mathrm{~m}$ in front of a research vessel. The ROV was equipped with a transducer that was pointed at the water surface, thereby increasing the volume of water sampled near the surface. Johnson (1996) towed a transducer from the side of a vessel at about 10m deep and aimed the transducer up to the surface.

For the study discussed in this report, we also developed techniques to sample the upper water column by incorporating elements used by Kofoot and Feil and addressing concerns about fish avoiding or moving away from the hydroacoustic sampling gear. Fish avoidance was an important consideration when the study design was developed. Fish avoidance behavior in response to a moving survey vessel and engine noise has been a problem with mobile surveys and a source of bias in estimation of fish numbers (MacLennan and Simmonds 1992; Lee et al. 2002). Changes in fish depth and swim speed (Olsen et al. 1983) as well as changes in fish density (Olsen 1990; Freon et al. 1993) have been observed and associated with boat avoidance. Our design methodology addressed these concerns by increasing the distance that we sampled away from the outboard motors of the research vessel. With the combination of adequate surface coverage and a sampling strategy that would reduce the avoidance of fish from our hydroacoustic sampling gear, we were able to meet our research goals.

The primary focus of our study was to collect basic data needed to design a behavioral guidance structure and surface bypass alternatives to increase overall project passage survival. Therefore, information was gathered to map and analyze the vertical and horizontal distribution of fish, flow, and rate of fish movement (flux) in The Dalles Dam forebay.

\subsection{Research Objectives}

The study area for this research extended from the spillway $1.8 \mathrm{~km}$ upstream in The Dalles Dam forebay. Hydroacoustic data on juvenile salmon-sized fish (90 to $120 \mathrm{~mm}$ for spring and 90 to $105 \mathrm{~mm}$ for summer) were collected during spring (May 2 to June 12) and summer (June 13 to July 25). The research objectives were to

1) Measure water velocity concurrently with hydroacoustic sampling of fish.

2) Determine vertical and horizontal distributions of fish.

3) Estimate the rate of horizontal fish movement (flux). 
4) Analyze the relationship between fish distribution and hydrodynamics, by assessing the following null hypotheses:

$\mathrm{H}_{\mathrm{o}}$ : Fish distribution does not change by season (spring/summer) or diel period (day/night). $\mathrm{H}_{\mathrm{o}}$ : Flow field hydrodynamics are not related to fish distribution. 


\subsection{Methods}

\subsection{Site Description}

The Dalles Dam is located at Columbia River km 309 and includes a spillway perpendicular to the main river channel, a powerhouse parallel to the main river channel, and earthen and rip-rap lined dams on the sides of the powerhouse and spillway (Figure 2.1). The Dalles Dam also allows for commercial navigation through a lock located near the Washington shore. It is the only dam in the lower Columbia River that has its powerhouse situated parallel to the banks of the river. The powerhouse is 636 meters (m) long; it has two fish units and 22 main generating units. The main units each have three intakes and the fish units each have two intakes. Flow through the main turbine units can range from about 250 to 480 cubic meters per second $\left(\mathrm{m}^{3} / \mathrm{s}\right)$ depending on load and turbine efficiency. The two fish units are located adjacent to Main Unit 1 . The average discharge through each of the two fish units is $74 \mathrm{~m}^{3} / \mathrm{s}$, the fish units provide flow to the adult fish channel.

An ice and trash sluiceway spans the entire length of the powerhouse above the turbine units. Skimmer gates for the sluiceway are located above every intake at each turbine unit and open into the ice-trash sluiceway channel. The discharge of the ice and trash sluiceway is typically $130 \mathrm{~m}^{3} / \mathrm{s}$. During the study period the three gates at Main Unit 1 were opened for a discharge of about $43 \mathrm{~m}^{3} / \mathrm{s}$ each (discharge varies with forebay elevation).

The spillway is $420 \mathrm{~m}$ long and has 23 bays numbered from the northwest to the southeast. Each bay is capable of opening to $3.65 \mathrm{~m}$, which spills a volume of water up to $510 \mathrm{~m}^{3} / \mathrm{s}$ through each spillbay. There are also two fish ladders for adult passage that have upstream exits on the northwest and northeast sides of the spillway.

The physical attributes of the forebay are notable. A deep basin is located just upstream of the powerhouse that has a maximum depth of about $95 \mathrm{~m}$. Downstream, the basin tapers into a shallower plane that leads to the spillway and powerhouse. There are designed cuts in the substrate that lead to the east end of the powerhouse and along the upstream face of the powerhouse. 


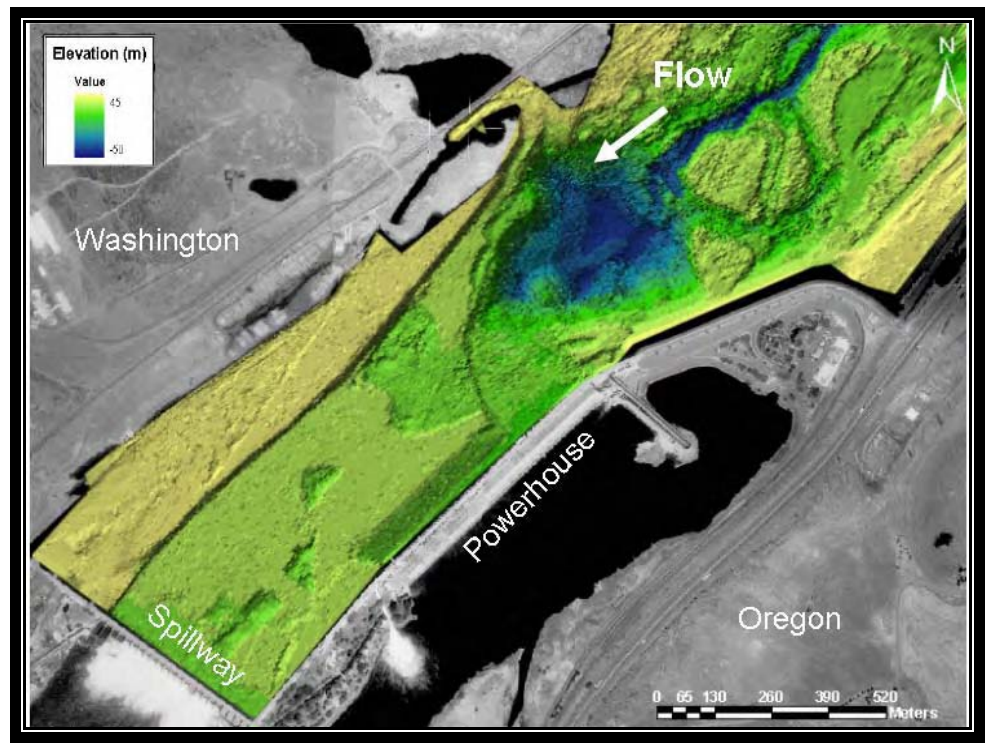

Figure 2.1. The Dalles Dam on the Columbia River showing the orientation of the powerhouse and spillway. The colored region displays the bathymetric surface of the area upstream of the dam where depth increases as the color hue darkens.

\subsection{Data Collection}

Data were collected using mobile and fixed-point surveys to determine the overall distribution of fish in the forebay and the relative rate of fish movement over time at fixed points (flux), respectively. The vertical and horizontal distribution of fish, fish density, and the flux of fish past fixed stations were estimated by season (spring or summer) and diel period (day or night), then were related to measured flow variables. Sampling was conducted one day and one night every week for six weeks in the spring (April to June) and six weeks in the summer (June to July) (Figure 2.2). One night was missed in summer due to high winds on too many consecutive days. Wind generates wave action, which can create too much noise for the hydroacoustic gear to differentiate fish from the background, particularly in the upper water column. We began sampling on days when the wind was less than 16 kilometers per hour (kph) and stopped sampling if the wind exceeded $24 \mathrm{kph}$.

We were unable to find published information on the effect of wind on the distribution of juvenile salmon. However it is reasonable that wave action caused by wind may affect the vertical distribution of fish. We assumed that our samples were representative of The Dalles Dam forebay, where it is often windy. 


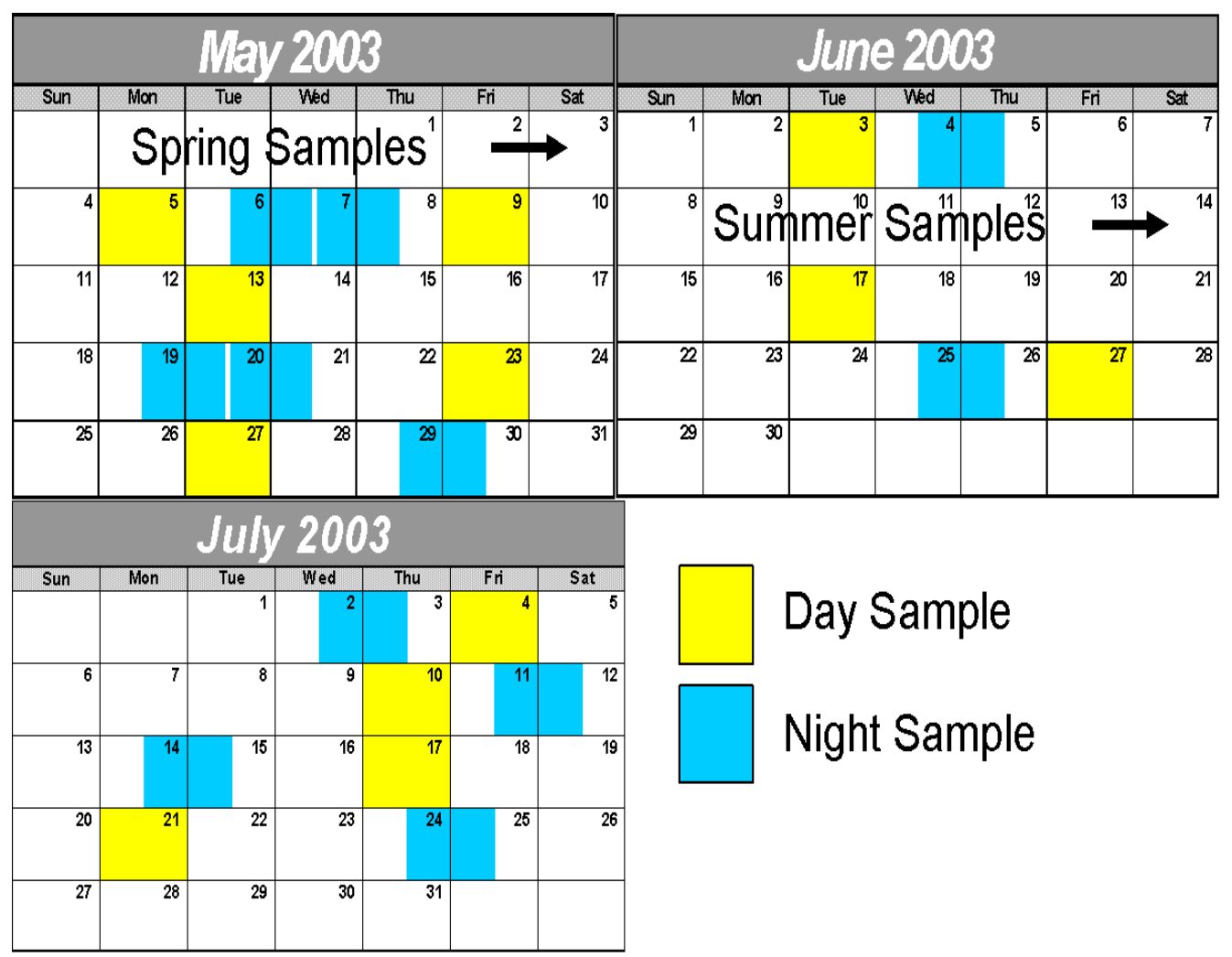

Figure 2.2. Sampling calendar for mobile and fixed hydroacoustic data collection in the forebay of The Dalles Dam.

\subsubsection{Sampling Equipment}

Sampling was conducted from two research vessels equipped with nearly identical aluminum catamaran sampling rafts. The hydroacoustic sampling equipment was located on the rafts, which were attached to the front of the research vessels with poles to maintain a distance of $17 \mathrm{~m}$ between the transducers and the vessels' outboard motors (Figure 2.3). The rafts were located in front of the research vessels and the transducers were pointed forward looking to minimize avoidance behavior by the fish.

Each raft was outfitted with two split-beam and four single-beam hydroacoustic transducers (see Figure 2.4). Split-beam hydroacoustic systems can measure relative differences in the target strength of ultrasonic echos, and thus the size of the fish located within the ensonified beam. Split beams are also capable of measuring movement direction through the acoustic beam by detecting the difference in phase shift (translated to angle and position) of the returning echo from each of the "splits," which are two ceramic semicircles that comprise the transducer. Single beams, on the other hand, are only capable of measuring the return-strength of the echo; therefore, they cannot measure the size difference or movement (direction) of fish within the ensonified volume of the acoustic beam. Single-beam transducers can only measure the presence or absence of a target above a predetermined threshold and the distance of the target from the transducer. 


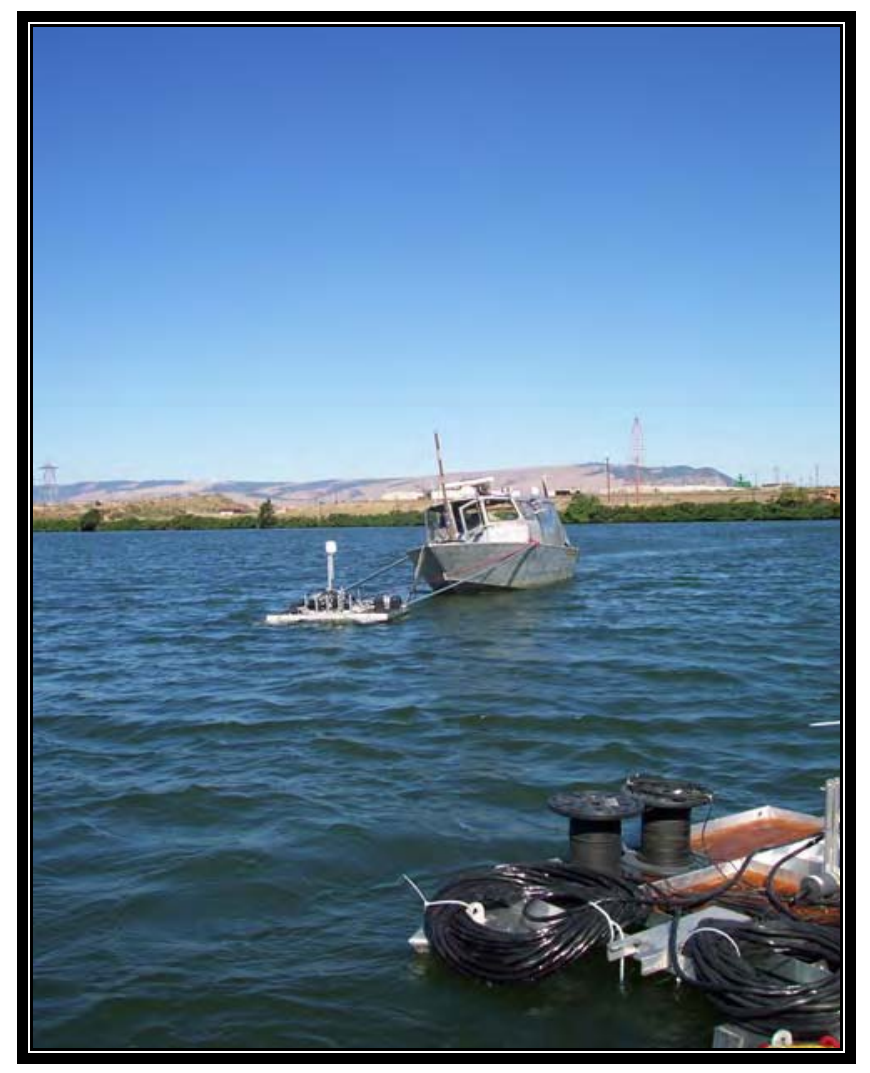

Figure 2.3. A mobile research vessel is shown pushing a sampling raft at a distance approximately $7 \mathrm{~m}$ forward of the bow and $17 \mathrm{~m}$ forward of the outboard motor.

The sampling raft for the mobile hydroacoustic survey was configured as follows. Two 420-kHz splitbeam Precision Acoustic Systems (PAS) hydroacoustic transducers (one $6^{\circ}$, one $12^{\circ}$ ) were connected to a fast multiplexer and sounder that transmitted at a rate of 33.33 pings per sec (pps), to provide a ping rate of 16.67 pps per transducer. Four $420-\mathrm{kHz}, 6^{\circ}$, PAS single-beam transducers were also multiplexed and connected to a sounder that sampled at $33.33 \mathrm{~Hz}$, providing a ping-rate of 8.33 pings/s for each of the transducers. The threshold setting for both the single and split beam sounders was $-56 \mathrm{~dB}$ re $\| 1 \mu \mathrm{Pa}$. The minimum range for sampling was $2 \mathrm{~m}$ for both the single and split-beam systems and the maximum range was $16.8 \mathrm{~m}$ and $17.4 \mathrm{~m}$ for the split-beam and single-beam sounders, respectively.

Five transducers were oriented to measure the volume of water forward of the sampling vessel (forwardlooking); the split-beam $6^{\circ}$ transducer and the four single-beam $6^{\circ}$ transducers. The forward-looking transducers were deployed about $0.5 \mathrm{~m}$ deep and sampled the upper $8.5 \mathrm{~m}$ of the water column in successive 1.7-m-depth bins from the surface (Figure 2.5). The $12^{\circ}$ split-beam transducer was aimed downward and deployed $0.5 \mathrm{~m}$ deep and sampled from 3 to $18 \mathrm{~m}$ deep. The transducers provided an estimate of the vertical distribution of fish by $1.7-\mathrm{m}$-depth intervals. 


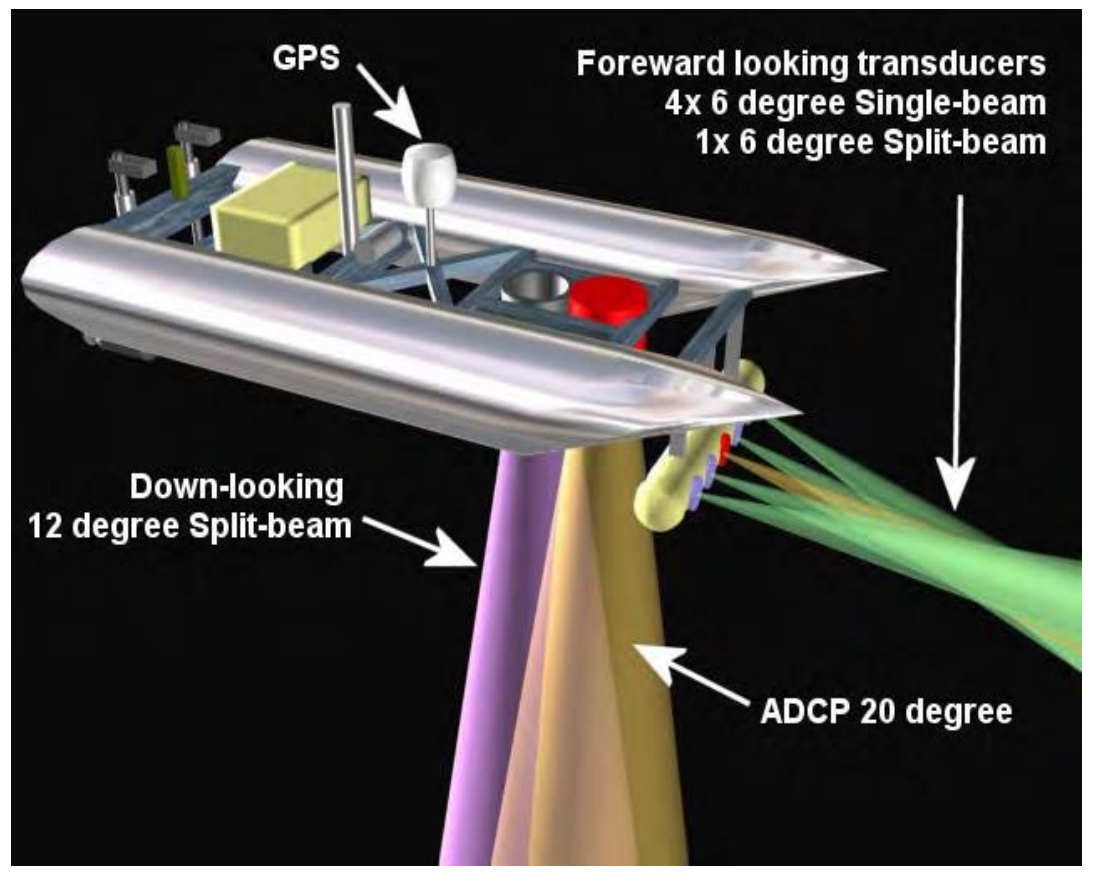

Figure 2.4. Mobile and fixed-point sampling raft, equipped with an attitude monitor (pitch/roll/heading), differential GPS, ADCP, and six hydroacoustic transducers for detecting fish.

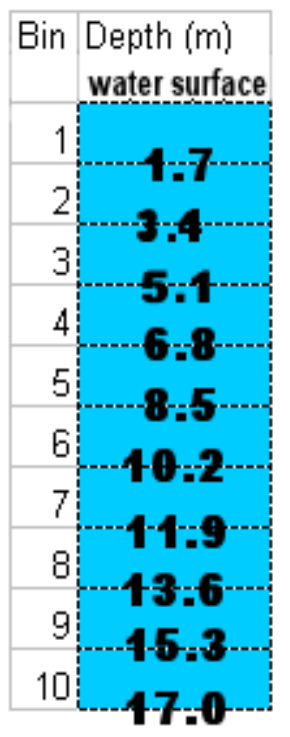

Figure 2.5. Vertical distribution of fish density was measured in "bins" at successive 1.7-meter depths from surface 
An RDI acoustic Doppler current profiler (ADCP) for measuring flow data was also deployed adjacent to the down-looking hydroacoustic transducer on each of the rafts (Figure 2.4). The ADCP measured threedimensional water velocities (magnitudes and directions) at $0.5-\mathrm{m}$ vertical increments throughout the sampling depth to associate with fish detections. The ADCP was a RDI 600-kHz Rio-Grande Workhorse $^{\mathrm{TM}}$ that was configured to collect velocity data for every ensemble ${ }^{\mathrm{a}}$ and sampled at a rate close to $1 \mathrm{pps}$ (sample rate changed with water depth) for every $0.5 \mathrm{~m}$ to a maximum depth of $64 \mathrm{~m}$.

A pitch and roll sensor, differential GPS, and compass were mounted on each raft to acquire position and orientation data for integration with flow and fish data sets. All fish and flow data were referenced to the GPS antenna and attitude sensor (pitch/roll/heading), which sampled at $1 \mathrm{~Hz}$ and $16 \mathrm{~Hz}$ respectively. In addition, all of the sampling equipment was referenced to Universal Time retrieved from the Global Positioning Satellites, either via the differential GPS or via a Meinberg ${ }^{\text {TM }}$ GPS clock that provided the time reference to the hydroacoustic data collection computers aboard each research vessel. An umbilical of communication and power cables extended from the sampling rafts to each of the research vessels.

\subsubsection{Mobile Surveys}

To conduct the mobile hydroacoustic surveys in the forebay at The Dalles Dam, the research vessel began at the Washington shore and traversed in a zig-zag pattern back and forth across the river 26 times ending at a spot $1.8 \mathrm{~km}$ upstream of the spillway, to cover a total area of approximately $668,000 \mathrm{~m}^{2}\left(0.67 \mathrm{~km}^{2}\right.$, Figure 2.6). The minimum distance of $180 \mathrm{~m}$ upstream of the spillway was set by the project to provide a safe zone in front of the open spillway. Traveling at about 2.5 knots, it typically took 6 hours to complete a mobile survey, which consisted of 26 transects.

\footnotetext{
${ }^{a}$ An ensemble is a full water-column profile of flow data.
} 


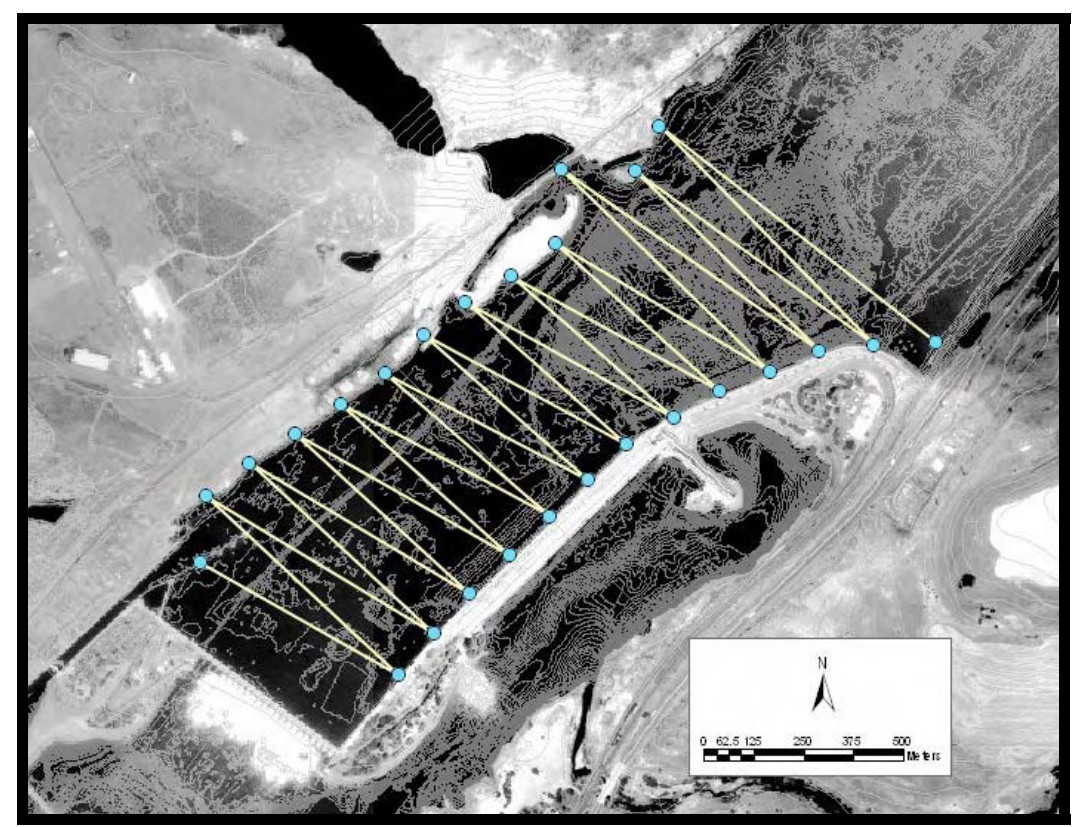

Figure 2.6. Mobile sampling transects in the forebay of The Dalles Dam. All transects were sampled during each sample period.

\subsubsection{Fixed-Point Surveys}

The mobile survey boat and a second research vessel were used to conduct fixed-point surveys to determine the rate of fish movement (fish flux) past 17 fixed-point sites in the forebay of The Dalles Dam. This second vessel acted as the safety boat while the mobile survey vessel was within the boat restricted zone (BRZ) of The Dalles Dam forebay. The second vessel's crew began fixed-point sampling when the mobile boat exited the BRZ. The second research vessel was equipped with a sampling raft similar to that of the mobile research vessel. It was attached to the side of the research vessel using aluminum poles. The sampling raft was configured nearly identically except that the ADCP was a RDI $1200-\mathrm{kHz}$ Rio-Grande Workhorse ${ }^{\mathrm{TM}}$ (instead of the $600-\mathrm{kHz}$ workhorse deployed on the mobile raft). The ADCP was configured to collect velocity data for every ensemble and sampled at a rate close to 1 pps (the sample rate changed with water depth) for every $0.5 \mathrm{~m}$ to a maximum depth of $32 \mathrm{~m}$ (not the 64-m depth of the mobile surveys).

All fish and flow data were referenced to the GPS antenna and attitude sensor (pitch/roll/heading), which sampled at $1 \mathrm{~Hz}$ and $10 \mathrm{~Hz}$, respectively. The electronic cables from each of the devices were combined to make a short umbilical that was secured to the data collection computers on the boat. The onboard systems were operated briefly at the beginning of each sample day to ensure that the hardware, software, and connections were intact and operating correctly. Once this was completed, the fixed-point surveys began. 
Our fixed-point point surveys were conducted at standard mooring buoys that were anchored at 17 sites in the forebay (Figure 2.7). The buoys included a 4-in.-diameter galvanized ring at the top providing an attachment point for the research boat. The buoys were originally arrayed in four lines of six buoys that extended across the river channel and perpendicular to the powerhouse. Requests from barge operators resulted in removal of some of the buoys in the navigation channel of the river and others buoys were lost during the course of the data collection season. The points shown in Figure 2.7 were those stations sampled for the majority of the spring and summer sampling period. Stations within a line were sampled in random order; the order that we sampled the lines was also randomized. The boat operator anchored to a buoy and turned off the engine, to reduce fish avoidance from the sampling area.

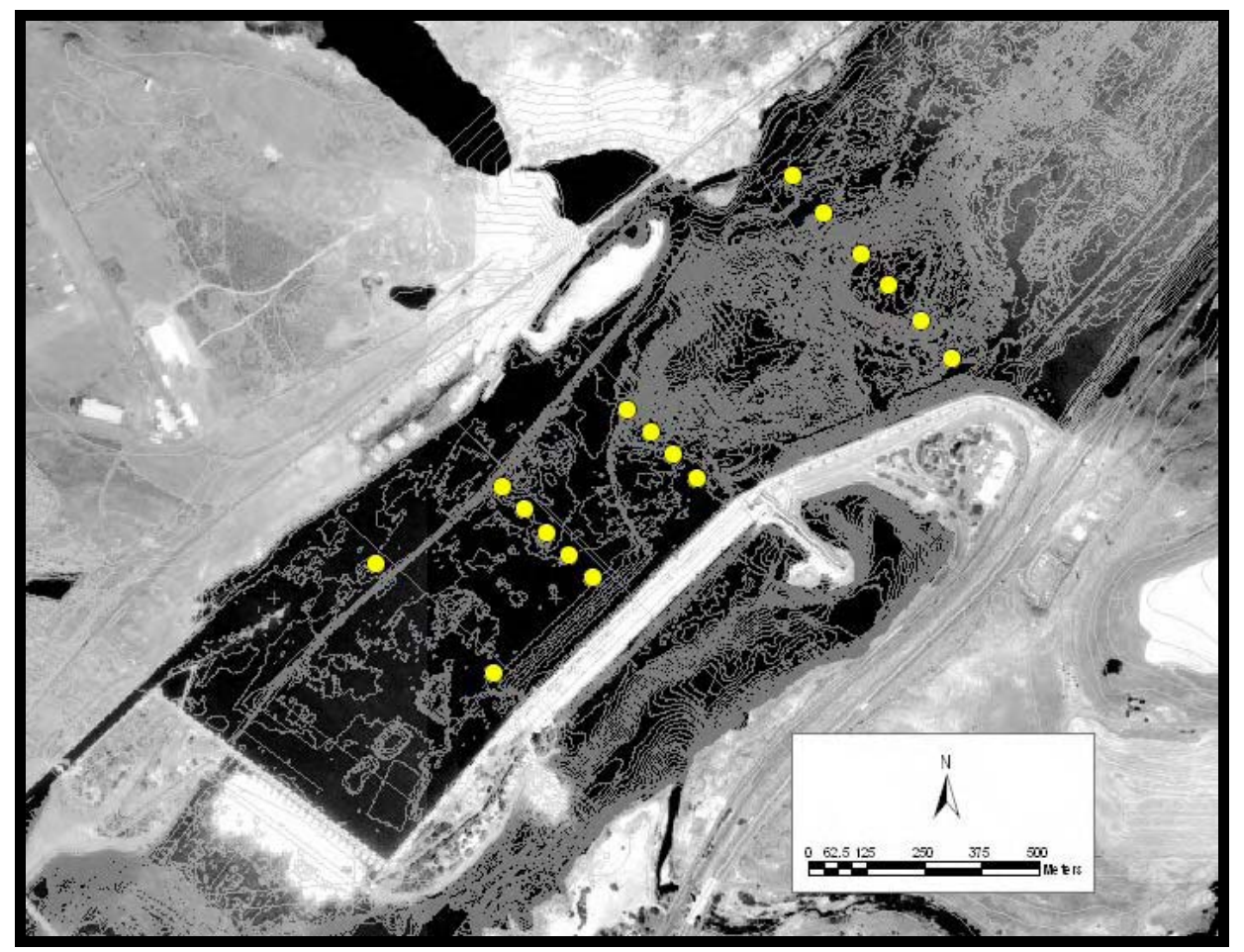

Figure 2.7. Fixed points located throughout The Dalles Dam forebay that were sampled during the study. Buoys were located at each of the points where a sampling vessel anchored for 10 minutes.

The PAS software, WinADCP, ${ }^{\mathrm{TM}}$ and Hyperterminal ${ }^{\mathrm{TM}}$ were initiated to begin data collection (Figure 2.8). Time and file name for each of the systems were noted after all systems began collection. Site number and anomalies, such as loss of GPS satellites, were also recorded. Data on fish and water velocity were collected for 10 minutes at each site. Time and file name on each system were noted at the end of the sample time and all systems were stopped. All stations in the three upstream lines were sampled once per sampling period for six days and six nights in the spring and six days and five nights in the summer. We were unable to sample for one night in the summer sampling period due to high winds. 


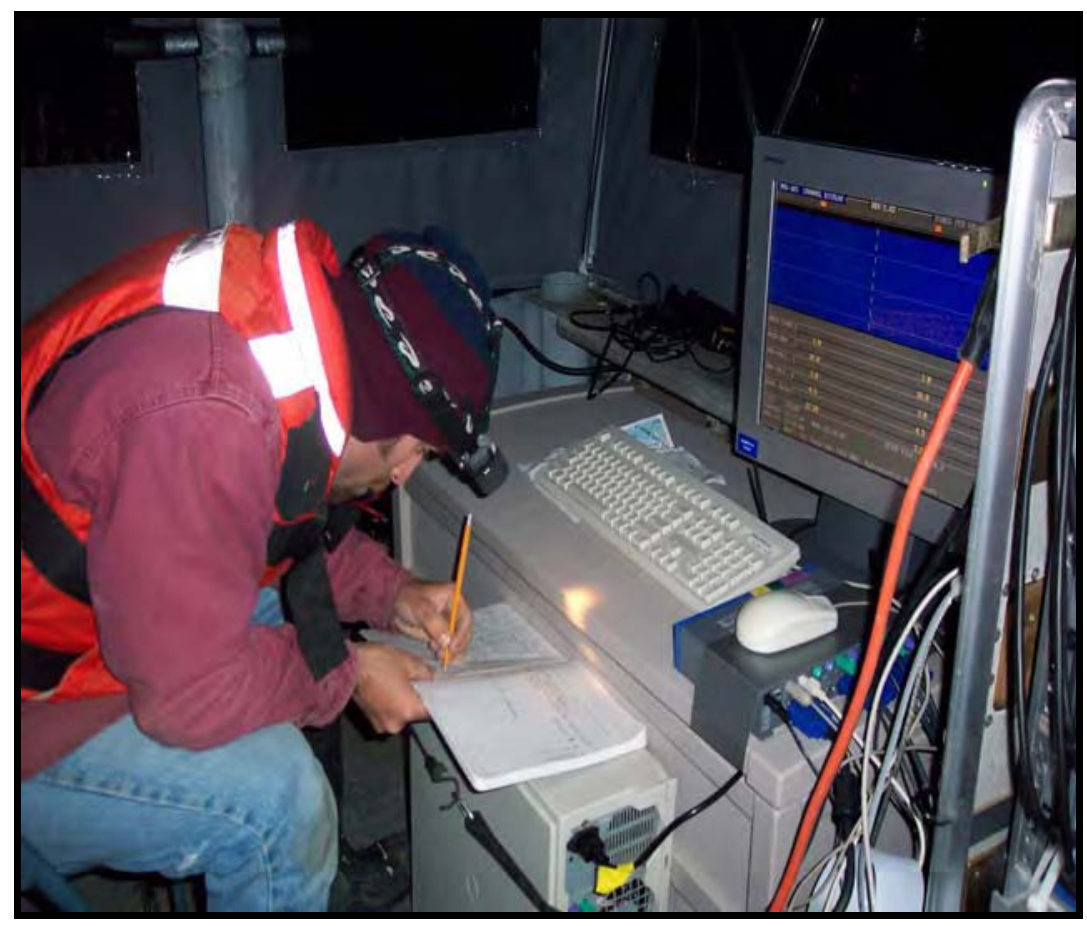

Figure 2.8. Data collection using four computers that monitored the sampling gear attached to the rafts on each boat. Two computers monitored the PAS sounders, one collected ADCP data, and another collected sample vessel orientation and position data. All were linked to a common time source recorded from GPS satellites.

\subsection{Data Processing}

Data files on fish targets and water velocity from the mobile and fixed-point sampling rafts were nearly identical in their output; however, the manner in which we processed the data provided by each raft was very different. With the mobile samples we sought to map the distribution of smolt-sized fish density by linking transects together through various methods of interpolation, thereby showing the relative concentration, lateral and vertical, of fish with respect to the environment of The Dalles Dam forebay. In contrast, with the fixed-point data we sought to describe the overall rate of movement of fish past set points distributed throughout the forebay.

A few preliminary steps were taken before we processed the data. These steps are necessary and inherent when processing hydroacoustic data on fish targets and have been used in varying degrees for earlier research efforts that utilized hydroacoustic technologies (Kofoot et al. 1996; Ploskey et al. 2001a,b). They include assumptions on the detectability of fish traveling through the hydroacoustic beams, the performance of a computer autotracker compared to a human tracker, and the aspect of the fish in the ensonified volume. 
The first step before final analysis was to quantify the detectability of fish passing through the ensonified volume of the transducer beams during mobile and fixed surveys. We decided to use the nominal beam width (i.e., $6^{\circ}$ for forward and $12^{\circ}$ for down-looking) of our transducers for spatial expansion calculations rather than estimating the effective beam width by using detectability models. The models employ variables such as water velocity components, the transducer beam pattern, trajectory, and range to determine the detectability of a fish passing through various parts of the transducer's beam. The detectability models recently developed by COE and PNNL were designed for use with stationary hydroacoustic sampling in dam structures such as turbine intakes and spillbays where flow velocity can reach speeds in excess of $9 \mathrm{~m} / \mathrm{s}$ and where the detectability of fish can vary greatly depending on a fish's position in the beam due to the speed of the fish traveling through the beam. Detectability modeling can also be done for mobile and semi-stationary research studies like this one, but the results would not likely be better than using the nominal beam width alone (Bill Nagy, pers. comm.).

To illustrate the point, our sampling craft speed did not exceed $1.2 \mathrm{~m} / \mathrm{s}$ and the maximum measured water velocity was $0.83 \mathrm{~m} / \mathrm{s}$. If these are combined, we would obtain a maximum speed of water under the vessel of $2.03 \mathrm{~m} / \mathrm{s}$. Using this speed to model a hypothetical fish that was passively traveling in the fastest moving water with the vessel traveling directly against the current $(2.06 \mathrm{~m} / \mathrm{s})$, the PAS sampling equipment would still detect five pings on that fish even if it passed through the smallest section of our sampling volume, given the ping rate (16.67 pings/s) and smallest beam diameter $(0.63 \mathrm{~m})$ of the downlooking transducer. However, this fish speed is unlikely if we reference previous acoustic telemetry projects where juvenile salmon speed was determined in the forebay of Bonneville Dam (Faber et al. 2001). There, nearly all of the juvenile Chinook and juvenile steelhead had travel speeds less than $1 \mathrm{~m} / \mathrm{s}$, where forebay water velocities were similar. In performing this hypothetical scenario and using previous data on fish swim speed in a hydroelectric dam forebay, we were confident that the fish we contacted would be detectable in all areas of the hydroacoustic beam during a sample.

The second step was to qualify the computer autotracker performance and compare its performance to a human tracker for both the mobile and fixed sites. The use and performance of the computer autotracker was qualified before the fish data were used in final analysis. We used the autotracker to process the mobile samples because we determined that it was identifying most of the echo patterns that a human tracker would have tracked. When the auto-tracker results were correlated to the human tracker for a $10 \%$ sub-sample of mobile survey data, the results produced an $\mathrm{R}^{2}$ of 0.88 , confirming that it was recording the majority of echo patterns that a human tracker would track. However, when the same correlation was performed on a sub-sample of data taken from the fixed-point survey boat, the correlation produced an $\mathrm{R}^{2}$ of 0.05 . This provided evidence that the autotracker was not performing well at the fixed points. The results were isolated to one hydroacoustic system on-board the fixed-point sampling vessel, and the poor correlation was likely caused by the autotracker misidentifying sources of noise as fish, and then recording the noise echoes as legitimate fish traces. Therefore, we processed a subset of fixed-point data by manually tracking the fish echoes for fixed-points located outside the boat restricted zone at The Dalles. Due to the time-consuming nature of manually tracking fish echoes, we were only able to include the study dates $5 / 13,5 / 19,5 / 20,5 / 23,6 / 3,6 / 4,6 / 25$, and $7 / 17$. The fixed points located within the BRZ at The Dalles were tracked for all study days. This was possible due to the use of the mobile tracking boat 
for monitoring those points, and the good performance of the autotracker when used to track the hydroacoustic systems of the mobile boat.

A third necessary step before the final processing of the data was to identify the size of the fish based on the target strength measured by the split-beam echo sounders. The target strength of a fish is dependent on the aspect of the fish relative to the hydroacoustic transducer (Love 1977), with the dorsal aspect of the fish producing the best repeatable measures for determining fish size based on target-strength. Size classification was necessary for this investigation to differentiate larger fish (adult salmon, shad, northern pikeminnow, sturgeon, etc.) from smolt-sized fish, so that we could accurately map the distribution of smolt-sized fish. The model produced by Love showed that the side aspect produced different target strengths than did the dorsal or ventral aspect, and the side aspect was more variable in its range of target strengths. The side aspect, head-on, or tail-on aspects of a fish would most likely be sampled by the forward-looking transducers due to the fish's general orientation of dorsal-ventral to the elevation plane (Love 1971; Arnold 1974). We therefore bypassed this variability by only using the percent composition of large to small fish for the forward-looking transducers as measured by the down-looking transducer that was interrogating the dorsal aspect of all fish targets. By doing this we made several assumptions: the first was that the fish were traveling in a dorsal-ventral aspect relative to the elevation plane for the down-looking transducer; and the second was that the fish sampled with the forward-looking transducers had the same large fish to small fish size ratio as the fish sampled with the down-looking transducer alone. We classified all fish <-34 $\mathrm{dB}$ re $\| 1 \mu \mathrm{Pa}$ as a smolt-sized fish in the spring sampling period, and all fish <-45 $\mathrm{dB}$ re $\| 1 \mu \mathrm{Pa}$ as smolt-sized fish in the summer sampling period. This corresponded to $\sim 320$ mm-sized fish in dorsal aspect for spring fish and 105-mm-sized fish in dorsal aspect for summer samples using Love’s equation (Love 1977).

Once the echoes were satisfactorily tracked, either through autotracking or manual means, and classified as either a large or small fish, fish tracks were then positioned in earth coordinates by using the GPS and pitch/roll/heading instruments onboard each of the rafts in the following manner. Pitch, roll, and heading data were recorded at $16 \mathrm{~Hz}$ and interspersed with records of GPS data recording at $1 \mathrm{~Hz}$. GPS data were output to a computer via National Marine Electronics Association (NMEA)-formatted output in the WGS84 decimal degrees format.

A small Visual Basic ${ }^{\mathrm{TM}}$ application was written to determine the composition of each line of data and to parse the components accordingly. The GPS latitude and longitude strings were then converted to Universal Transverse Mercator (UTM) coordinates in North American Datum of 1927 (NAD27) OregonNorth State Plane and expressed in eastings and northings. The time component of the GPS string was combined with the file date and converted to Julian seconds (seconds after January 1, 2003, 00:00:01). GPS data were interpolated over the pitch/roll data that occurred within that second. The application then exported pitch, roll, heading, easting, northing, and Julian seconds in a comma-delimited format.

A second Visual Basic ${ }^{\mathrm{TM}}$ application was coded to handle merging of fish data and GPS/PR data. The application also computed the echo movement vectors and average fish movement vectors. GPS/PR data were imported and coupled to the fish data by Julian seconds to determine the location of the boat at the 
time of the echo return. The real position of the hydroacoustic transducer head was calculated by combining the GPS position with the measured distance between the transducer head and the GPS antenna. The Cartesian position of the echo relative to the transducer was calculated using the conversion equations for the PAS split-beam coordinate systems and the range on the single-beam system. The real echo position was then calculated by adding the relative echo position to the real transducer position and rotating the values using pitch, roll, heading, and measured transducer angle for split beams and range for single beams. The corrections for pitch, roll, and magnetic declination were applied to the real echo position calculation. Echo vector components $(\mathrm{u}, \mathrm{v}, \mathrm{w})$ were calculated by subtracting the real position of each echo from the real position of the previous echo. Boat position and Julian seconds for each fish were determined as the median position and time of the transducer for that set of echoes. Fish vector components were calculated as an average of the echo vector components. These data comprised the mobile and fixed data for mapping the distribution and flux of fish.

Based on our selected methods of data collection and data processing, we made the following assumptions when analyzing the mobile and fixed hydroacoustic data:

1) Wind does not significantly alter the distribution of juvenile salmon in The Dalles Dam forebay.

2) Fish do not avoid our sampling apparatus, as to cause a reduced estimate of fish density.

3) The use of the nominal beam width in fish density calculations was sufficient to estimate fish density for all size classes of fish.

4) The autotracker performed as well as a human tracker and was consistent across samples.

5) The down-looking transducers sampled the same proportion of fish in each size class (smoltsized, larger than smolt-sized), for each grid point, and for each depth bin as the forward-looking transducers.

6) Fish that were less than $-56 \mathrm{~dB}$ ref $1 \mu \mathrm{Pa}$ were smaller than smolt-sized fish in the spring and summer, and fish less than $-34 \mathrm{~dB}$ ref $1 \mu \mathrm{Pa}$ (spring) and less than $-45 \mathrm{~dB}$ ref $1 \mu \mathrm{Pa}$ (summer) were smolt-sized fish. Fish greater than $-34 \mathrm{~dB}$ ref $1 \mu \mathrm{P}$ were classified as large, non-smolt fish.

7) The target strength of the fish was equal across species, and the fish returned a target strength representative of its size from the dorsal aspect, relative to the acoustic beam.

8) The positing of the fish within a grid unit was sufficiently accurate to calculate a relative fish density within that grid area.

9) The movement of the fish population relative to the time required to sample the population was negligible.

10) For seasonally pooled data, the average environmental condition for all samples was representative and could be compared to the average fish density by grid location. Also, the average fish density by grid location was representative of the migrating smolt population. 


\subsubsection{Mobile Survey Analysis}

\subsubsection{Lateral Fish Distribution}

The mobile hydroacoustic data were used to map the lateral distribution of smolt-sized fish in The Dalles Dam forebay. This involved a multi-step process to expand the number of fish sampled by the hydroacoustic equipment to a density of fish per unit volume of water. The first step in this process was to divide the forebay into grid sections that were aligned with the spillway and powerhouse. The grid sections that we used were $61 \mathrm{~m}$ per side (200 ft x $200 \mathrm{ft}$ ) and included all of the water located from the surface to the bottom within each square grid (Figure 2.9). Once the grid boundaries were defined, the volume of water sampled in each grid was calculated. There were between 200 and 230 grid units sampled in the mobile samples. The number of units varied because of slight variations in the transects of the mobile survey due to river conditions.

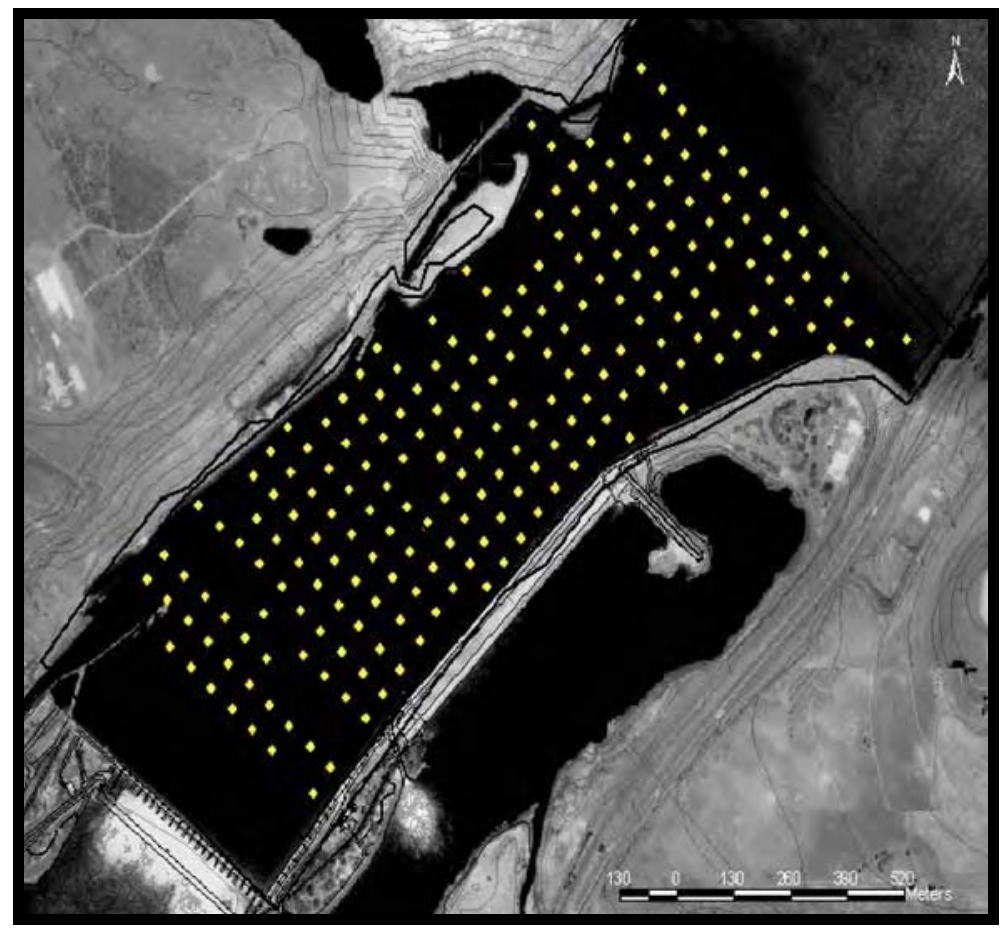

Figure 2.9. Grid used to summarize mobile hydroacoustic data. Grid units were 61-m square, with the centroid of the grid shown as a yellow square. Centroids were assigned a fish density based on the number of fish and the volume of water sampled within the grid.

The volume of water that was sampled within each grid unit (61 $\mathrm{m}$ x $61 \mathrm{~m}$ ) was calculated as follows. The down-looking transducer was sampling from $3 \mathrm{~m}$ to $16.8 \mathrm{~m}$ deep and each ping was interrogating a water volume that was essentially the shape of a $12^{\circ}$ cone. When the cone shape was extended along the transect lines and cut by the grid sides, the shape of the volume sampled became a prism of a known volume. The forward-looking transducers were also sampling in the shape of a cone $\left(6^{\circ}\right)$, but because 
they were sampling the volume of water directly forward and in the direction of travel of the sampling vessel, the volume of water sampled per transducer became the area at the base of the cone at $17.6 \mathrm{~m}$, extended to the distance of travel across the grid. This volume was essentially the shape of a cylinder (Figure 2.10). Once the volume of water sampled in each grid unit was known, we expanded the number of fish contacted within that grid unit to the total volume of water within each grid unit, in order to provide a relative fish density expressed as fish $/ \mathrm{m}^{3}$.

$$
\text { FishDensity }=\frac{\text { number_of _ fish_sampled }}{\text { volume_of _ water_sampled }}
$$

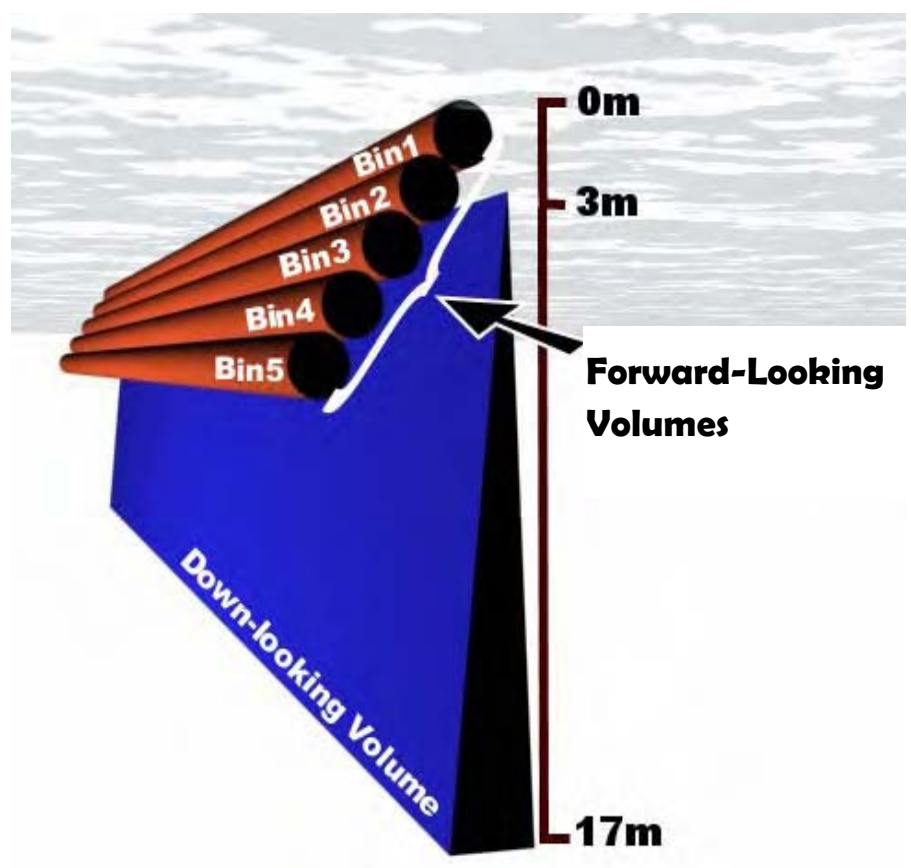

Figure 2.10. Sample volumes of the forward and down-looking transducers aboard the mobile sampling vessel. The sample volume begins at $3 \mathrm{~m}$ below the water surface for the down-looking transducer and ends at $16.8 \mathrm{~m}$. The five cylindrical sampling volumes of the forward-looking transducers had a diameter equal to the diameter of the beam at the maximum range of $16.8 \mathrm{~m}$ for split beams and $17.6 \mathrm{~m}$ for single beams. Fish that entered these volumes were tallied by autotracking software developed by COE and PNNL.

The expansion method also had to be adjusted so that a representative map could be generated. A fish density was assigned to a grid unit if the volume of water sampled within the grid was over $2 \%$ of the actual volume of water located within that grid. When fish densities were calculated from volumes of less than $2 \%$, the results were not included due to the asymptotic error expansion inequality whereby the fish 
density volume increased exponentially as the percent of water volume approached zero. The asymptote of the inflated values began to level at about $2 \%$ of the sampling volume (see Figure 2.11). Therefore, only grid units that had a sample volume greater than $2 \%$ of the total grid volume were included in the mapping of fish density.

Fish Density Distribution on the Night of May 29, 2003

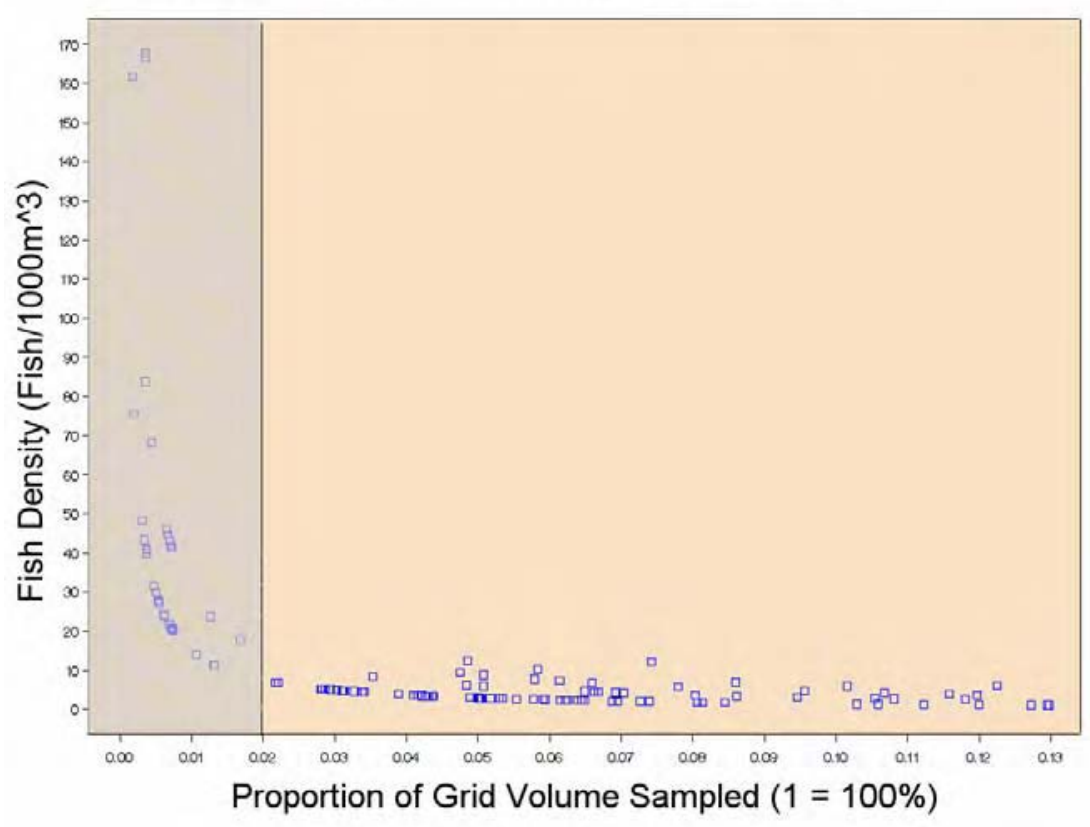

Figure 2.11. This graph shows the relationship between the proportion of the volume of water sampled per grid unit and the calculated fish density for that grid unit. Elevated values are seen where the proportion of study volume was less than $2 \%$. These density calculations are not likely representative of the actual density, but rather are a by-product of expansion.

Classifying the size of fish sampled was the final step before mapping the distribution. We used the sample of fish contacted by the split-beam transducers to estimate the number of fish for each class (smolt-sized and larger than smolt-sized) that were contacted by the single-beam transducers. We established the following criteria for size classification of single-beam-detected fish. If more than five fish contacts occurred within a grid unit by two split-beam transducers, the percentage of smolt-sized fish to larger fish in that unit was used to estimate the percentage of smolt-sized fish to large fish that were contacted by the single-beam transducers. If the number of fish contacted was less than five, then the percentage of smolt-sized fish to large fish for that day's entire sample of split-beam-counted fish in all units was used to classify size class for that grid unit. Finally, an inverse distance interpolation method was used to map the distribution of the two size classes of fish (smolt-sized and larger than smolt-sized), for each sample period. Sample periods were also combined to display the mean fish density by diel period (day/night) and season (spring/summer). 


\subsubsection{Vertical Fish Distribution}

The vertical distribution of fish was estimated using slightly different methods than the lateral distribution, but still relied on the volume of water sampled for each section of the water column sampled. We estimated the percentage of fish distributed by bin, which was the distance every $1.7 \mathrm{~m}$ from the water surface to $17 \mathrm{~m}$ deep. The bin size was chosen based on the diameter of the single-beam transducer at its maximum sampling range; this was because the single beam transducers were unable to resolve the vertical position of the fish on a finer scale than $1.7 \mathrm{~m}$. Therefore we adjusted the number of fish sampled at each bin based upon the volume of water sampled at each bin, which was the sum of the volume sampled by the forward and down-looking transducers through each bin range (i.e. 0 m-1.7 m, 1.7 m-3.4 $\mathrm{m}$, etc). The vertical distribution of smolt-sized fish was calculated over each sample period. These estimates were also combined over diel period and season for specific areas in the forebay where we divided the river into 15 regions corresponding to the Washington bank, mid-channel and Oregon bank and distance downstream in the forebay to the spillway (Figure 2.12).

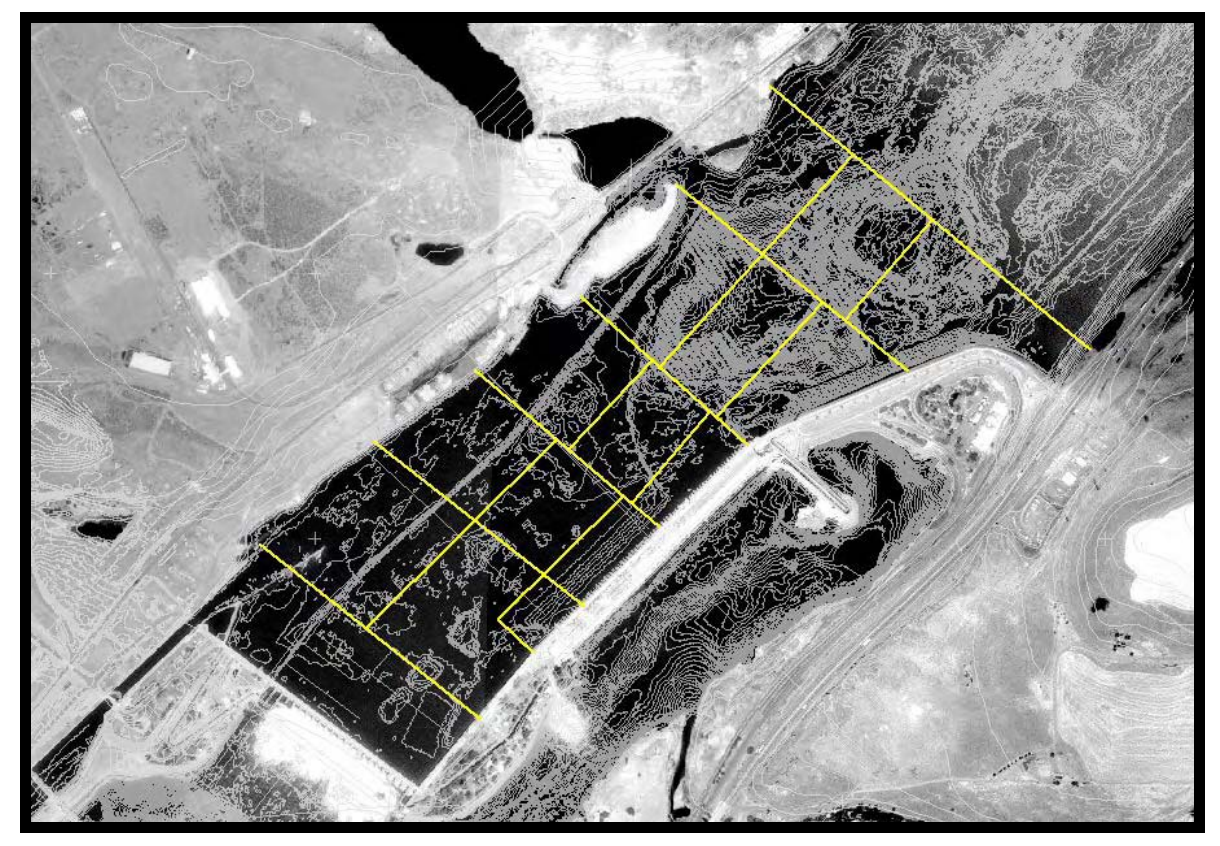

Figure 2.12. The forebay of The Dalles Dam with grids defined by region. The vertical distribution was calculated for each of these regions. 


\subsubsection{Fixed-Point Analyses}

The summary analysis of the fixed-point data was focused on two attributes of juvenile salmon behavior exhibited at those points: 1) the number of fish passing each point over time (flux), and 2) the movement/direction of fish past each point. Fish flux was determined by first calculating the percent of smolt-sized fish detected by the split beam transducers that fit the small fish criteria (target strength less than $-34 \mathrm{~dB}$ in spring, $-45 \mathrm{~dB}$ in summer) during a 10-minute sample. This percentage was then applied to the single-beam data in order to get a complete fish count at each fixed site. The flux was adjusted to reflect the number of fish passing an individual point over a one-minute period for the volume of water sampled at that point.

Split-beam hydroacoustics were used to determine the movement of fish past each point. The movement of fish past each point was determined by three methods: 1) the movement of fish in $20^{\circ}$ increments about a $360^{\circ}$ range, 2) the net downstream movement of fish, and 3) the net movement of fish in the direction of the spillway. The movement of fish in $20^{\circ}$ increments was quantified by point and displayed as a rose graph (see Figure 3.24) with greater numbers of fish moving in one $20^{\circ}$ increment expressed as a longer $20^{\circ}$ slice. The net fish movement was displayed as the difference between the downstream and upstream moving fish by calculating those fish with headings within $90^{\circ}$ of the average water heading, or channel heading, and the fish within $90^{\circ}$ of the opposite two-dimensional vector to the water heading or channel heading.

\subsubsection{Flow Data}

\subsubsection{Mobile Samples}

Mobile ADCP data were collected with a 600-kHz RDI Rio-Grande Workhorse. ${ }^{\mathrm{TM}}$ The data were averaged into four-ping ensembles and eventually grouped by grid unit to compare to the fish density data. ADCP data quality was examined and a small percentage of data cells were found to be contaminated by electronic interference, or "cross-talk" from an external source. The most likely source of the cross-talk was the acoustic signal from the downward-oriented split-beam transducer. The affected cells were examined and found to have low correlation values. Correlation is a measure of data quality that is an optional output from ADCP data files. It is a convenient filter when bad data cells are found. Correlation values of about 128 are considered excellent; we eliminated all data cells with correlation values lower than 110 . The average water velocity heading and magnitude were then used for analysis.

We did not find any spatial patterns of low-quality ADCP data. Our measurements were pooled for a large sample area including an average of 49 samples per data point (average samples/grid point/sample day). Again this was an attempt to determine the average flow condition for a large $(61 \mathrm{~m} \times 61 \mathrm{~m} \times 17 \mathrm{~m})$ water volume. The number of samples per grid point were sufficient to accomplish this task. 


\subsubsection{Fixed-Point Samples}

Mobile data were sampled with a 1200-kHz RDI Rio-Grande Workhorse ${ }^{\mathrm{TM}}$ and averaged into 25-ping ensembles. The 1200-kHz system also experienced cross-talk, which could be filtered. Unfortunately the $1200-\mathrm{kHz}$ system was unable to track the bottom for most of the fixed-point surveys at The Dalles due to its use of a higher frequency. Without the bottom tracking ability, the ADCP failed to provide the acoustic beam with a reference for its internal pitch/roll and heading sensors; thus, it was providing inaccurate heading information for the water flow vectors. We therefore assigned the nearest mobile grid to each of the fixed points in order to provide a directional measure of water velocity that could be compared to fish movement, where the greatest distance between mobile grid point and fixed point was $58 \mathrm{~m}$. Points taken that were sampled by the mobile boat were still accurate, since that vessel was equipped with the $600-\mathrm{kHz}$ model.

\subsection{Project Operations}

Total project operations for The Dalles Dam for each of the sample days is displayed in Figure 2.13. The graph shows that springtime discharges were higher than summer discharges, with the flow leveling off around July 10. The spill discharge was consistently about $40 \%$ of total project discharge.
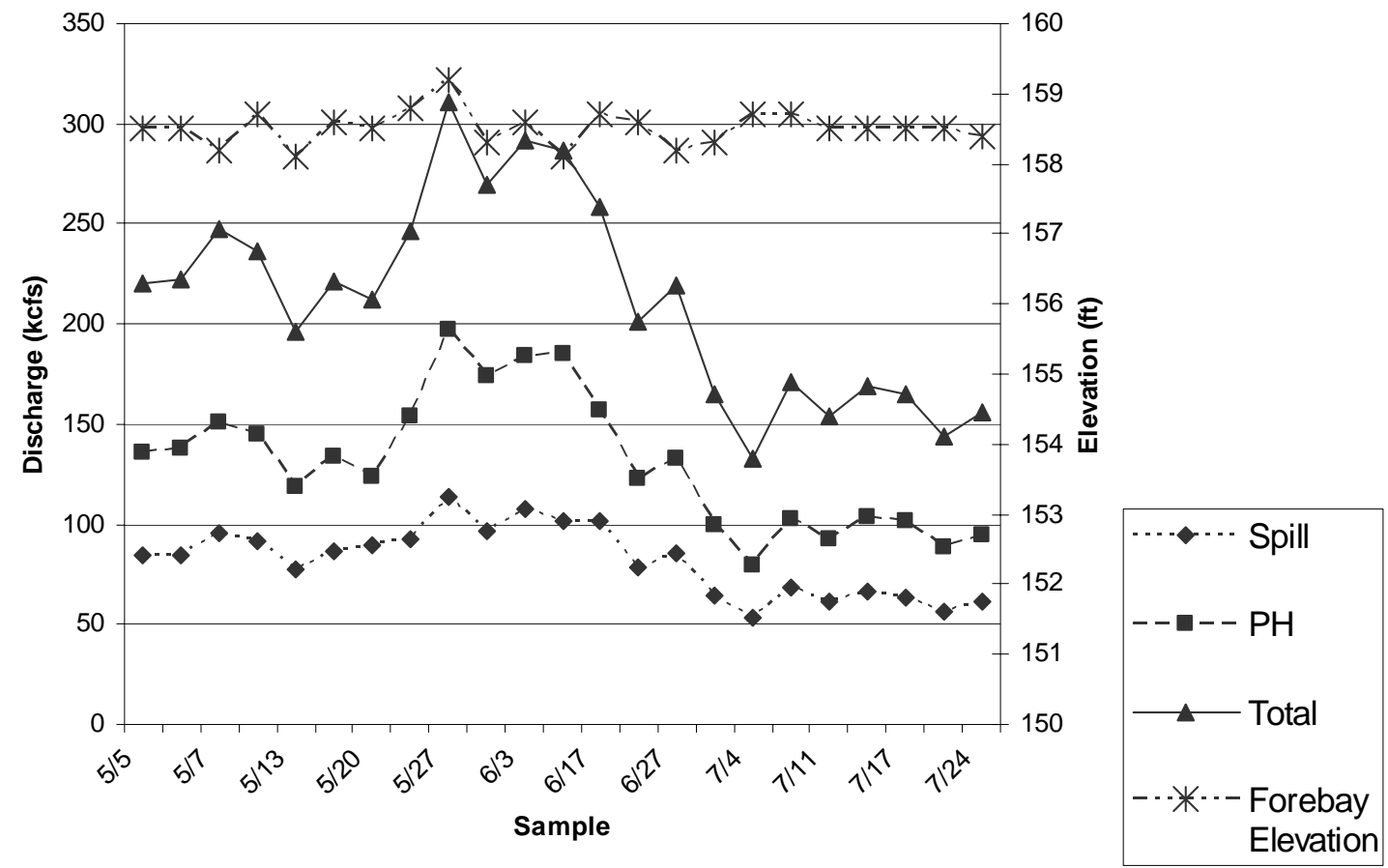

Figure 2.13. Total project flow (spill and turbine) and forebay elevation shown for each of the sampling periods in 2003. 


\subsection{Smolt Passage during Study Period}

The spring and summer outmigration periods were primarily delineated by the presence or absence of subyearling Chinook salmon. The spring outmigration period from April to early June was distinguished by the diversity of species composition with juvenile sockeye, yearling Chinook, coho, and steelhead migrating during this time period (Figure 2.14). Their migration past The Dalles Dam was nearly complete by mid-June, when the sub-yearling Chinook salmon were traveling downstream. The results section of this report displays data on the distribution of fish in categories based on spring and summer periods. In summer the majority of hydroacoustic echoes of small fish would likely be from subyearling Chinook, and in the spring the echoes sampled would be a mix of juvenile salmonids.

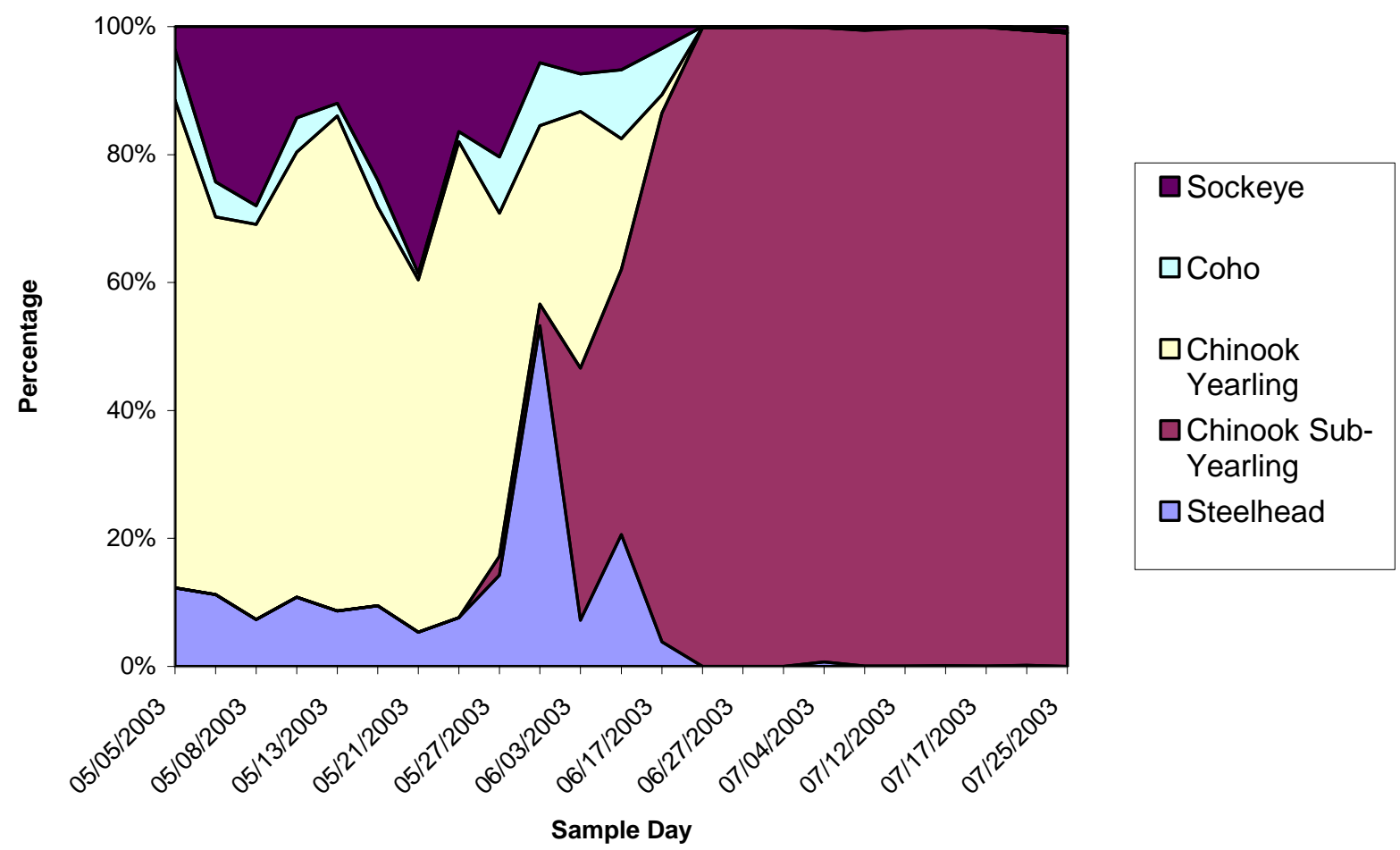

Figure 2.14. The percent of smolt passage by species, provided by the FishPassage Center and taken from the smolt passage index at the Juvenile Bypass Facility at John Day Dam for each day sampled. 
Distribution and Flux of Fish in the Forebay of The Dalles Dam in 2003 


\subsection{Results}

The results for this investigation are presented in two parts. The first was an analytical approach that was conducted by Skalski and Dillingham and sought to relate the distribution of smolt-sized fish to the hydrologic and bathymetric data. This analysis is described in Appendix A. The second was primarily descriptive where we displayed the flow environment, the distribution of fish, and the flux of fish to 1.8 km upstream of The Dalles Dam spillway. The descriptive data are presented in Chapter 3. With the descriptive approach we produced maps of fish distribution for every sample period and divided the distributions by fish size-class where large fish were classified as targets $>=-34 \mathrm{~dB}$ ref $\| 1 \mu \mathrm{PA}$, for spring and summer samples, and smolt-sized fish were classified as targets $<-34 \mathrm{~dB}$ ref $\| 1 \mu \mathrm{PA}$ for spring samples and $=<-45 \mathrm{~dB}$ ref || $1 \mathrm{uPA}$ for summer samples. These distribution maps are displayed as larger format maps in Appendices B, C, D, and E.

Comparisons of the fish distributions were done by diel period and season and are displayed in Appendix F. The vertical distribution of the fish is summarized by sampling period and location and is displayed in Appendix G. And finally, the flux of fish and the relation of fish movement past fixed points to the flow at those points is summarized in Appendices $\mathrm{H}$ and I. The results displayed in this section are summaries of the flow, lateral, and vertical fish distributions, and fish flux. All are combined into four categories that describe each diel period and sampling period and correspond to spring day, spring night, summer day, and summer night. These categories have been used in prior research investigations of fish distribution at The Dalles Dam (Ploskey et al. 2001b). Also, the species composition of outmigrating juvenile salmon for the spring and summer was markedly different, making them distinct populations. The forebay flow environment is described first to provide a backdrop for comparison to the fish distributions.

\subsection{Flow}

Flow was summarized as the mean water-column velocity for each season/diel category and is displayed as the mean of all mobile ADCP samples taken during the corresponding time periods. The pattern of flow (direction and relative velocity magnitude) in The Dalles Dam forebay was similar for each category although the relative velocity magnitude ${ }^{a}$ for summer flow was generally less than for spring flow by location (Table 3.1, Figures 3.1-3.4). Velocity magnitude was relatively higher in areas adjacent to the powerhouse across to the Washington shore, as well as in the area directly upstream of Spill Bays 1 through 10. The area upstream of the powerhouse that comprised the deepest region of the forebay had lower-velocity magnitudes than adjacent regions. Shallow outcroppings upstream of the deep basin typically had relatively high mean water-column velocity magnitudes. The direction of flow was also similar for all categories with the majority of flow vectors that were upstream of the powerhouse having a

\footnotetext{
${ }^{a}$ Velocity magnitude is the square root of the sum of squared velocity vector components $\mathrm{u}, \mathrm{v}$, and $\mathrm{w}$.
} 
heading that was parallel to the main channel. The majority of water velocity vectors then changed heading and pointed toward the powerhouse at the east end and continued to point toward the powerhouse for the downstream length of the powerhouse. The velocity heading was more perpendicular to the powerhouse as distance to the powerhouse decreased.

Table 3.1. Mean, minimum, and maximum water velocity magnitude for ADCP measurements taken during spring day, spring night, summer day, and summer night samples.

\begin{tabular}{|r|c|c|c|c|}
\hline & \multicolumn{4}{|c|}{ Velocity Magnitude (cm/s) } \\
\cline { 2 - 5 } & Spring Day & Spring Night & Summer Day & Summer Night \\
\hline Mean & 40.8 & 39.6 & 31.3 & 28.7 \\
\hline Minimum & 6.1 & 7.1 & 6.5 & 3.5 \\
\hline Maximum & 76.1 & 70.4 & 66.6 & 77.0 \\
\hline
\end{tabular}

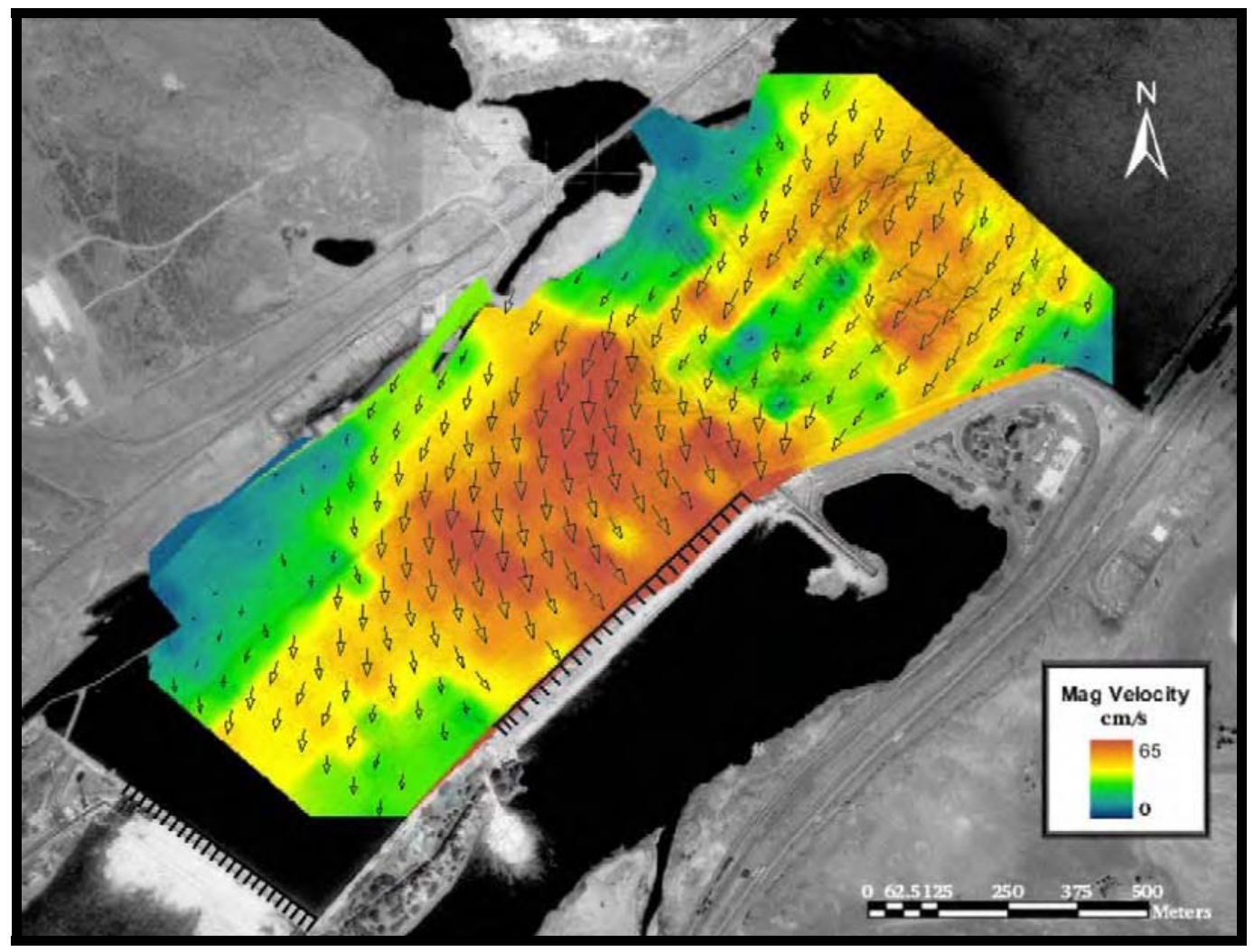

Figure 3.1. Mean water-column direction and magnitude for ADCP-measured velocities in the forebay of The Dalles Dam during spring daytime samples. Arrow size is a function of velocity magnitude and velocity magnitude increases from blue to orange color hues. The bathymetric contour is shown in the background. 


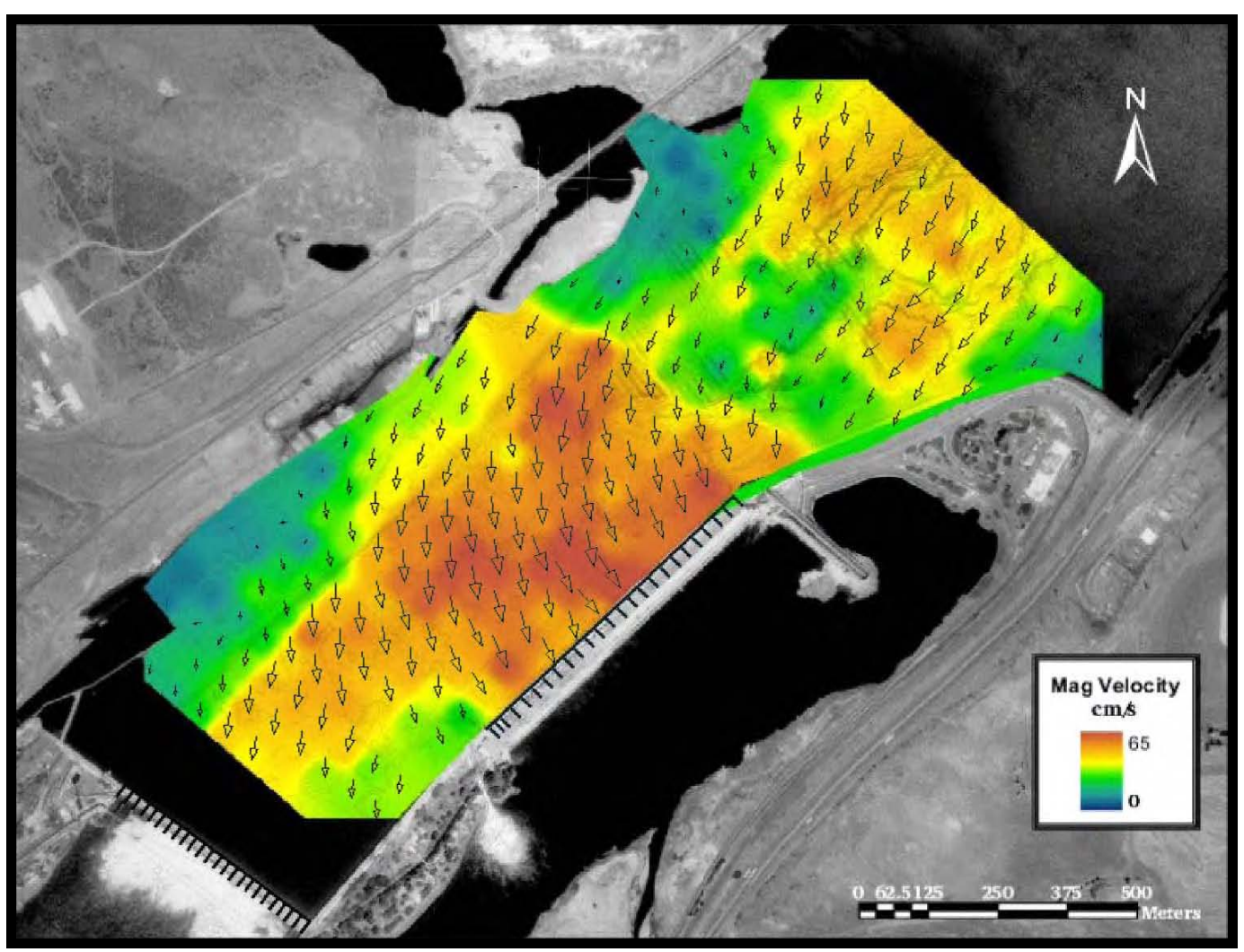

Figure 3.2. Mean water-column direction and magnitude for ADCP-measured velocities in the forebay of The Dalles Dam for spring nighttime samples. Arrow size is a function of velocity magnitude and velocity magnitude increases from blue to orange color hues. The bathymetric contour is shown in the background. 


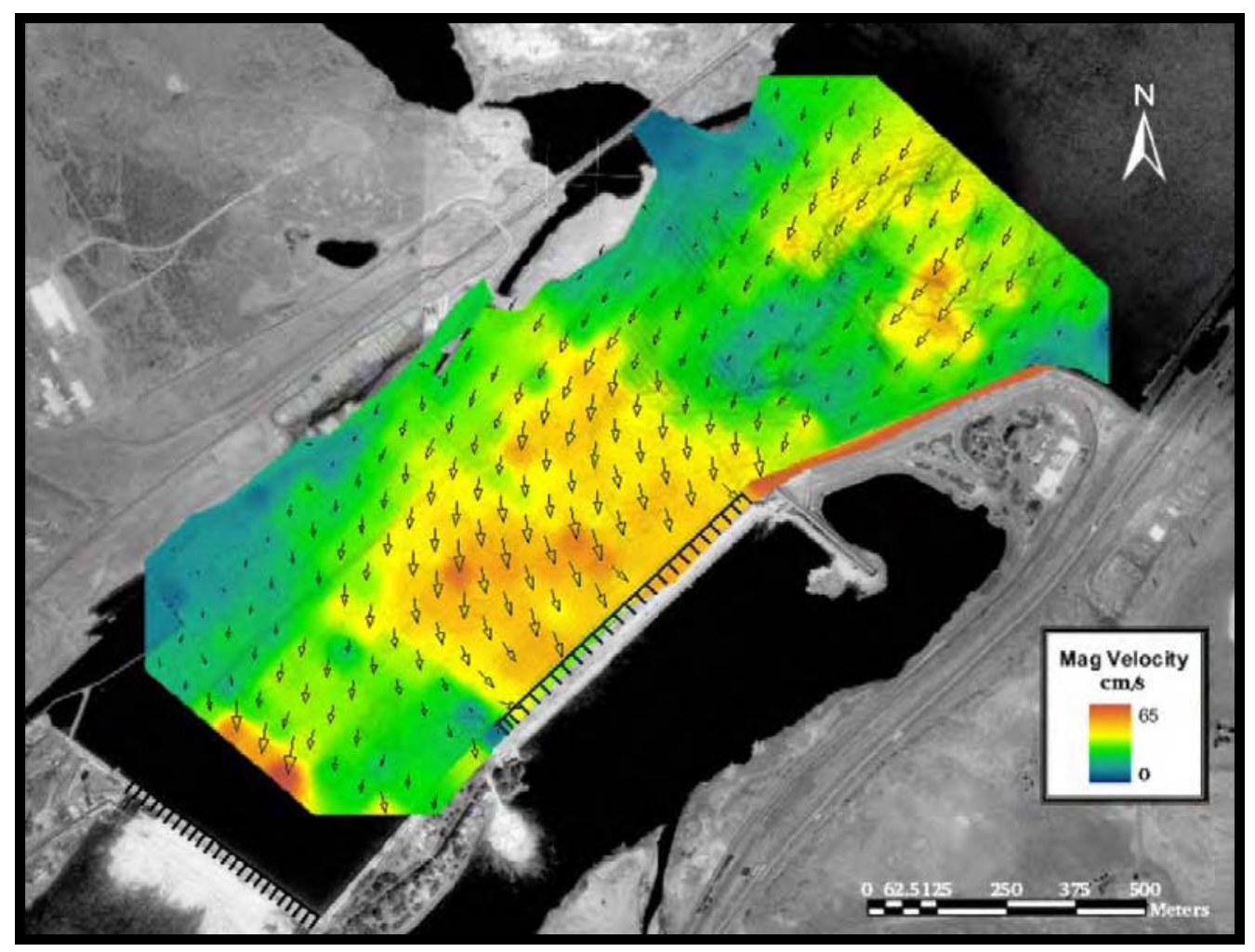

Figure 3.3. Mean water-column direction and magnitude for ADCP-measured velocities in the forebay of The Dalles Dam for summer daytime samples. Arrow size is a function of velocity magnitude and velocity magnitude increases from blue to orange color hues. The bathymetric contour is shown in the background. 


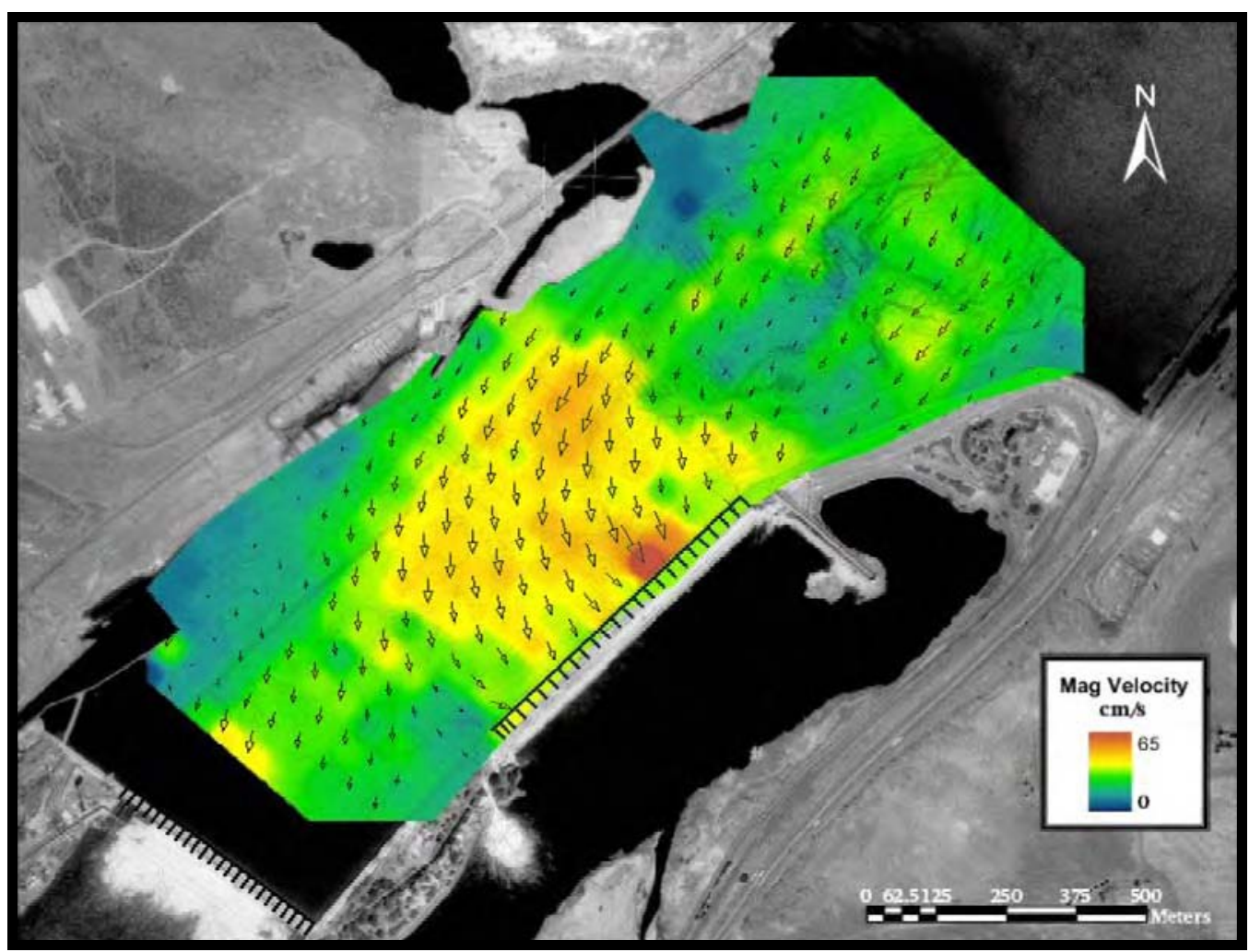

Figure 3.4. Mean water-column direction and magnitude for ADCP-measured velocities in the forebay of The Dalles Dam during summer nighttime samples. Arrow size is a function of velocity magnitude and velocity magnitude increases from blue to orange color hues. The bathymetric contour is shown in the background.

\subsection{Lateral Distributions Summarized by Sample Period}

The lateral distribution of smolt-sized fish was summarized by category for Figures 3.5 to 3.12. The distributions shown were the mean values of each grid point that was sampled a minimum of three times during the time period that defined each category (spring day, spring night, summer day, and summer night). Describing the spring daytime samples from upstream to downstream, the distribution of fish showed higher concentrations of smolt-sized fish in the main river channel (thalweg), on the north-east side of the river, and following to the south end of the river channel toward the east end of the powerhouse. Areas adjacent to the sluiceway also had high concentrations of smolt-sized fish. Lower densities of smolt-sized fish were seen at the shallower outcropping mid-channel on the upstream portion of the sample, as well as in the majority of water on the north side of the channel.

Spring nighttime samples had similar distributions of smolt-sized fish, although higher densities of fish were seen on the north side of the channel nearest the spillway, and the density of smolt-sized fish was 
more evenly distributed along Main Units 1 through 7 in contrast to the high concentration seen adjacent to the sluiceway during spring daytime samples. The density of smolt-sized fish adjacent to the powerhouse units had higher concentrations of fish distributed near the fish units and Main Units 1 through 4 (Figure 3.6) and a relatively consistent density of fish adjacent to the remaining turbine units. Spring nighttime densities also showed a peak in areas adjacent to the fish units and Main Units 1 through 4 but had higher densities of smolt-sized fish adjacent to Main Units 15 to 18 and 21 and 22 on the east side of the powerhouse. Variations in smolt-sized fish distributions can be seen for individual sampling days in Appendix D.

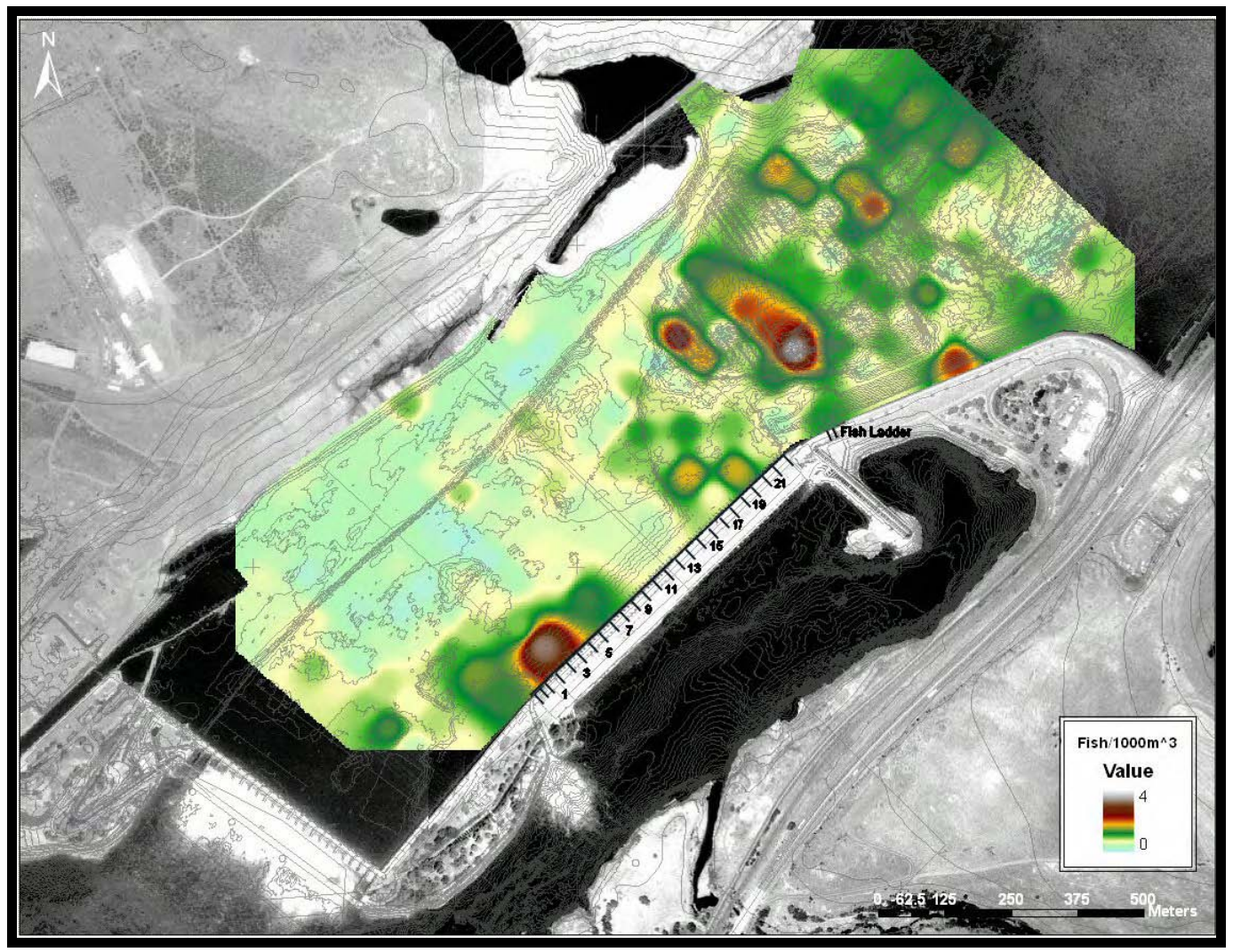

Figure 3.5. Mean smolt-sized fish density for spring daytime mobile (<-34 dB) samples. Densities were interpolated between grid points, where each grid was sampled between three and six times during spring daytime samples. The bathymetric contour is shown in the background. 


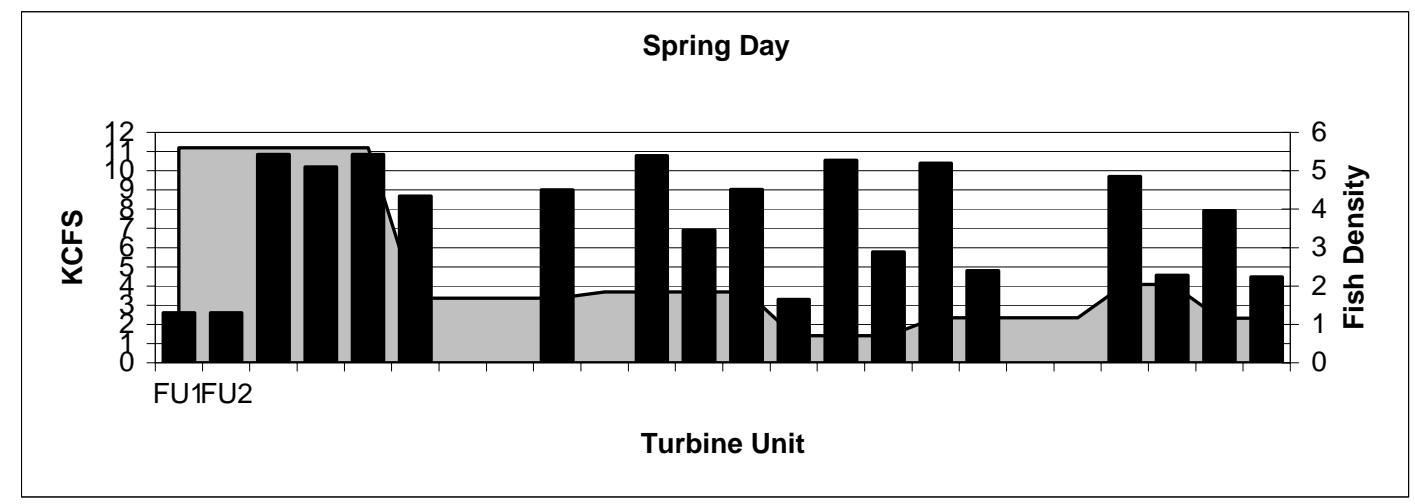

Figure 3.6. Mean turbine unit operations (black bars) in $1000 \mathrm{ft} / \mathrm{s}$ increments for all samples during spring day plotted against the smolt-sized fish density per $1000 \mathrm{~m}^{3}$ (gray area) within $60 \mathrm{~m}$ of each turbine unit.

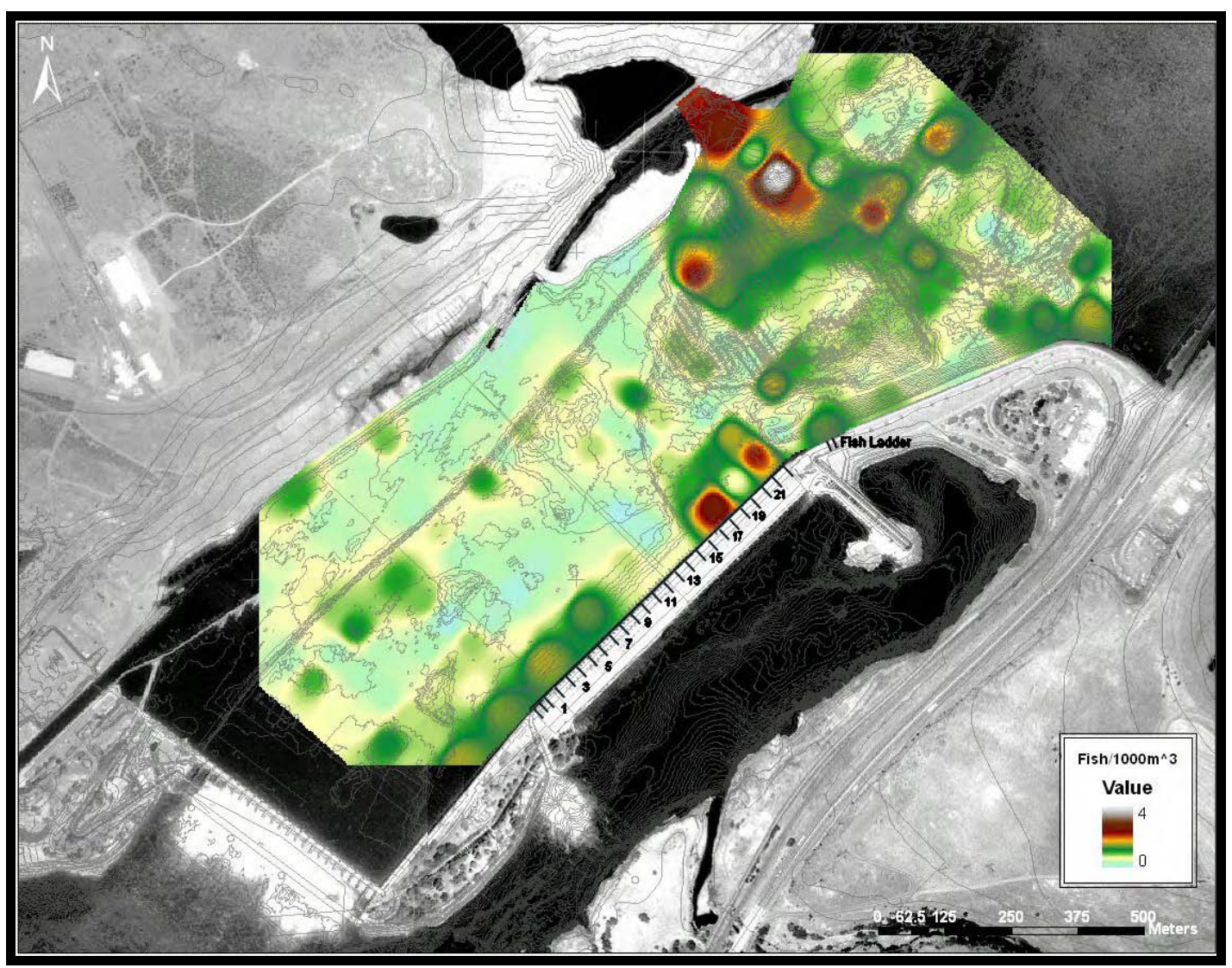

Figure 3.7. Mean smolt-sized fish density for spring nighttime mobile samples $(<-34 \mathrm{~dB})$. Densities were interpolated between grid points, where each grid was sampled between three and six times during spring nighttime samples. The bathymetric contour is shown in the background. 


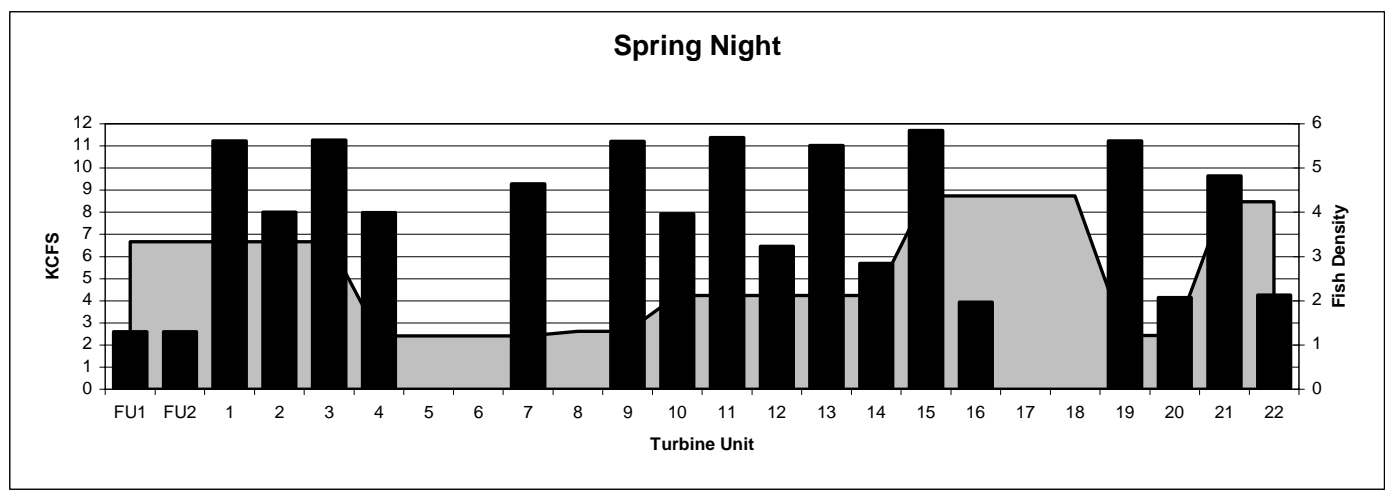

Figure 3.8. Mean turbine unit operations (black bars) in $1000 \mathrm{ft} / \mathrm{s}$ increments for all samples during spring night plotted against the smolt-sized fish density per $1000 \mathrm{~m}^{3}$ (gray area) within $60 \mathrm{~m}$ of each turbine unit.

Summertime samples had similar distributions to springtime samples, although the scale for fish densities was adjusted down in order to show the relative differences of fish density in the forebay at The Dalles Dam, because we measured a less dense population of smolt-sized fish in the summertime. Springtime samples had a value of four fish/1000 $\mathrm{m}^{3}$ as the upper limit for displaying those values, and summertime samples had three fish/1000 $\mathrm{m}^{3}$ set as the upper limit for display purposes.

Summer daytime samples showed higher densities of smolt-sized fish in the thalweg, within the northern and southern channels upstream of the powerhouse and then again along the upstream face of the powerhouse. Higher densities were observed in summer daytime hours than during nighttime hours. There were also higher densities of smolt-sized fish in the northern portion of the channel up-river from the spillway in the day than at night.

An observable difference was noticed in the region adjacent to the fish units and sluiceway when spring fish density distributions were compared to summer fish density distributions. The density of fish was greater in areas adjacent to the sluiceway in the springtime than in the summertime. The density of summer smolt-sized fish along the powerhouse was less for nighttime samples than daytime samples with only one remarkable spike in density distribution in front of Main Units 19 and 20 for the summer daytime samples. The density of fish adjacent to other turbine units was fairly constant for both summer daytime and nighttime samples. 


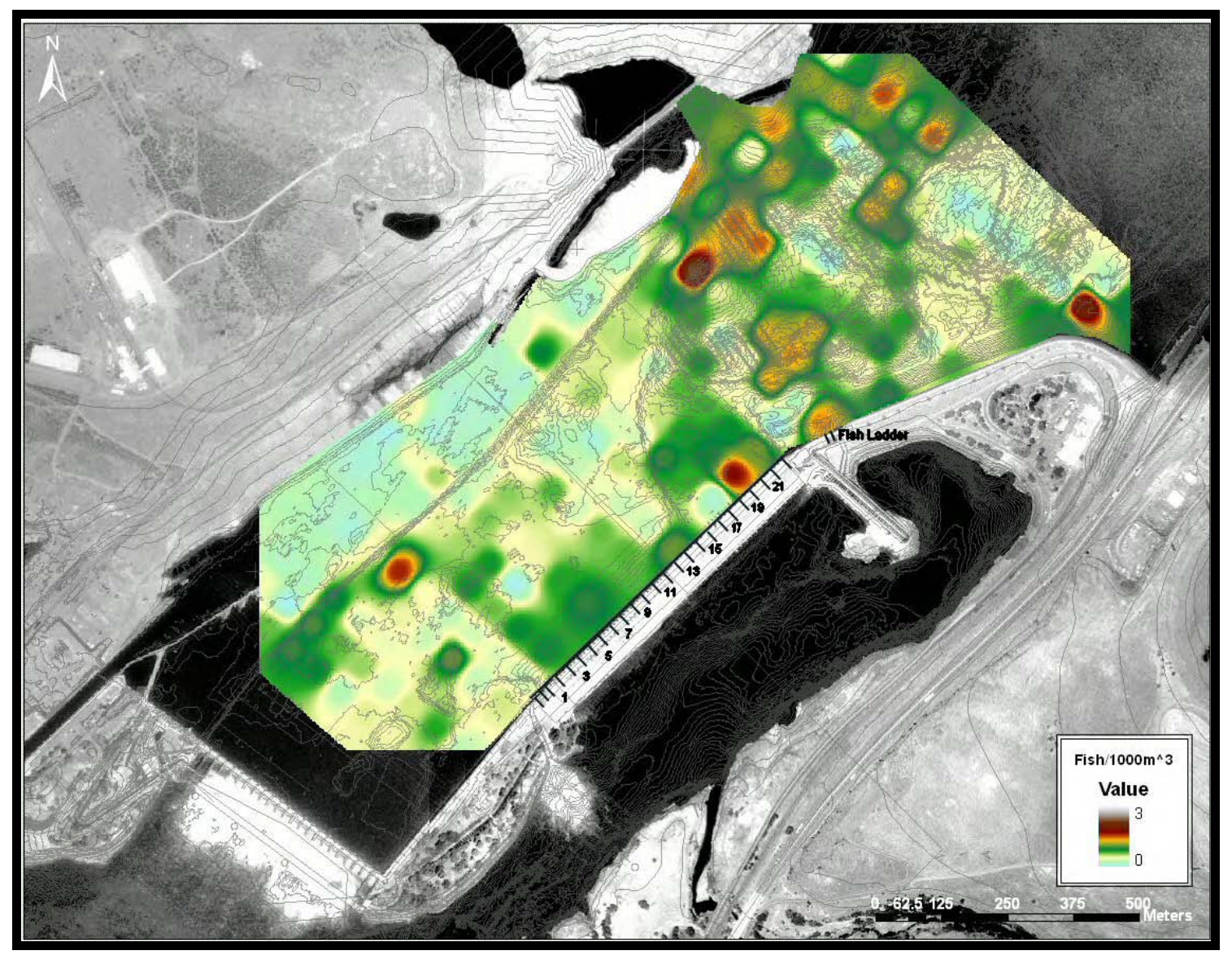

Figure 3.9. Mean smolt-sized fish density for summer daytime mobile samples $(<-45 \mathrm{~dB})$. Densities were interpolated between grid points, where each grid was sampled between three and six times during summer daytime samples. The bathymetric contour is shown in the background.

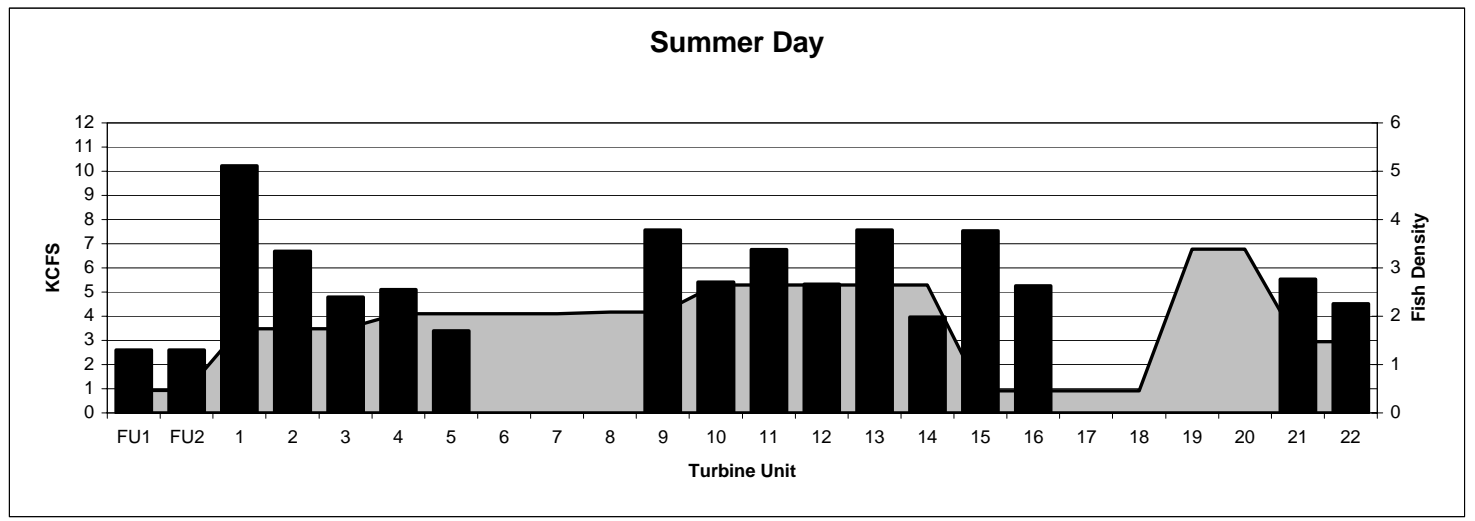

Figure 3.10. Mean turbine unit operations (black bars) in $1000 \mathrm{ft} / \mathrm{s}$ increments for all samples during summer day plotted against the smolt-sized fish density per $1000 \mathrm{~m}^{3}$ (gray area) within $60 \mathrm{~m}$ of each turbine unit. 


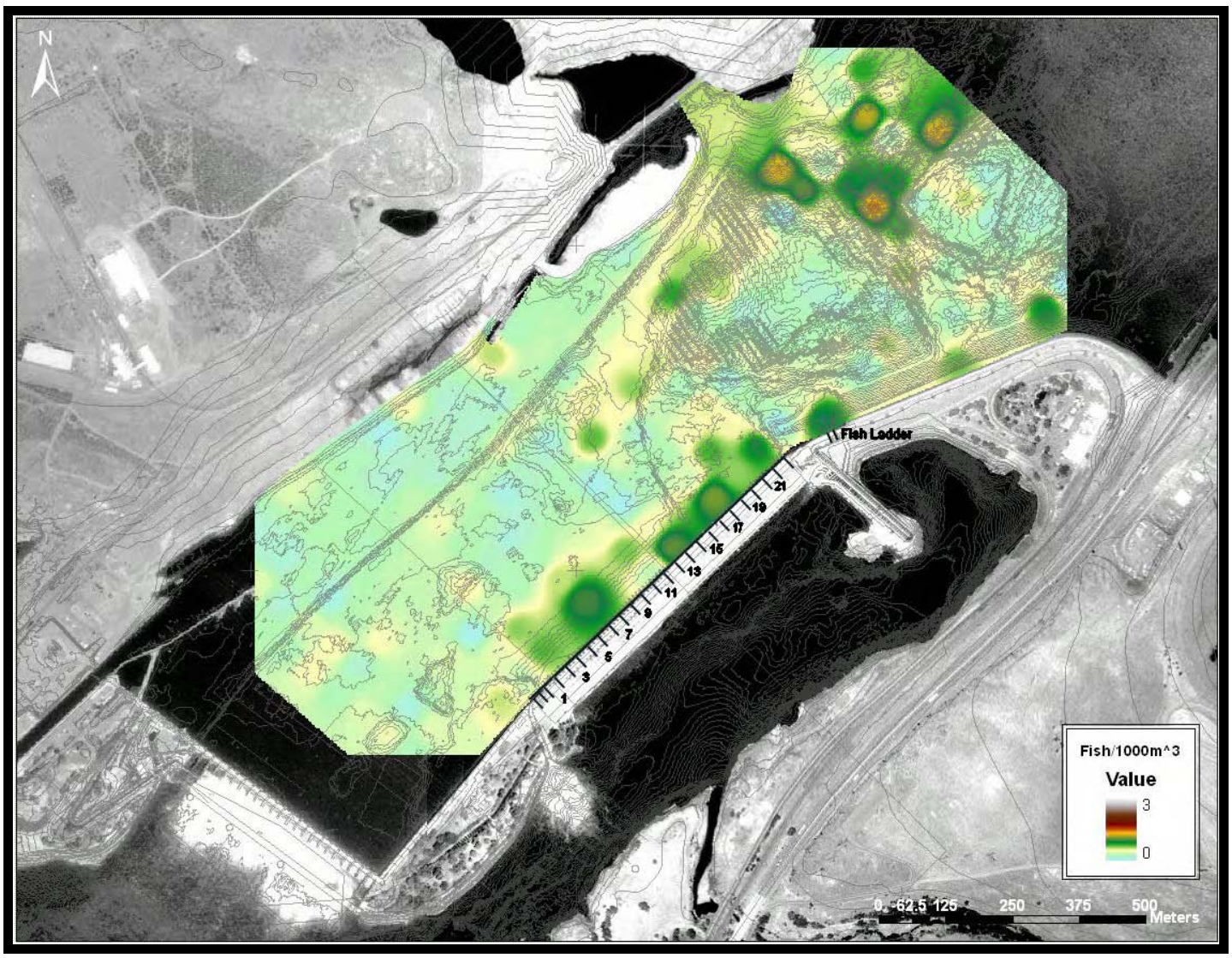

Figure 3.11. Mean smolt-sized fish density for spring daytime mobile samples $(<-45 \mathrm{~dB})$. Densities were interpolated between grid points, where each grid was sampled between three and six times during summer nighttime samples. The bathymetric contour is shown in the background.

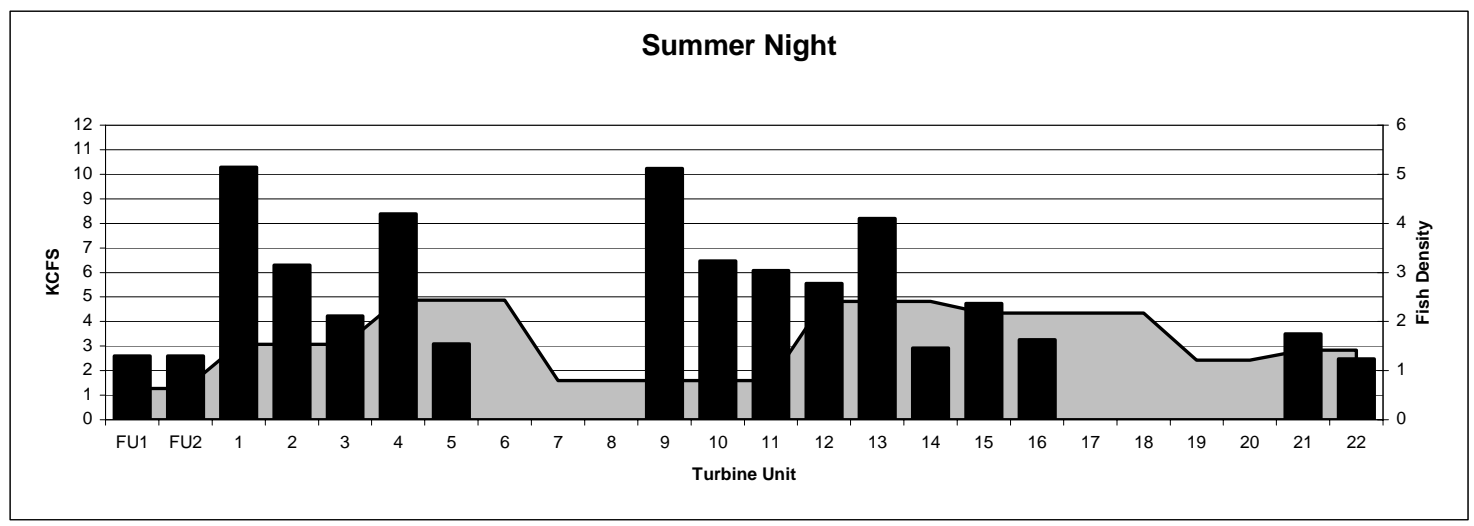

Figure 3.12. Mean turbine unit operations (black bars) in $1000 \mathrm{ft} / \mathrm{s}$ increments for all samples during summer night plotted against the smolt-sized fish density per $1000 \mathrm{~m}^{3}$ (gray area) within $60 \mathrm{~m}$ of each turbine unit. 
The observed density of smolt-sized fish in the forebay of The Dalles Dam was compared to the Smolt Passage Index (SPI) at John Day Dam to ascertain if the densities of fish observed in the forebay at The Dalles Dam corresponded to the number of juvenile salmon passing John Day Dam. This index did not take into account the influx of juvenile salmon from the Deschutes River, the only major tributary to the Columbia River between John Day Dam and The Dalles Dam forebay. Nevertheless we expected a high correlation between the SPI at John Day Dam and our measurements. We did observe high correlations with spring nighttime and summer daytime samples; however, spring daytime and summer nighttime samples did not correlate well with the SPI at John Day Dam (Table 3.2).

The best correlation of fish density in the forebay at The Dalles Dam and the SPI at John Day Dam during springtime was for juvenile salmon that were counted the day of the sample, suggesting a relatively short travel time between John Day Dam and The Dalles Dam for those fish. The summer daytime fish correlations were mixed, but the best correlation was between fish density and SPI for the day prior to our sample, suggesting a longer travel time to The Dalles Dam forebay for those fish.

However, we also tested how our estimates of fish density compared with the upstream migration of adult shad at The Dalles Dam and found some correlation. Their numbers passing The Dalles Dam for the day of the sample correlated best with the summer nighttime samples and increased the correlation value of fish density with the summer daytime samples. This suggests that adult shad likely influenced the summertime samples of fish density, even with thresholds set at $-45 \mathrm{~dB}$ ref || $1 \mu \mathrm{Pa}$. The effect was more influential for summer nighttime samples than daytime samples, in reference to those correlation values. The influx of juvenile salmon that originated from the Deschutes River watershed could have also contributed to the lower correlation observed for spring daytime and summer nighttime samples.

Table 3.2. Correlation values (r) of the comparison between the total smolt-passage index (SPI) at John Day Dam and the average smolt-sized fish density measured in the forebay at The Dalles Dam for each study period. Also included for summer samples was the total up-river migrating shad count at The Dalles Dam for the sample day. The average smolt-sized fish density for each sample at John Day Dam was correlated for the day of each sample, the day prior to each sample, and for 2 days prior to each sample. This was combined with the total shad count at the ladders of The Dalles Dam for summer samples. The best correlated results are shown in bold for each study period.

\begin{tabular}{|c|c|c|c|c|c|}
\hline & & Spring Day & Spring Night & Summer Day & Summer Night \\
\hline \multirow{3}{*}{$\begin{array}{l}\text { Day of } \\
\text { Sample }\end{array}$} & \multirow{3}{*}{$\begin{array}{r}\text { Smolt } \\
\text { Shad }+ \text { Smolt } \\
\text { Shad }\end{array}$} & 0.1831 & 0.7106 & 0.5049 & -0.7062 \\
\hline & & & & 0.6743 & -0.3743 \\
\hline & & & & 0.6737 & 0.2484 \\
\hline \multirow{2}{*}{$\begin{array}{l}\text { Day Prior to } \\
\text { Sample }\end{array}$} & \multirow{2}{*}{$\begin{array}{r}\text { Smolt } \\
\text { Shad }+ \text { Smolt }\end{array}$} & -0.2280 & 0.4184 & 0.6039 & -0.6379 \\
\hline & & & & 0.8001 & -0.1403 \\
\hline \multirow{2}{*}{$\begin{array}{l}2 \text { Days Prior } \\
\text { to Sample }\end{array}$} & \multirow{2}{*}{$\begin{array}{r}\text { Smolt } \\
\text { Shad }+ \text { Smolt }\end{array}$} & -0.1052 & 0.3561 & 0.5228 & -0.1774 \\
\hline & & & & 0.6455 & -0.0548 \\
\hline
\end{tabular}


In addition to summarizing the distribution of smolt-sized fish, we also summarized the distribution of larger-than-smolt-sized fish ( $>=-34 \mathrm{~dB} \|$ ref $1 \mu \mathrm{Pa}$ ), which can be found in Appendices $\mathrm{C}$ and E. Generally, the distribution of large fish was concentrated near the shorelines, adjacent to the upstream exits of the fish ladders, and at the shallow outcroppings that are mid-channel upstream of the deep basin (Figure 3.13). This distribution was fairly consistent throughout the season, with the exception of sample periods when large numbers of shad were passing The Dalles Dam on their way upstream. During these times, we observed high densities of large fish within the thalweg. Because we mapped the distributions of fish larger than smolt-sized as well as smolt-sized fish, we were able to compare the distributions of the two groups. In doing so we determined areas that had greater proportions of larger fish than smaller fish and vice versa.

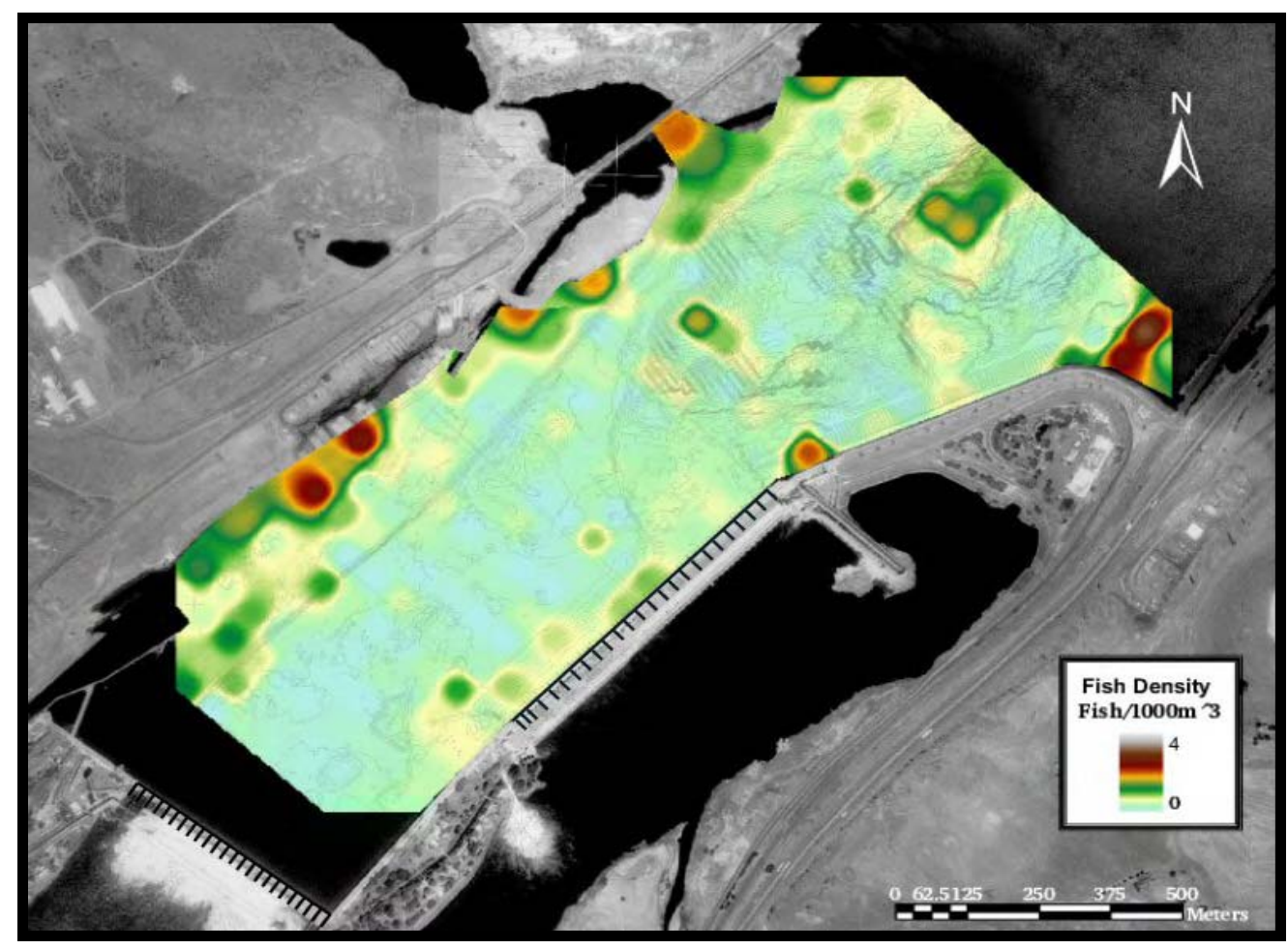

Figure 3.13. Mean large fish densities (targets $>=-34 \mathrm{~dB} \|$ ref $1 \mu \mathrm{Pa}$ ) for spring daytime samples. Densities were interpolated between grid points for all samples taken during that time period. The bathymetric contour is shown in the background.

The map on Figure 3.14 was generated by subtracting the relative proportion (\%) of larger fish from the relative proportion of smolt-sized fish to generate a distribution map that displays areas of higher concentrations of smolt-sized fish to large fish and visa versa. Larger fish were seen to have greater proportions distributed in shallow areas throughout the forebay, as well as outside the upstream exits to the fish ladders (orange hues). In contrast, the greater proportion of smolt-sized fish were observed in the main channel and in deeper areas of the river channel. 


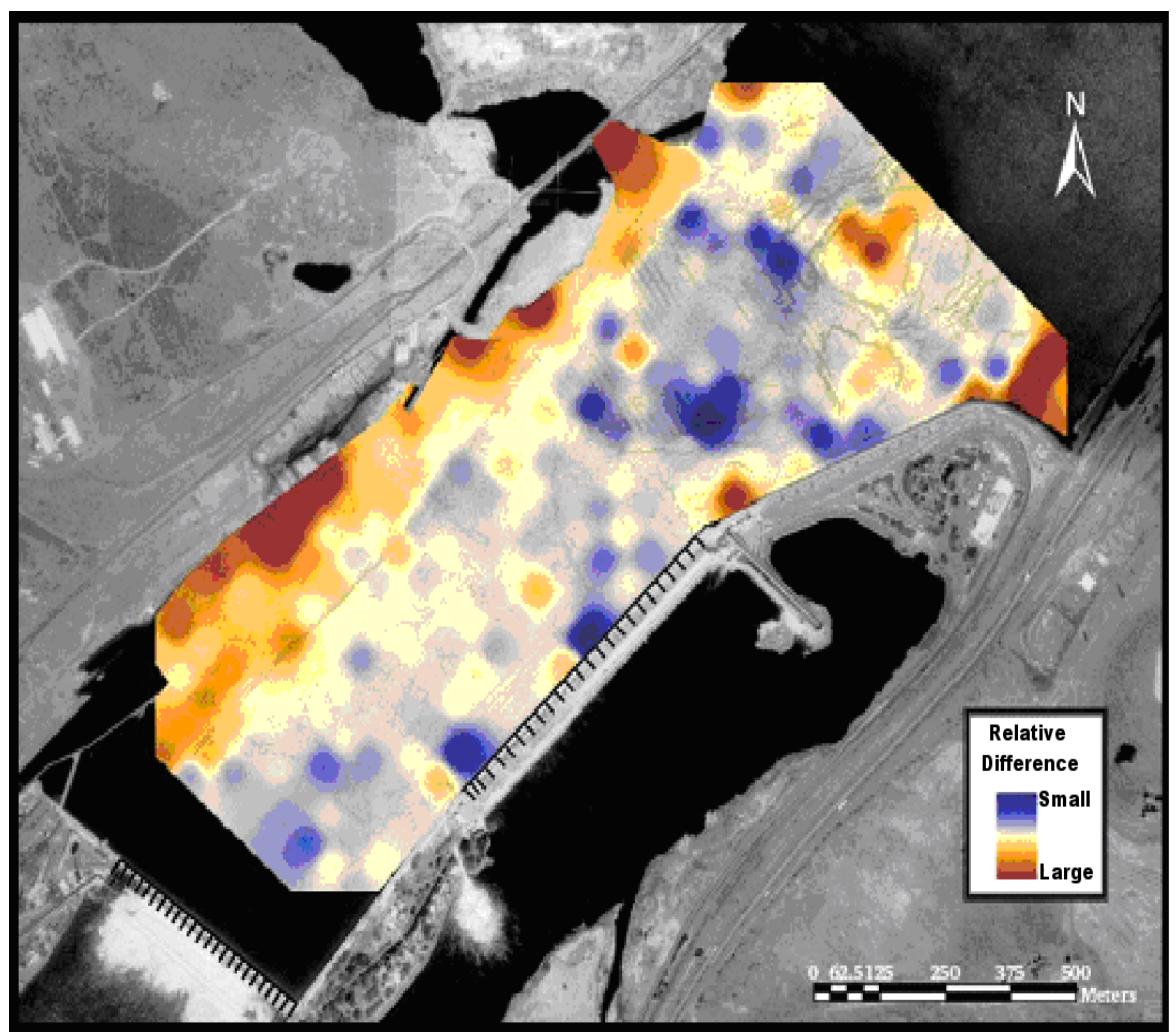

Figure 3.14. The distribution of large fish in relation to small fish for spring daytime samples. Areas with relatively high concentrations of large fish are orange in hue, and areas with relatively high concentrations of small fish are blue in hue.

\subsection{Vertical Distribution Summarized by Period}

The vertical distribution of smolt-sized fish was summarized by sample period (category). Spring nighttime fish were generally distributed lower in the water column than spring daytime fish (Figure 3.15). In contrast, summer nighttime fish were distributed higher in the water column than daytime fish. The majority of summertime fish were distributed higher in the water-column than springtime fish. In both spring and summer, the majority of fish were distributed in the upper $3.4 \mathrm{~m}$ of the water column for daytime and nighttime samples. 


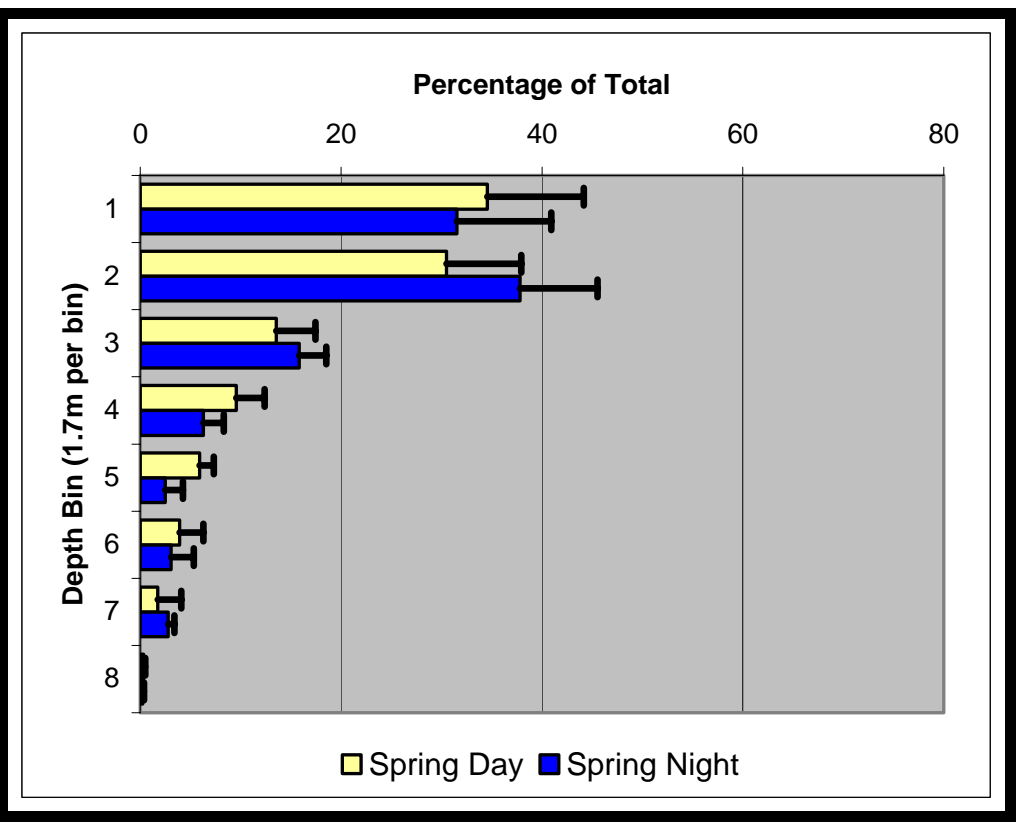

Figure 3.15. Mean vertical distribution of smolt-sized fish for spring daytime and spring nighttime samples. Error bars are the standard deviation of the sample.

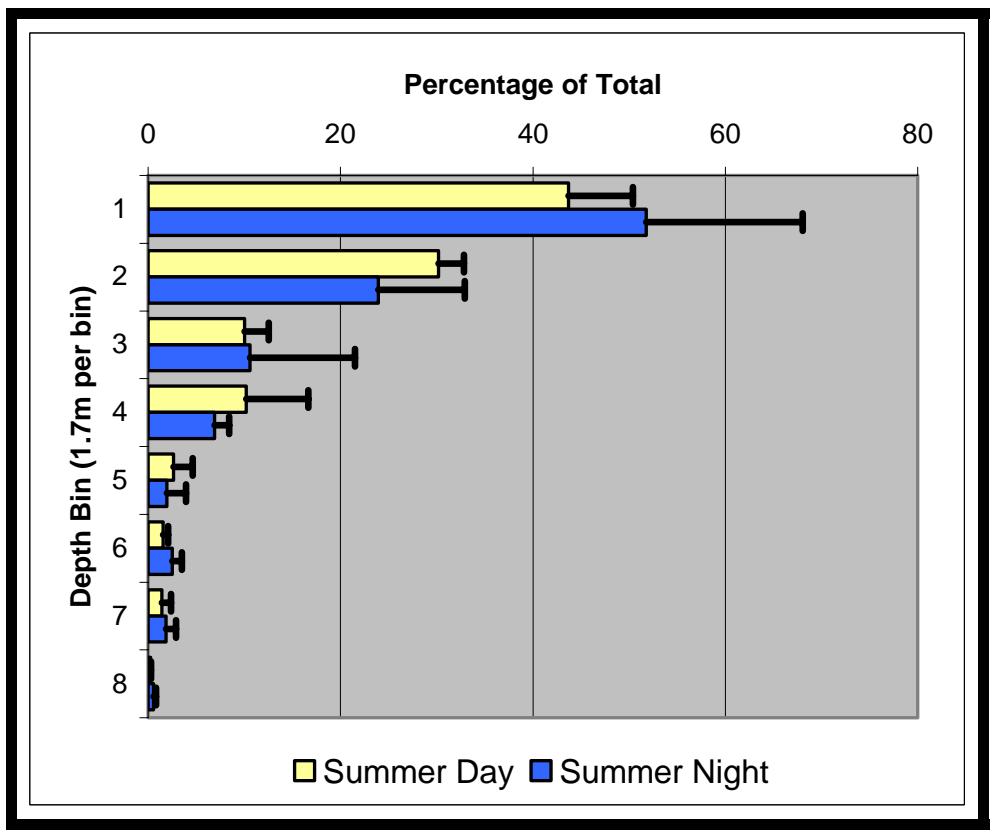

Figure 3.16. Mean vertical distribution of smolt-sized fish for summer daytime and summer nighttime samples. Error bars are the standard deviation of the sample. 
When we examined the vertical distribution of fish by location we found that smolt-sized fish for spring daytime samples were generally distributed shallower in the areas adjacent to the shorelines and deeper in the mid channel and near the sluiceway (Figure 3.17). Spring nighttime samples showed that the distribution of smolt-sized fish was higher in the water column than during daytime samples for all areas of the forebay. The mid-channel and upstream area still showed fish distributed higher in the water column, but overall, the fish were distributed higher in the water column regardless of location in the forebay for spring nighttime samples (Figure 3.18). Summer samples for day and night showed a similar vertical distribution of smolt-sized fish (Figures 3.19, 3.20). They were similarly distributed in all areas of the forebay except for the central channel near the upstream boundary of our sample and near the sluiceway where fish were distributed deeper in the water column.

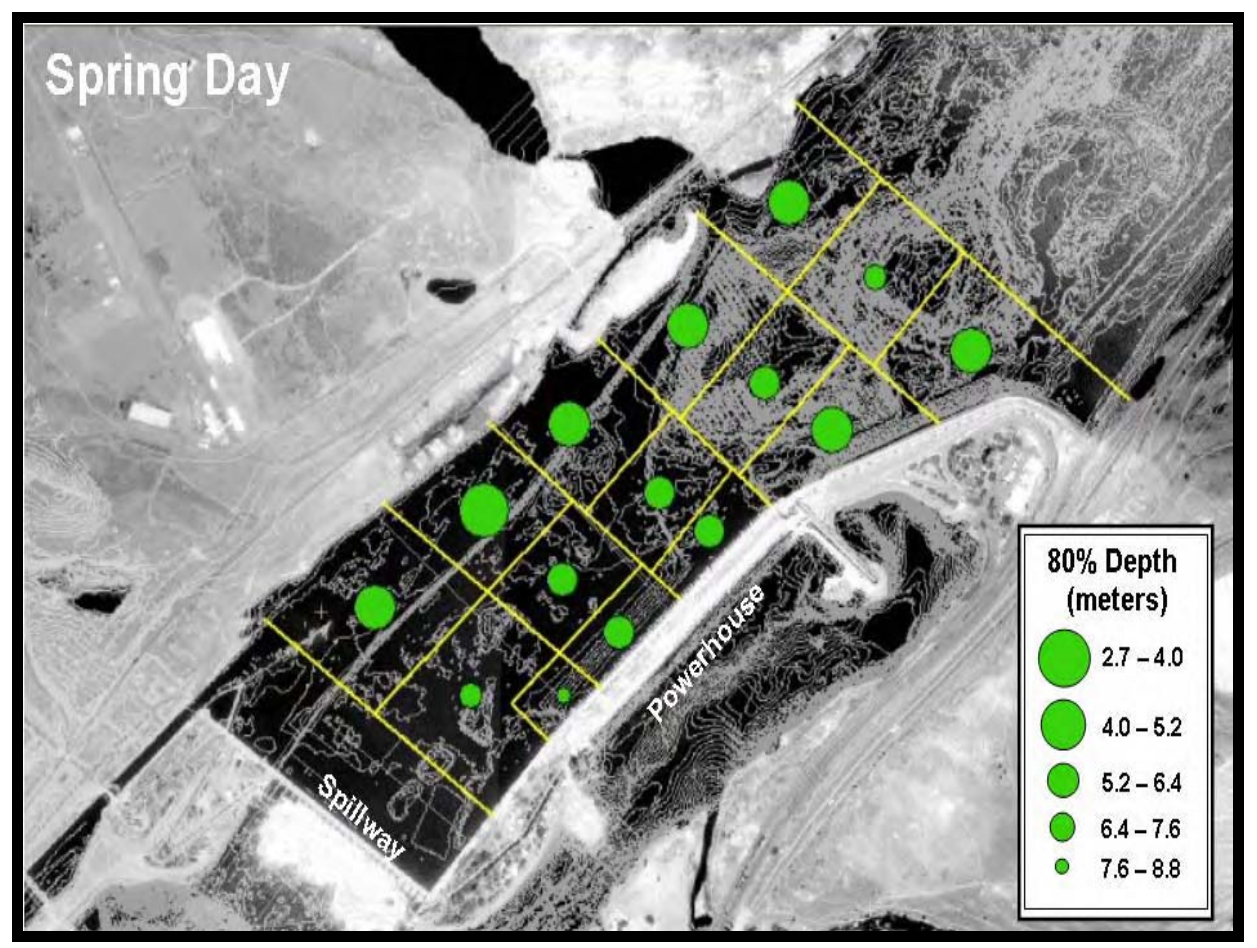

Figure 3.17. The depth that $80 \%$ of smolt-sized fish were above in the watercolumn for spring daytime samples. Circle size is a function of the $80 \%$ depth, where large circles indicate shallower distribution than the smaller circles. 


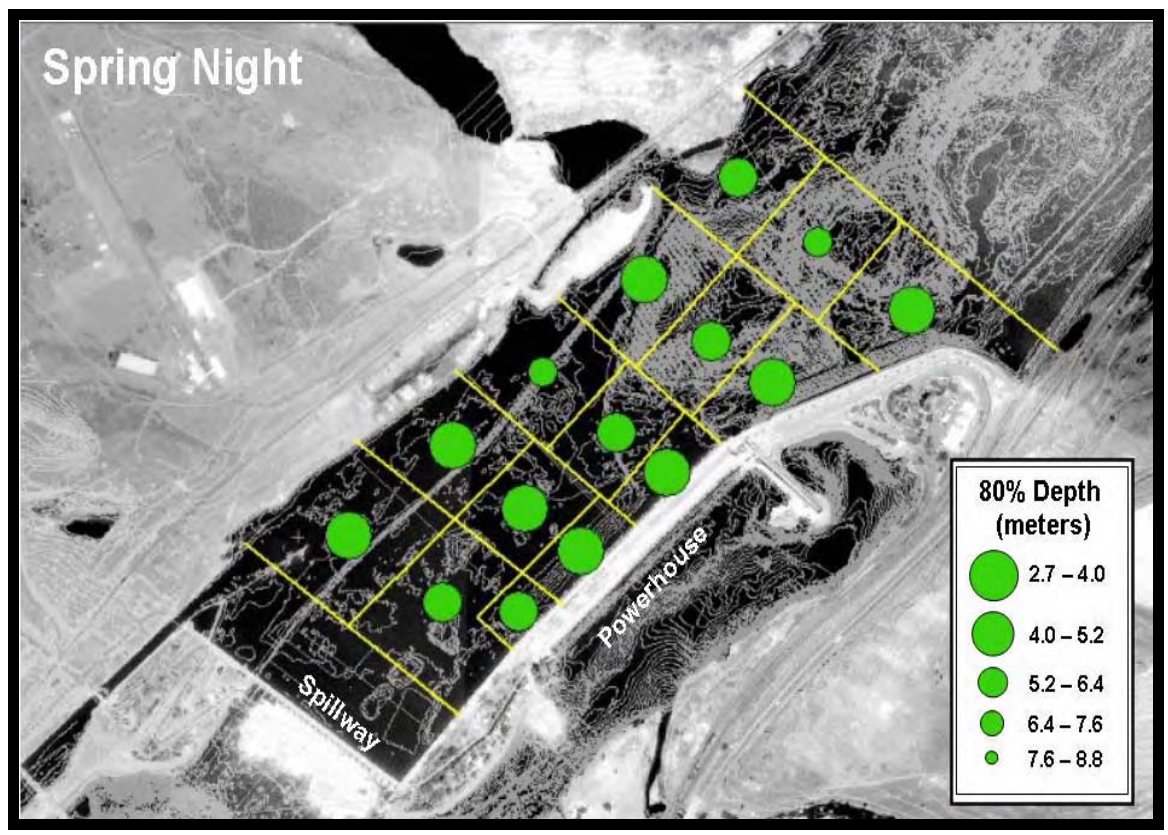

Figure 3.18. The depth that $80 \%$ of smolt-sized fish were above in the watercolumn for spring nighttime samples. Circle size is a function of the $80 \%$ depth, where large circles indicate shallower distribution than the smaller circles.

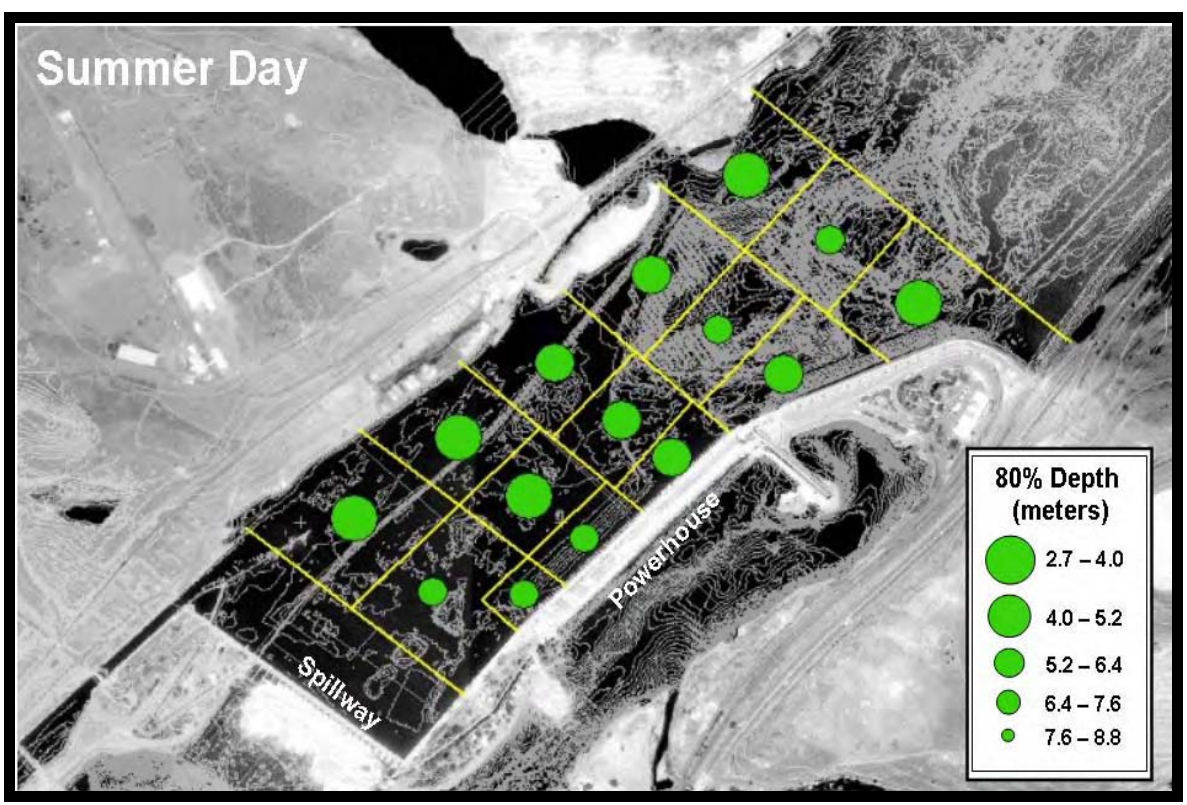

Figure 3.19. The depth that $80 \%$ of smolt-sized fish were above in the watercolumn for summer daytime samples. Circle size is a function of the $80 \%$ depth, where large circles indicate shallower distribution than the smaller circles. 


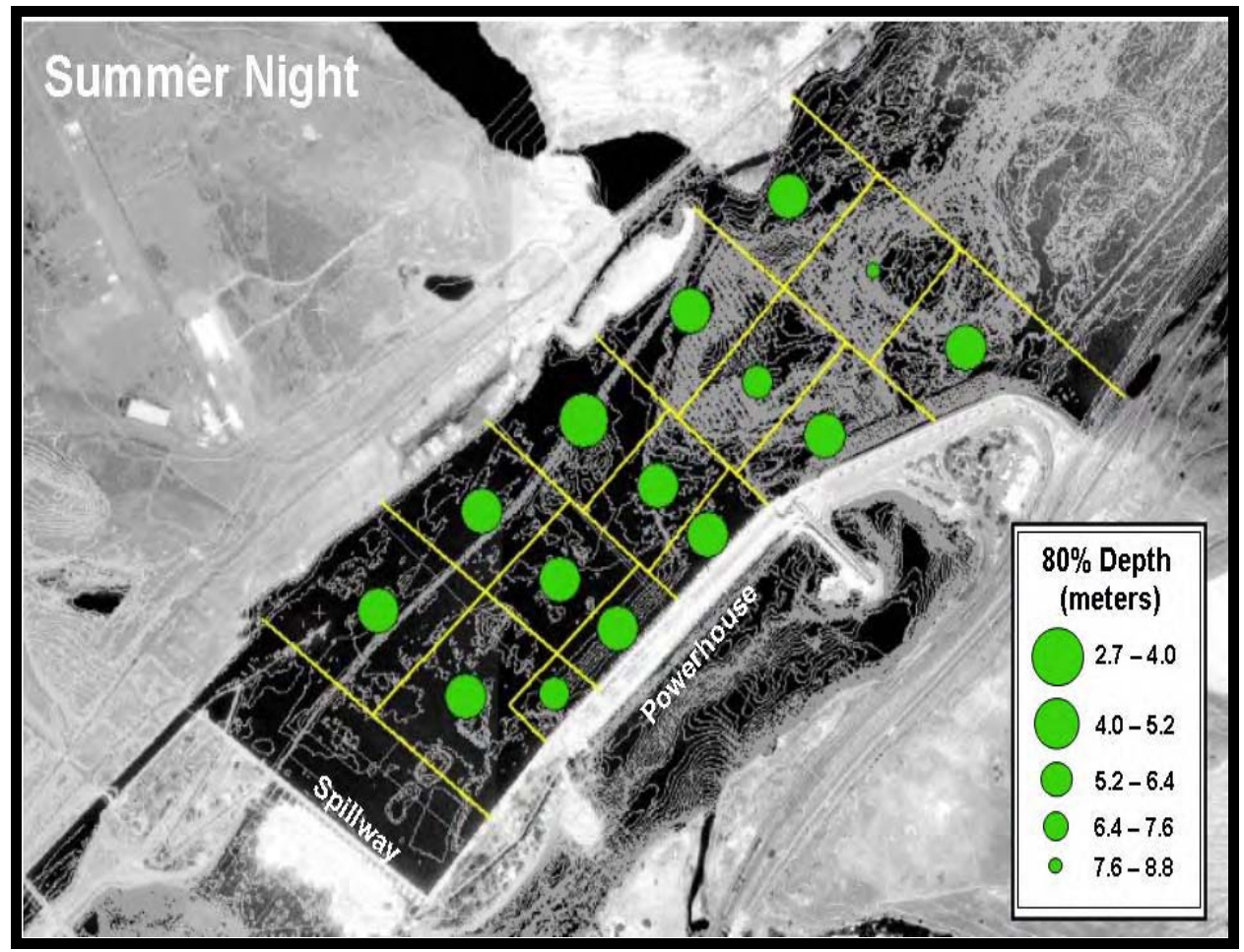

Figure 3.20. The depth that $80 \%$ of smolt-sized fish were above in the watercolumn for summer nighttime samples. Circle size is a function of the $80 \%$ depth, where large circles indicate shallower distribution than the smaller circles.

\subsection{Flux and Relative Movement of Smolt-Sized Fish}

Movement of fish was derived from fixed point data whereby the down-looking transducer provided all of the direction-of-travel data for smolt-sized fish, and the combined forward-looking and down-looking transducers provided the number of fish contacted over time (flux). All data for fixed points were displayed in four separate formats for the four sampling categories and are shown as large-format maps in Appendices $\mathrm{H}$ and $\mathrm{I}$. The formats represent the total flux of fish past fixed points over time (gross movement), the net upstream or downstream movement of fish, the net up-channel or down-channel movement of fish, and the distribution of movement at each fixed point. The spring daytime samples are shown in this section to discuss the meaning of the maps, as the large-format maps located in the appendices are better for viewing. All maps had a representative water velocity vector in $\mathrm{m} / \mathrm{s}$ plotted with the fixed point. The vector was the mean water-column velocity for the nearest sample taken from the mobile sampling boat. 


\subsubsection{Fish Flux}

We plotted the flux of fish as different sized circles at the position of each fixed-point sample, where the circle size was a function of the number of fish detected by all six transducers at that point over time. Spring daytime samples are shown in Figure 3.21; plots for other categories are given in Appendix I.

Spring daytime samples showed more fish contacted near the powerhouse and in the mid-channel in the center of the powerhouse compared to the other points. The central and most upstream point on the east end of the powerhouse had the highest flux of fish for the eastern most points (Figure 3.21). Spring nighttime samples had the most fish contacts over time at the point located in the north-east channel, as well as at the point closest to the powerhouse on the east end. All other points had similar fish flux values. We saw remarkably fewer fish at fixed points over time during summertime samples than during springtime samples. The maximum number of fish per minute changed from 15 smolt-sized fish/min in the springtime to five smolt-sized fish/min during summertime samples.

Summertime samples at fixed points differed somewhat from those in spring due to the inadvertent removal of fixed-point buoys along the north shore by barges. The fixed points that remained were mostly to the south of the center of the river channel. At those points, the number of fish contacts were highest at the points closest to the powerhouse on two downstream point lines for summer daytime samples, and in the center of the channel on the downstream most line. All other points for summer daytime samples had relatively few contacts for that time period. Summer nighttime samples had the most contacts nearest to the east end of the powerhouse and at the point closest to the south east shore and relatively few contacts for the remainder of the points. 


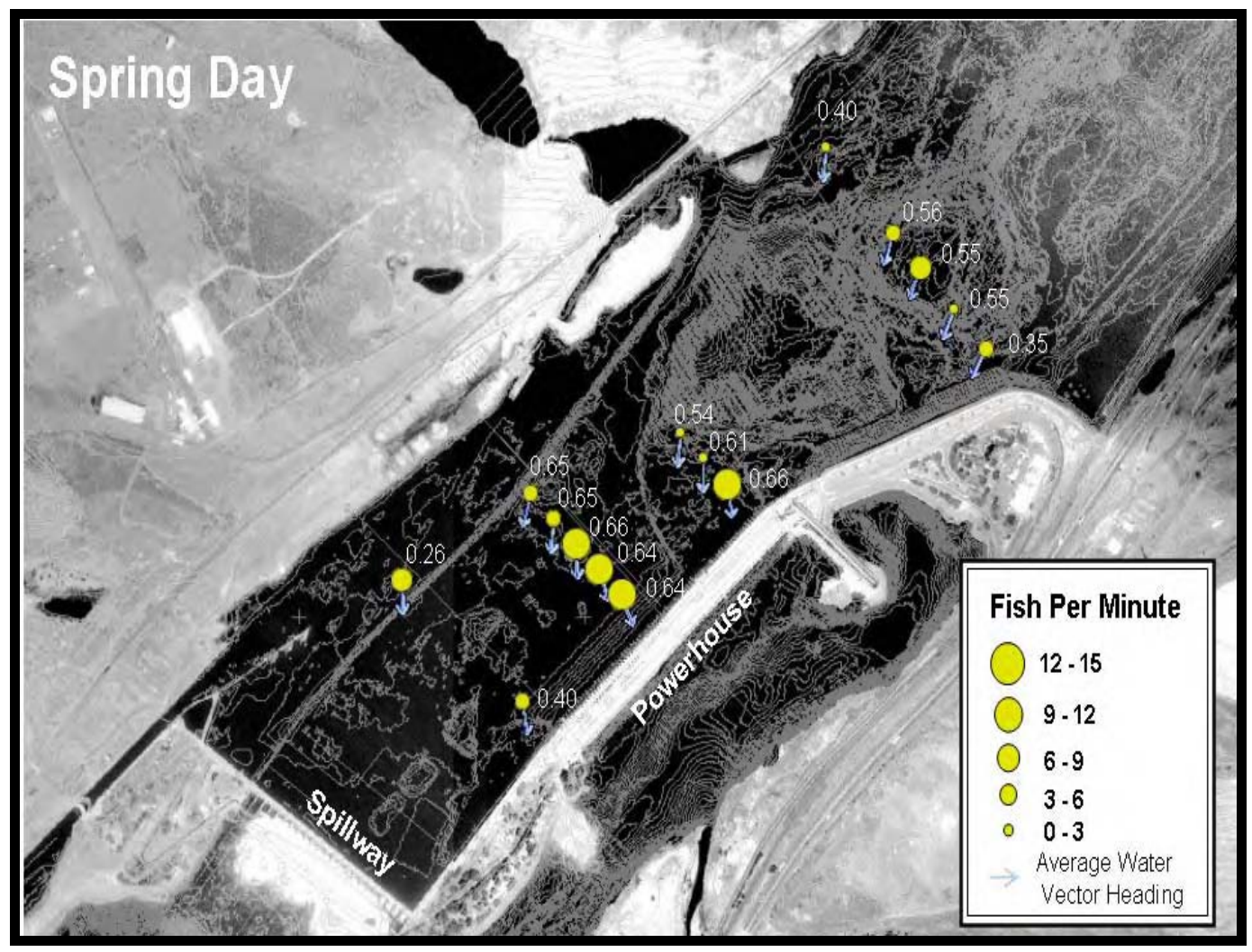

Figure 3.21. The number of smolt-sized fish contacted at each point per minute during spring daytime samples. Circles are located at fixed point surveys and have a size that is a function of the number of fish contacted at that point for all six transducers monitoring the site. Mean water-column velocity heading is shown in blue, and the water velocity magnitude value is displayed next to the point in $\mathrm{m} / \mathrm{s}$.

\subsubsection{Net Fish Movement}

The net movement of fish upstream or downstream was also determined at each fixed point (Figure 3.22). Spring daytime samples are shown in Figure 3.22, plots for other categories are given in Appendix H. Smolt-sized fish movement was determined from the down-looking split-beam data whereby a downstream fish was counted if the fish heading was within $\pm 90^{\circ}$ of the mean water vector, and an upstream fish was counted if the fish heading was within $\pm 90^{\circ}$ of the mean water vector $-180^{\circ}$. The difference of these two values determined the net movement of fish passed each point in the upstream or downstream direction. These figures are displayed in Appendix I. Spring daytime had a general net movement of smolt-sized fish in the downstream direction for the two most upstream point transects; however, the points west to the powerhouse showed an overall upstream movement of fish that was greatest in the center of the river channel. This followed with the spring nighttime samples, although we observed more fish moving in the downstream direction for the upstream two point transects, and the movement along the north side of the channel and central to the powerhouse showed more downstream 
movement. The location of points and net fish movement at those points for spring samples suggests a circulation of smolt-sized fish in the forebay whereby fish on the west end of the powerhouse are moving upstream and fish on the east end are moving downstream. Smolt-sized fish near the sluiceway had a net movement upstream for both spring daytime and nighttime.

For summer daytime samples, smolt-sized fish movement in the downstream direction was greatest in the line of points central to the powerhouse and close to zero net fish movement upstream or downstream for all other sample points. Summer nighttime data was sparse and did not show any remarkable patterns of movement.

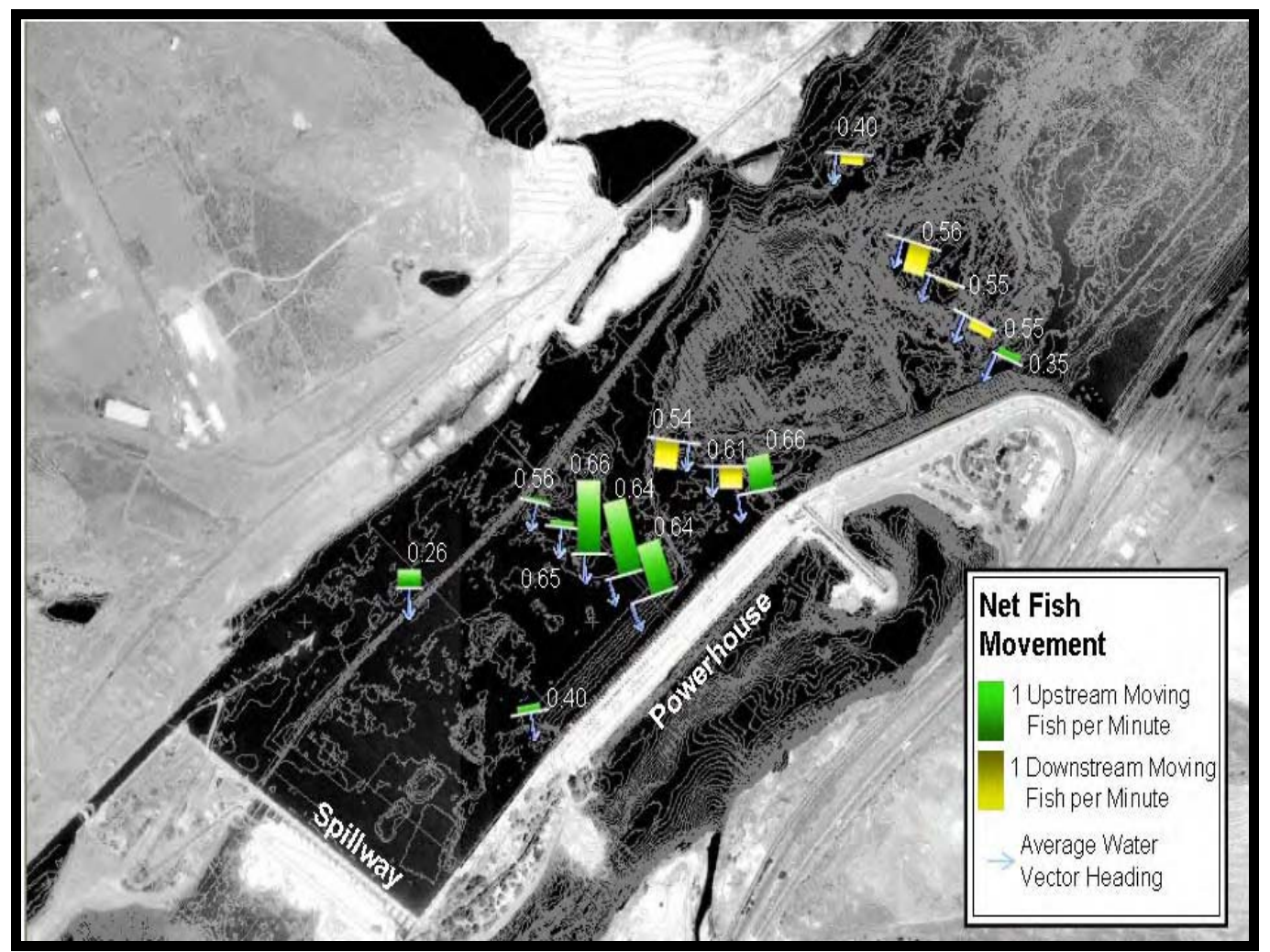

Figure 3.22. The net movement of smolt-size fish contacted at each point per minute during spring daytime samples relative to flow. Net movement downstream is displayed in yellow, and net movement upstream is green. Mean water-column velocity heading is shown in blue, and the water velocity magnitude value is displayed next to the point in $\mathrm{m} / \mathrm{s}$.

We also determined the movement of smolt-sized fish relative to the heading of the river channel, in order to ascertain how fish were moving with respect to the spillway direction. Spring daytime samples are shown in Figure 3.23, plots for other categories are given in Appendix H. For net small fish movement versus river channel, a similar calculation to that made for movement with respect to water heading was calculated using a channel heading of $225^{\circ}$. Movement patterns observed for the spring daytime, spring nighttime, and summer daytime samples were similar to those found for the net fish movement relative to water heading. Smolt-sized fish were generally moving southwest upstream of the east end of the 
powerhouse and northeast on the central to west-end of the powerhouse. On the north side of the channel, smolt-sized fish were moving toward the spillway during spring nighttime samples. Summer daytime samples showed a net fish movement toward the spillway for all points in the furthest west line of points, and again the summer nighttime samples had very little data to comment upon.

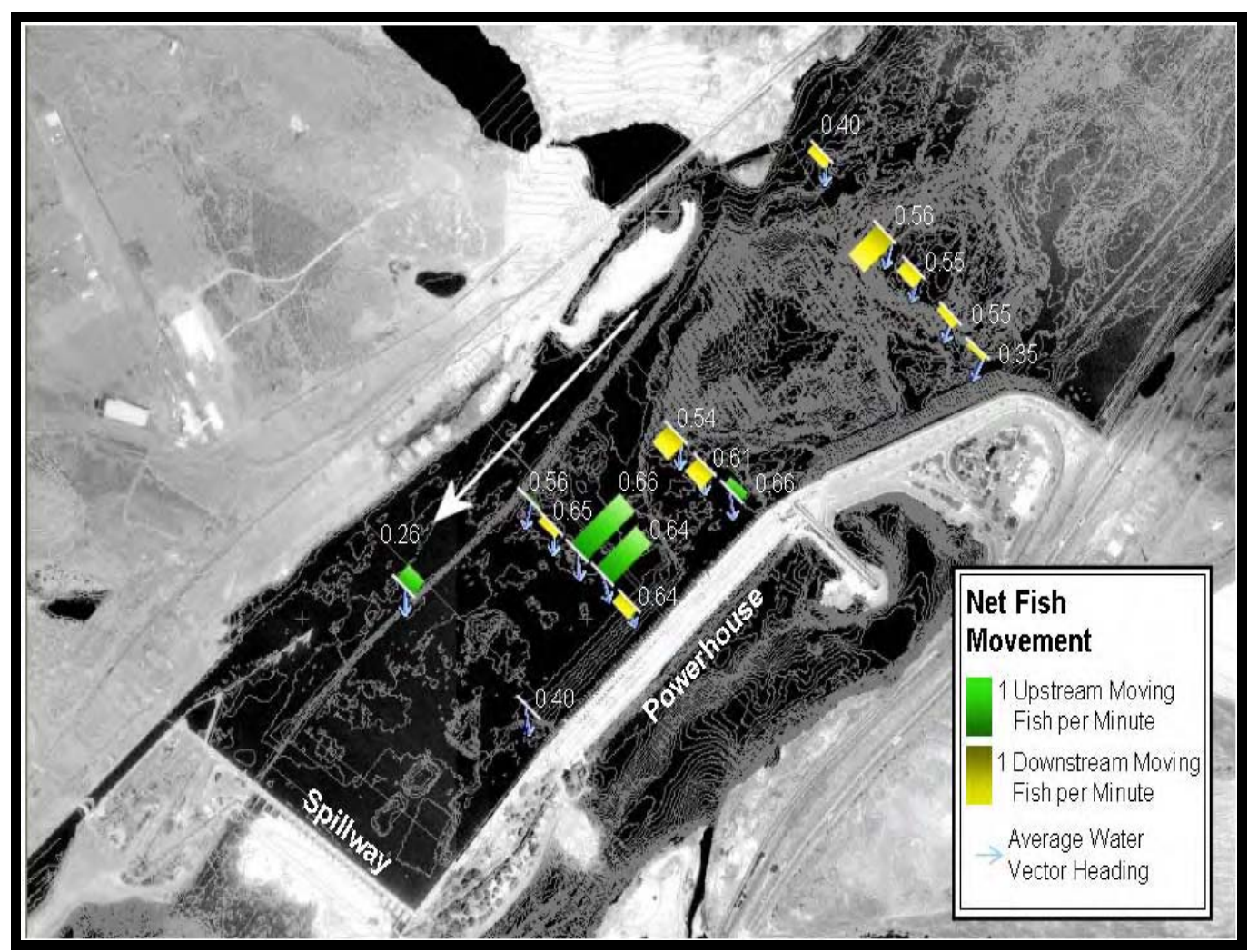

Figure 3.23. The net movement of smolt-size fish contacted at each point per minute during spring daytime samples relative to channel direction (white arrow). Net movement to the southwest is displayed as yellow and net movement to the northeast is green. Mean water column velocity heading is shown in blue, and the water velocity magnitude value is displayed next to the point in $\mathrm{m} / \mathrm{s}$.

\subsubsection{Fish Movement Direction}

Rose plots were generated based on the percentage of smolt-sized fish traveling in a direction and divided into $20^{\circ}$ increments, where the slice size is a function of percentage traveling in that direction (spring daytime samples are shown in Figure 3.24, other categories are shown in Appendix H). Mean water heading was also displayed. All samples for the spring and summer periods showed smolt-sized movement patterns that were evenly distributed in all directions for the majority of points. The major exceptions were for two fixed points located in the point line that was adjacent to the easternmost end of the powerhouse and comprised the two northern most points on that line. At those points, the movement 
of fish always directed downstream, suggesting a very directed movement pattern in that portion of the forebay of The Dalles Dam.

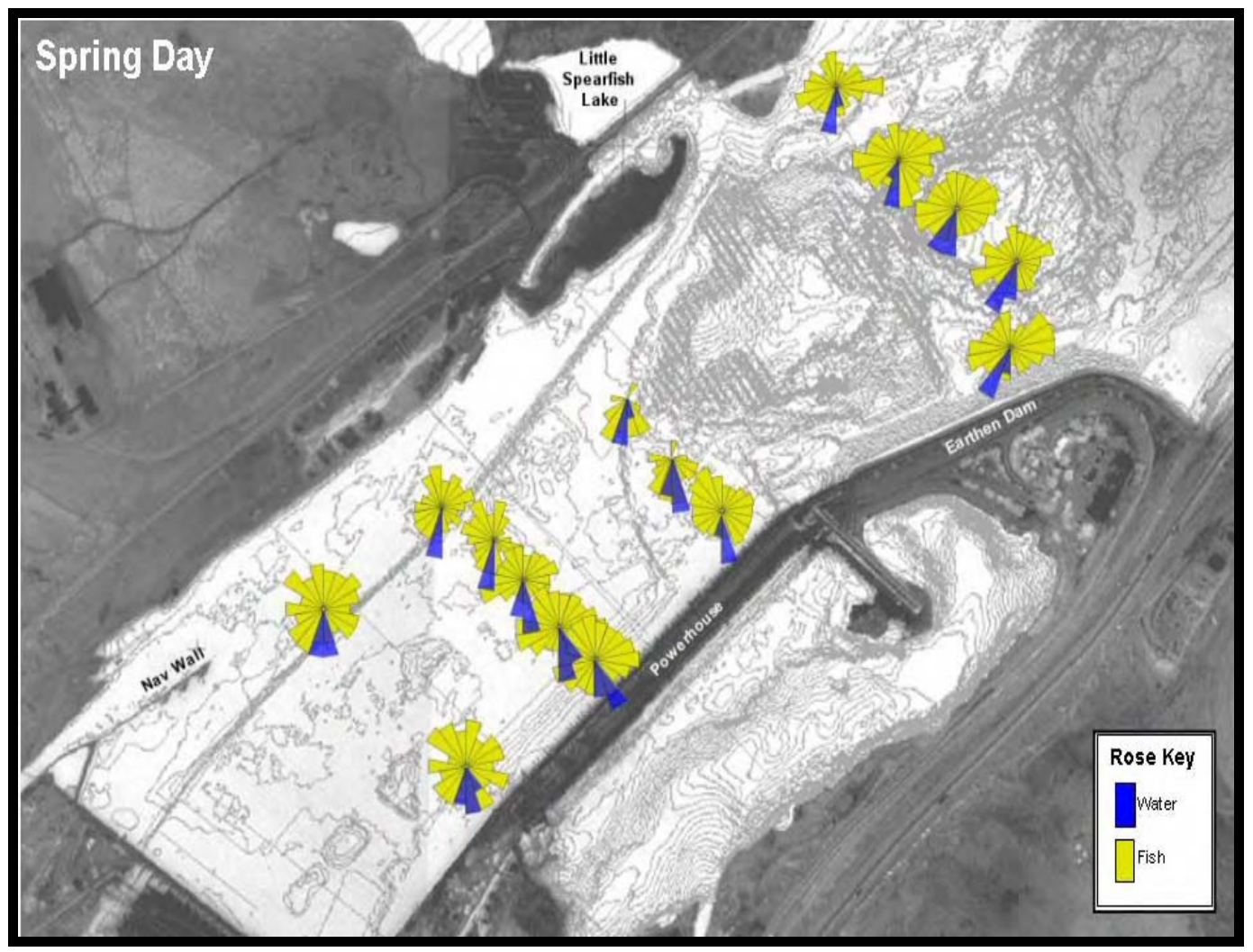

Figure 3.24. The movement distribution of smolt-sized fish contacted at each point during spring daytime samples (yellow) relative to flow (blue). Rose plots were generated based on the percentage of smolt-sized fish traveling in a direction and divided into $20^{\circ}$ increments, where the slice-size is a function of percentage traveling in that direction. Flow headings were summarized for the entire water column in $0.5-\mathrm{m}$ increments.

Finally, we compared the flux of smolt-sized fish sampled at fixed points (total number over time) to the average of the three closest smolt-sized fish density values from grid points generated from mobile surveys to determine if a relationship existed between the fish flux and fish density observed. Grid points were no greater than $50 \mathrm{~m}$ from each fixed point. In doing so we found no relationship between our flux measurements and our fish density measurements (see Figure 3.25), suggesting that the relative movement of fish is not strongly related to the density of fish measured. Also, this relationship did not improve when we divided the sample into study periods and produced similar $\mathrm{R}^{2}$ values. 


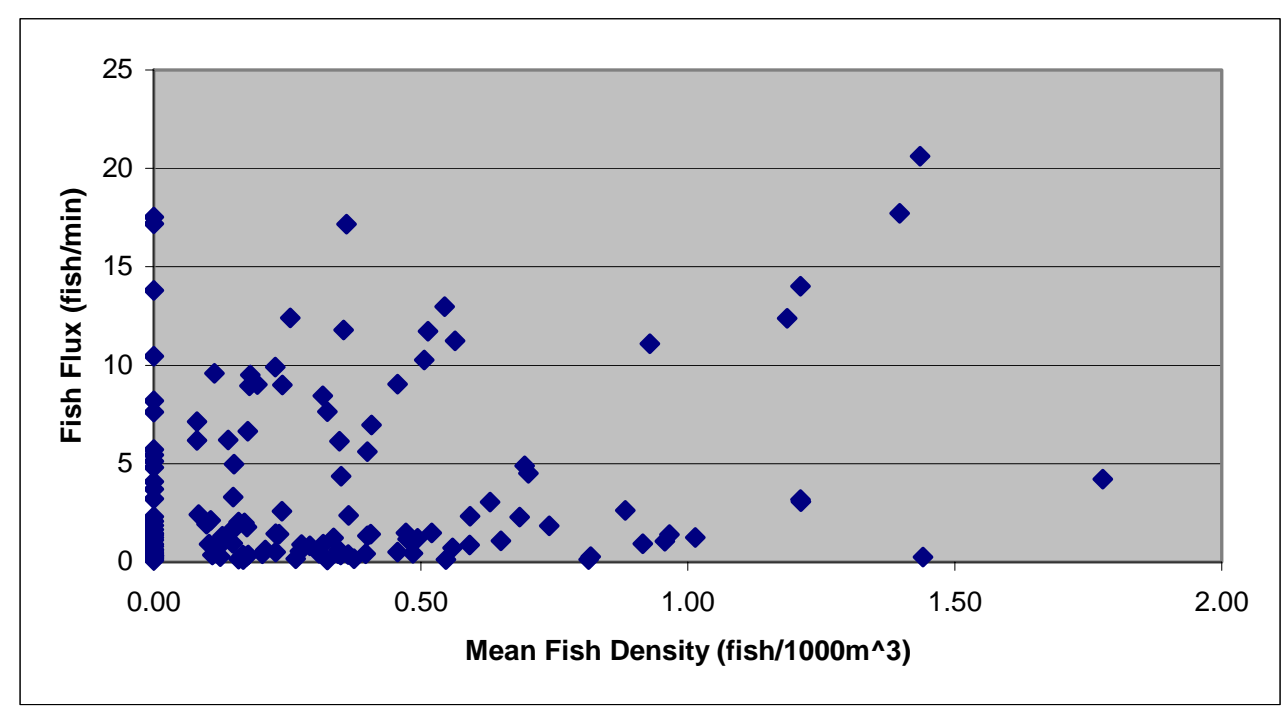

Figure 3.25. Relationship between the flux of fish sampled at fixed points and the average of the three closest smolt-sized fish density values from grid points generated from mobile surveys. Grid points were no greater than $50 \mathrm{~m}$ from each fixed point. 
Distribution and Flux of Fish in the Forebay of The Dalles Dam in 2003 


\subsection{Discussion}

The discussion focuses on mobile hydroacoustic data collected by PNNL from May to July of 2003 and its implications for a behavioral guidance structure and surface flow bypass of juvenile salmon at The Dalles Dam. A proposal for the use of a guidance structure in the forebay at The Dalles Dam, a modified version of the Behavioral Guidance Structure (BGS) located at Lower Granite Dam, has recently been suggested by the U.S. Army Corps of Engineers and regional resource managers as a potential alternative for juvenile salmon passage at The Dalles Dam to improve the passage survival of juvenile salmon at the dam. The structure would provide a diversion for turbine passage of juvenile salmonids and guide them to the spillway. The distribution of juvenile salmonids (smolt) -sized fish and the flow environment will be discussed in relation to placement of a potential guidance structure.

\subsection{Flow and Fish Distribution}

Flow is an important environmental factor that influences the migration routes of juvenile salmon in an open river. Numerous investigations have provided evidence that in the open river channel the primary route of migrating juvenile salmon is within the bulk flow (thalweg), which usually contains the highest water velocities (Dehart 1991; Moser et al. 1991; Nelson et al. 1994). Studies also show, however, that juvenile salmon alter their behavior as they encounter structures such as a hydropower dam, where they tend to actively search for surface routes and are reluctant to sound with the bulk flow to pass via turbine routes (Andrew and Green 1960; Marquette and Long 1971).

Fish passage results have bolstered these findings by showing that routes of passage that draw water at the surface have a greater success at passing juvenile salmon by the dams in proportion to the amount of water passing those routes (Adams and Rondorf 2001; Johnson 1996). Such is the case at The Dalles Dam, which has high sluiceway passage under various conditions in comparison to the very small portion of total river flow that passes through the sluiceway (Holmberg et al. 1997; Ploskey et al. 2001a). The extent to which this behavior is exhibited in areas close to dam structure was found to change by diel period and between species, as is reported by Solonsky et al. (1995) where they found that juvenile Chinook were more apt to sound than juvenile steelhead at Cowlitz Falls Dam. Also Cash et al. (2003) observed differences between steelhead and yearling Chinook salmon in the guidance of juvenile salmon along a log-boom at Lower Granite Dam. The flow regime in the forebay at The Dalles Dam will undoubtedly influence the success of any behavioral guidance structure.

Using flow measurements recorded in The Dalles Dam forebay with an ADCP, Skalski and Dillingham statistically defined a relationship between the flow and the distribution of smolt-sized fish, which is summarized in Appendix A. Skalski and Dillingham found relationships that could predict some of the observed findings for the ambient environmental variables, including flow. Flow duration and magnitude were shown for the four sample categories (spring/summer, day/night) in Figures 3.1 through 3.4. The primary heading of flow upstream of the powerhouse was in the southwesterly direction (with the channel), and a route of higher velocities was observed north of the center of the channel (e.g., thalweg). 
However, once flow passed a line that extended from the east end of the powerhouse orthogonally across to the Washington shore (Figure 4.1), the heading of flow began to point south and east toward the powerhouse along its entire length.

The velocities in this region were generally higher than the rest of the forebay, and the thalweg was broad and less defined. This was observed in all four categories (spring day and night, summer day and night). A juvenile salmon traveling in this section of the river would be influenced by the heading of flow toward the powerhouse due to the flow through the generating units at the powerhouse. The heading direction for flow in this river section was toward the powerhouse even when project operations included spill, which passed up to $40 \%$ of the total river flow during our study period.

Any forebay structure that would take advantage of the current flow regime in The Dalles Dam forebay would have to be oriented in such a way as to facilitate the movement of smolts toward the spillway, first by placing the guidance device so that the structure encounters the thalweg in an area closest to the spillway. Then, conditions must exist along the structure that facilitate the movement of juvenile salmon along and not under the structure, so that they reach and pass via the spillway. The distribution of fish in the forebay was measured to provide insight into how this might be accomplished or to initiate thought on other bypass alternatives.

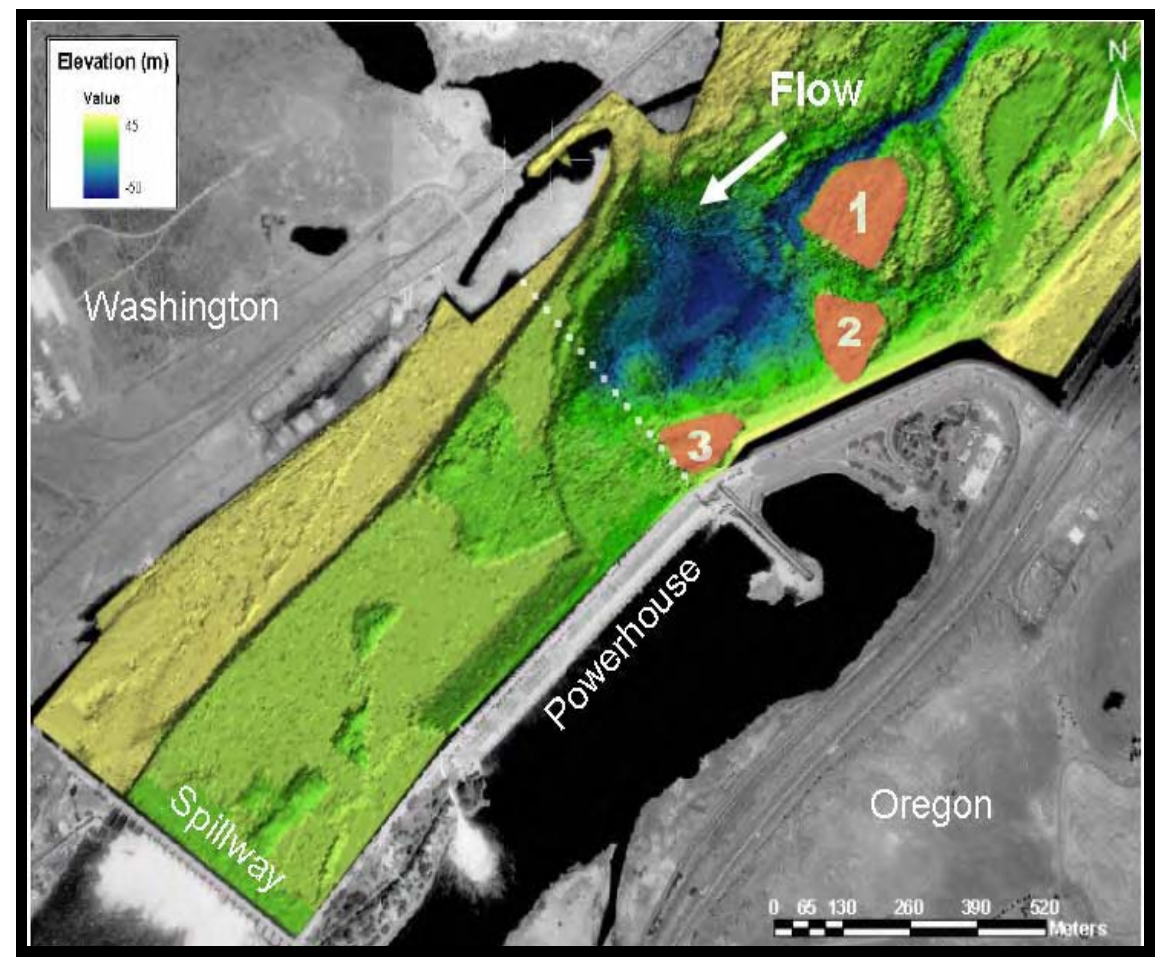

Figure 4.1. Bathymetric map of the forebay at The Dalles Dam. Highlighted areas 1, 2, and 3 were shallow regions where very low densities of smolt-sized fish were observed. Dotted line shows point at which main flow turned south toward the power house. 


\subsection{Distribution Determined by Mobile Hydroacoustics}

\subsubsection{Lateral Distribution of Smolt-Sized Fish}

We determined the distribution of smolt-sized fish using mobile hydroacoustics. Three assumptions were made in order to generate the distribution maps: 1) the movement of the fish population relative to the time required to sample the population was negligible; therefore we assumed that the fish population used to create the distribution maps was representative of an instantaneous map of fish distribution; 2) the target strength of the fish was equal across species and the aspect of the fish relative to the acoustic beam was such that the fish returned the target strength representative of its size from the dorsal aspect; and 3) the proportion of large fish to small fish was not influenced by their location in the water column. Regarding the first assumption, it actually took 6 hours to complete a full sample. Therefore, to account for the bias that a migrating population would introduce, we measured the rate of passage over time at various points in the forebay to determine the extent of the smolt migration over time (flux). Assumption two was typical of prior investigations that used mobile hydroacoustic techniques (Kofoot et al. 1996). And the extent that the distribution data may be impacted by assumption three was not investigated thoroughly during this study; however, any future research efforts that use similar techniques should incorporate this into a study plan.

Very low densities of smolt-sized fish were observed above the three shallow structures highlighted in Figure 4.1, as 1, 2, and 3. These areas showed high densities of larger-than-smolt-sized fish; these areas also had higher velocity water flow in comparison to the rest of the forebay. This may suggest an avoidance response by smolt-sized fish in these areas, possibly due to the presence of large fish (predators). The relative distribution of smolt-sized fish for the four summarized categories may have also influenced their route of passage at The Dalles Dam, especially if they were distributed near the spillway or powerhouse. Higher densities of fish were observed on the north side of the channel for summer daytime samples, where they would be more available to a route of downstream direct passage to the spillway. High densities of fish were observed along the face of the powerhouse for all samples, which made those fish more susceptible to turbine passage. The susceptibility of these fish to turbine passage increases at night where juvenile Chinook salmon and steelhead have been observed to pass more quickly and directly in the direction of flow. This behavior was observed at Bonneville Dam where Faber et al. (2001) saw a large increase in direct-path fish passing the dam with the flow during nighttime hours in contrast to more milling during the daytime hours. Ploskey et al. (2001a) also observed a pulse of passage at The Dalles Dam during the first few hours of darkness.

Some notable differences were also seen between seasonal/diel categories. We observed diel differences in spring samples with higher densities of smolt-sized fish observed on the north side and close to the spillway in the nighttime samples than in the daytime samples. More fish were distributed at the sluiceway during the daytime, possibly due to milling in this region during the day from previous investigations at Lower Granite Dam and Bonneville Dam, where milling behavior was more prevalent during the daytime than at night (Cash et al. 2003; Faber et al. 2001). Summer results showed greater 
densities of smolt-sized fish in the entire sample during daytime than during nighttime samples, although summertime samples may have been affected by the presence of American shad for that period.

Correlation of the mean fish density of our samples with the total smolt-passage index (SPI) at John Day Dam yielded some interesting results. The spring nighttime and summer daytime samples yielded the best correlations of density to SPI (Table 3.2, $\mathrm{r}=0.71, \mathrm{r}=0.60$ respectively), where the SPI was taken the same day as the sample in spring and the day prior to the sample in summer. Holmberg et al. (1997) observed a median travel time of 11 hours for juvenile salmon from John Day Dam to The Dalles Dam during spring samples. The mean travel time was 16 hours for summer samples. This likely explains why the best correlative results for spring samples was with SPI the day of the sample, and the best correlative for summer samples was with SPI the day prior to the sample.

However spring daytime and summer nighttime were less correlated with our sample and cannot be explained in the same manner. There were several confounding factors that may have influenced the correlation of smolt-sized fish density to SPI. One was the lack of smolt-timing information for the Deschutes River, which intersects Lake Celilo (The Dalles Dam Pool) between John Day and The Dalles Dam. The outmigration of juvenile salmon in this watershed would be unaccounted for in the SPI for John Day Dam. Holmberg et al. (1997) also reported a broad range of travel times to The Dalles Dam from John Day Dam, possibly due to delay in certain regions of Lake Celilo.

Also the presence of American shad during the summer samples likely influenced the density distribution maps for our summertime samples. When comparing the mean fish density sampled to the SPI at John Day plus the shad count at The Dalles Dam, the correlation improved for summer daytime samples as well as for summer nighttime samples $(r=0.8, r=0.24)$ of fish density. The target strength of an American shad can be similar to that of a smolt. Knowing this, we attempted to mitigate the bias that would be introduced to our sample of smolt-sized fish by setting the target strength of our targets at -45 $\mathrm{dB}$ ref $\| 1 \mathrm{uPA}$ for summer samples. This has benefited studies using fixed hydroacoustics at The Dalles Dam (Ploskey et al. 2001a), but the presence of American shad were still likely to have influenced our density counts.

\subsubsection{Vertical Distribution of Smolt-Sized Fish}

The vertical distribution of smolt-sized fish was skewed toward the upper water column for all season/diel categories. Summer fish were distributed higher than spring fish when comparing the depth, where 80\% of fish were above that depth. Springtime fish were higher in the water column during the nighttime than during the daytime, and summertime fish were not observed to exhibit a diel pattern. A guidance structure that might by built to influence the passage route of juvenile salmon need only be $6 \mathrm{~m}$ deep to directly influence more than $80 \%$ of the smolt-sized population at The Dalles Dam. However, the vertical distribution at The Dalles Dam was also varied depending on location in the forebay. Smolt-sized fish were deeper in the center of the channel than near the north and south banks. They were also deeper near the sluiceway than at other areas of the forebay with comparable depths within the same season/time 
category. Therefore, developers should consider the specific vertical distribution in the area where the behavioral guidance structure might be deployed. Species-specific differences may also influence the vertical distribution. For instance, Clark and Levy (1988) observed that juvenile sockeye salmon were distributed deeper in the water column than is typical for juvenile Chinook or steelhead during their outmigration period.

\subsection{Fish Flux and Movement}

The juvenile salmon population we sampled was an outmigrating population traveling downriver. Thus they were in a constant "flux" of movement. It was assumed that any map of distribution we created for a sample was of a population that did not move during the sample period, or similarly that the population's movement did not affect their relative density and distribution. To examine the validity of this assumption we also measured the rate of fish passage by specific points in the forebay. One method used to quantify the relationship between fish flux and distribution was to compare the measured density of fish observed close to the location of a fixed point to that fixed point's value for fish flux (Figure 3.25). When this comparison was made, no significant correlation was observed for the relationship. However, the fish-flux vessel was also taking measurements over the sample time period (usually 6 hours), moving from point to point, which introduces a similar assumption: that the migration characteristics of the sample population are the same at each fixed point over the time period of the sample. Therefore the comparison of datasets relied on two similar assumptions, one for the mobile transects and one for the fixed stations. Only if the mobile hydroacoustic vessel and fixed-point vessel were sampling the same area at the same time would these values be directly comparable, and this was not the case during our study. To capture the fish flux for a sample that also uses mobile hydroacoustics, any future investigation should deploy transducers at fixed points for the entire time that it takes to complete a mobile sample, thereby assessing the true flux of fish during that time period.

Although the values for fish flux relied on similar assumptions as the mobile hydroacoustics data, the flux at each of the points provided valuable data for our investigation in that it yielded both the rate of fish passage over time and their direction of travel past each point. Smolt-sized fish had the greatest rate of movement past fixed points that were located closest to the dam and consistently for the point closest to the east end of the dam. The net movement of fish was downstream past those points located east of the powerhouse and upstream in areas close to the dam from the middle of the powerhouse downstream, with the exception of two points on the north side of the forebay, where net movement was also downstream.

Springtime data on fish flux provided results that had greater numbers of fish passing fixed points over time than did summertime samples. Summertime samples were also fewer due to the removal of several of our fixed points by barges; therefore, the summer samples lacked those points to compare with the spring points. The pattern for the net movement of fish (Figure 3.23) suggests that fish may circulate in the forebay due to their consistent downstream movement away from the dam and then exhibit net upstream movement near the dam structure and on the downstream end of the powerhouse. Spring daytime and nighttime samples for the two downstream points on the north side of the channel had net downstream movement toward the spillway, suggesting movement in that direction of the spillway and on 
the north ends of the channel. Summer data was less conclusive due to the low numbers of contacts during that time.

Movement data for fixed points was also summarized by the use of rose plots. Rose plots were generated to provide finer-scale directional movement than the net-movement graphs could provide. However, the data obtained from the rose plots was mostly unremarkable in that they did not show trends in directional movement except for two upstream points located near the east side of the powerhouse. Those points consistently reported smolt-sized fish moving only in the downstream direction. The movement direction for all other points throughout the forebay was distributed throughout the $360^{\circ}$ range without notable trends. They did however support net movement of fish with or against the flow and channel, which provided valuable insight into the movement of smolt-sized fish throughout the forebay at The Dalles Dam. 


\subsection{Conclusions and Recommendations}

\subsection{Conclusions}

The sample categories of fish distribution (spring/summer, day/night) shared key findings:

- High densities of smolt-sized fish were observed on the north side of the channel.

- Shallow, high water velocity areas on the south side of the channel had relatively low densities of smolt-sized fish compared to adjacent regions. Larger than smolt-sized fish were distributed in these areas.

- The vertical distribution of fish was concentrated in the upper $5.3 \mathrm{~m}$ of the water column, regardless of time of day or season.

- Smolt-sized fish were deeper in the center of the channel than at the edges.

- The flux of fish was highest near the powerhouse and on the northeast side of the channel.

- Net movement of fish was downstream or with the channel in areas upstream of the powerhouse, but was less directed downstream in areas near the powerhouse.

Findings for the sample categories, however, diverged on several accounts:

- In the spring, smolt-sized fish were distributed higher in the water column at night than during the day.

- Smolt-sized fish were distributed higher in the water column during summer than during spring.

- $\quad$ The density of smolt-sized fish was less during the summer than during the spring. 


\subsection{Recommendations}

Any guidance structure that is placed in the forebay must take advantage of the flow regime and smolt distribution characteristics that presently exist in the forebay at The Dalles Dam. It should properly divert flow in the direction that is desired for the movement of juvenile salmon. If the movement of flow is orthogonal to a behavioral guidance structure, the structure would be similar to the top of the intakes of the turbine units at the powerhouse for a juvenile salmon. Given the information we obtained from ADCP measurements, this may be difficult in the forebay at The Dalles Dam, but the use of project operations in combination with the proper placement of the structure may encourage the movement of juvenile salmon toward spillway passage routes. Potential also exists to use the bathymetry on the east end of the powerhouse (the shallow, high water-velocity areas on the south side of the channel) to aid in the placement of a guidance device, because of the low densities of smolt-sized fish observed in this area, as it may act as a natural barrier to smolt passage.

If a behavioral guidance structure is deemed to be a reasonable approach to juvenile salmon passage at The Dalles Dam, we make the following recommendations:

1. Adjust powerhouse operation priorities so that the main flow encounters the guidance structure at a point nearest the spillway.

2. Create flow parallel to the guidance structure, not perpendicular to it.

3. Provide necessary attractant flow at spillway.

4. Build a structure with at least $6 \mathrm{~m}$ of depth.

5. Consider surface flow bypass alternatives at spillway and powerhouse.

6. Investigate further the relationship between bathymetry and fish distribution in the forebay in the shallow regions with high water velocities adjacent to the embankment at the east end of the powerhouse. 


\subsection{References}

Adams, N.S. and D.W. Rondorf. 2001. Juvenile Chinook Salmon and Steelhead Passage in the Forebay of Lower Granite Dam Relative to Surface Bypass Collector and Behavioral Guidance Structure Tests. Annual Report for 1998. Prepared for U.S. Army Corps of Engineers, Walla Walla District, Walla Walla, Washington.

Allen, M.B. and eight co-authors. 2000. Movement, Distribution and Behavior of Radio-Tagged Yearling and Sub-Yearling Chinook Salmon in the Tailrace of The Dalles Dam, 1999. Annual Report of Research, 1999, by the U.S. Geological Survey to the U.S. Army Corps of Engineers - Portland District, Portland, Oregon.

Allen, M.B. and nine co-authors. 2001. Movement, Distribution and Behavior of Radio- Tagged Yearling Chinook Salmon in the Tailrace of The Dalles Dam, 2000. Annual Report of Research, 2000, by the U.S. Geological Survey to the U.S. Army Corps of Engineers - Portland District, Portland, Oregon.

Andrew, F.J. and G.H. Geen. 1960. "Sockeye and pink salmon production in relation to proposed dams in the Fraser River system.” Bulletin XI, International Pacific Salmon Fisheries Commission, New Westminister, B.C., Canada:

Arnold, G.P. 1974. “Rheotropism in fishes.” Biological Review. 49:515-576.

BioSonics, Inc. 1997. Hydroacoustic Evaluation and Studies at The Dalles Dam, Spring/ Summer 1996. U.S. Army Corps of Engineers - Portland District, Portland, Oregon.

Cash, K.M., T.W. Hatton, E.C. Jones, R.J. Magie, and N.S. Adams. 2003. Three-dimensional fish tracking to evaluate the removable spillway weir at lower granite dam during 2003. Anadromous Fish Evaluation Program (AFEP) for the U.S. Army Corps of Engineers.

Clark, C.W. and D.A. Levy. 1988. "Diel vertical migrations by juvenile sockeye salmon and the antipredation window.” American Naturalist 131:271-290.

DeHart, M. 1991. Memorandum for ESA Record. May 15, 1991. Submitted to the National Marine Fisheries Service, Portland, Oregon,

Faber, D.M., M.A. Weiland, R.A. Moursund, T.J. Carlson, N. Adams, and D. Rondorf. 2001. Evaluation of the Fish Passage Effectiveness of Bonneville I Prototype Surface Collector Using ThreeDimensional Ultrasonic Fish Tracking. PNNL-13526, Report to U.S. Army Corps of Engineers - Portland District, by Pacific Northwest National Laboratory, Richland, Washington.

Feil, D.H. and D.W. Rondorf. 2000. Horizontal and Vertical Distribution of Juvenile Salmonids in the Columbia River in Relation to Total Dissolved Gas. Final report by U.S. Geological Survey Biological Resources Division, to U.S. Army Corps of Engineers - Portland District, Portland, Oregon. 
Freon, P., M. Soria, C. Mullon, and F. Gerlotto. 1993. "Diurnal variation in fish density estimate during acoustic surveys in relation to spatial distribution and avoidance reaction.” Aquatic Living Resources. 6:221-234.

Giorgi, A.E. and J.R. Stevenson. 1995. A Review of Biological Investigations Describing Smolt Passage Behavior at Portland District Corps of Engineer Projects: Implications in Surface Collection Systems. By Don Chapman Consultants, Inc. for the U.S. Army Engineer District, Portland, Oregon.

Hensleigh, J.E. and nine co-authors. 1999. Movement, Distribution, and Behavior of Radio-Tagged Juvenile Chinook Salmon and Steelhead in John Day, The Dalles and Bonneville Dam Forebays, 1997. Annual Report of Research, 1997, by the U.S. Geological Survey to the U.S. Army Corps of Engineers -Portland District, Portland, Oregon.

Holmberg, G.S. and eight co-authors. 1997. Movement, Distribution, and Behavior of Radio-Tagged Juvenile Chinook Salmon in John Day, The Dalles, and Bonneville Dam Forebays, 1996. Annual Report of Research, 1996, by the U.S. Geological Survey to the U.S. Army Corps of Engineers - Portland District, Portland, Oregon.

Johnson, G.E. 1996. Fisheries Research on Phenomena in the Forebay of Wells Dam in Spring 1995 Related to the Surface Flow Smolt Bypass. U.S. Army Corp of Engineers - Walla Walla District, Walla Walla, Washington.

Johnson, G.E., M. Hanks, J. Hedgepeth, B. McFadden, R.A. Moursund, R.P. Mueller, and J.R. Skalski. 2003. Hydroacoustic evaluation of turbine intake J-occlusions at The Dalles Dam in 2002. PNWD-3226, prepared for the U. S. Army Corps of Engineers, Portland District, by Battelle Pacific Northwest Division. Richland, Washington.

Kofoot, E.E, D.H. Feil, R.D. Garland, M.E. Hanks, and D.W. Rondorf. 1994. "Use of hydroacoustics in assessing the migrational behavior of juvenile spring Chinook salmon and steelhead in Lower Granite Reservoir.” In Migrational Characteristics of Juvenile Spring Chinook and Steelhead in Lower Granite Reservoir and Tributaries, Snake River. (ed. D.W. Rondorf and M.J. Banach), pp. 76-107, US Army Corps of Engineers, Walla Walla, Washington.

Kofoot, E.E., M.E. Hanks, and J.B. Oleyar. 1996. "Distribution of juvenile salmonids in the forebay of Lower Granite Dam detected during mobile hydroacoustic surveys.” In Migrational Characteristics of Juvenile Spring Chinook Salmon and Steelhead in the Forebay of Lower Granite Dam Relative to the 1996 Surface Bypass Collector Tests. (ed. Adams et al. 1996) pp. 6-1 to 6-62. Report to the U.S. Army Corps of Engineers, Contract E86930151, Walla Walla, Washington.

Lee, Y.W., T. Mukai, and K. Iida. 2002. “The applications of image processing technology for analysis of fish school behavior: evaluation of fish school behavior response to the approaching vessel using scanning sonar.” ICES Journal of Marine Science.

Love, R.H. 1971. "Dorsal-aspect target strength of an individual fish.” Journal of the Acoustical Society of America, 49:816-23. 
Love, R.H. 1977. “Target strength of an individual fish at any aspect.” Journal of the Acoustical Society of America, 62:1397-1403.

MacLennan, D.N. and E.J. Simmonds. 1992. Fisheries Acoustics. Chapman and Hall, London.

Marquette, W.M. and C.W. Long. 1971. "Laboratory studies of screens for diverting juvenile salmon and trout from turbine intakes.” Transactions of the American Fisheries Society 3:439-447.

Moser, M.L., A.F. Olson, and T.P. Quinn. 1991. "Riverine and estuarine migratory behavior of coho salmon (Oncorhynchus kisutch) smolts.” Can.J.Fish.Aquaqt.Sci. 48:1670-1678.

Moursund, R.A., K.D. Ham, B. McFadden, and G.E. Johnson. 2001. Hydroacoustic Evaluation of Downstream Fish Passage at The Dalles Dam in 2000. Draft Final Report by Battelle to the U.S. Army Corps of Engineers - Portland District, Portland, Oregon.

Moursund, R.A., K.D. Ham, P.S. Titzler, R.P. Mueller, G.E. Johnson, J. Hedgepeth, and J.R. Skalski. 2002. Hydroacoustic Evaluation of Fish Passage at The Dalles Dam in 2001. Report prepared for the U. S. Army Engineer District, Portland, by Battelle, Pacific Northwest Division, Richland, Washington.

National Marine Fisheries Service. 1995. Biological Opinion on 1994-1998 Operation of the Federal Columbia River Power System and Juvenile Transportation Program. National Marine Fisheries Service, Seattle, Washington.

National Marine Fisheries Service. 2000. Reinitiation of Consultation on Operation of the Federal Columbia River Power System, Including the Juvenile Fish Transportation Program, and 19 Bureau of Reclamation Projects in the Columbia Basin. Biological Opinion ed. National Marine Fisheries Service, Northwest Region: Seattle, Washington.

Nelson, W.R., L.K. Freidenburg, and D.W. Rondorf. 1994. “Chapter 3. Swimming performance of subyearling Chinook salmon.” In Identification of the spawning, rearing and migratory requirements of fall Chinook salmon in the Columbia River B, National Biological Survey, Columbia River Research Laboratory.

Olsen, K., J. Angell, F. Pettersen, and A. Lovik. 1983. "Observed fish reactions to a surveying vessel with special reference to herring, cod, capelin and polar cod.” In Symposium on Fisheries Acoustics, (ed. Nakken, O. and S.C. Venema) Bergen, Norway. FAO Fish. Rep. 300, 131-8.

Olsen, K. 1990. "Fish behavior and acoustic sampling.” Rapp. P. -v. Reun. Cons. Perm. Int. Explor. Mer. 189, 147-58.

Ploskey, G.R., P.N. Johnson, W.T. Nagy, M.G. Burczynski, and L.R. Lawrence. 1998. Hydroacoustic Evaluations of Juvenile Salmonid Passage at Bonneville Dam including Surface-Collection Simulations. Technical Report EL-98-4, U.S. Army Engineer Waterways Experiment Station, Vicksburg, MS. 
Ploskey, G.R., T. Poe, A. Giorgi and G.E. Johnson. 2001a. Synthesis of radio telemetry, hydroacoustic, and survival studies of juvenile salmon at The Dalles Dam (1982-2000). Final Report prepared for the U.S. Army Corps of Engineers - Portland District, Portland, Oregon, by Battelle Pacific Northwest Division, Richland, Washington.

Ploskey, G.R., M.E. Hanks, G.E. Johnson, W.T. Nagy, C.R. Schilt, L.R. Lawrence, D.S. Patterson, P.N. Johnson, and J.R. Skalski. 2001b. Hydroacoustic Evaluation of Juvenile Salmon Passage at The Dalles Dam: 1999. Technical Report ERDC/EL TR-01-11, U.S. Army Engineer Research and Development Center, Waterways Experiment Station, Vicksburg, Mississippi.

Solonsky, A., D. Postelwait, D. Thompson, and R. Moulton. 1995. “Development of a surface collection system for juvenile salmonids at the Cowlitz Falls hydroelectric project.” In Waterpower 95. Proceedings of the International Conference on Hydropower, San Francisco, CA ,July 25-28, 1995. Published by the American Society of Civil Engineers, New York.

Sheer, M.B., G.S. Holmberg, R.S. Shively, H.C. Hansel, T.L. Martinelli, T.P. King, C.N. Frost, and T.P. Poe. 1997. Movement and Behavior of Radio-Tagged Juvenile Spring and Fall Chinook Salmon in The Dalles and John Day Forebays, 1995. U.S. Geological Survey, Cook, Washington. 


\title{
Appendix A
}

\section{Predicting Smolt Densities Using Hydrologic}

\section{and Bathymetric Data in the Forebay of The Dalles Dam}

\author{
Prepared for: \\ Derrek Faber \\ Pacific Northwest National Laboratory \\ 308 Evergreen Drive \\ North Bonneville, Washington 98639
}

\author{
Prepared by: \\ John R. Skalski \\ Peter W. Dillingham \\ Columbia Basin Research \\ School of Aquatic and Fishery Sciences \\ University of Washington \\ 1325 Fourth Avenue, Suite 1820 \\ Seattle, Washington 98101
}





\section{Appendix A \\ Predicting Smolt Densities Using Hydrologic and Bathymetric Data in the Forebay of The Dalles Dam}

\section{Executive Summary}

Regression analysis was used to model the spatial pattern in smolt densities in the forebay of The Dalles Dam. Data on smolt densities were available from 23 hydroacoustic surveys conducted spring and summer 2003. Multivariate regression models were unable to explain the variability in smolt densities between replicate surveys within a season (i.e., spring or summer) and photoperiod (i.e., day or night). The between-survey variability was attributed to hydroacoustic sampling error; hence, modeling focused on predicting the spatial patterns averaged across replicates. The best fit, stepwise, and parsimonious model included 19 parameters to explain smolt densities over 257 grid locations.

The stepwise model had an $\mathrm{R}^{2}$ value of 0.24 out of a total $\mathrm{R}^{2}=0.66$ available using unique indicator variables for each grid location. In other words, the regression model described about $26 \%$ of the total variability by the most parameterized model. The predicted fish densities described the general pattern of low and high fish densities. The model was incapable of explaining the fine-scale differences in fish densities between neighboring grid locations. 


\section{Contents}

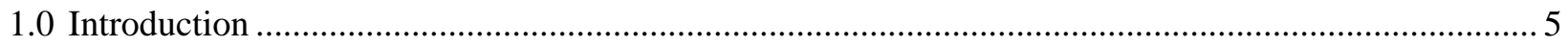

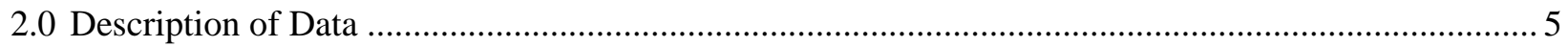

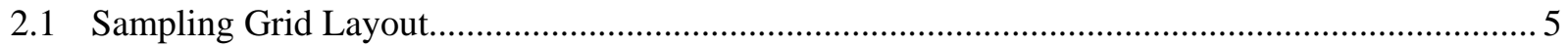

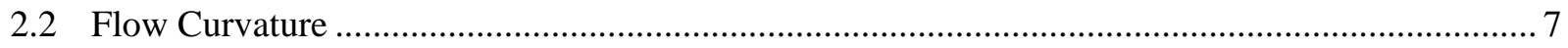

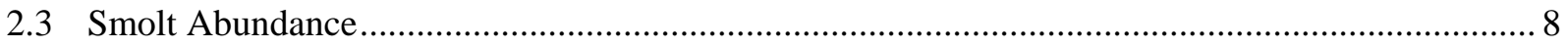

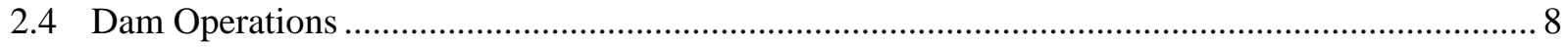

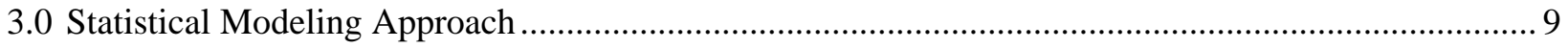

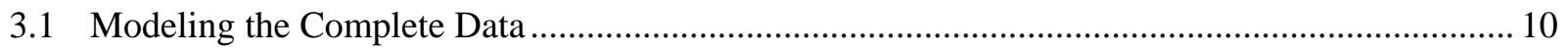

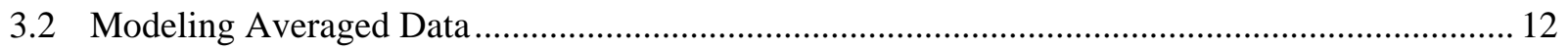

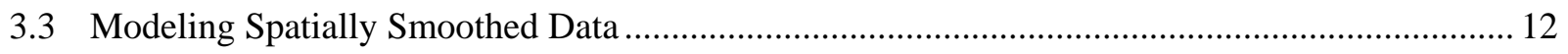

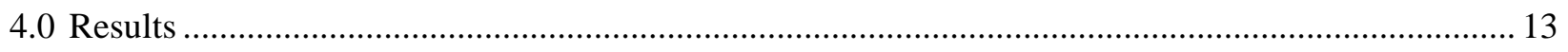

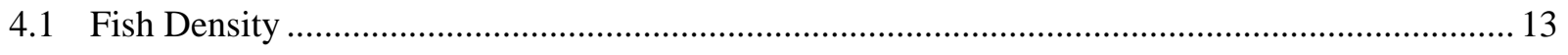

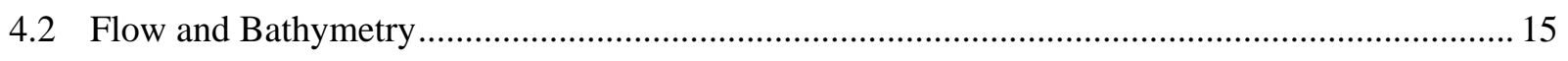

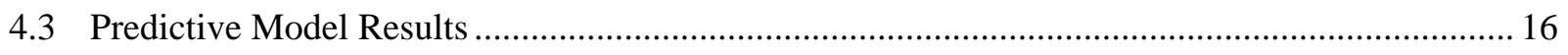

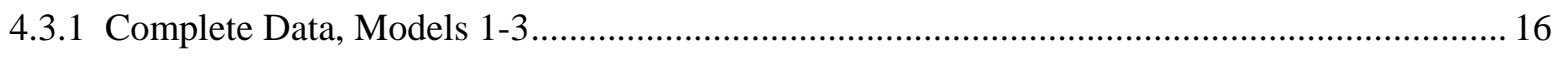

4.3.2 Photoperiod-Season Averaged Data ................................................................................. 18

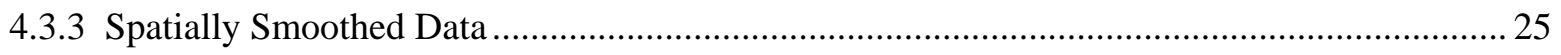

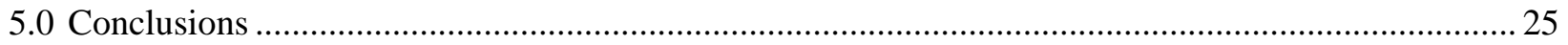

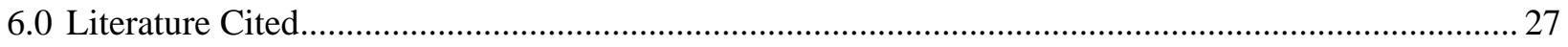




\section{Figures}

Figure 1. Grid locations sampled during a typical survey …....................................................... 6

Figure 2. Histograms of fish density from (a) 0-2 per $1000 \mathrm{~m}^{3}$ and from (b) 2-10 per $1000 \mathrm{~m}^{3} \ldots \ldots \ldots \ldots . . . . .14$

Figure 3. Histogram of photoperiod-season averaged data................................................................ 15

Figure 4. Flow direction and magnitude and fish density for summer-day-averaged data....................... 16

Figure 5. Relationship between flow, bathymetry, and fish density ................................................. 17

Figure 6. Distribution in fish density on (a) June 17, (b) July 4, (c) July 17, and

(d) averaged over all summer days in 2003.

Figure 7. Fish density, predicted density, and residual magnitudes for spring days............................... 21

Figure 8. Fish density, predicted density, and residual magnitudes for spring nights ............................ 22

Figure 9. Fish density, predicted density, and residual magnitudes for summer days............................. 23

Figure 10. Fish density, predicted density, and residual magnitudes for summer nights .......................24

\section{Tables}

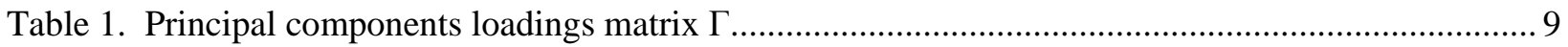

Table 2. Summary of $\mathrm{R}^{2}$ values for different datasets and fitted regression models using

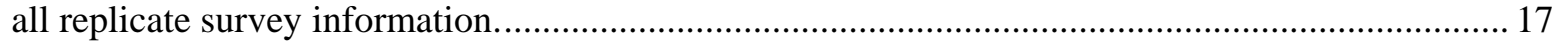

Table 3. Summary of $\mathrm{R}^{2}$ values for different regression models using the four photoperiod -seasonal averages. 20

Table 4. Summary of the $\mathrm{R}^{2}$ values for different regression models. 26 


\subsection{Introduction}

The goal of this statistical analysis was to relate smolt densities in the forebay of The Dalles Dam with hydrologic and bathymetric data. Smolt densities were estimated using hydroacoustic techniques at systematic locations in the forebay of The Dalles Dam during spring and summer 2003. The surveys were repeated within each season as well as during daylight and nighttime hours. Regression techniques were used to predict the observed fish densities based on flow and current information and water depths. Multiple regression equations were constructed to predict the smolt densities based on the best fit, parsimonious model.

\subsection{Description of Data}

Twenty-three acoustic fish surveys were undertaken from May to July 2003. Fish densities were estimated via acoustic surveys during transects across the forebay of The Dalles Dam. The forebay was divided into quadrates and the data from the transect used to estimate fish densities within each square. Additionally, river current or flow data, river depth, dam operations, and smolt passage indices (Fish Passage Center) were recorded.

\subsection{Sampling Grid Layout}

The forebay of The Dalles dam was divided into square grid locations measuring 200 feet per side, placed in rows and columns following an approximate SW by SE orientation (Figure 1). Twenty-seven downstream columns and 18 cross-stream rows are represented. Twenty-three surveys were conducted from May 5, 2003 through July 25, 2003. There were six spring-day, six spring-night, six summer-day, and five summer-night surveys conducted. There were $N=257$ grid locations surveyed at least once during the study, and data was typically gathered for 170 to 210 grid locations during each survey. In total, there were 4279 measurements conducted during all 23 surveys.

The bathymetry of the Columbia River around and just upriver of The Dalles Dam can be described as a deep, narrow channel running through the central portion of the river that opens into a broad and deep hole just upriver of the first turbines. The channel then gets less deep and curves towards the power units. Between this area and the spillway, there is a more shallow area with less variation in depth. 


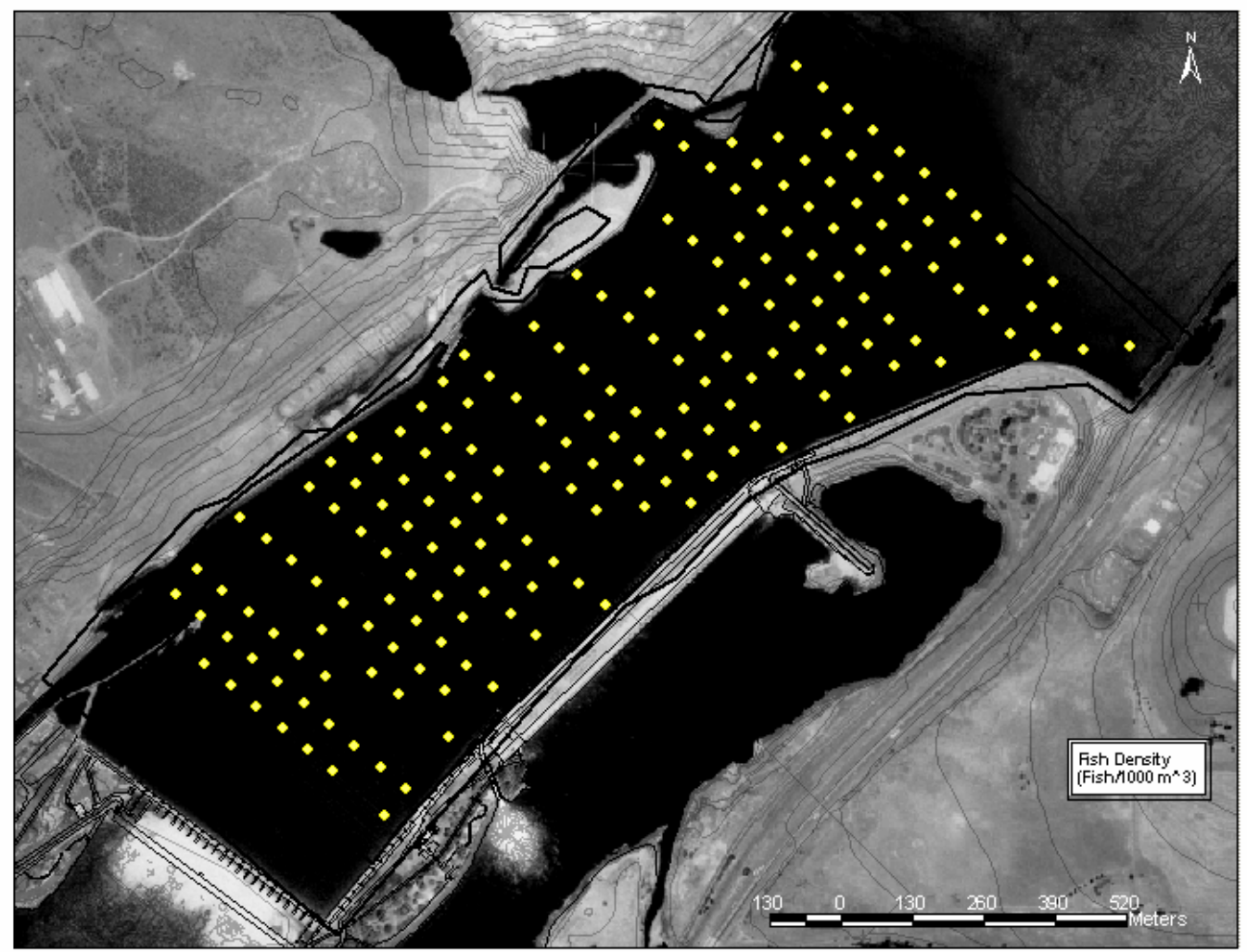

Figure 1. Grid locations sampled during a typical survey (Derrek Faber, Pacific Northwest National Laboratory).

\subsubsection{Fish Density}

Fish density was estimated via acoustic surveys along transects across the forebay of The Dalles Dam on the Columbia River. Because smolt passage was of primary interest, fish density was divided into small fish density ( $<34 \mathrm{~dB}$ in spring, $<45 \mathrm{~dB}$ in summer) and large fish density ( $>34 \mathrm{~dB}$ in spring, $>45 \mathrm{~dB}$ in summer). Small fish density (fish units under $1000 \mathrm{~m}^{3}$ ) was the dependent variable of primary interest.

\subsubsection{Water Flow}

Water flow was measured in both magnitude and direction. Flow velocity vectors were originally provided in vertical, northern, and eastern components. For descriptive and interpretive purposes, the northern and eastern flow vectors were translated into downstream (approximately SW), and cross-stream (approximately SE) components. Total river flow and upper 6 meter river flow vectors were measured. Because approximately $80 \%$ of smolt were located in the upper 6 meters of the water column, we chose to use upper 6 meter data for analysis purposes. However, upper river flow and total river flow were highly 
correlated ( $r>0.9$ for downstream, cross-stream, and magnitude measures, $r=0.68$ for vertical component).

Flow data were collected from a sensor attached to the boat. For most surveys, 5-10\% of grid locations with fish density data did not have corresponding flow data. We wished to have complete flow data for analysis purposes. Consequently, for locations missing flow data, we used linear regression to estimate the missing values. We used approximate downstream column location and cross-stream row location, as well as adjusting for the individual survey, to predict missing flow data. This generally worked well for downstream flow $\left(\mathrm{R}^{2}=0.75\right)$, cross-stream flow $\left(\mathrm{R}^{2}=0.79\right)$, and flow magnitude $\left(\mathrm{R}^{2}=\right.$ 0.76), although not as well for vertical flow $\left(R^{2}=0.10\right)$

\subsection{Flow Curvature}

In addition to flow direction and magnitude, we calculated the extrinsic curvature, $\kappa$, of the downstream and cross-stream flow (Millman and Parker 1977). This, together with flow, allowed us to measure how rapidly the river is moving at each location as well as how quickly the flow curve changes. In grid locations where nearby grid locations have similar flow, the extrinsic curvature is close to zero; in locations where nearby locations have distinctly different flows, the extrinsic curvature will be large in magnitude, although it may be either positive or negative. We were not concerned about the direction of curvature, so considered the magnitude of the extrinsic curvature $(|\kappa|)$.

The curvature, $\kappa$, is calculated as follows:

$$
\kappa=\frac{v_{D} \cdot \frac{d v_{C}}{d t}-v_{C} \cdot \frac{d v_{D}}{d t}}{\left(v_{D}^{2}+v_{C}^{2}\right)^{3 / 2}}
$$

where $v_{D}$ is the downstream flow component and $v_{C}$ is the cross-stream flow component. Additionally, $\frac{d v_{D}}{d t}$ and $\frac{d v_{C}}{d t}$ are approximated by the following equations:

$$
\begin{gathered}
\frac{d v_{D}}{d t} \approx \frac{\Delta v_{D}}{\Delta t} \approx \frac{v_{D}-v_{D, \text { upriver }}}{d_{c m} / v_{D}}, \text { and } \\
\frac{d v_{C}}{d t} \approx \frac{\Delta v_{C}}{\Delta t} \approx \frac{v_{C}-v_{C, \text { crossriver }}}{d_{c m} / v_{C}}
\end{gathered}
$$

where 


$$
\begin{aligned}
& d_{c m}=\text { the distance between grid location centers, equal to } 6096 \mathrm{~cm} \text {, } \\
& v_{D \text {,upriver }}=\text { the downstream flow one grid column upriver, } \\
& v_{C \text {,crossiver }}=\text { the cross-stream flow one grid row away from the power turbines. }
\end{aligned}
$$

In some locations, such as grid locations at the edge of the grid, where downstream flow one grid column upriver or cross-stream flow one grid row away from power turbines does not exist, similar calculations were performed using flow values from one grid column downriver or one grid row towards the power turbines in their place.

\subsection{Smolt Abundance}

With the idea that more fish in total will lead, on average, to more fish locally, total smolt passage through the river is expected to play an important role in localized fish density between surveys. Two methods of measuring smolt passage were available. Smolt passage counts and species composition adjusted for travel time were measured at the Bonneville Dam. As an alternative measure of smolt passage, mean small fish density was calculated across all grid locations sampled in each survey. In an exploratory data analysis, we found that adjusting for mean small fish density $\left(\mathrm{R}^{2}=0.13\right)$ was preferred to adjusting for the smolt passage index $\left(\mathrm{R}^{2}=0.01\right)$.

\subsection{Dam Operations}

In addition to fish densities and flow data, dam operations at both the spillway and power turbines were available for each of the 23 surveys. During the surveys, power units 6, 8, 17, and 18, and spillways 16-23 were not in use. There was a high level of correlation among subsets of the 33 power units and spillways in use during the surveys. Thus, to limit the number of explanatory variables in the model, principal components analysis was performed on the dam operation variables. We chose to keep enough principal components to account for $90 \%$ of the variation seen in the data. This led us to consider eight principal components related to dam operations. The principal components are calculated by multiplying the transpose of the loadings matrix by the turbine and spillway flow data $\left(\Gamma^{\prime} X, \Gamma\right.$ is presented in Table 1). However, $\Gamma$ is based on the relationships between the various turbines and spillways. If the relationship changed, then a different loadings matrix would need to be calculated, and different principal components would result. 
Table 1. Principal components loadings matrix $\Gamma$.

\begin{tabular}{|c|c|c|c|c|c|c|c|c|}
\hline \multirow{2}{*}{$\begin{array}{c}\text { Power unit or } \\
\text { spillway }\end{array}$} & \multicolumn{8}{|c|}{ Principal component } \\
\hline & 1 & 2 & 3 & 4 & 5 & 6 & 7 & 8 \\
\hline Unit 1 & 0.239 & -0.029 & 0.113 & 0.048 & -0.357 & 0.010 & -0.062 & -0.174 \\
\hline Unit 2 & 0.160 & -0.007 & -0.128 & -0.012 & 0.310 & 0.202 & -0.167 & -0.378 \\
\hline Unit 3 & 0.164 & -0.069 & 0.253 & 0.140 & 0.250 & 0.029 & -0.098 & 0.267 \\
\hline Unit 4 & 0.160 & 0.005 & -0.280 & -0.197 & 0.112 & 0.187 & -0.045 & 0.097 \\
\hline Unit 5 & -0.142 & 0.027 & 0.113 & 0.521 & -0.082 & 0.123 & 0.084 & 0.513 \\
\hline Unit 7 & 0.167 & -0.007 & 0.212 & -0.218 & 0.190 & -0.310 & -0.375 & 0.131 \\
\hline Unit 9 & 0.119 & -0.065 & 0.277 & 0.214 & -0.085 & 0.134 & -0.250 & -0.164 \\
\hline Unit 10 & 0.195 & 0.008 & -0.290 & -0.082 & -0.008 & 0.184 & 0.037 & 0.252 \\
\hline Unit 11 & 0.117 & -0.087 & 0.251 & 0.236 & 0.275 & 0.036 & 0.302 & -0.179 \\
\hline Unit 12 & 0.140 & 0.085 & -0.243 & 0.000 & -0.422 & 0.041 & -0.049 & 0.108 \\
\hline Unit 13 & 0.100 & -0.083 & 0.348 & 0.121 & -0.004 & 0.304 & 0.076 & -0.020 \\
\hline Unit 14 & 0.202 & -0.018 & -0.288 & 0.132 & 0.077 & -0.085 & 0.021 & -0.071 \\
\hline Unit 15 & 0.212 & -0.054 & 0.130 & -0.235 & -0.208 & 0.256 & 0.197 & 0.086 \\
\hline Unit 16 & 0.172 & 0.147 & -0.244 & 0.237 & 0.067 & -0.183 & 0.116 & -0.029 \\
\hline Unit 19 & 0.215 & -0.111 & 0.168 & -0.149 & 0.057 & -0.116 & -0.304 & -0.046 \\
\hline Unit 20 & 0.229 & 0.007 & -0.041 & 0.334 & 0.042 & -0.038 & -0.091 & -0.233 \\
\hline Unit 21 & 0.189 & 0.026 & 0.161 & -0.116 & -0.389 & 0.172 & 0.227 & -0.291 \\
\hline Unit 22 & 0.177 & 0.067 & -0.259 & 0.320 & -0.039 & -0.218 & 0.063 & -0.166 \\
\hline Spillway 1 & 0.273 & -0.114 & 0.018 & -0.039 & -0.031 & -0.115 & 0.103 & 0.074 \\
\hline Spillway 2 & 0.186 & -0.264 & -0.040 & 0.040 & -0.021 & -0.071 & 0.022 & 0.110 \\
\hline Spillway 3 & 0.190 & -0.264 & -0.040 & 0.016 & -0.022 & -0.031 & 0.020 & 0.082 \\
\hline Spillway 4 & 0.191 & -0.259 & -0.047 & 0.010 & 0.029 & 0.023 & 0.042 & 0.159 \\
\hline Spillway 5 & 0.194 & -0.258 & -0.046 & -0.001 & 0.019 & -0.005 & 0.043 & 0.121 \\
\hline Spillway 6 & 0.175 & -0.277 & -0.045 & 0.010 & -0.021 & -0.083 & 0.003 & 0.121 \\
\hline Spillway 7 & 0.126 & 0.236 & 0.153 & -0.158 & 0.048 & -0.214 & 0.334 & 0.092 \\
\hline Spillway 8 & 0.148 & 0.232 & 0.151 & -0.088 & 0.021 & -0.318 & 0.221 & 0.050 \\
\hline Spillway 9 & 0.156 & 0.224 & 0.150 & -0.041 & -0.045 & -0.324 & 0.147 & 0.039 \\
\hline Spillway 10 & 0.132 & 0.278 & 0.047 & 0.125 & -0.014 & 0.015 & -0.163 & -0.025 \\
\hline Spillway 11 & 0.114 & 0.305 & 0.004 & -0.025 & 0.104 & 0.205 & -0.100 & 0.039 \\
\hline Spillway 12 & 0.127 & 0.299 & 0.024 & 0.027 & 0.003 & 0.170 & -0.130 & 0.095 \\
\hline Spillway 13 & 0.145 & 0.273 & 0.024 & 0.179 & -0.051 & 0.107 & -0.104 & 0.085 \\
\hline Spillway 14 & 0.189 & 0.233 & -0.004 & -0.118 & -0.047 & 0.093 & -0.249 & 0.200 \\
\hline Spillway 15 & 0.157 & 0.117 & -0.060 & -0.132 & 0.402 & 0.311 & 0.338 & 0.005 \\
\hline
\end{tabular}

\subsection{Statistical Modeling Approach}

We chose to work in a generalized linear regression framework (GLM) (Nelder and Wedderburn 1972), which models normal, Poisson, exponential, gamma, and other distributions easily. This reduces to traditional linear regression when a normal distribution is assumed, but is flexible enough to handle transformations of linear predictors (the link function) and non-constant variance. After exploratory data analysis, we used Poisson regression for modeling purposes. Poisson regression uses a log-link function for modeling the mean response, assumes that the variance is proportional to the mean (times a scale 
parameter $\varphi$ when robust Poisson regression, quasi-likelihood, is used), and that the deviance function is properly calculated as

$$
\text { Deviance }=\sum_{y \neq 0} 2 \cdot(y \cdot \log (y / E(y))-(y-E(y)))+\sum_{y=0}-2 \cdot(y-E(y)) \text {. }
$$

We looked to see if separate models were necessary for different time periods, for example modeling spring days separately from summer nights, or if all data could be modeled together. Thus, regression models were performed on all data, and also on subsets of data restricted by photoperiod and season. If results were similar across the subsets, we would choose to model all of the data together, but if there were substantial differences, then we would choose to keep the data separate. Additionally, models with time-averaged outcome variables were modeled using robust Poisson regression, because averaging values reduces the variance. Computations were performed in S-Plus.

\subsection{Modeling the Complete Data}

For the complete dataset typically comprising $75-80 \%$ of $N=257$ grid locations across each of 23 surveys, we first considered a nearly saturated model (Model 1) where the only source of unexplained variability in small fish density was the variation seen during repeated measurements at each grid location within a photoperiod and season. This model provided approximately the same level of information that a map of averaged fish means by location would provide, and is as follows:

$$
\begin{aligned}
\ln (E(y \mid l, p, s))= & \beta_{0}+\beta_{l} \cdot l+\beta_{p} \cdot p+\beta_{s} \cdot s+\beta_{l, p} \cdot l \cdot p+\beta_{l, s} \cdot l \cdot s \\
& +\beta_{p, s} \cdot p \cdot s+\beta_{l, p, s} \cdot l \cdot p \cdot s+\ln (\mathrm{smolt})
\end{aligned}
$$

where

$$
\begin{aligned}
& y=\text { the fish density per } 1000 \mathrm{~m}^{3}, \\
& l=\text { a categorical variable representing grid location, } \\
& p=\text { a categorical variable representing the photoperiod (day or night), } \\
& s=\text { a categorical variable representing the season (spring or summer), } \\
& \ln (\text { smolt) = an adjustment for the survey mean smolt density. }
\end{aligned}
$$

We also considered a limited model (Model 2), which modeled small fish density as a function of season, photoperiod, flow variables, dam operation principal components, river depth at each grid location, and smolt passage. Model 2 tests how much of the variation can be described by measurable explanatory variables other than location, and can be described as follows: 


$$
\begin{aligned}
\ln (E(y \mid p, s, \text { flow, dam operations }))= & \beta_{0}+\beta_{p} \cdot p+\beta_{s} \cdot s+\beta_{p, s} \cdot p \cdot s+ \\
& \beta_{f_{D}} \cdot f_{D}+\beta_{f_{C}} \cdot f_{C}+\beta_{f_{V}} \cdot f_{V}+\beta_{f_{M}} \cdot f_{M} \\
& +\beta_{\kappa} \cdot|\kappa|+\beta_{d} \cdot d+\sum_{i=1}^{8} \beta_{D, i} \cdot D_{i}+\ln (\text { smolt }) .
\end{aligned}
$$

In addition to model 1 variables, the following variables were defined:

$$
\begin{aligned}
& f_{D}=\text { the downstream flow component, } \\
& f_{C}=\text { the cross-stream flow component, } \\
& f_{V}=\text { the vertical flow component, } \\
& f_{M}=\text { the flow magnitude, } \\
& \kappa=\text { the flow curvature, } \\
& d=\text { the average river depth for the grid location, } \\
& D_{i}=\text { the ith dam operation principal component. }
\end{aligned}
$$

We also considered a variation of Model 2 for use in stepwise regression that included all two-way interactions of season, photoperiod, flow, and dam operation variables.

Finally, we considered the nearly saturated model (Model 1) combined with flow variables, dam operation principal components, river depth at each grid location, and smolt passage (additional Model 2 variables), to create a third model (Model 3). This model tests how much additional variation can be explained after adjusting for spatial location, and is as follows:

$$
\begin{aligned}
\ln (E(y \mid p, s, l \text {, flow, dam operations }))= & \beta_{0}+\beta_{l} \cdot l+\beta_{p} \cdot p+\beta_{s} \cdot s+\beta_{l, p} \cdot l \cdot p+\beta_{l, s} \cdot l \cdot s \\
& +\beta_{p, s} \cdot p \cdot s+\beta_{l, p, s} \cdot l \cdot p \cdot s \\
& +\beta_{f_{D}} \cdot f_{D}+\beta_{f_{C}} \cdot f_{C}+\beta_{f_{V}} \cdot f_{V}+\beta_{f_{M}} \cdot f_{M} \\
& +\beta_{\kappa} \cdot|\kappa|+\beta_{d} \cdot d+\sum_{i=1}^{8} \beta_{D, i} \cdot D_{i}+\ln (\mathrm{smolt}) .
\end{aligned}
$$

Additionally, we eliminated grid locations next to turbines, where fish tended to accumulate based on dam operations and would not, we felt, be comparable to locations in the rest of the river. However, models with these locations included performed similarly to models with them excluded. 


\subsection{Modeling Averaged Data}

In addition to modeling the raw data, we averaged fish density and explanatory data across seasons and photoperiods. Consequentially, each grid location could have up to four photoperiod-season averaged values, one for each of spring days, spring nights, summer days, and summer nights. Thus, we use the same variables to model fish density, except that photoperiod-season averaged values are used instead of individual survey values. For the averaged data, Model 1 is a saturated model $\left(\mathrm{R}^{2}=1, \mathrm{df}=0\right)$ since there are no repetitions within a photoperiod and season at a grid location. The most comparable model accounts for photoperiod and season interactions, and adds a location-specific intercept (Model 4), as follows:

$$
\ln (E(y \mid l, p, s))=\beta_{0}+\beta_{l} \cdot l+\beta_{p} \cdot p+\beta_{s} \cdot s+\beta_{p, s} \cdot p \cdot s+\ln (\text { smolt }) .
$$

Model 2 translates directly to the averaged data, allowing us to model averaged fish densities as a function of average values of flow variables, dam operation principal components, river depth at each grid location, and smolt passage (Model 5):

$$
\begin{aligned}
\ln (E(y \mid p, s, \text { flow, dam operations }))= & \beta_{0}+\beta_{p} \cdot p+\beta_{s} \cdot s+\beta_{p, s} \cdot p \cdot s+\beta_{f_{D}} \cdot f_{D} \\
& +\beta_{f_{C}} \cdot f_{C}+\beta_{f_{V}} \cdot f_{V}+\beta_{f_{M}} \cdot f_{M}+\beta_{\kappa} \cdot|\kappa| \\
& +\beta_{d} \cdot d+\sum_{i=1}^{8} \beta_{D, i} \cdot D_{i}+\ln (\text { smolt }) .
\end{aligned}
$$

Additionally, we looked a variation of model 5 that included all main effects and two-way interaction terms remaining after a stepwise regression was performed (Model $5_{\text {stepwise) }}$ ).

Finally, similar to Model 3, we combined Models 4 and 5 to model the additional variation that can be explained by flow, dam, depth, and smolt variables after adjusting for location (Model 6):

$$
\begin{aligned}
\ln (E(y \mid p, s, l \text {, flow, dam operations }))= & \beta_{0}+\beta_{l} \cdot l+\beta_{p} \cdot p+\beta_{s} \cdot s+\beta_{p, s} \cdot p \cdot s \\
& +\beta_{f_{D}} \cdot f_{D}+\beta_{f_{C}} \cdot f_{C}+\beta_{f_{V}} \cdot f_{V}+\beta_{f_{M}} \cdot f_{M} \\
& +\beta_{\kappa} \cdot|\kappa|+\beta_{d} \cdot d+\sum_{i=1}^{8} \beta_{D, i} \cdot D_{i} \\
& +\ln (\text { smolt }) .
\end{aligned}
$$

\subsection{Modeling Spatially Smoothed Data}

One of the difficulties with analyzing the fish data was the large differences in fish density seen between neighboring data points. This could be caused by measurement noise in the density estimation process or be part of the underlying process of fish distribution, and is presumably a combination of the 
two. Any attempt to model noisy data is inherently limited by the level of noise relative to the underlying process in the data, often referred to as the signal to noise ratio. One possible solution to this modeling problem is to "de-noise" the original data, and model the de-noised data. With this in mind, we spatially smoothed the averaged data using three methods: loess smoothing, ordinary kriging and universal kriging.

A variation of Model 5 was run using the spatially smoothed data in place of the photoperiod-season averaged data, to see if the covariates of interest did a better job predicting the smoothed data than they did predicting the original data. That is,

$$
\begin{aligned}
\ln \left(E\left(y_{\text {smoothed }} \mid p, s \text {, flow, dam operations }\right)\right)= & \beta_{0}+\beta_{p} \cdot p+\beta_{s} \cdot s+\beta_{p, s} \cdot p \cdot s \\
& +\beta_{f_{D}} \cdot f_{D}+\beta_{f_{C}} \cdot f_{C}+\beta_{f_{V}} \cdot f_{V} \\
& +\beta_{f_{M}} \cdot f_{M}+\beta_{\kappa} \cdot|\kappa|+\beta_{d} \cdot d \\
& +\sum_{i=1}^{8} \beta_{D, i} \cdot D_{i}+\ln (\text { smolt }) .
\end{aligned}
$$

Additionally, we modeled how well the smoothed data predicted the original, photoperiod-season averaged data, that is,

$$
\ln \left(E\left(y \mid y_{\text {smoothed }}, \text { smolt }\right)\right)=\beta_{0}+\beta_{1} \cdot y_{\text {smoothed }}+\ln (\text { smolt }) \text {. }
$$

We compared how well the model fit the smoothed data $\left(R_{7}^{2}\right)$ together with how well the smoothed data fit the noisy data $\left(R_{8}^{2}\right)$, and compared that to the original, non-smoothed fit from Model $5\left(R_{5}^{2}\right)$. If $R_{7}^{2} \cdot R_{8}^{2}>R_{5}^{2}$, we would conclude that there was a benefit to smoothing the data and modeling the smoothed data. However, if $R_{7}^{2} \cdot R_{8}^{2} \leq R_{5}^{2}$ or $R_{7}^{2} \cdot R_{8}^{2} \approx R_{5}^{2}$, we would conclude that there was no substantial benefit to smoothing the data for modeling purposes.

\subsection{Results}

\subsection{Fish Density}

Fish density data was extremely non-normal (Figure 2). A high percentage (33\%) of the observations found no fish. The lower threshold of detection is approximately 0.04 to 0.10 fish per 1000

cubic meters. Photoperiod-season averaged data was somewhat smoother, had less extreme outliers, and had a considerably smaller percentage (12\%) of observations with no fish (Figure 3). 

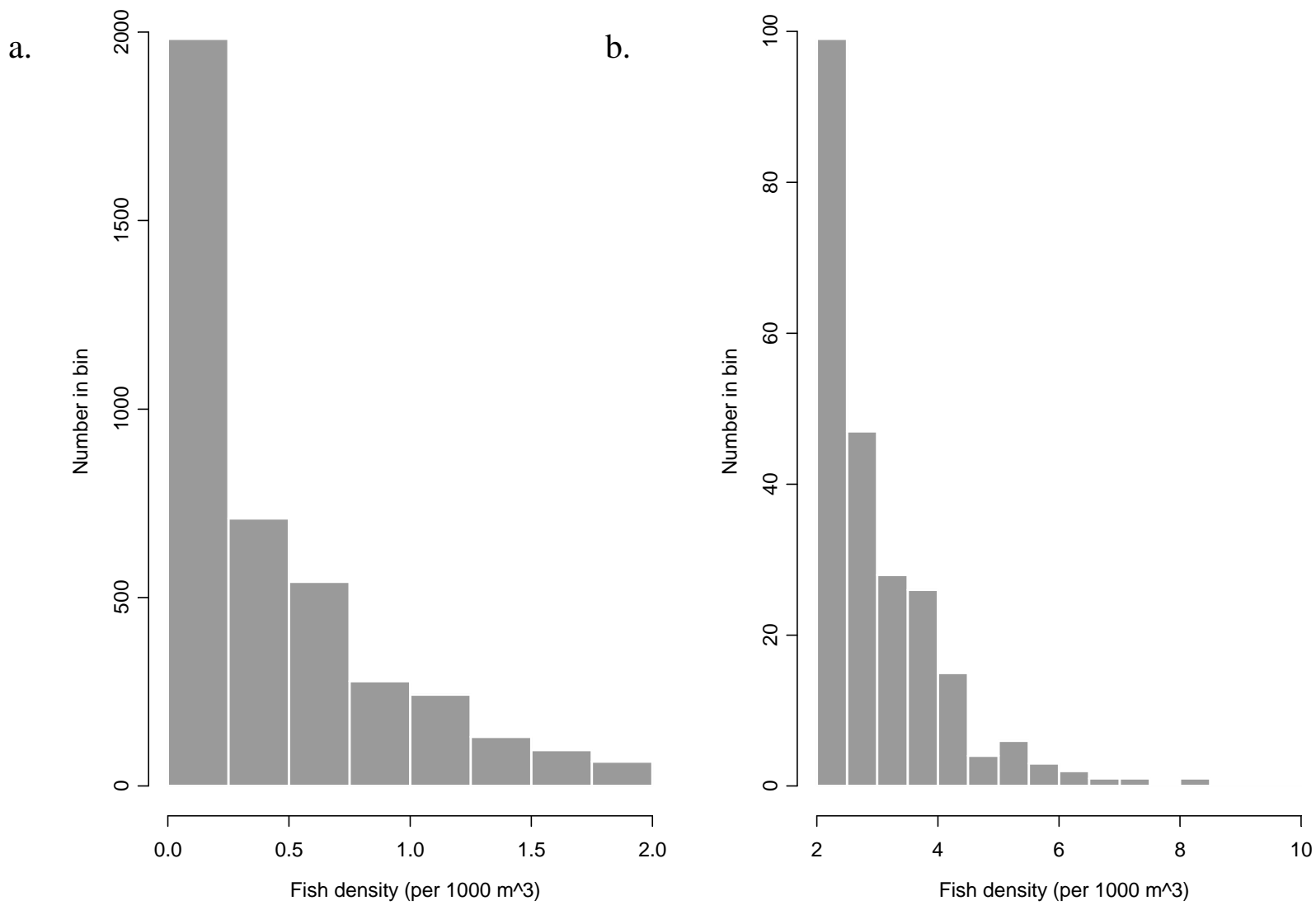

Figure 2. Histograms of fish density from (a) $0-2$ per $1000 \mathrm{~m}^{3}$ and from (b) 2-10 per $1000 \mathrm{~m}^{3}$. Note the change in scale on the y axis. 


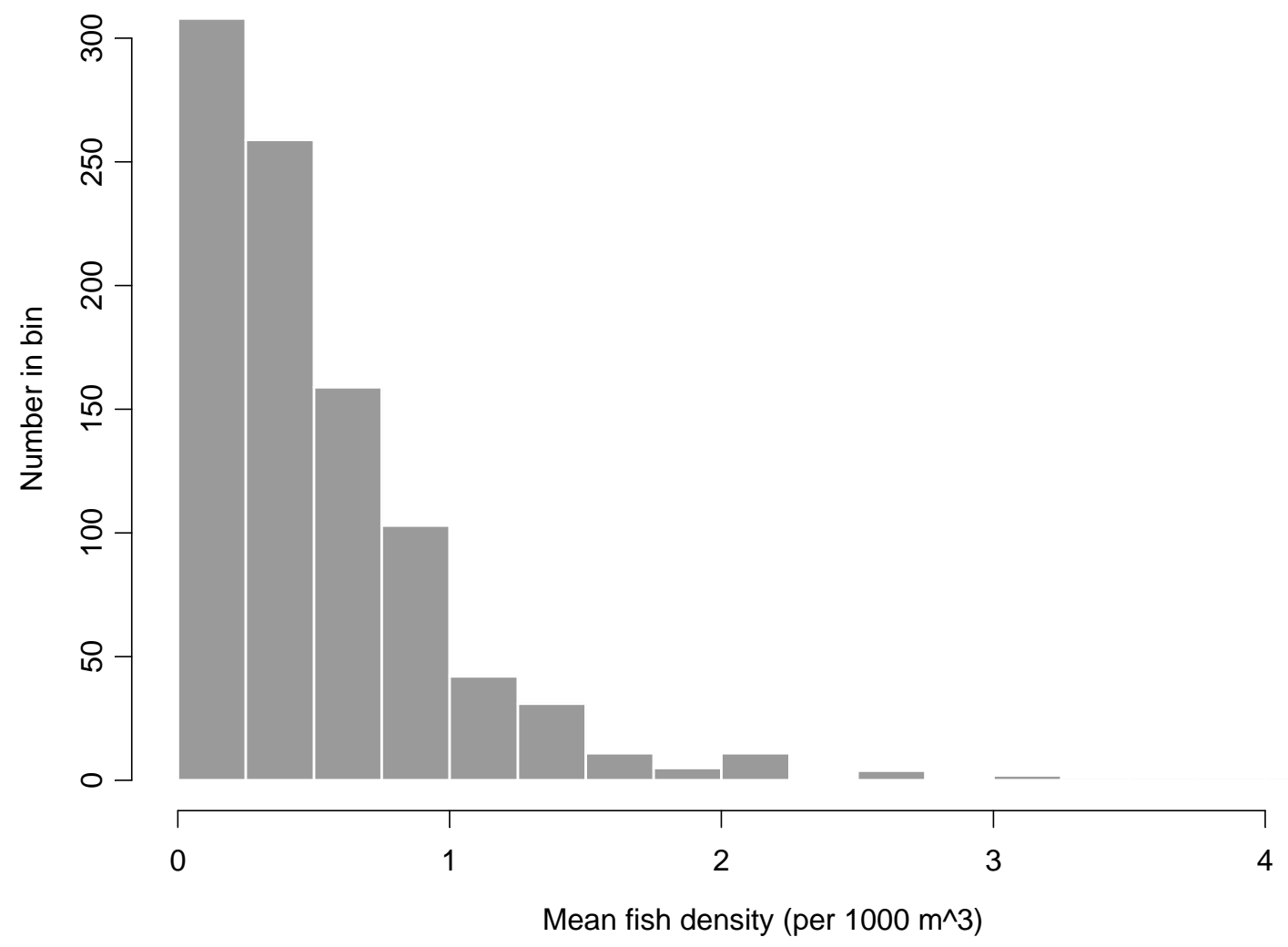

Figure 3. Histogram of photoperiod-season averaged data.

\subsection{Flow and Bathymetry}

The main river flow tended to follow the upriver bathymetry and then curve towards the power turbines. Downstream and cross-stream flow at each grid location were highly correlated from survey to survey. However, there was little consistency in vertical flow between surveys. For example, the May 5th survey and the July 17th survey had correlations of $r=0.76$ for downstream flow and $r=0.68$ for cross-stream flow, but essentially no correlation $(r=0.02)$ in vertical flow. The highest concentration of fish tended to follow river flow from the main channel upstream through to where it curves towards the power turbines; however, there was a great deal of variation (Figure 4). We saw no clear, strong, and simple relationships between flow, bathymetry and fish density (Figure 4), with the exception of variables inherently related to each other, such as flow magnitude and downstream flow (Figure 5). 


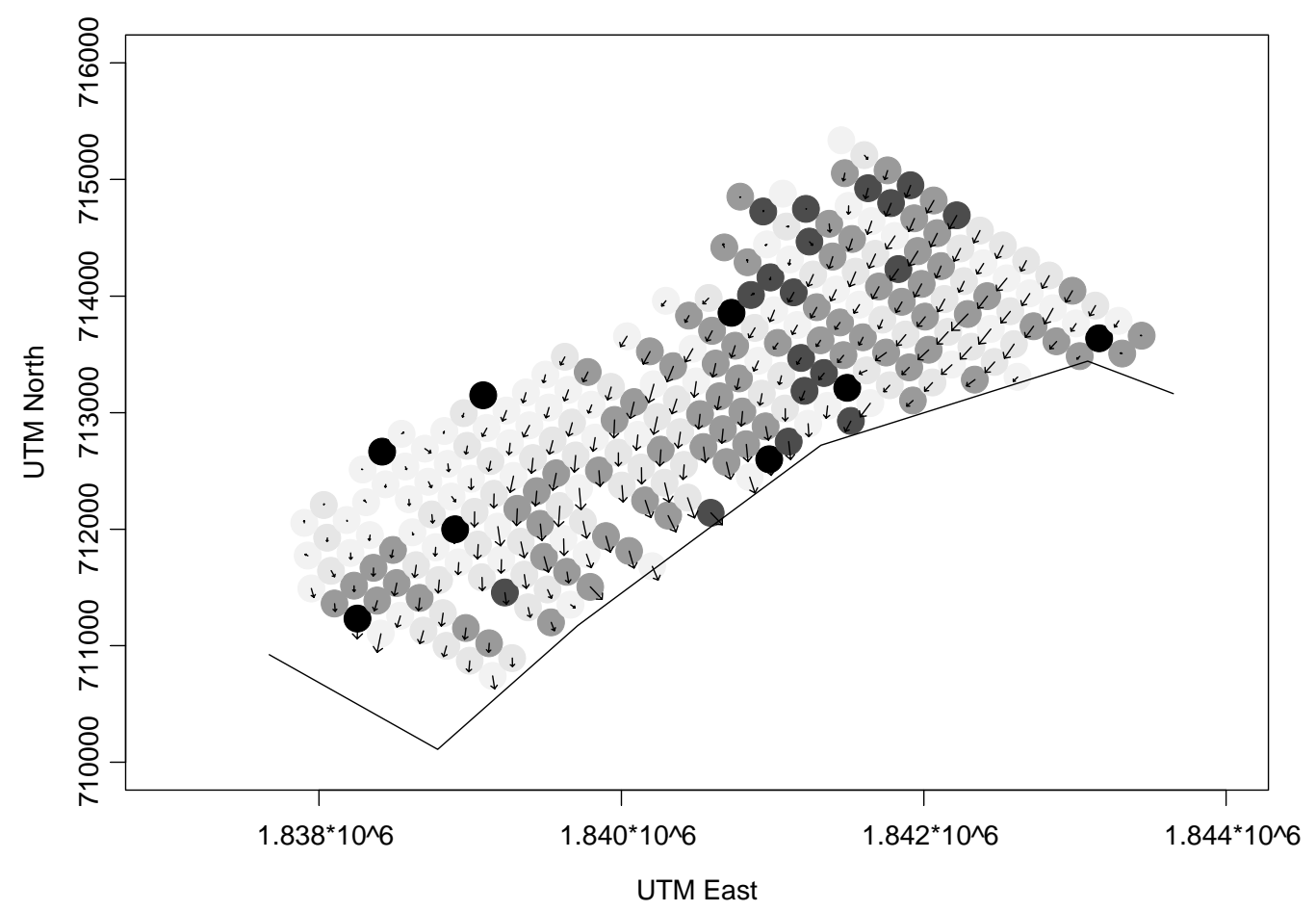

Figure 4. Flow direction (arrow) and magnitude (arrow length) and fish density (darker shades represent greater fish density) for summer-day-averaged data.

\subsection{Predictive Model Results}

Unlike many analyses where hypotheses testing is of paramount concern, the goal of this modeling was to explain as much of the variation as possible, and to see whether or not a model with a few covariates could adequately replace one with many spatial covariates in terms of its ability to predict fish abundance. In general, we were unable to substantially improve upon or replace the spatial location model. This means that a map of photoperiod-season averaged data is neither adequately replaced nor substantially supplemented by knowledge of flow, depth, or dam operations.

\subsubsection{Complete Data, Models 1-3}

For the complete data, the nearly saturated Model 1 with location-specific indicator variables only explains a small fraction of the total variability in the data $\left(\mathrm{R}^{2}=0.40\right)$, indicating a large amount of sampling and natural variability cannot be explained by season, photoperiod, or location. Subsets of this model restricted to a specific season and photoperiod yielded similar levels $\left(R^{2}=0.36\right.$ to 0.44$)$ of unexplained variability (Table 2 ). These $\mathrm{R}^{2}$ values provide an upper bound on how well a predictive model with hydrologic data could do under best circumstances. 


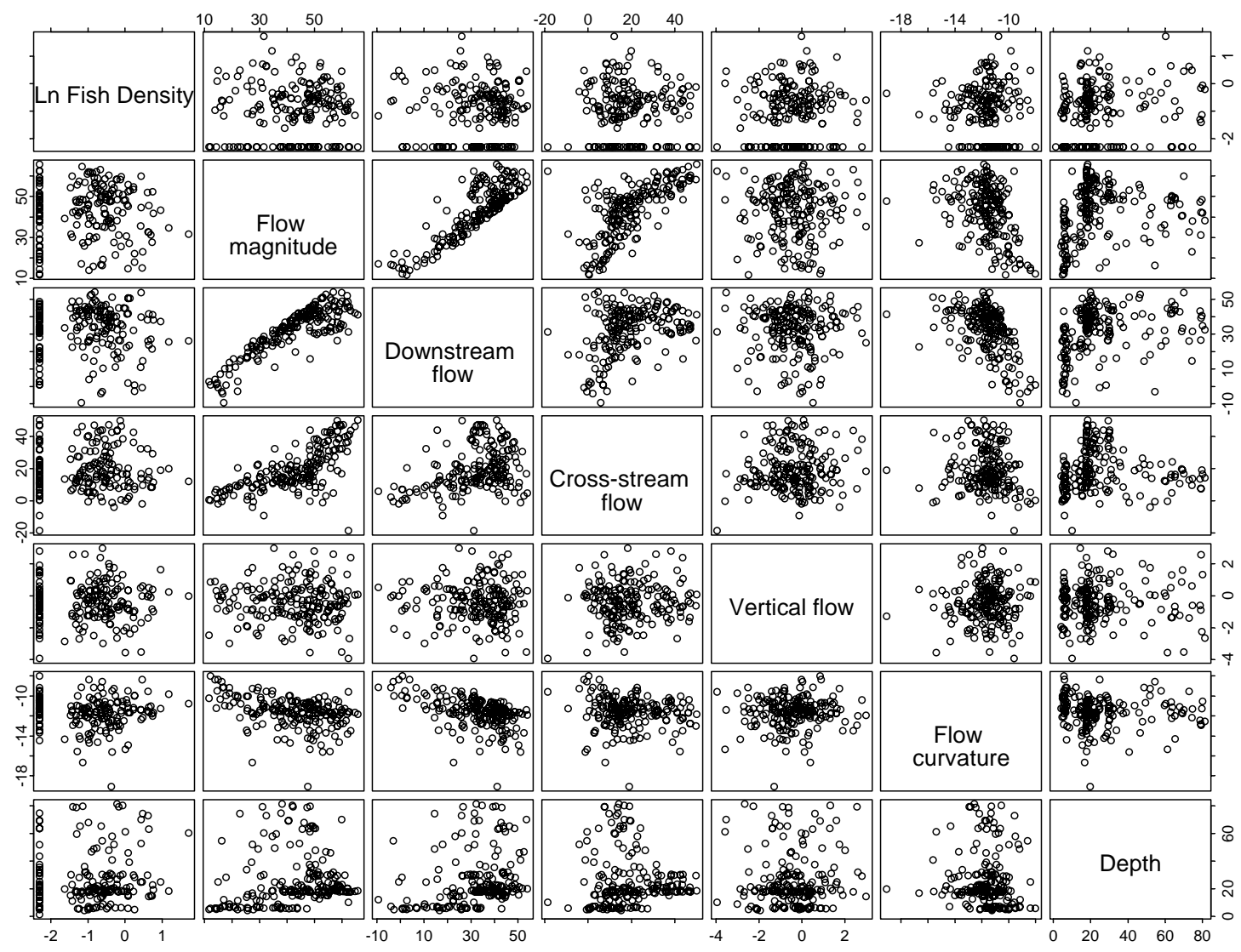

Figure 5. Relationship between flow, bathymetry, and fish density (May 5, 2003 data used for illustrative purposes).

Table 2. Summary of $\mathrm{R}^{2}$ values for different datasets and fitted regression models using all replicate survey information.

\begin{tabular}{|c|c|c|c|c|}
\hline \multirow[b]{2}{*}{ Dataset } & \multirow{2}{*}{$\begin{array}{l}\text { Number of } \\
\text { Surveys }\end{array}$} & \multicolumn{3}{|c|}{$\mathrm{R}^{2}$} \\
\hline & & Model 1 & Model 2 & Model 3 \\
\hline All season and periods & 23 & 0.40 & 0.07 & 0.42 \\
\hline Spring days only & 6 & 0.39 & 0.10 & 0.42 \\
\hline Spring nights only & 6 & 0.44 & 0.10 & 0.46 \\
\hline Summer days only & 6 & 0.36 & 0.05 & 0.40 \\
\hline Summer nights only & 5 & 0.39 & 0.04 & 0.41 \\
\hline
\end{tabular}


The covariate model, Model 2, with season, photoperiod, flow, dam operation, and bathymetry variables only explained a limited amount of variation. A main effects version of Model 2 had R2 $=0.07$ (Table 2), while a model with two-way interactions remaining after a stepwise regression had R2 $=0.10$. The distinction between Models 1 and 2 is Model 1 had an indicator variable for each grid location while Model 2 used flow and dam operations to explain the spatial variation in smolt densities. Many of the interaction terms remaining in the model have difficult substantive interpretations, and many covariates are highly correlated with each other. While significant effects for flow, depth, season and photoperiod were found, the level of variation explained by this model was a small fraction of that explained by Model 1 (i.e., R2 $=0.04-0.10$ out of R2 $=0.36-0.44$ ). Thus, Model 2 is not a suitable replacement for Model 1 .

The fullest model, Model 3, which included location as well as all explanatory variables (main effects only), did not substantially improve on Model 1 ( $R 2=0.42$, compared to R2 $=0.40$ for Model 1 , a 5\% improvement). Model 1 attempts to explain the spatial pattern in smolt densities with indicator variables for grid locations, season, and photoperiod. What remains unexplained by Model 1 is then the variability in fish density pattern between replicate surveys. Model 3 attempts to model the unexplained between-replicate variable by flow and dam operational covariates. The starkly small improvement in R2 values between Models 1 and 3 (Table 2) suggests the covariates cannot explain that variability. Instead, that between-replicate variability is sampling error, and the best approach is to simply model the photoperiod-seasonal averages.

The conclusion from this section are as follows:

1. The best predictive model will not be able to explain more than approximately $40 \%$ (i.e., $\mathrm{R}^{2}=$ 40) of the spatial pattern in smolt densities at the forebay of The Dalles Dam.

2. The river flow and dam operational covariates do not appear to be capable of explaining much of the spatial pattern in smolt densities $\left(\mathrm{R}^{2} \leq 0.10\right)$.

3. The spatial patterns across replicate surveys are not appreciably different, and the differences cannot be explained by existing covariates.

4. Modeling the spatial patterns using just average results across replicate surveys will be sufficient in model construction.

The next section describes the modeling of the average spatial patterns within each of the four photoperiod-seasonal datasets.

\subsubsection{Photoperiod-Season Averaged Data}

Averaging the fish density data across the five or six replicate surveys within a photoperiod and season is one approach to reducing sampling noise (Figure 6). Averaging was performed on a grid-point basis across the replicate surveys. The spatial pattern of average deviation was then used in the regression analyses. 
(a)

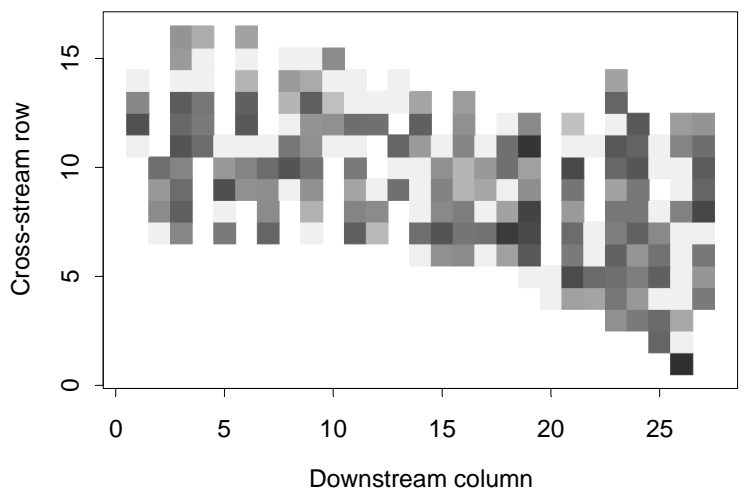

(c)

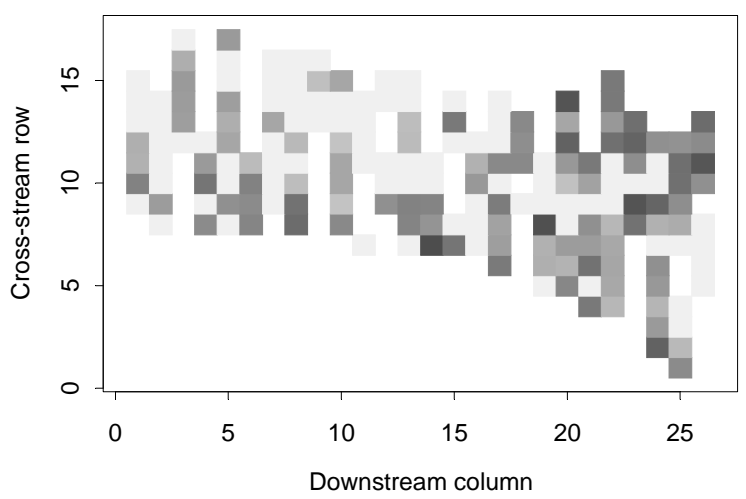

(b)

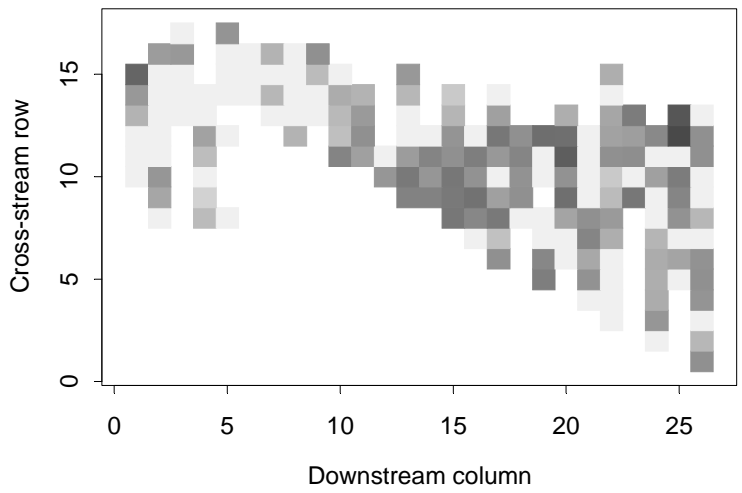

(d)

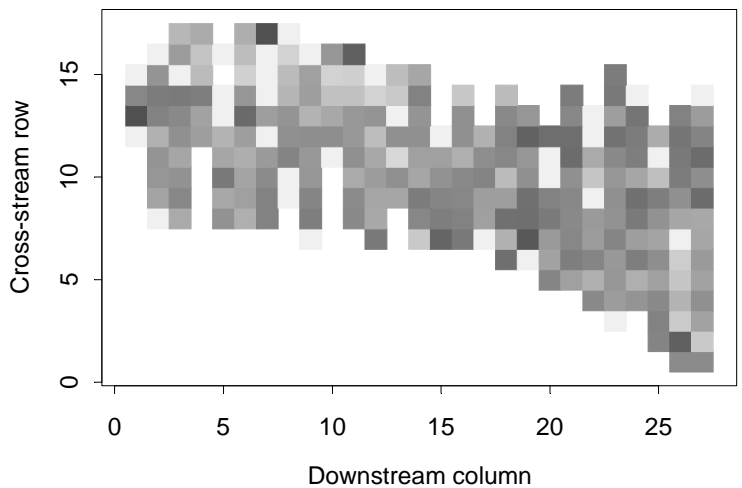

Figure 6. Distribution in fish density on (a) June 17, (b) July 4, (c) July 17, and (d) averaged over all summer days in 2003 (darker shades represents more fish).

The first analysis used the four photoperiod-seasonal datasets and used indicator variables for season-by-photoperiod interactions and grid locations. This model, Model 4, explained most of the variation seen $(\mathrm{R} 2=0.66)$, suggesting that averaging across replicates was a worthwhile de-noising strategy. Again, this model provides an indication of the upper bound on the performance of any predictor model with flow and dam operational covariates. Model 5 then analyzes the same dataset using indicator variables for photoperiod-season and continuous variables for flow, bathymetry, and dam operations, resulting in an R2 $=0.19$ (Table 3). Model 6 used all the indicator variables associated with Model 4 and the continuous variables of Model 5 to produce an R2 $=0.69$. Thus, the flow and dam operational variables contribute little beyond grid-specific indicators.

To identify the best-fit predictive models, stepwise regression analysis was performed. The stepwise regression analysis for Model 5stepwise accounted for the following:

a. Average smolt density 
b. Indicator variables for photoperiod-season

c. Continuous variables for flow, dam operations, and their interactions

Table 3. Summary of $\mathrm{R}^{2}$ values for different regression models using the four photoperiod-seasonal averages.

\begin{tabular}{cccccc}
\hline & & \multicolumn{3}{c}{$\mathrm{R}^{2}$} \\
Dataset & $\begin{array}{c}\text { Number } \\
\text { of Cases }\end{array}$ & Model 4 & Model 5 & Model 6 & Model 7 \\
\cline { 3 - 6 } $\begin{array}{c}\text { Season and } \\
\text { Photoperiod Averages }\end{array}$ & 4 & 0.66 & 0.19 & 0.69 & 0.24 \\
\hline
\end{tabular}

Criteria for inclusion of a variable was a decrease in AIC $\left(\right.$ AIC $=$ Deviance $\left.+2 \cdot s c a l e \cdot d f_{\text {residual }}\right)$. The scale parameter was set equal to 1.5 . The stepwise regression selected a model with 19 parameters and had an R2 $=0.24$, a 26\% improvement over the main effects model. Figures 7-10 graphically depict the observed average fish densities, the predicted deviations, and residuals from the fitted model. There was some variation in the predictive ability between different photoperiods and seasons. The models preformed better describing nighttime variation and somewhat better describing spring variation (R2 = 0.21 for spring days, $\mathrm{R} 2=0.34$ for spring nights, $\mathrm{R} 2=0.14$ for summer days, and $\mathrm{R} 2=0.30$ for summer nights). The estimates came from the equation:

$$
\begin{aligned}
\ln (E(y \mid p, s, \text { flow, dam operations }))= & -1.84-0.31 \cdot p+0.32 \cdot s+0.40 \cdot p \cdot s \\
& -0.02 \cdot f_{C}-0.14 \cdot f_{V}+2678 \cdot|\kappa|+0.003 \cdot d+0.40 \cdot d \cdot f_{C} \\
& +0.058 \cdot D_{1}-0.275 \cdot D_{2}+0.390 \cdot D_{3}+0.359 \cdot D_{4} \\
& +0.448 \cdot D_{7}+0.168 \cdot D_{8} \\
& +0.185 \cdot D_{1} \cdot D_{3}-0.256 \cdot D_{2} \cdot D_{4}-0.309 \cdot D_{3} \cdot D_{7} \\
& +0.08 \cdot f_{V} \cdot D_{2}+7721 \cdot|\kappa| \cdot D_{8}+\ln (\mathrm{smolt})
\end{aligned}
$$

where $\mathrm{p}=1$ for days, $\mathrm{p}=0$ for nights, and $\mathrm{s}=1$ for spring, $\mathrm{s}=0$ for summer.

This model is intended for predictive, not interpretive purposes. It is difficult to interpret this model. For example, note that there is no downstream flow velocity (fD) component to the regression model. This does not mean that there is no relationship between downstream flow velocity and fish density. Downstream flow velocity is higher in spring than summer, higher when cross-stream flow is high, and is also positively correlated with dam operation principal components 1 and 3 . The inclusion of those variables in the model acts at some level as a proxy for downstream flow velocity in the model. Many other variables are similarly related, and are consequently equally difficult to draw conclusions from. 

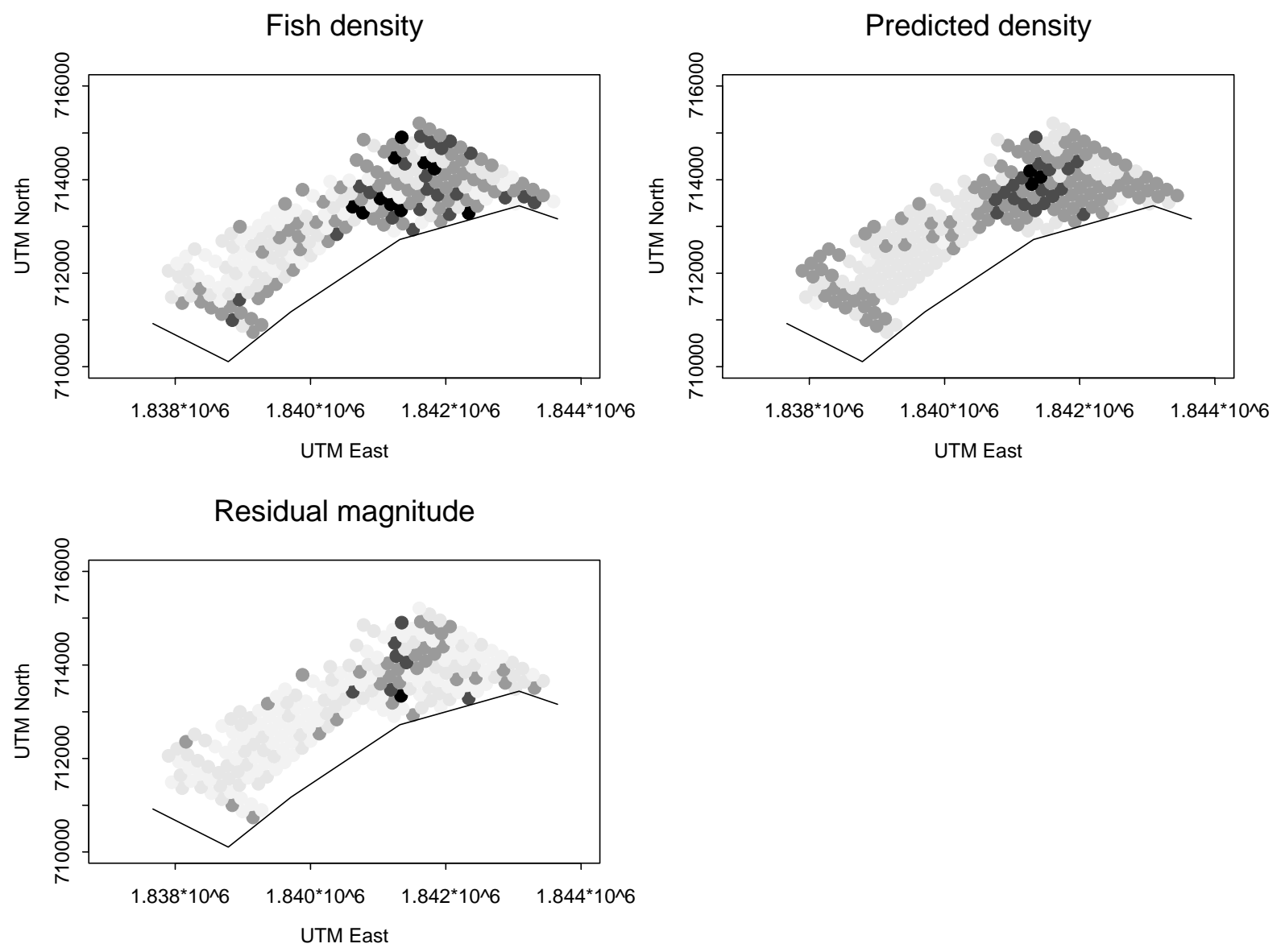

Figure 7. Fish density, predicted density, and residual magnitudes for spring days (darker colors represent higher fish densities). 

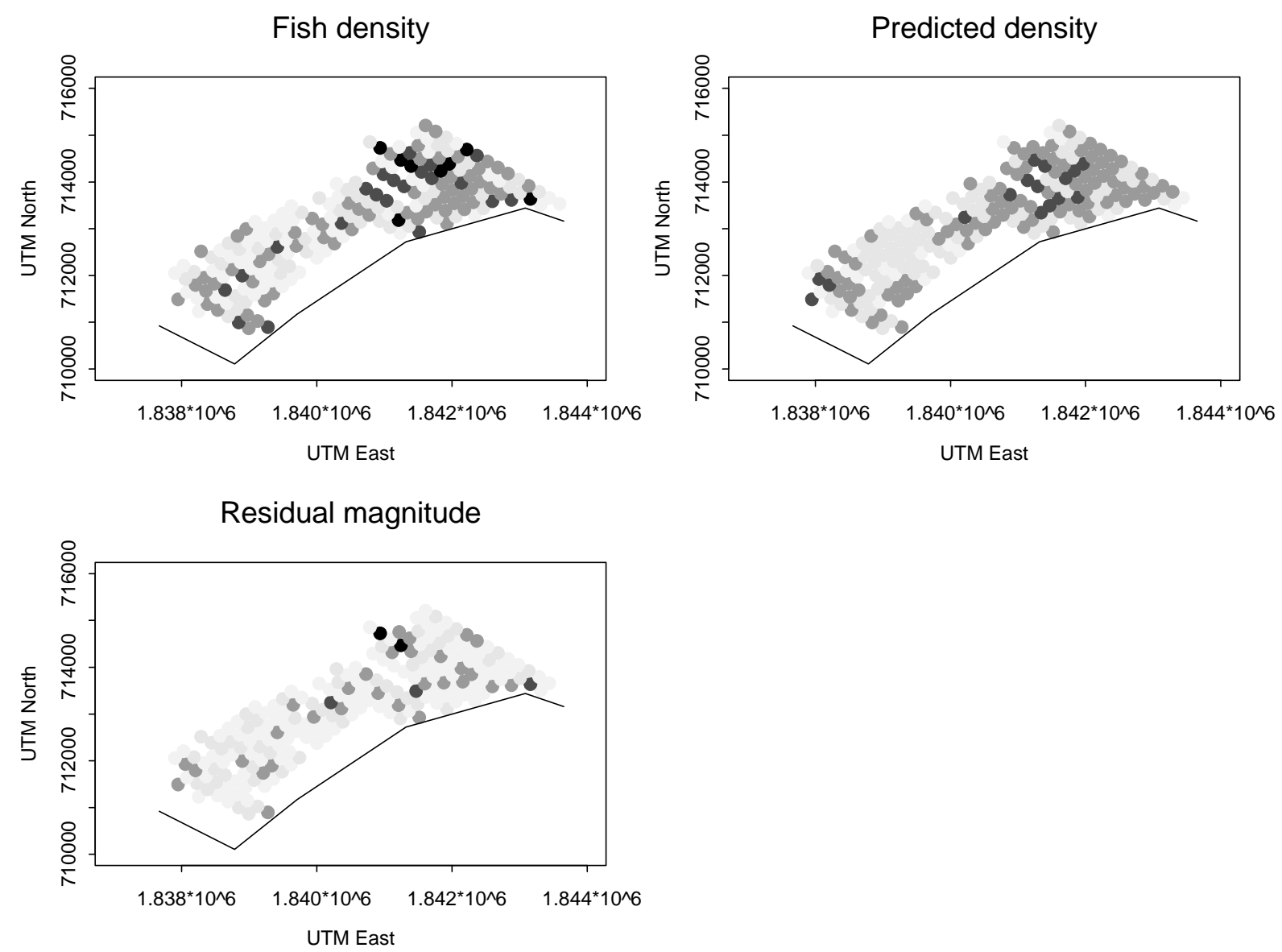

Figure 8. Fish density, predicted density, and residual magnitudes for spring nights (darker colors represent higher fish densities). 

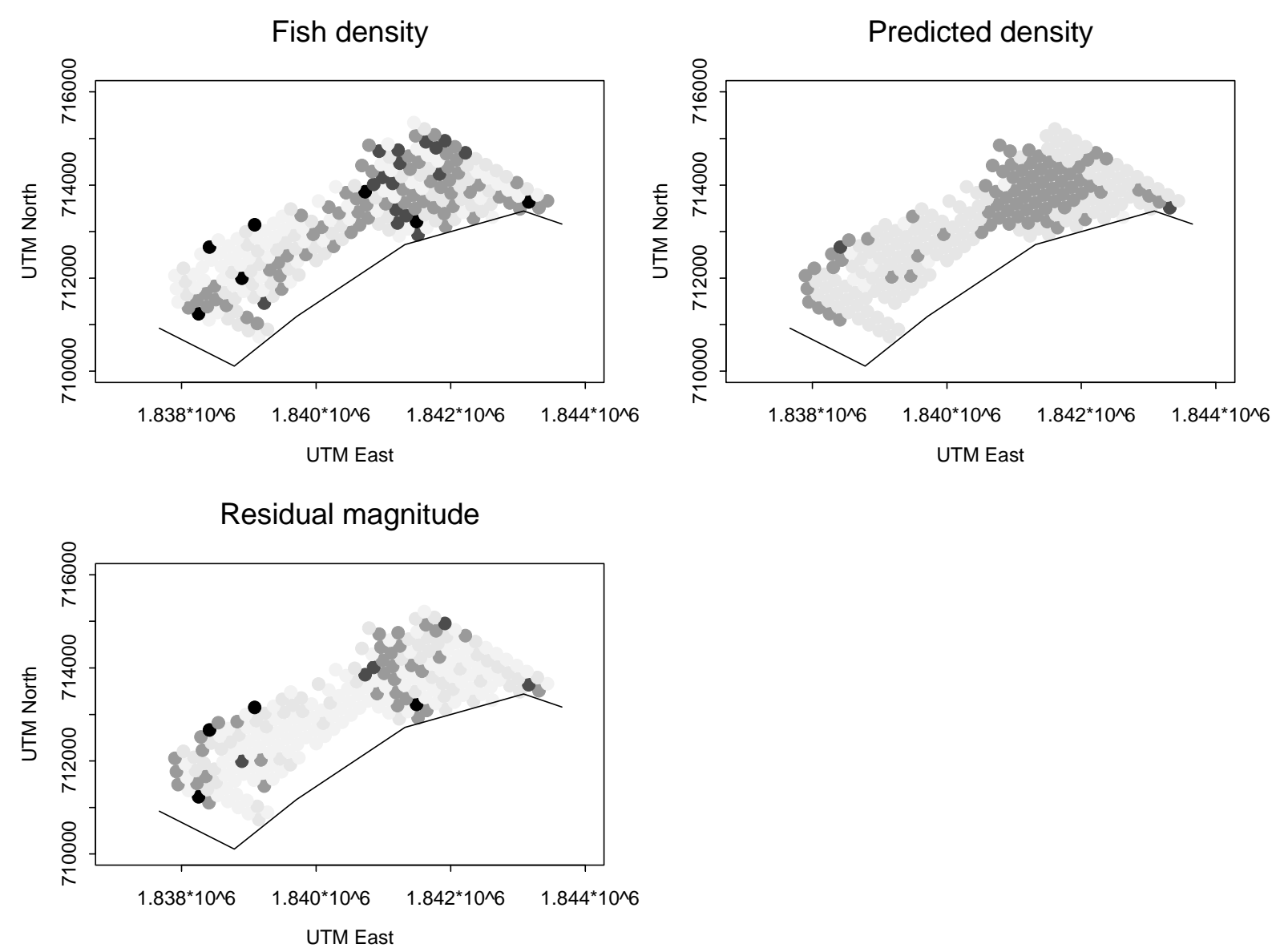

Figure 9. Fish density, predicted density, and residual magnitudes for summer days (darker colors represent higher fish densities). 
Fish density
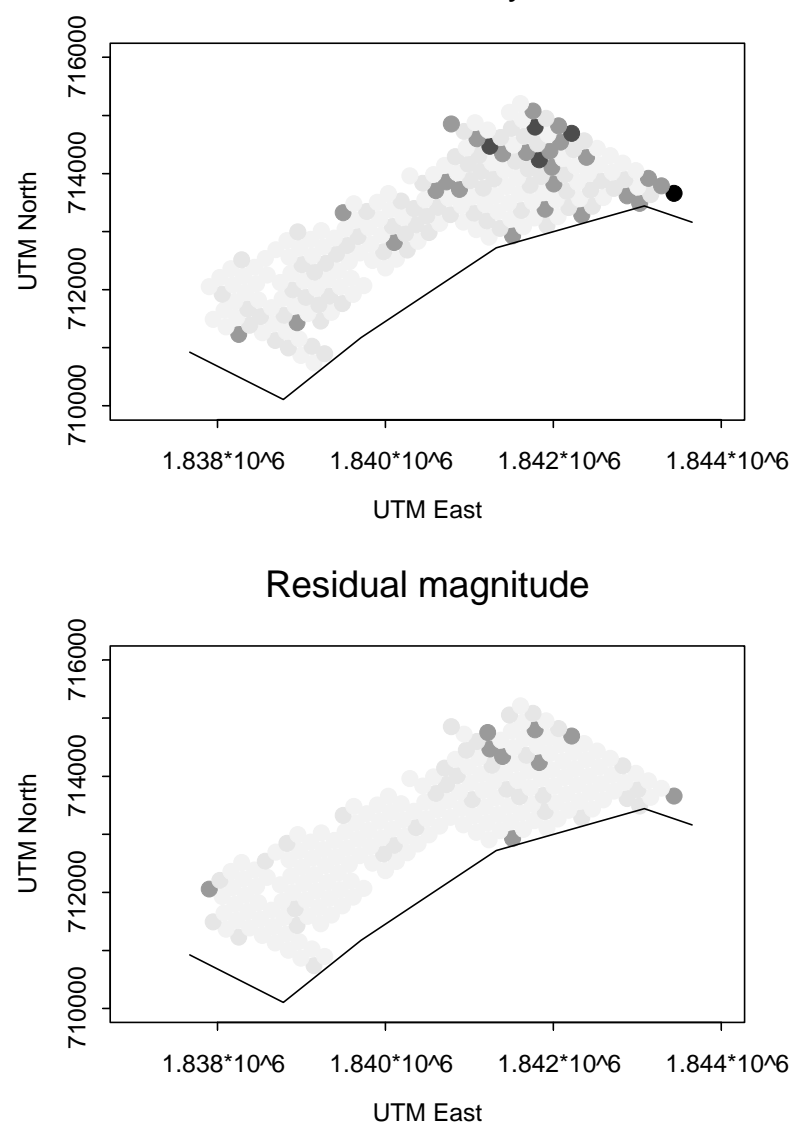

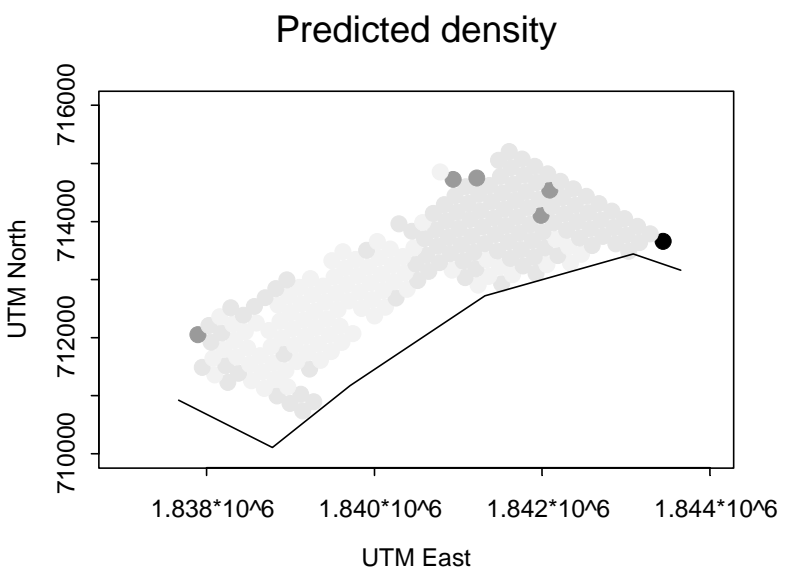

Figure 10. Fish density, predicted density, and residual magnitudes for summer nights (darker colors represent higher fish densities). 


\subsubsection{Spatially Smoothed Data}

The photoperiod-season averaged data has large differences in fish density between neighboring locations. These spikes may be a result of localized differences in fish density or may be mostly noise. If the spikes are mostly noise, then we might consider the spatially smoothed values as more representative of the true fish density than the measured values. We could then model the smoothed fish densities given flow, dam operation, bathymetry, and smolt passage rather than modeling the averaged densities. However, if the spikes represent true, localized variations in density, then we must also consider how well the smoothed data predicts the photoperiod-season averaged data (Model 8) in combination with how well the smoothed densities are predicted by Model 7 covariates.

Data was smoothed with loess, ordinary kriging, and universal kriging. We were able to predict spatially smoothed data with flow, dam operations, bathymetry, and smolt passage variables (Model 7) considerably better than we were able to predict photoperiod-season averaged data (Table 4). Ordinary kriging performed better than universal kriging or loess smoothing in our approach. We could explain approximately $50 \%$ of the variation in kriged fish density with flow, dam operation, bathymetry, and smolt passage, compared to approximately $20 \%$ of the variation in the photoperiod-season averaged data (Model 5). However, the smoothed data did not predict the averaged data particularly well (Model 8; $\mathrm{R}^{2}$ between 0.34 and 0.44 for ordinary kriging). When Model 7 and Model 8 are considered in tandem for kriged data, there is no improvement over Model 5. Thus, if the localized spikes in fish density represent real variations in fish density, then there is no benefit to kriging, but if the localized spikes are strictly or mostly noise, then there is a benefit to kriging. Because it is unclear whether the localized peaks are real or an artifact of sampling error, we chose not to rely on this analytical option. Instead, we recommend the results of Section 4.3.2 be used in predicting localized fish densities.

\subsection{Conclusions}

The covariates concerning river flow, dam operations, and bathymetry did little to explain the differences in observed fish densities between replicate fish surveys within a photoperiod-season (R2 = 0.42 versus $\mathrm{R} 2=0.40$ for a model without the covariates). This result suggested the best approach would be to model the average spatial distribution of fish within a photoperiod and season. The $\mathrm{R}^{2}=0.40$ from a regression model with unique indicator variables for each grid location also suggested that at best a regression model might describe $40 \%$ of the overall variability. 
Table 4. Summary of the $\mathrm{R}^{2}$ values for different regression models. The $\mathrm{R}^{2}$ is associated with regressing ambient data against the spatially smoothed data. $\mathrm{R}_{8}^{2}$ is associated with regressing the ambient covariates directly against the seasonal average spatial fish densities.

\begin{tabular}{ccccc}
\hline Smoothing Method & $\mathrm{R}_{7}^{2}$ & $\mathrm{R}_{8}^{2}$ & $\mathrm{R}_{7}^{2} \cdot \mathrm{R}_{8}^{2}$ & $\mathrm{R}_{5}^{2}$ \\
\hline Loess smoothing & & & & \\
Spring day & 0.20 & 0.26 & 0.05 & 0.16 \\
Spring night & 0.37 & 0.42 & 0.16 & 0.15 \\
Summer day & 0.20 & 0.31 & 0.06 & 0.18 \\
Summer night & 0.23 & 0.28 & 0.07 & 0.16 \\
Ordinary kriging & & & 0.14 & 0.29 \\
Spring day & 0.38 & 0.36 & 0.19 & 0.15 \\
Spring night & 0.56 & 0.34 & 0.19 & 0.18 \\
Summer day & 0.48 & 0.39 & 0.21 & 0.16 \\
Summer night & 0.49 & 0.44 & & 0.29 \\
Universal kriging & & & 0.10 & 0.15 \\
Spring day & 0.31 & 0.32 & 0.17 & 0.18 \\
Spring night & 0.53 & 0.32 & 0.19 & 0.19 \\
Summer day & 0.49 & 0.38 & 0.40 &
\end{tabular}


Using stepwise regression, a model with indicators for season and photoperiod interactions plus continuous flow, dam operations, and bathymetry covariates and their interactions produced an R2 $=0.24$. This $\mathrm{R} 2$ value is relative to an $\mathrm{R} 2=0.66$ achieved using the averaged data and unique grid location indicator variables. In other words, the fitted covariate model did $36 \%$ as well as the most parameterized indicator model in describing mean spatial trends. Generally, the fitted regression models failed to adequately predict the fish densities in the northeastern corner of the survey grid where fish densities were the highest (Figures 7-10). Nevertheless, the stepwise regression model was able to capture the general trend in smolt densities in the forebay of The Dalles Dam (Figures 7-10). Areas of generally higher or lower fish densities were predicted well. What the stepwise or fully parameterized indicator models (i.e., Models 1 and 4) could do well was predict the small-scale localized variability in fish densities between neighboring grid locations. Whether that localized variability is real or not is unknown. The regression on the survey averages assumes that variation is real. If not, the smoothed datasets based on kriging would be more appropriate. Persistence of localized peaks in density after averaging across replicated surveys suggests that the localized variability is real and cannot be ignored.

\subsection{Literature Cited}

Millman, R. S., and G. D. Parker. 1977. Elements of differential geometry. Prentice-Hall, Englewood Cliffs, New Jersey.

Nelder, J. A., and R. W. M. Wedderburn. 1972. Generalized linear models. Journal of the Royal Statistical Society, Series A (General) 135(3):370-384. 
A. 28 


\section{Appendix B}

Water Velocity Magnitude in the Forebay of The Dalles Dam 
B. 2 

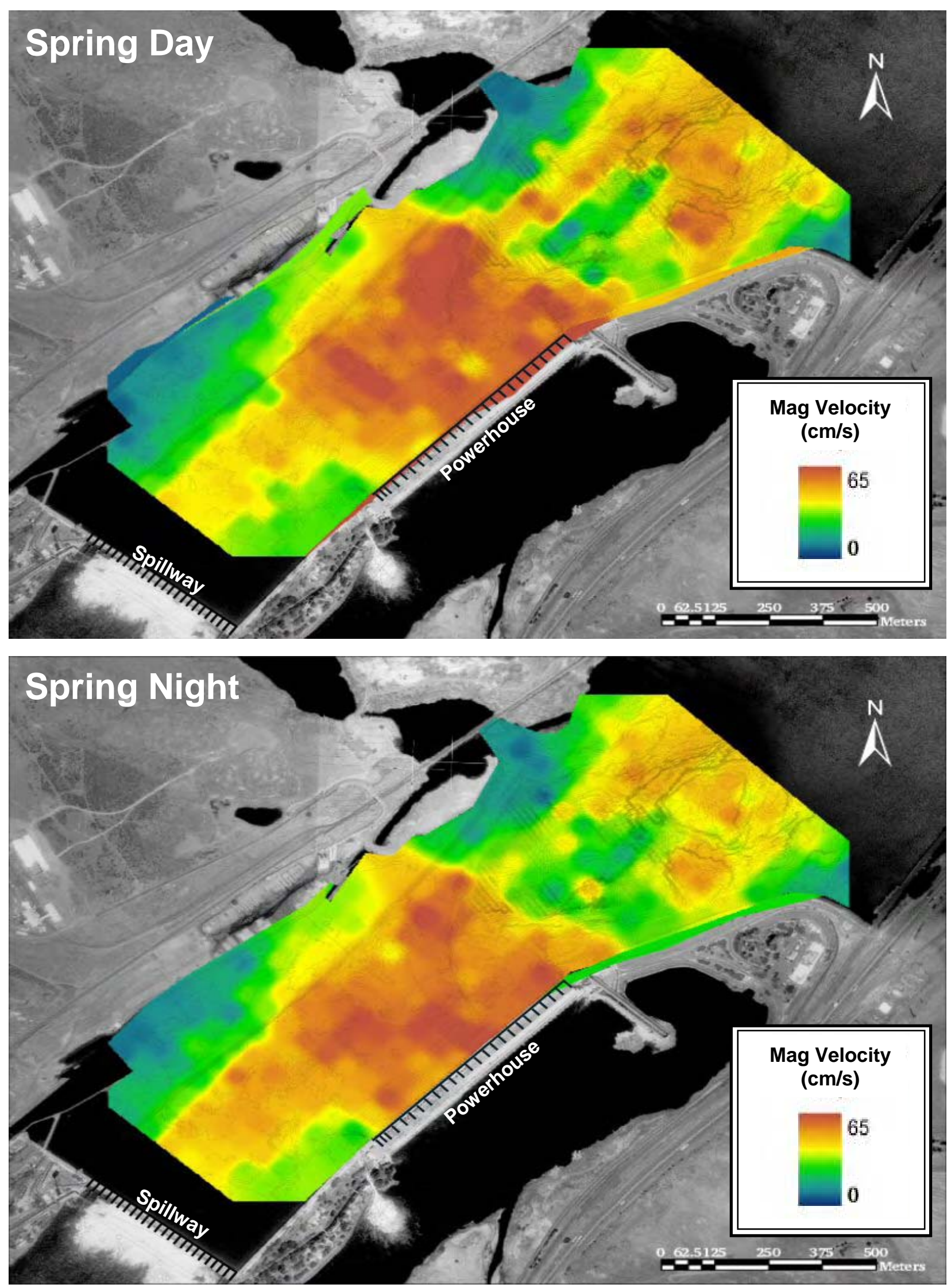

Figure B.1. The mean water velocity magnitude in $\mathrm{cm} / \mathrm{s}$ for springtime samples, during the day and night. Water velocity magnitude was measured from a 600-KHz RDI acoustic Doppler current profiler Rio Grande ${ }^{\mathrm{TM}}$ and averaged over four pings. 

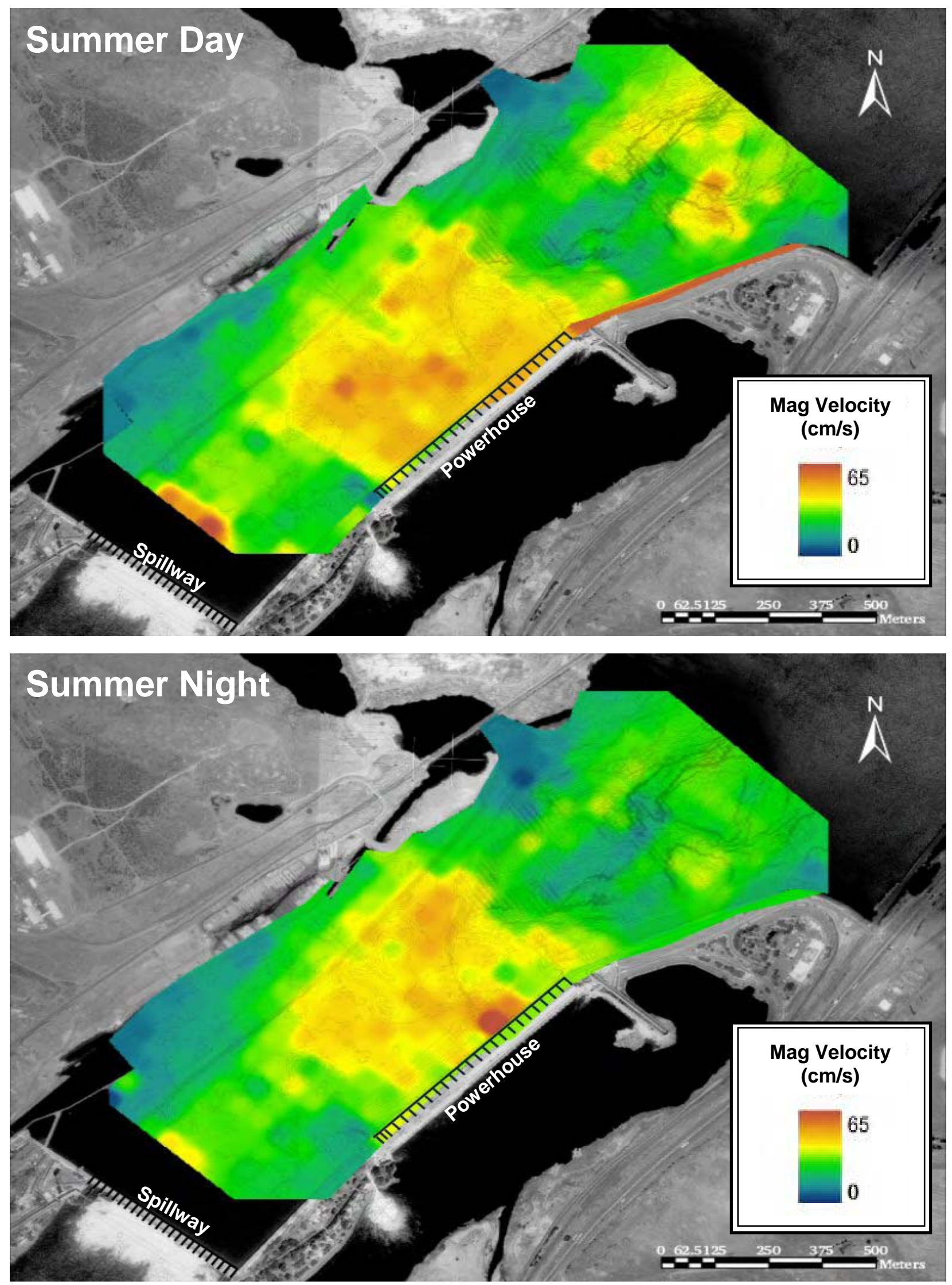

Figure B.2. The mean water velocity magnitude in $\mathrm{cm} / \mathrm{s}$ for summertime samples, during the day and night. Water velocity magnitude was measured from a 600-KHz RDI acoustic Doppler current profiler Rio Grande ${ }^{\mathrm{TM}}$ and averaged over four pings. 

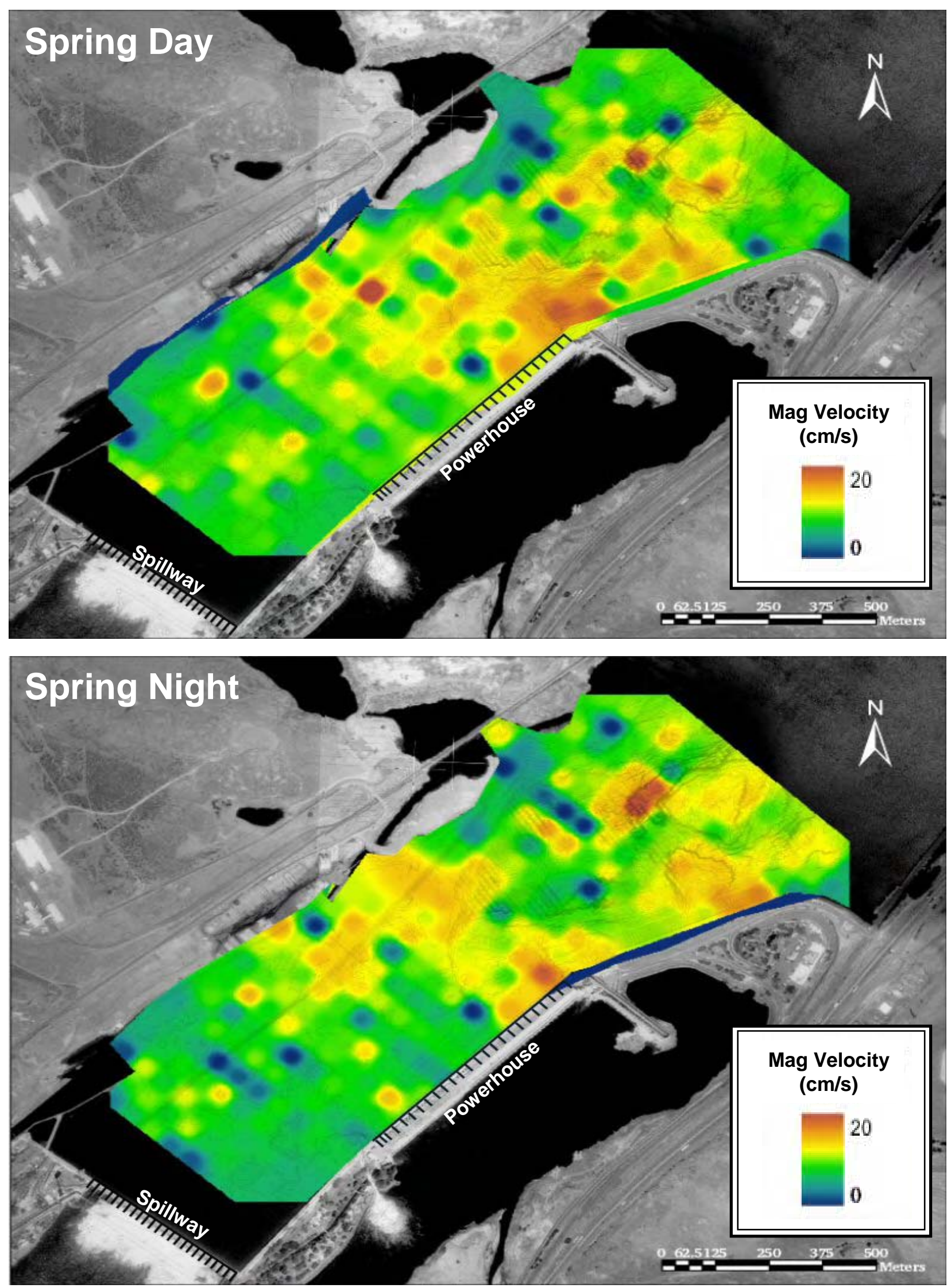

Figure B.3. The standard deviation in water velocity magnitude in $\mathrm{cm} / \mathrm{s}$ for springtime samples, during the day and night. Water velocity magnitude was measured from a $600-\mathrm{KHz} \mathrm{RDI}$ acoustic Doppler current profiler - Rio Grande ${ }^{\mathrm{TM}}$ and averaged over four pings. 

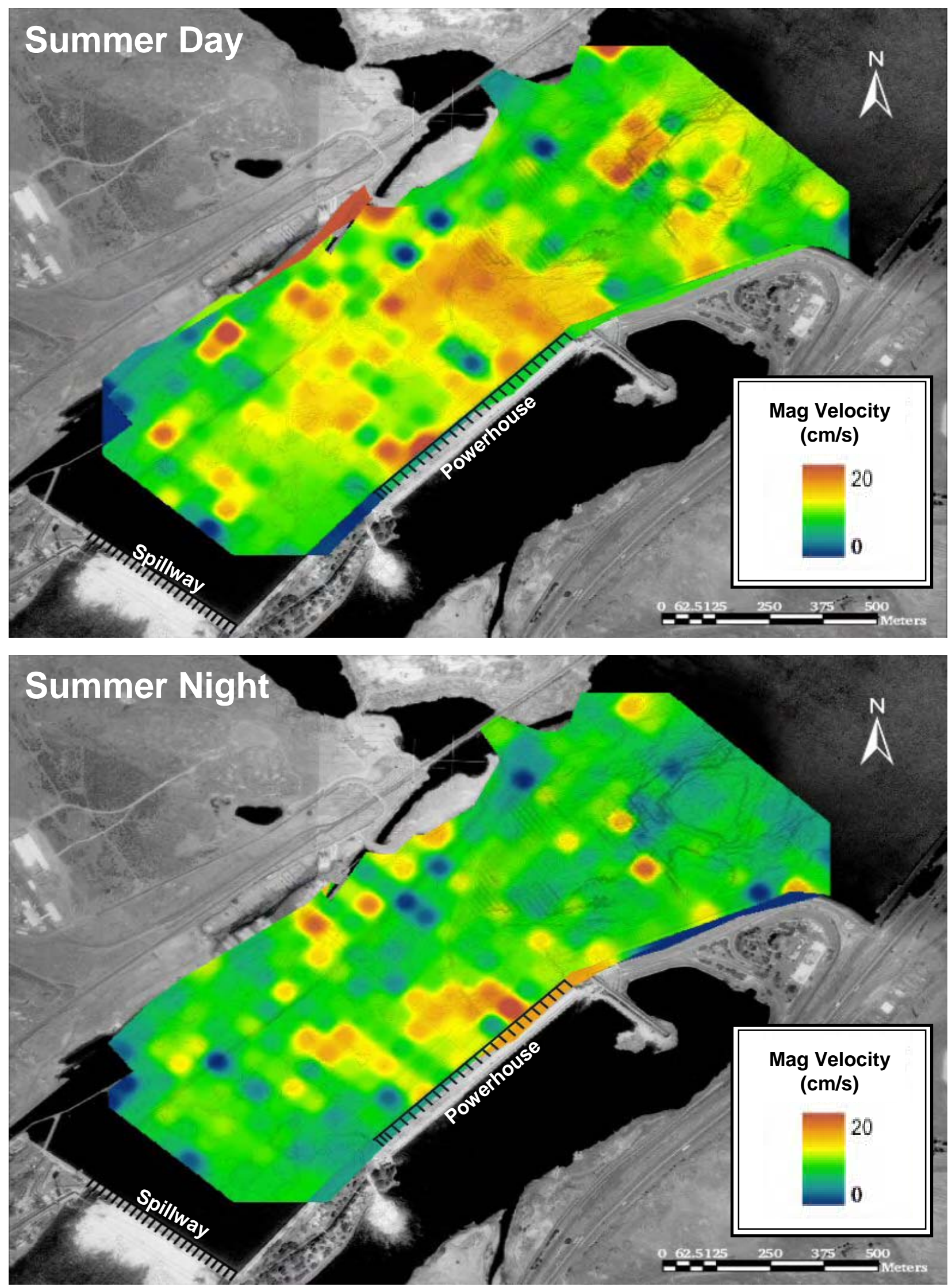

Figure B.4. The standard deviation in water velocity magnitude in $\mathrm{cm} / \mathrm{s}$ for summertime samples, during the day and night. Water velocity magnitude was measured from a $600-\mathrm{KHz} \mathrm{RDI}$ acoustic Doppler current profiler - Rio Grande ${ }^{\mathrm{TM}}$ and averaged over four pings. 
Appendix C

The Mean Distribution of Smolt-Sized and Larger-than-Smolt-Sized Fish, as Determined by Mobile Hydroacoustic Sampling in the Forebay of The Dalles Dam, 2003 
C. 2 

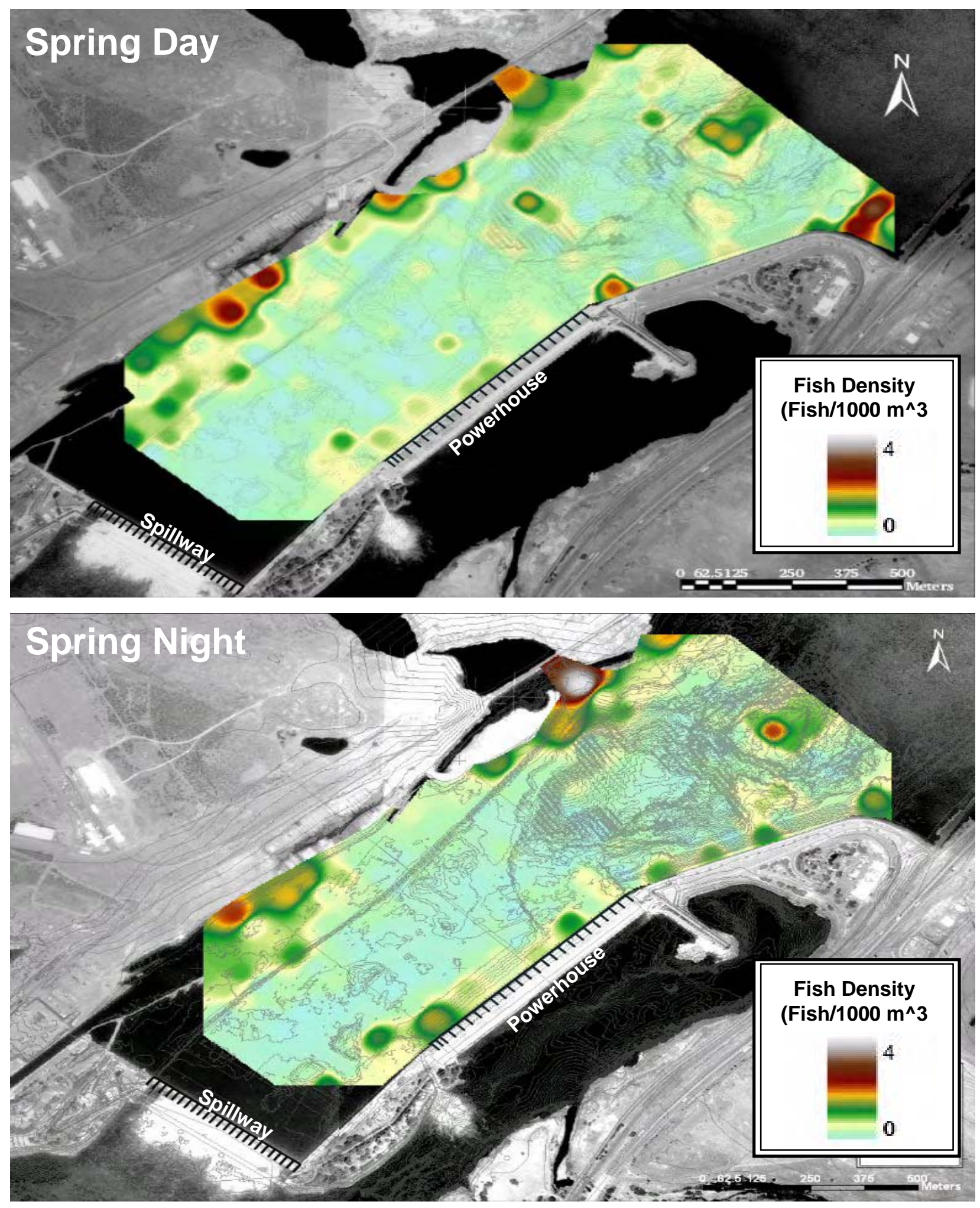

Figure C.1. The mean fish density for fish targets $>-34 \mathrm{~dB}$ re//1 $\mu \mathrm{Pa}$, which are larger than smolt-sized fish, for springtime samples, during the day and night. Six days and six nights were sampled in May and June to comprise springtime samples. 

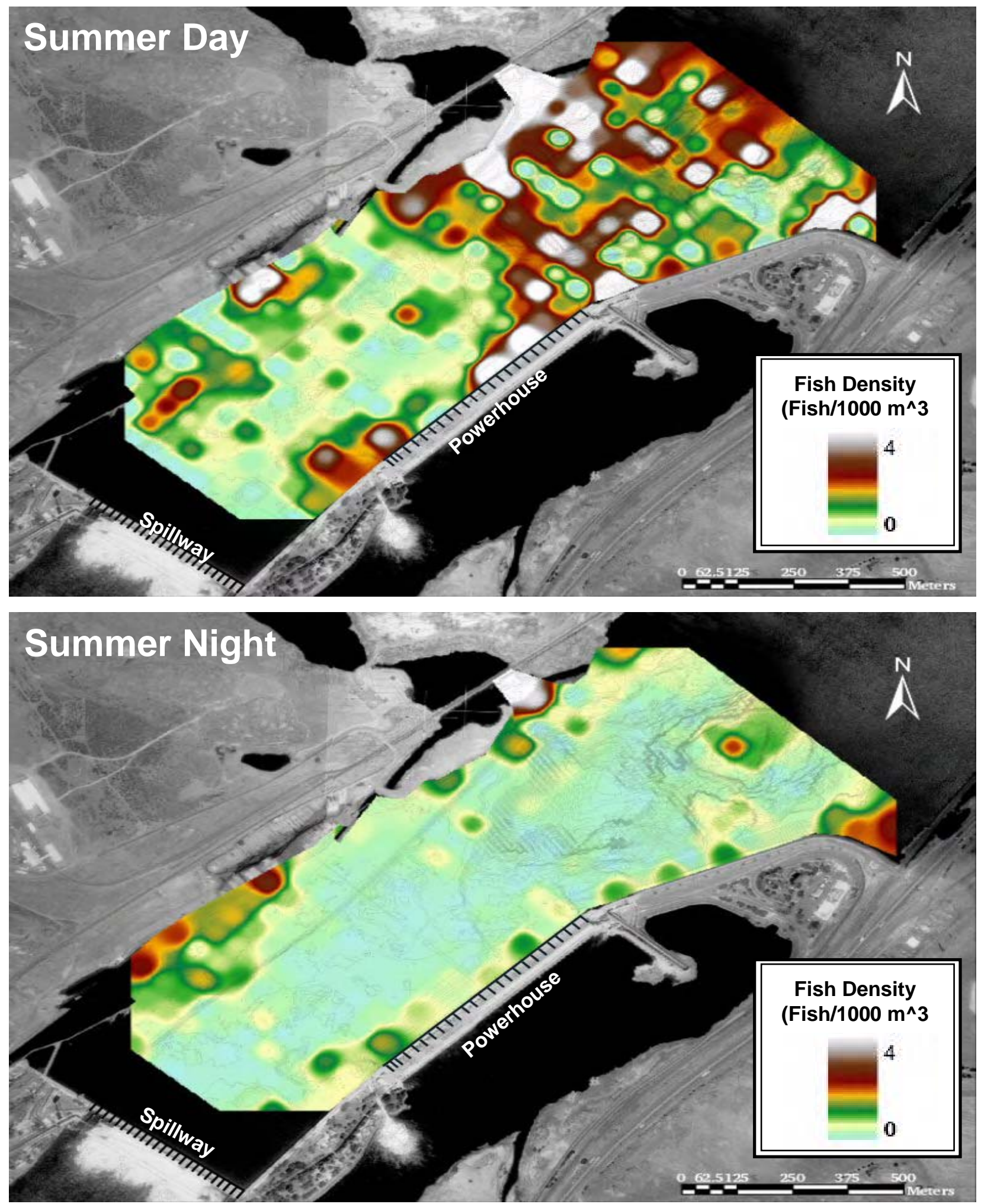

Figure C.2. The mean fish density for fish targets $>-34 \mathrm{~dB}$ re//1 $\mathrm{PPa}$, which are larger than smolt-sized fish, for summertime samples, during the day and night. Six days and five nights were sampled in June and July to comprise summertime samples. 

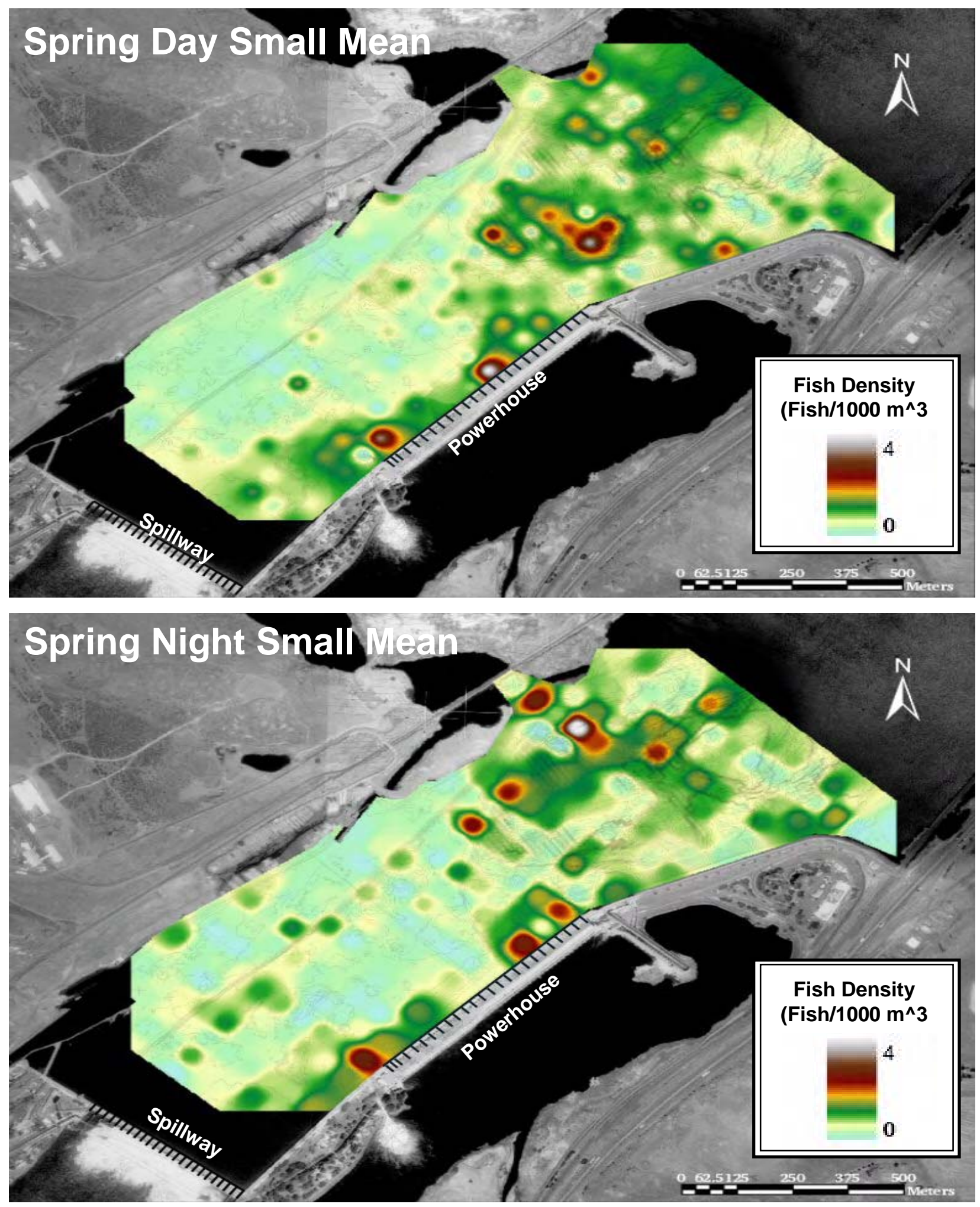

Figure C.3. The mean fish density for fish targets $<-34 \mathrm{~dB}$ re//1 $\mu \mathrm{Pa}$, which are smolt-sized fish, for springtime samples during the day and night. Six days and six nights were sampled in May and June to comprise springtime samples. 

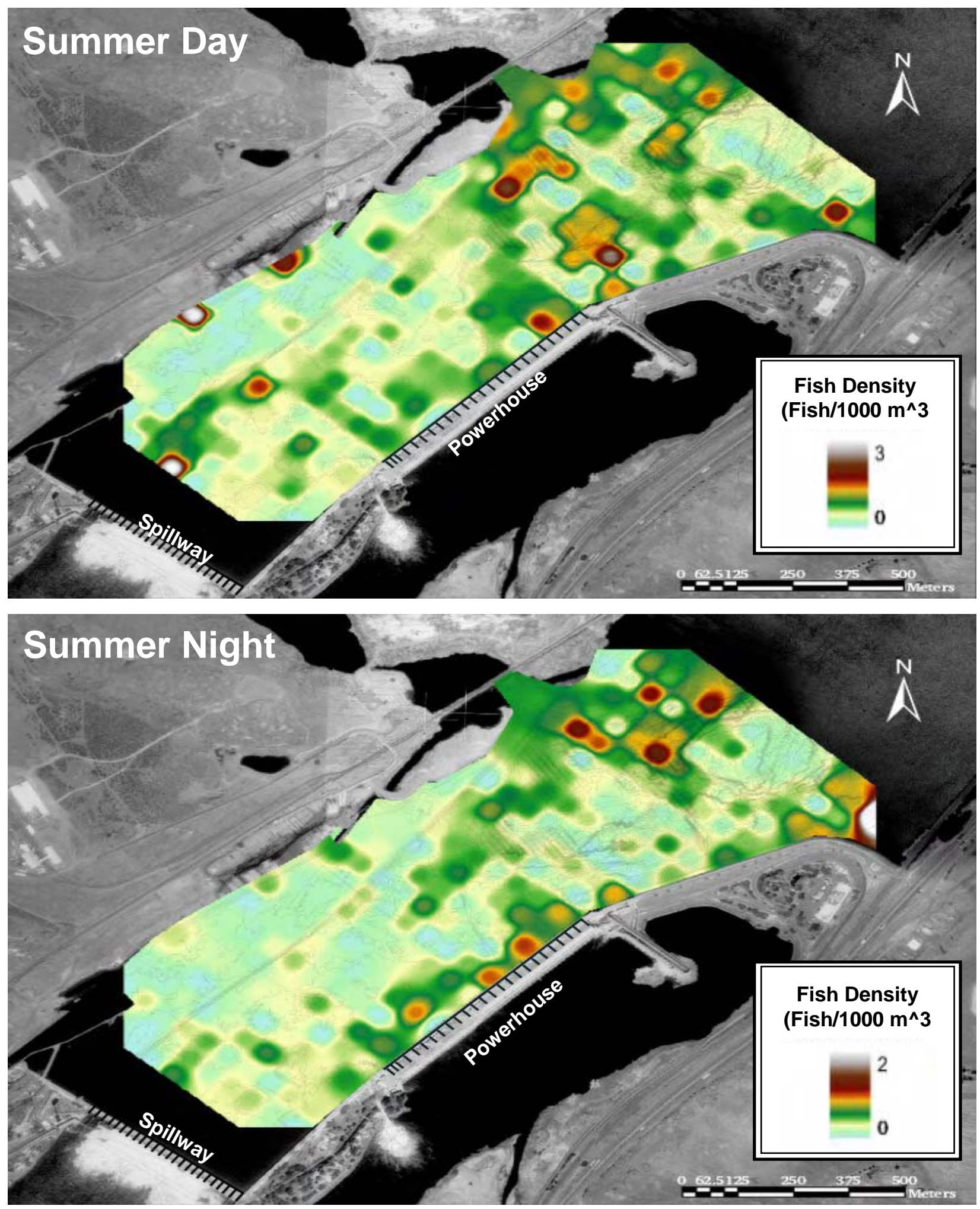

Figure C.4. The mean fish density for fish targets $<-45 \mathrm{~dB}$ re//1 $\mu \mathrm{Pa}$, which are subyearling chinooksized fish, for summertime samples during the day and night. Six days and five nights were sampled in June and July to comprise summertime samples. 


\section{Appendix D}

Smolt-Sized Fish Distribution as Determined by Mobile Hydroacoustic Sampling for Each Sample Day in the Forebay of The Dalles Dam, Spring and Summer 2003 


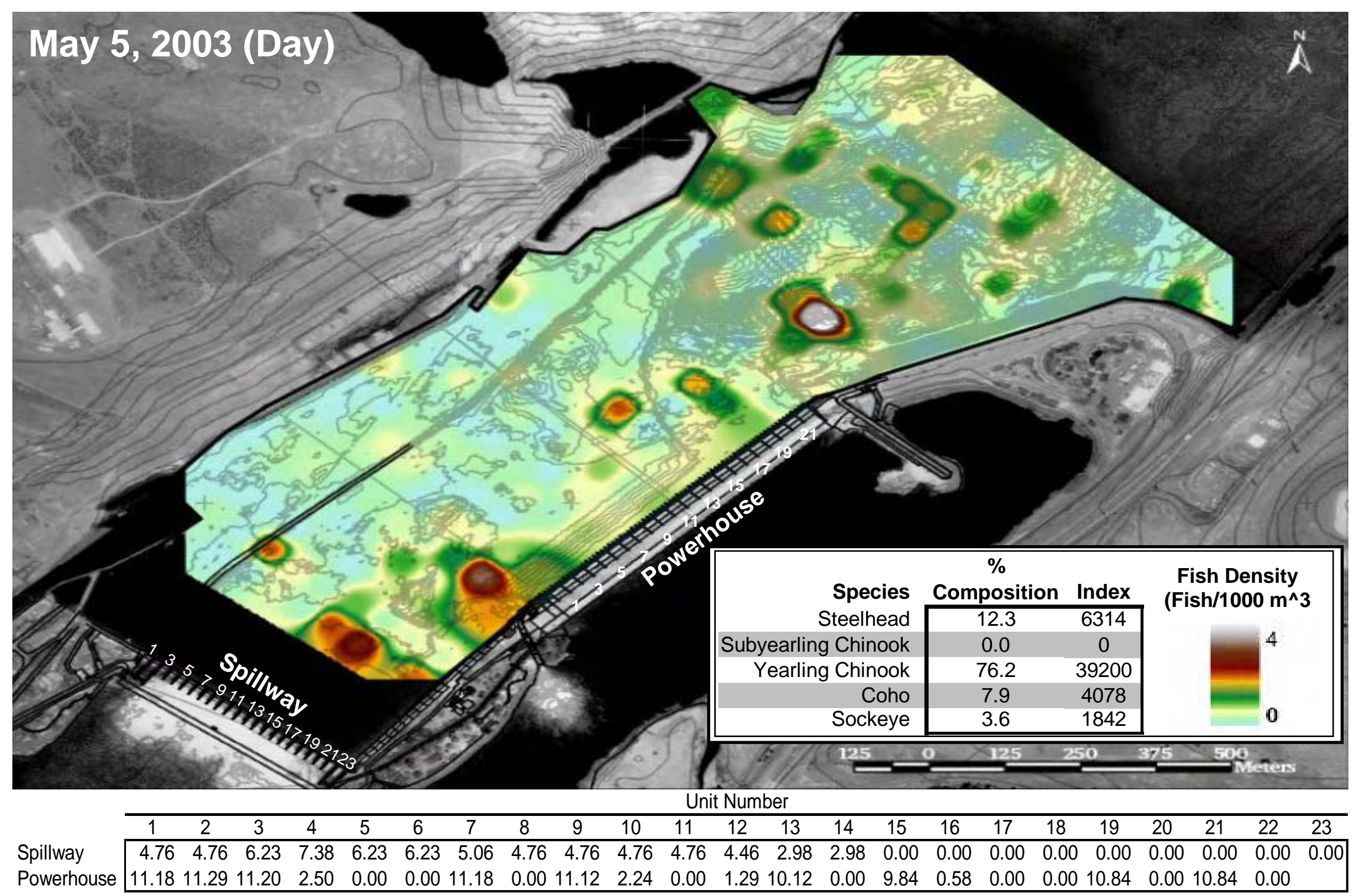

Figure D.1. Small fish density in the forebay of The Dalles Dam. Small fish in the spring were those with a target strength $<-34 \mathrm{~dB}$ re//1 $\mu \mathrm{Pa}$. The

$\square$ table shows mean unit discharge (kcfs) through each unit of the powerhouse and the spillway during the period of fish data collection for that day.

$\dot{\omega}$ The legend table displays the percent species composition of juvenile salmon passing John Day Dam for the same day. Median travel time to The Dalles Dam from John Day Dam of radio-telemetry tracked fish was 11 hrs from previous years (Holmberg et al. 1996). 


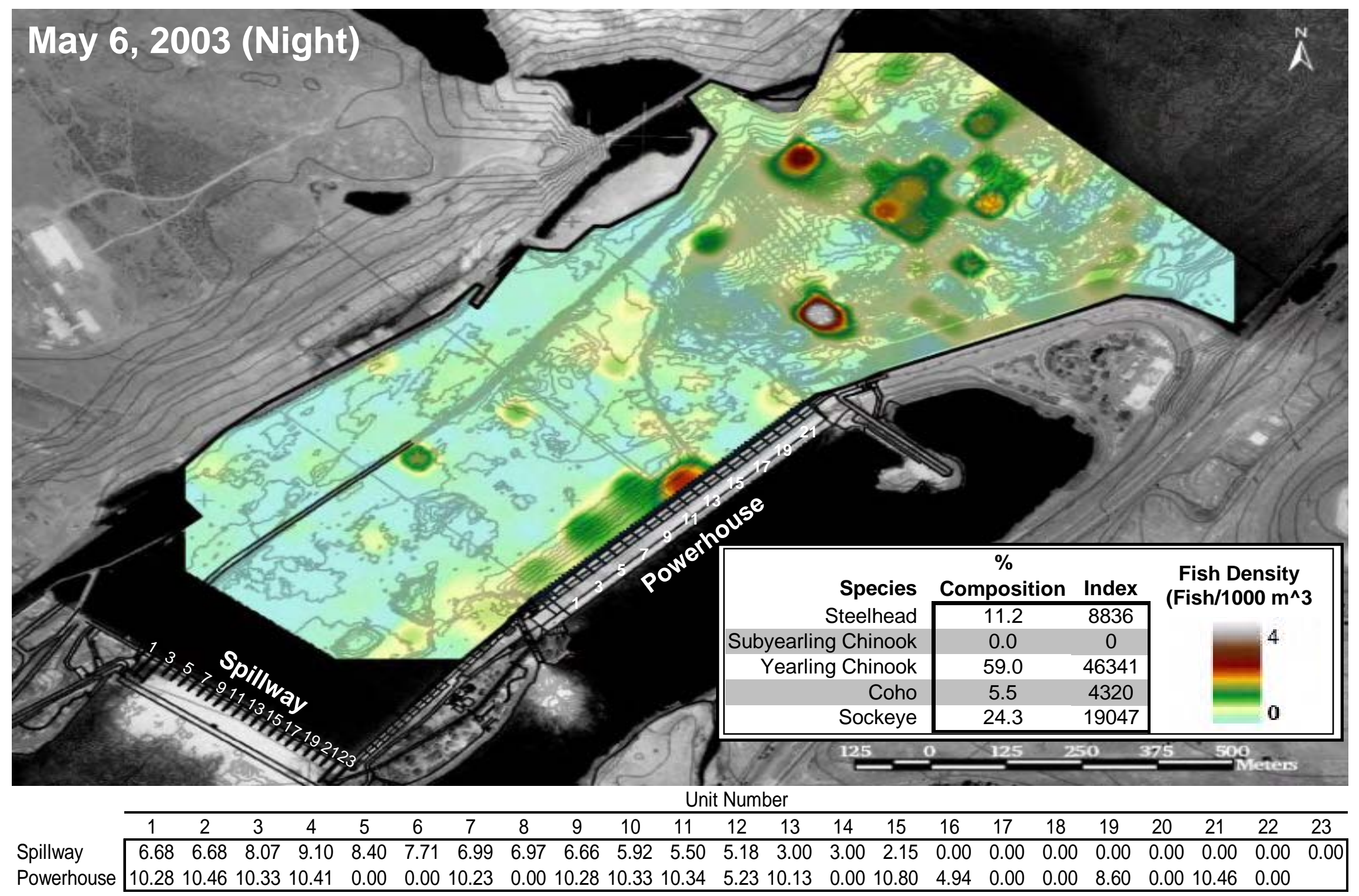

Figure D.2. Small fish density in the forebay of The Dalles Dam. Small fish in the spring were those with a target strength $<-34 \mathrm{~dB}$ re//1 $\mu \mathrm{Pa}$. The

. table shows mean unit discharge (kcfs) through each unit of the powerhouse and the spillway during the period of fish data collection for that day.

$\therefore$ The legend table displays the percent species composition of juvenile salmon passing John Day Dam for the same day. Median travel time to The Dalles Dam from John Day Dam of radio-telemetry tracked fish was 11 hrs from previous years (Holmberg et al. 1996). 


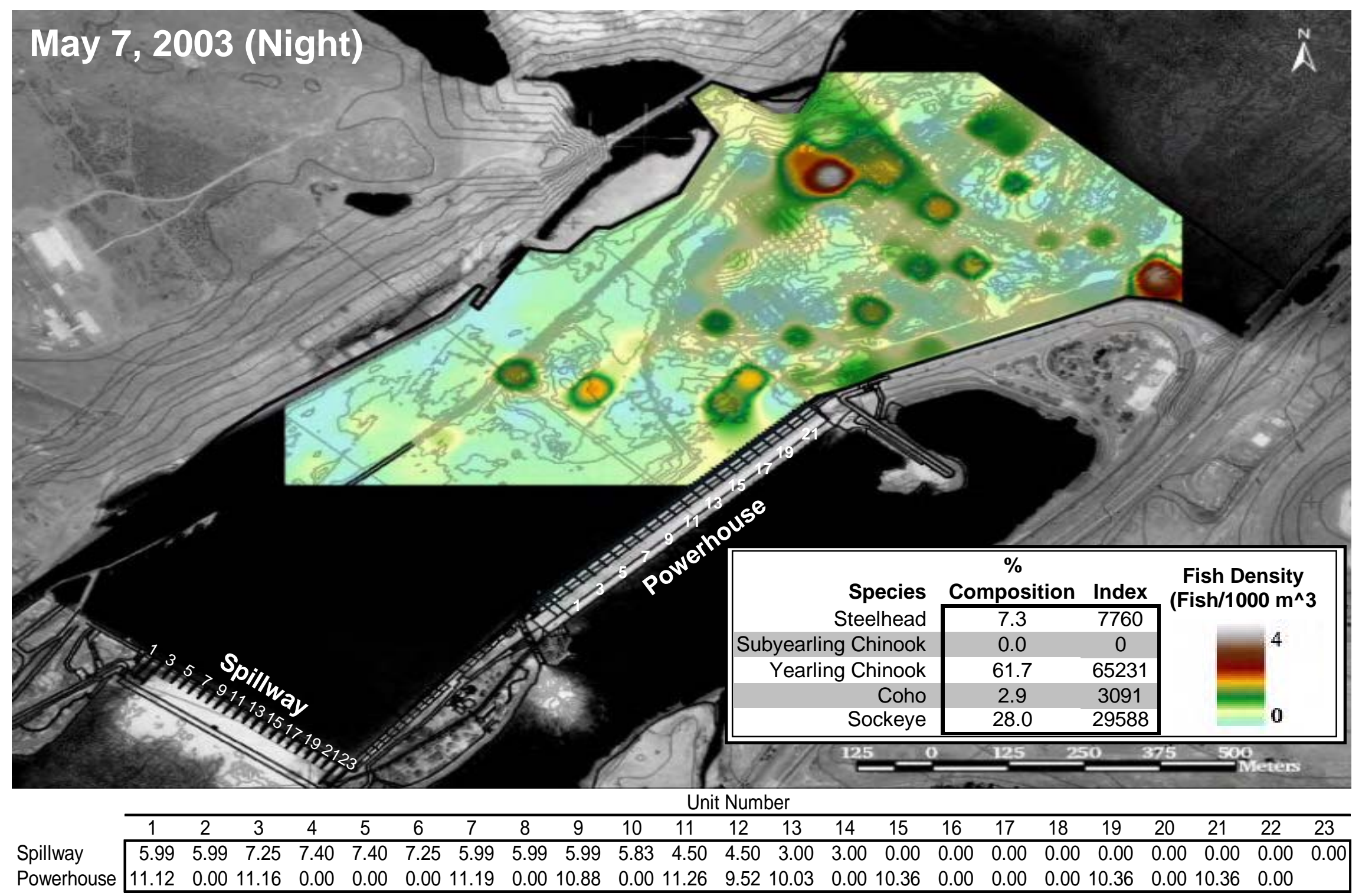

Figure D.3. Small fish density in the forebay of The Dalles Dam. Small fish in the spring were those with a target strength $<-34 \mathrm{~dB}$ re//1 $\mu \mathrm{Pa}$. The

$\square$ table shows mean unit discharge (kcfs) through each unit of the powerhouse and the spillway during the period of fish data collection for that day.

ir The legend table displays the percent species composition of juvenile salmon passing John Day Dam for the same day. Median travel time to The Dalles Dam from John Day Dam of radio-telemetry tracked fish was 11 hrs from previous years (Holmberg et al. 1996). 


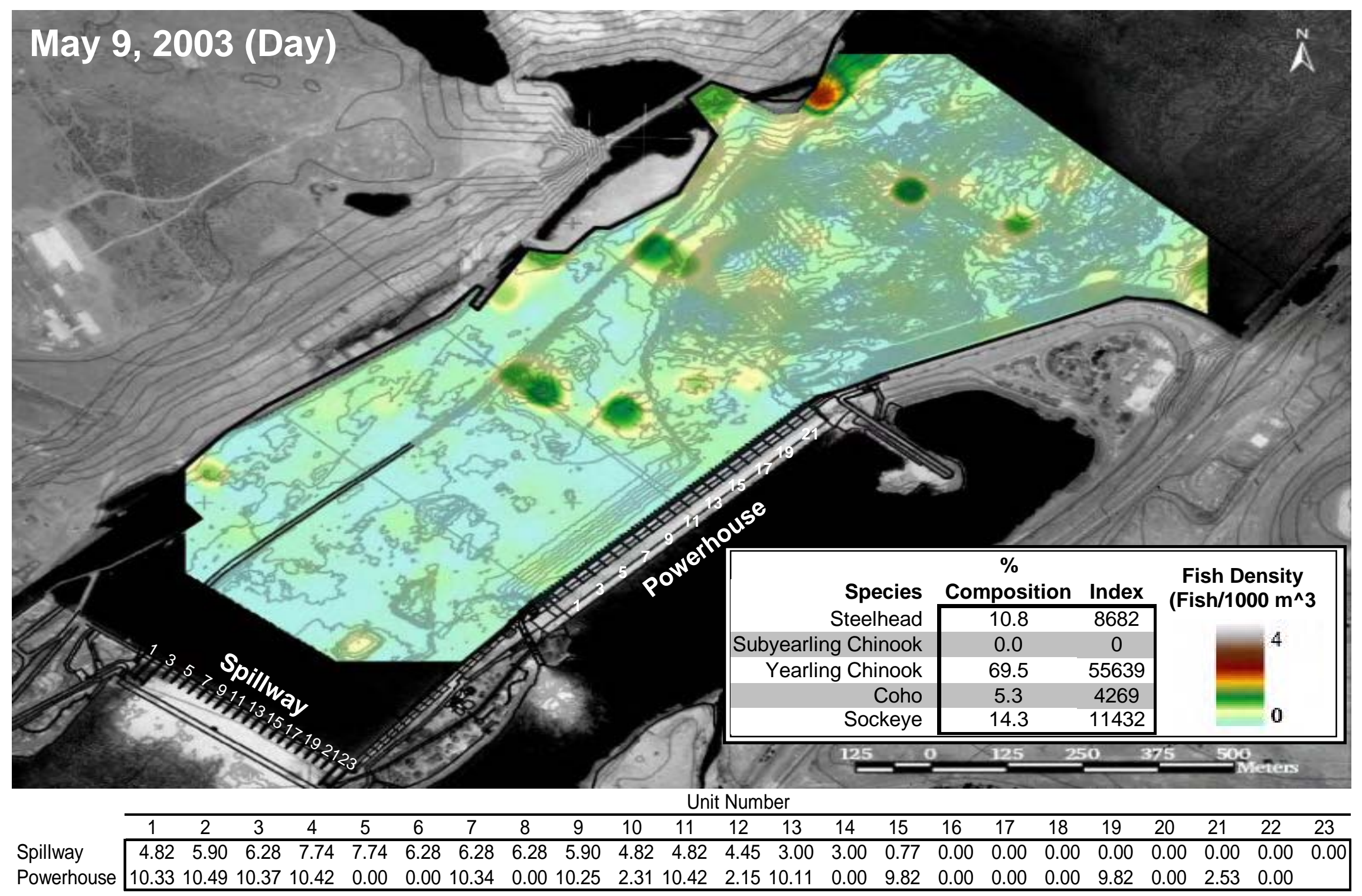

Figure D.4. Small fish density in the forebay of The Dalles Dam. Small fish in the spring were those with a target strength $<-34 \mathrm{~dB}$ re//1 $\mu \mathrm{Pa}$. The

. table shows mean unit discharge (kcfs) through each unit of the powerhouse and the spillway during the period of fish data collection for that day.

$\sigma$ The legend table displays the percent species composition of juvenile salmon passing John Day Dam for the same day. Median travel time to The Dalles Dam from John Day Dam of radio-telemetry tracked fish was 11 hrs from previous years (Holmberg et al. 1996). 


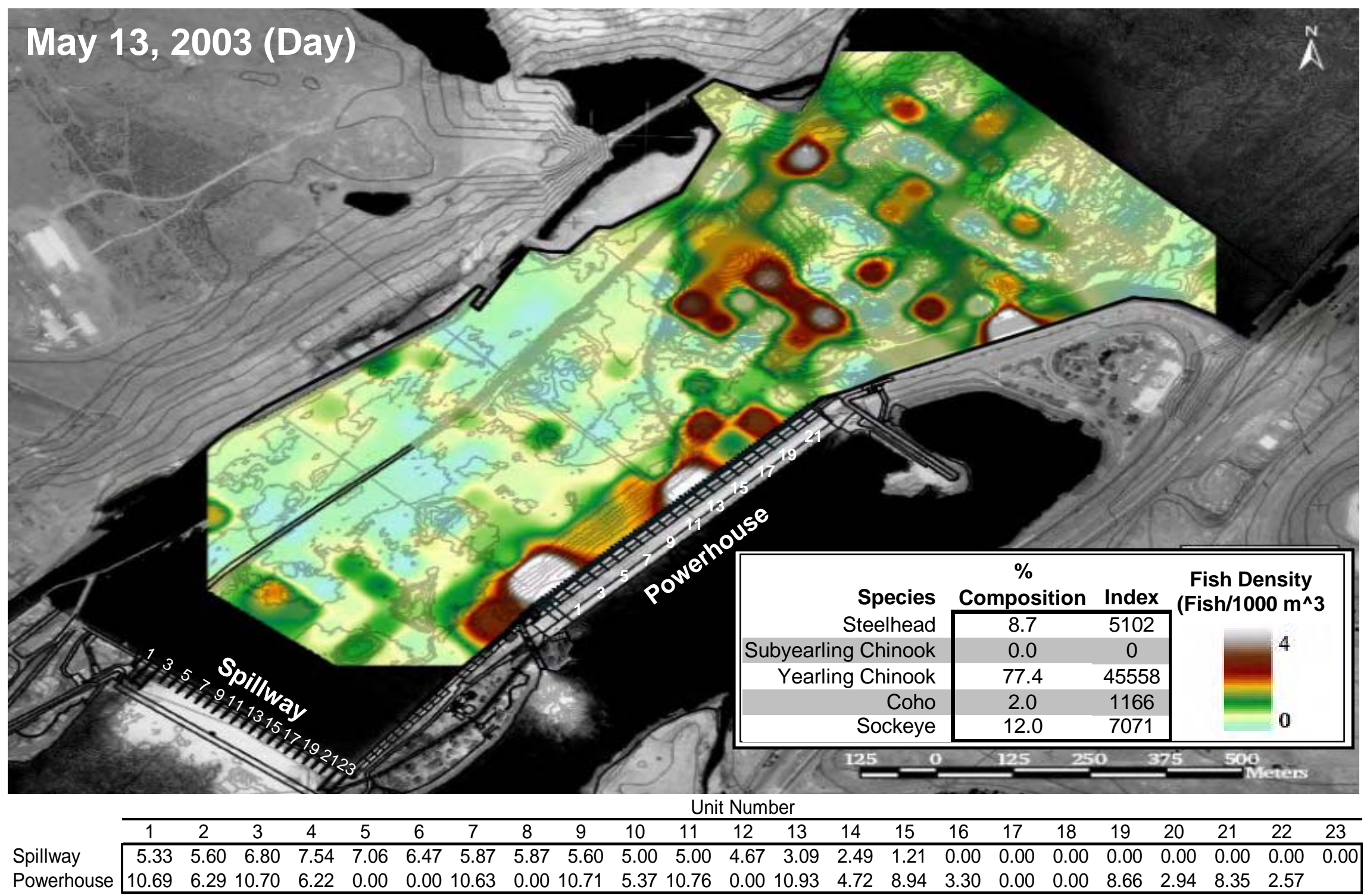

Figure D.5. Small fish density in the forebay of The Dalles Dam. Small fish in the spring were those with a target strength $<-34 \mathrm{~dB}$ re//1 $\mu \mathrm{Pa}$. The

$\square$ table shows mean unit discharge (kcfs) through each unit of the powerhouse and the spillway during the period of fish data collection for that day.

$\checkmark$ The legend table displays the percent species composition of juvenile salmon passing John Day Dam for the same day. Median travel time to The Dalles Dam from John Day Dam of radio-telemetry tracked fish was 11 hrs from previous years (Holmberg et al. 1996). 


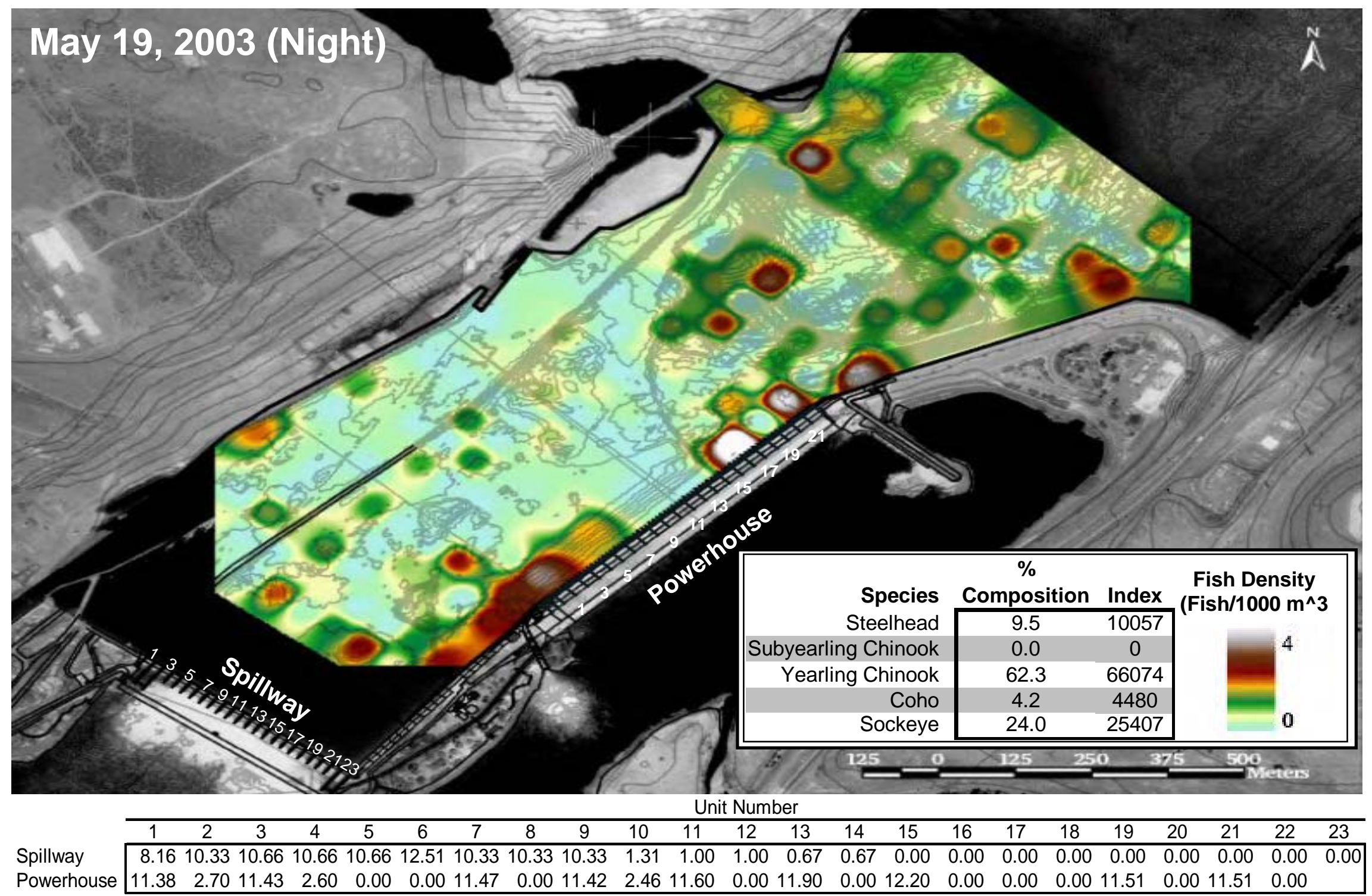

Figure D.6. Small fish density in the forebay of The Dalles Dam. Small fish in the spring were those with a target strength $<-34 \mathrm{~dB}$ re//1 $\mu \mathrm{Pa}$. The

table shows mean unit discharge (kcfs) through each unit of the powerhouse and the spillway during the period of fish data collection for that day.

$\infty$ The legend table displays the percent species composition of juvenile salmon passing John Day Dam for the same day. Median travel time to The Dalles Dam from John Day Dam of radio-telemetry tracked fish was 11 hrs from previous years (Holmberg et al. 1996). 


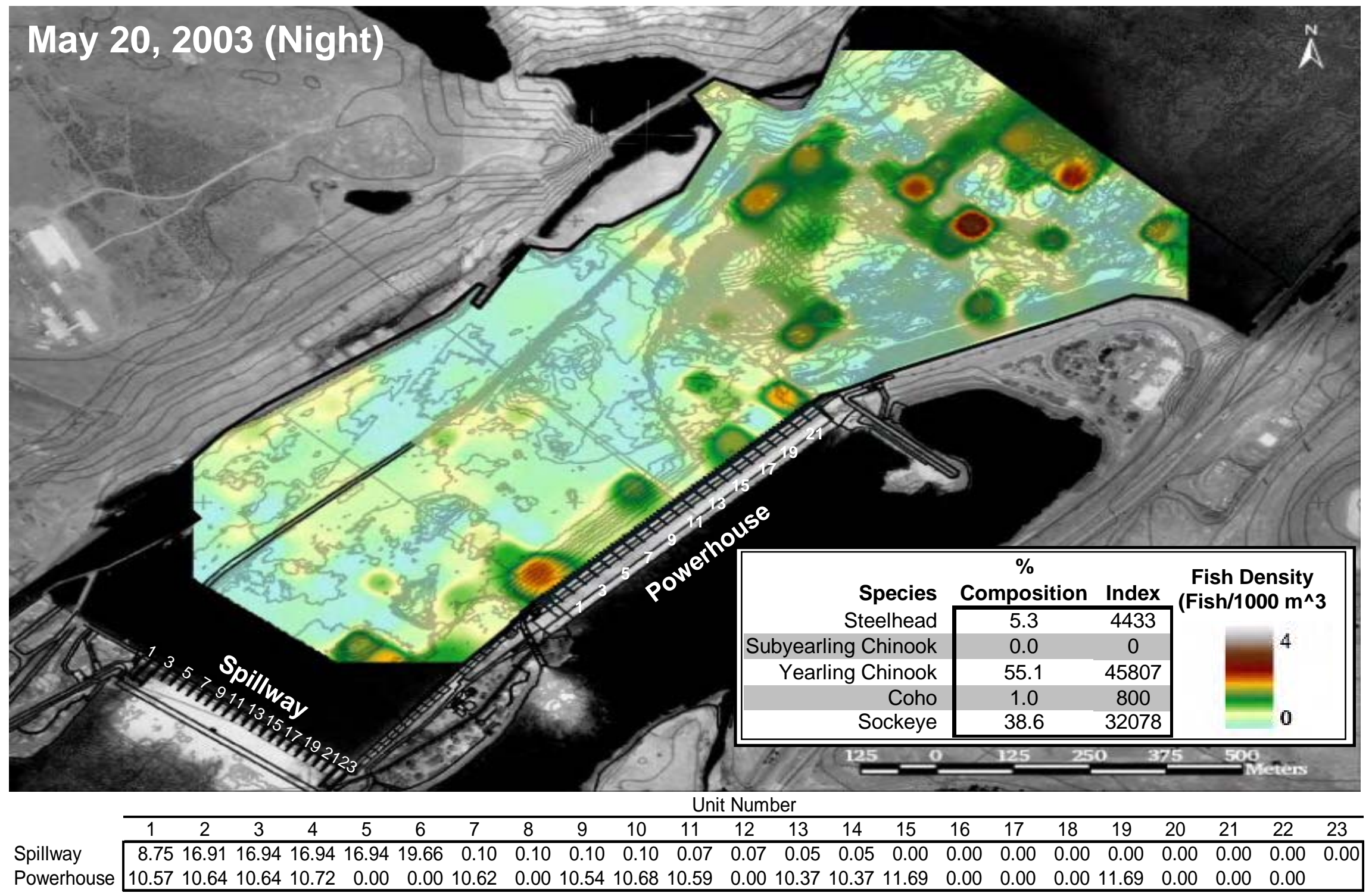

Figure D.7. Small fish density in the forebay of The Dalles Dam. Small fish in the spring were those with a target strength $<-34 \mathrm{~dB}$ re//1 $\mu \mathrm{Pa}$. The

$\square$ table shows mean unit discharge (kcfs) through each unit of the powerhouse and the spillway during the period of fish data collection for that day.

6 The legend table displays the percent species composition of juvenile salmon passing John Day Dam for the same day. Median travel time to The Dalles Dam from John Day Dam of radio-telemetry tracked fish was 11 hrs from previous years (Holmberg et al. 1996). 


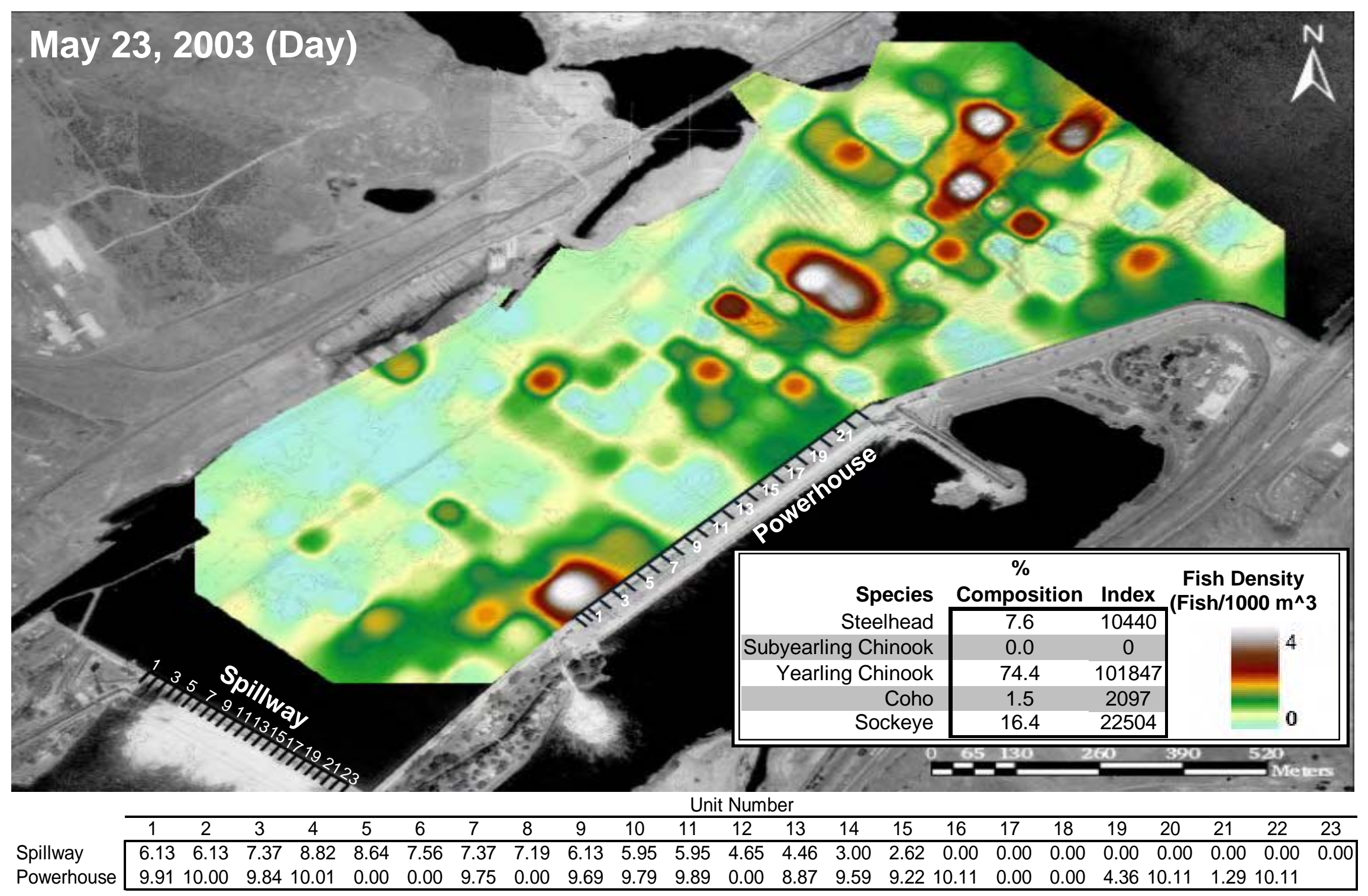

Figure D.8. Small fish density in the forebay of The Dalles Dam. Small fish in the spring were those with a target strength $<-34 \mathrm{~dB}$ re//1 $\mu \mathrm{Pa}$. The table shows mean unit discharge (kcfs) through each unit of the powerhouse and the spillway during the period of fish data collection for that day. The legend table displays the percent species composition of juvenile salmon passing John Day Dam for the same day. Median travel time to The Dalles Dam from John Day Dam of radio-telemetry tracked fish was 11 hrs from previous years (Holmberg et al. 1996). 


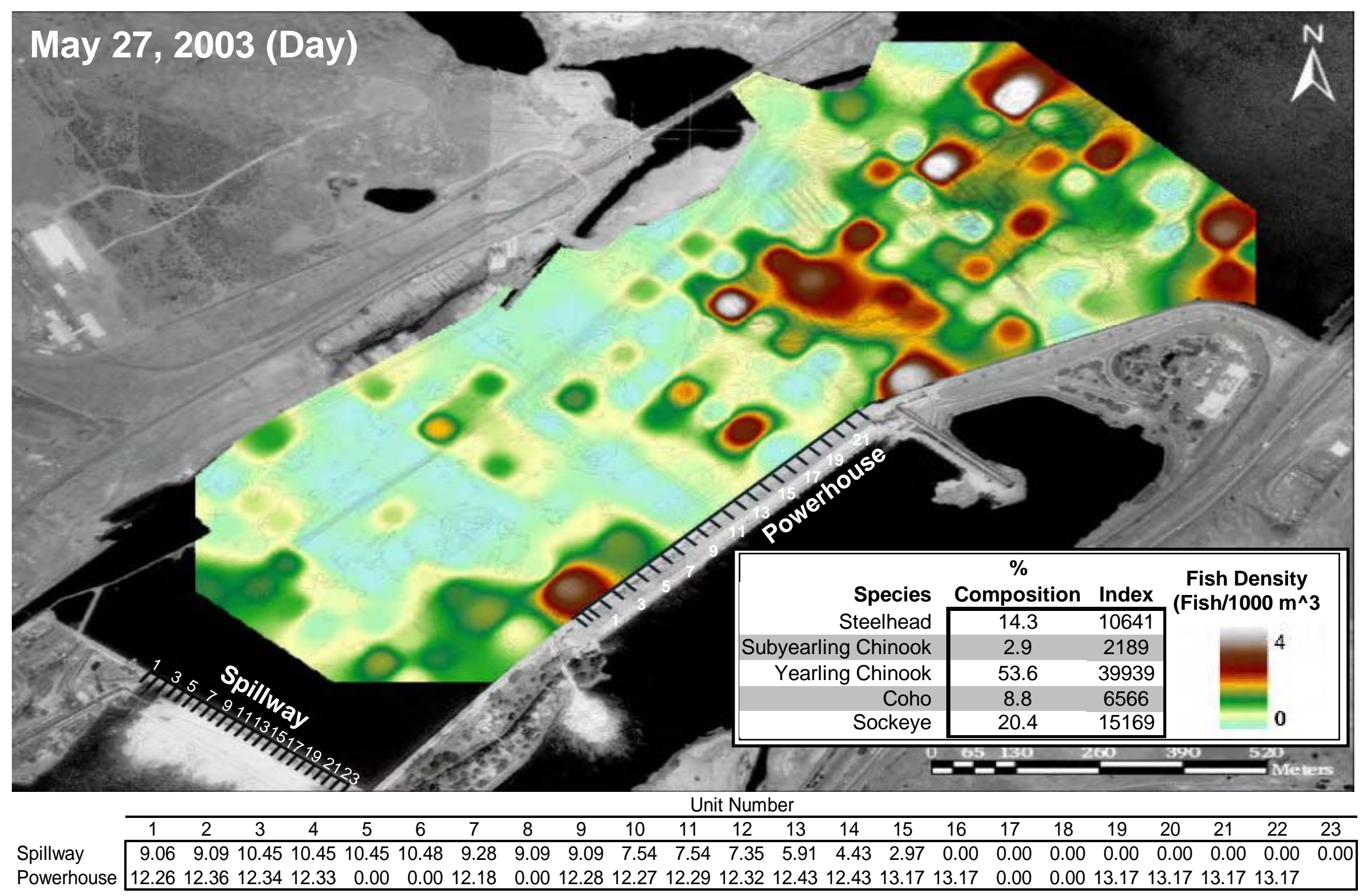

Figure D.9. Small fish density in the forebay of The Dalles Dam. Small fish in the spring were those with a target strength $<-34 \mathrm{~dB}$ re//1 $\mu \mathrm{Pa}$. The

$\square$ table shows mean unit discharge (kcfs) through each unit of the powerhouse and the spillway during the period of fish data collection for that day.

$\mapsto \quad$ The legend table displays the percent species composition of juvenile salmon passing John Day Dam for the same day. Median travel time to The Dalles Dam from John Day Dam of radio-telemetry tracked fish was 11 hrs from previous years (Holmberg et al. 1996). 


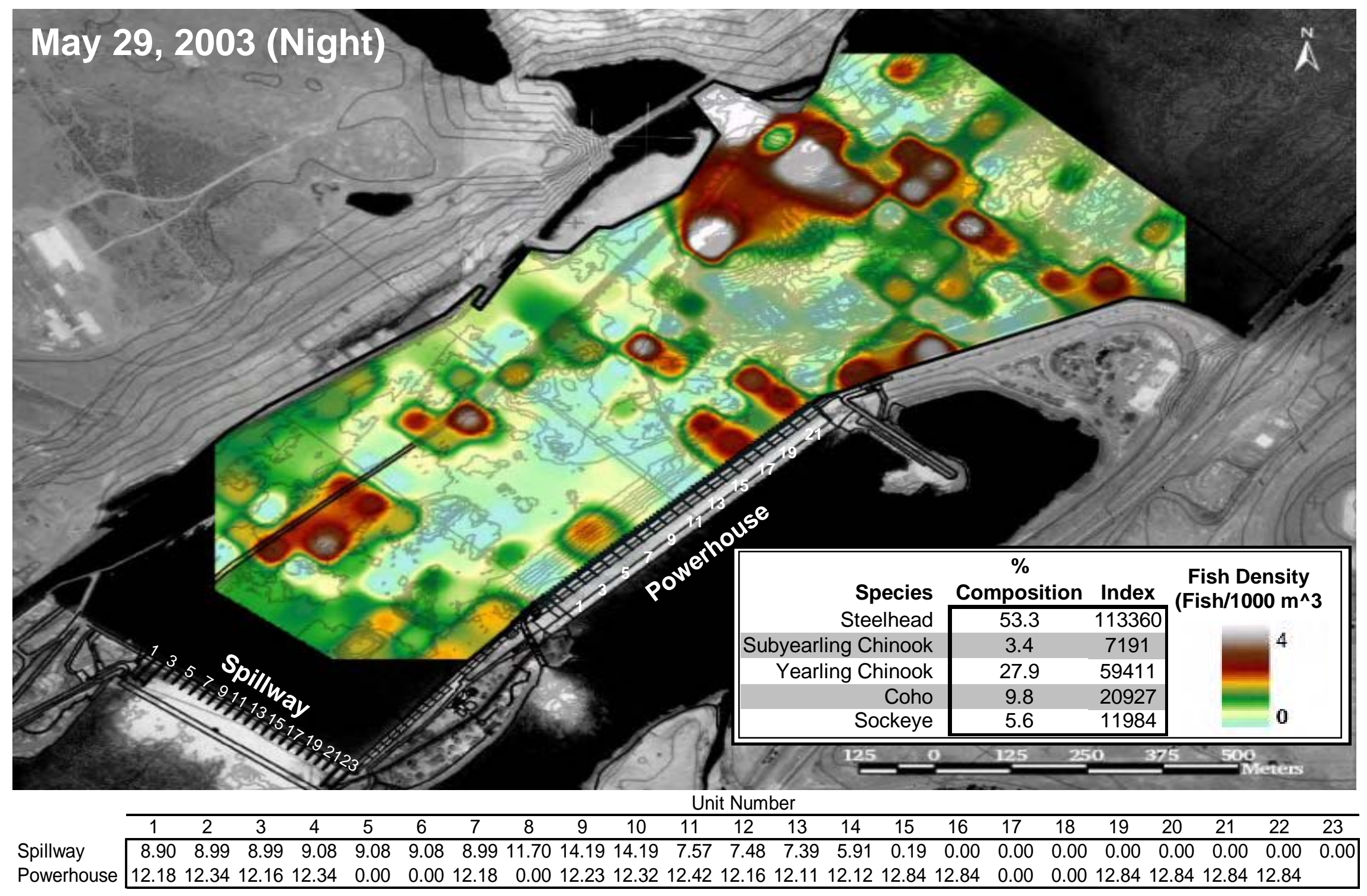

Figure D.10. Small fish density in the forebay of The Dalles Dam. Small fish in the spring were those with a target strength $<-34 \mathrm{~dB}$ re//1 $\mu \mathrm{Pa}$. The $\because$ table shows mean unit discharge (kcfs) through each unit of the powerhouse and the spillway during the period of fish data collection for that day. $\stackrel{\vec{\sim}}{\sim}$ The legend table displays the percent species composition of juvenile salmon passing John Day Dam for the same day. Median travel time to The Dalles Dam from John Day Dam of radio-telemetry tracked fish was 11 hrs from previous years (Holmberg et al. 1996). 


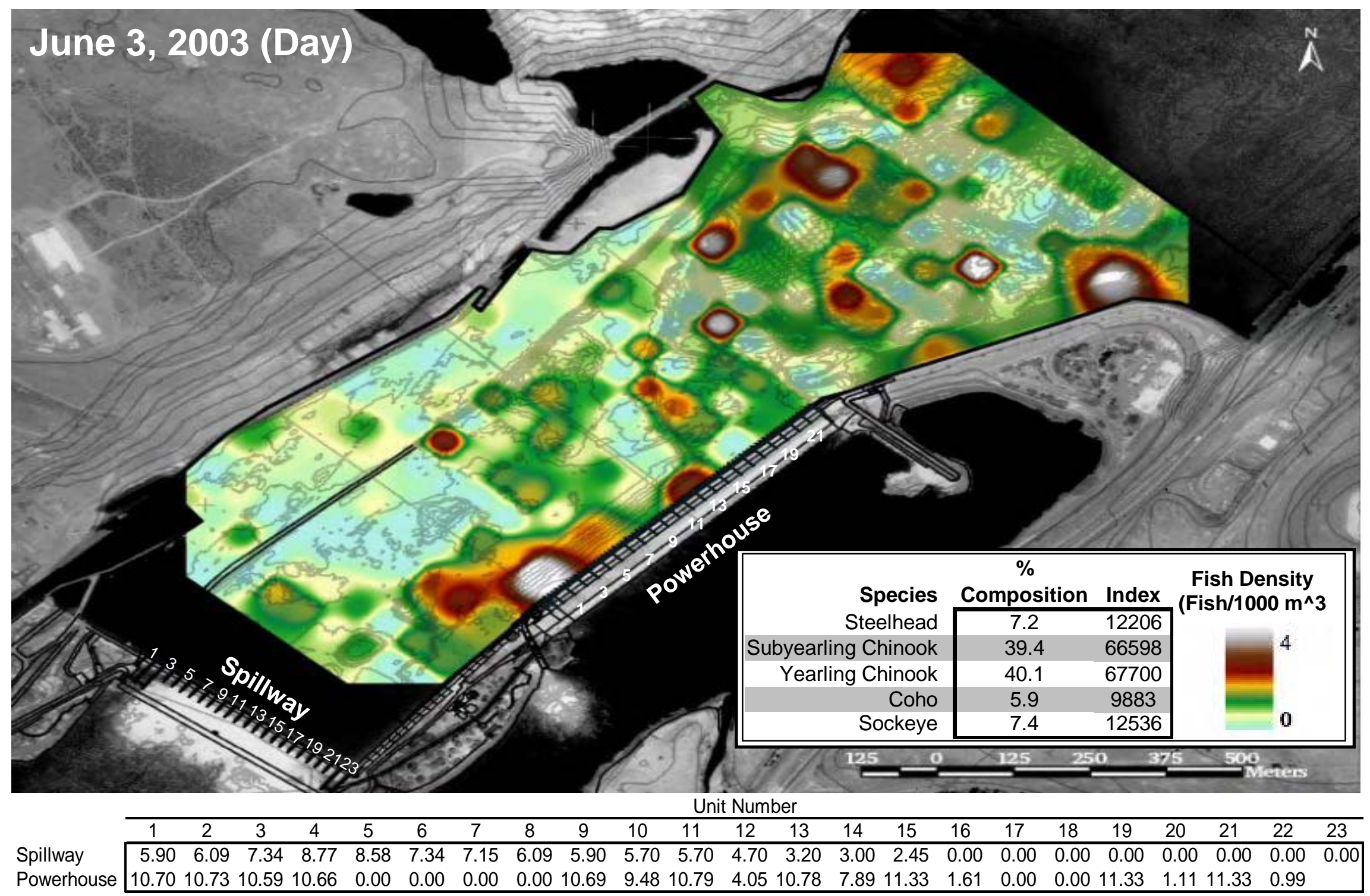

Figure D.11. Small fish density in the forebay of The Dalles Dam. Small fish in the spring were those with a target strength $<-34 \mathrm{~dB}$ re//1 $\mu \mathrm{Pa}$. The $\square$ table shows mean unit discharge (kcfs) through each unit of the powerhouse and the spillway during the period of fish data collection for that day. $\stackrel{\vec{\omega}}{ }$ The legend table displays the percent species composition of juvenile salmon passing John Day Dam for the same day. Median travel time to The Dalles Dam from John Day Dam of radio-telemetry tracked fish was 11 hrs from previous years (Holmberg et al. 1996). 


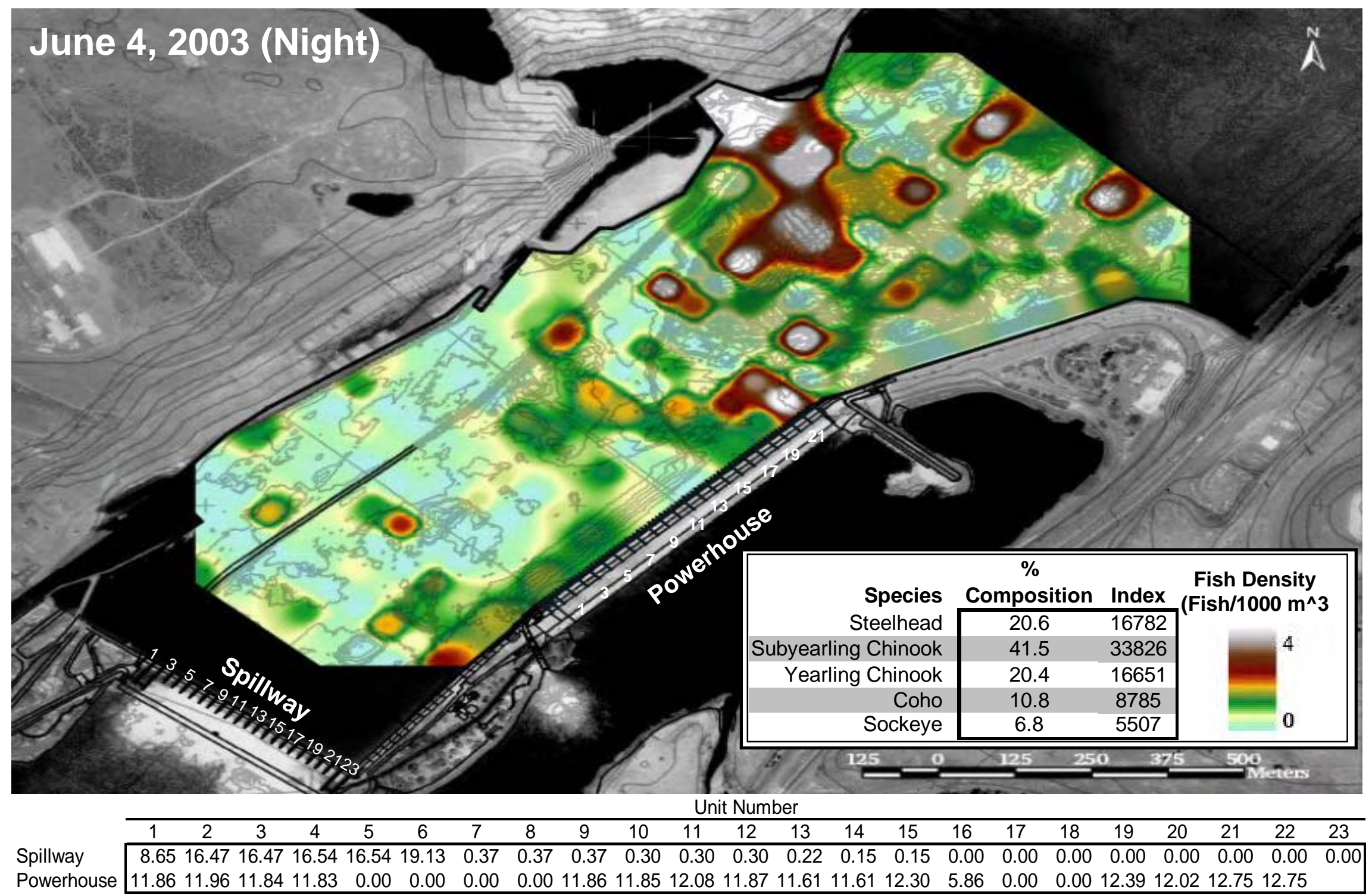

Figure D.12. Small fish density in the forebay of The Dalles Dam. Small fish in the spring were those with a target strength $<-34 \mathrm{~dB}$ re//1 $\mu \mathrm{Pa}$. The $\square$ table shows mean unit discharge (kcfs) through each unit of the powerhouse and the spillway during the period of fish data collection for that day.

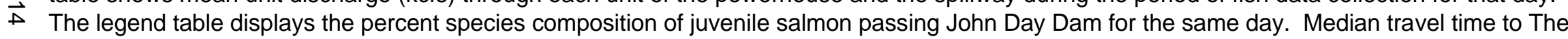
Dalles Dam from John Day Dam of radio-telemetry tracked fish was 11 hrs from previous years (Holmberg et al. 1996). 


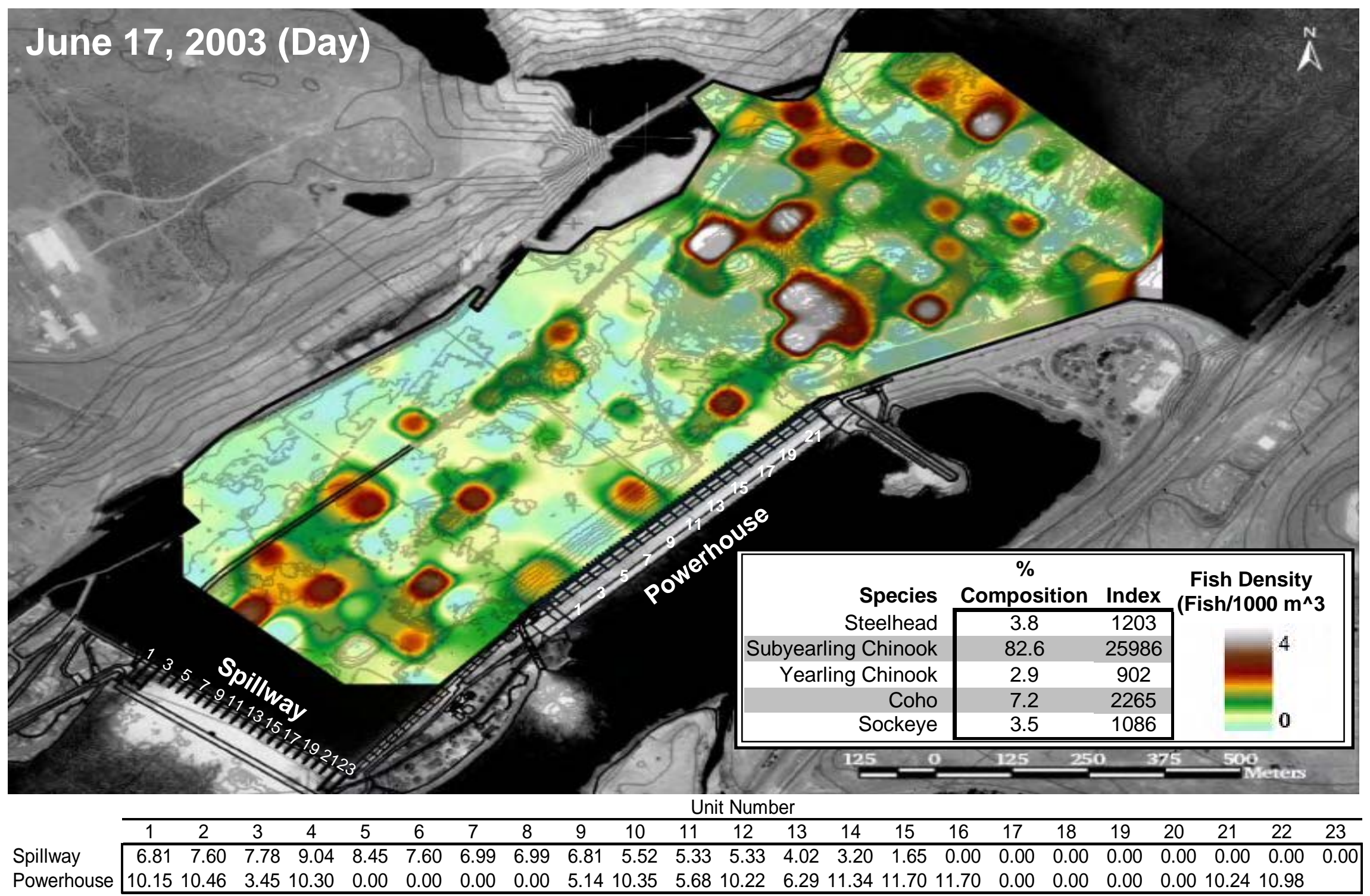

Figure D.13. Small fish density in the forebay of The Dalles Dam. Small fish in the spring were those with a target strength $<-45 \mathrm{~dB}$ re//1 $\mu \mathrm{Pa}$. The $\square$ table shows mean unit discharge (kcfs) through each unit of the powerhouse and the spillway during the period of fish data collection for that day. $\mathfrak{v}$ The legend table displays the percent species composition of juvenile salmon passing John Day Dam for the same day. Median travel time to The Dalles Dam from John Day Dam of summer radio-telemetry tracked fish was $16 \mathrm{hrs}$ from previous years (Holmberg et al. 1996). 


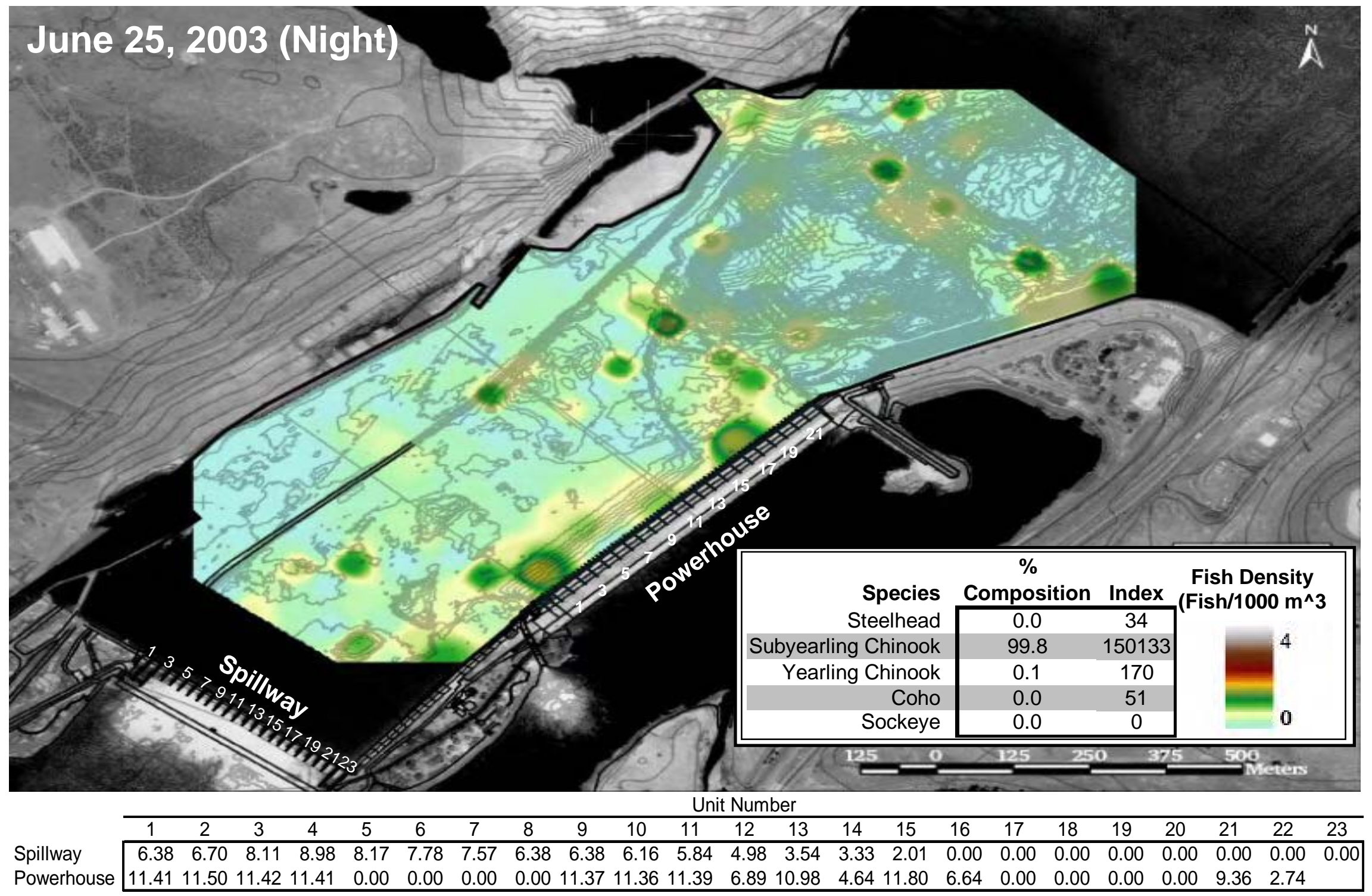

Figure D.14. Small fish density in the forebay of The Dalles Dam. Small fish in the spring were those with a target strength $<-45 \mathrm{~dB}$ re//1 $\mu \mathrm{Pa}$. The $\square$ table shows mean unit discharge (kcfs) through each unit of the powerhouse and the spillway during the period of fish data collection for that day. $\vec{\sigma}$ The legend table displays the percent species composition of juvenile salmon passing John Day Dam for the same day. Median travel time to The Dalles Dam from John Day Dam of summer radio-telemetry tracked fish was $16 \mathrm{hrs}$ from previous years (Holmberg et al. 1996). 


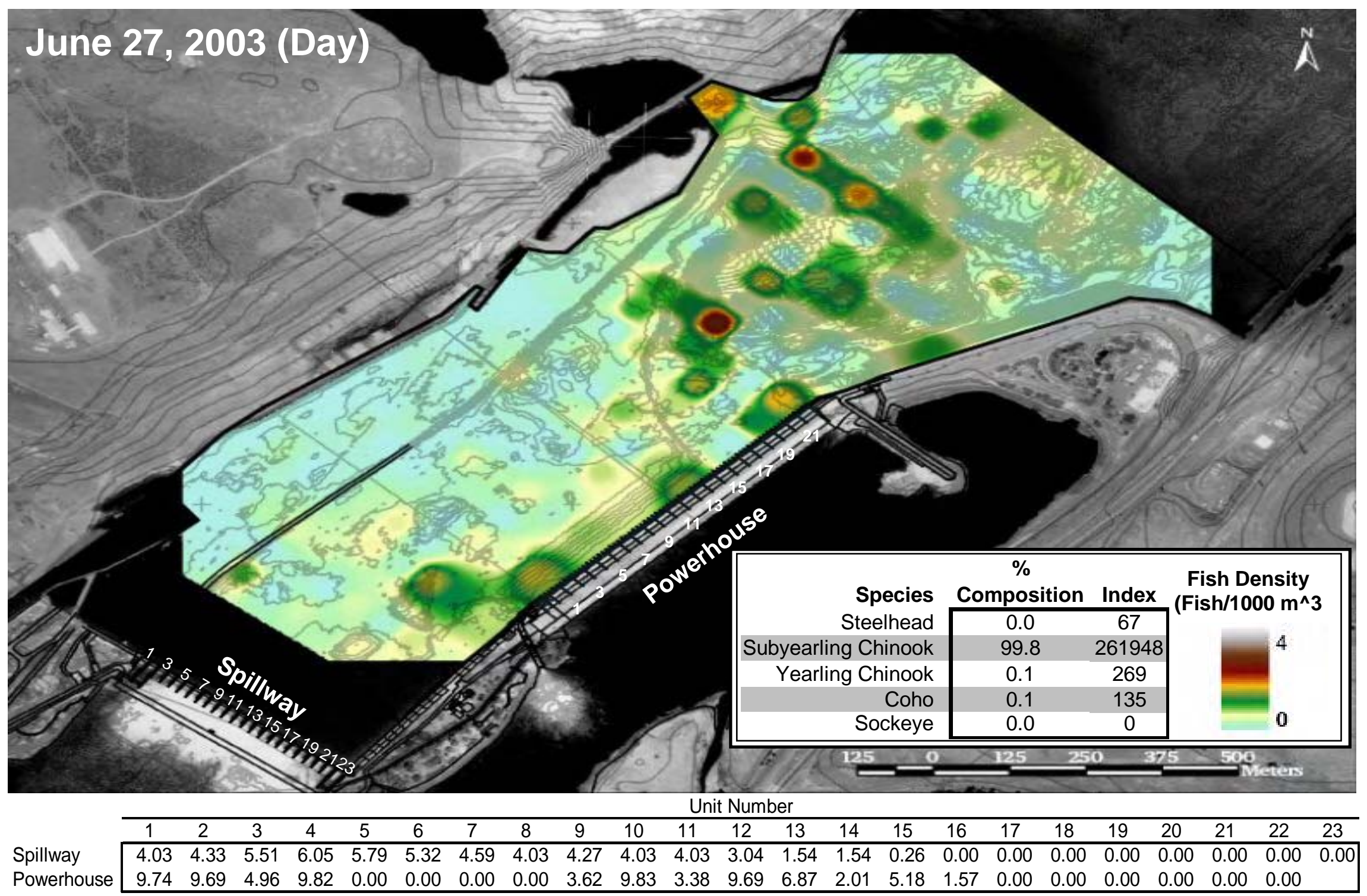

Figure D.15. Small fish density in the forebay of The Dalles Dam. Small fish in the spring were those with a target strength $<-45 \mathrm{~dB}$ re//1 $\mu \mathrm{Pa}$. The $\square$ table shows mean unit discharge (kcfs) through each unit of the powerhouse and the spillway during the period of fish data collection for that day. $\checkmark$ The legend table displays the percent species composition of juvenile salmon passing John Day Dam for the same day. Median travel time to The Dalles Dam from John Day Dam of summer radio-telemetry tracked fish was $16 \mathrm{hrs}$ from previous years (Holmberg et al. 1996). 


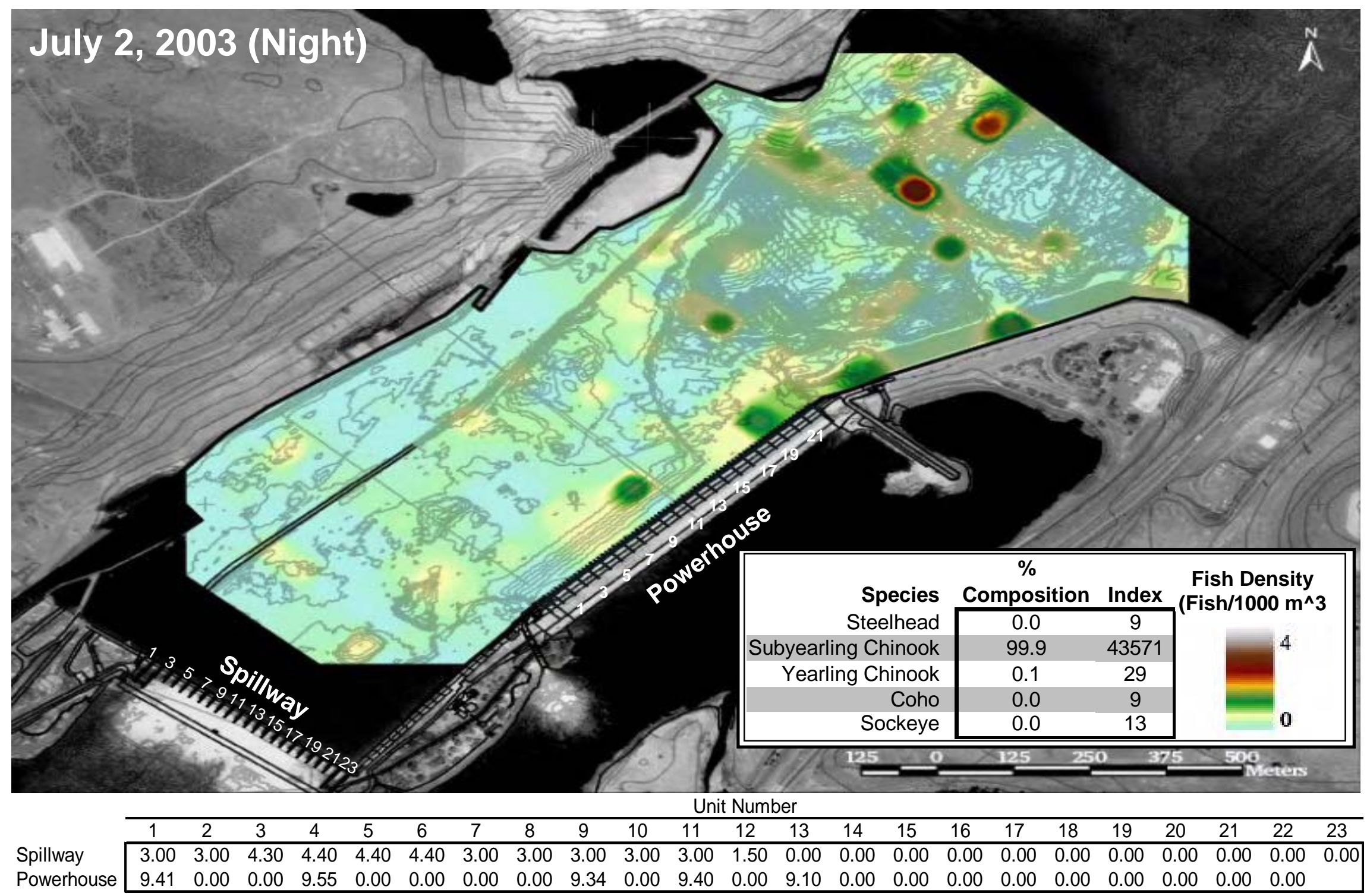

Figure D.16. Small fish density in the forebay of The Dalles Dam. Small fish in the spring were those with a target strength $<-45 \mathrm{~dB}$ re//1 $\mu \mathrm{Pa}$. The $\square$ table shows mean unit discharge (kcfs) through each unit of the powerhouse and the spillway during the period of fish data collection for that day. $\triangleright$ The legend table displays the percent species composition of juvenile salmon passing John Day Dam for the same day. Median travel time to The Dalles Dam from John Day Dam of summer radio-telemetry tracked fish was $16 \mathrm{hrs}$ from previous years (Holmberg et al. 1996). 


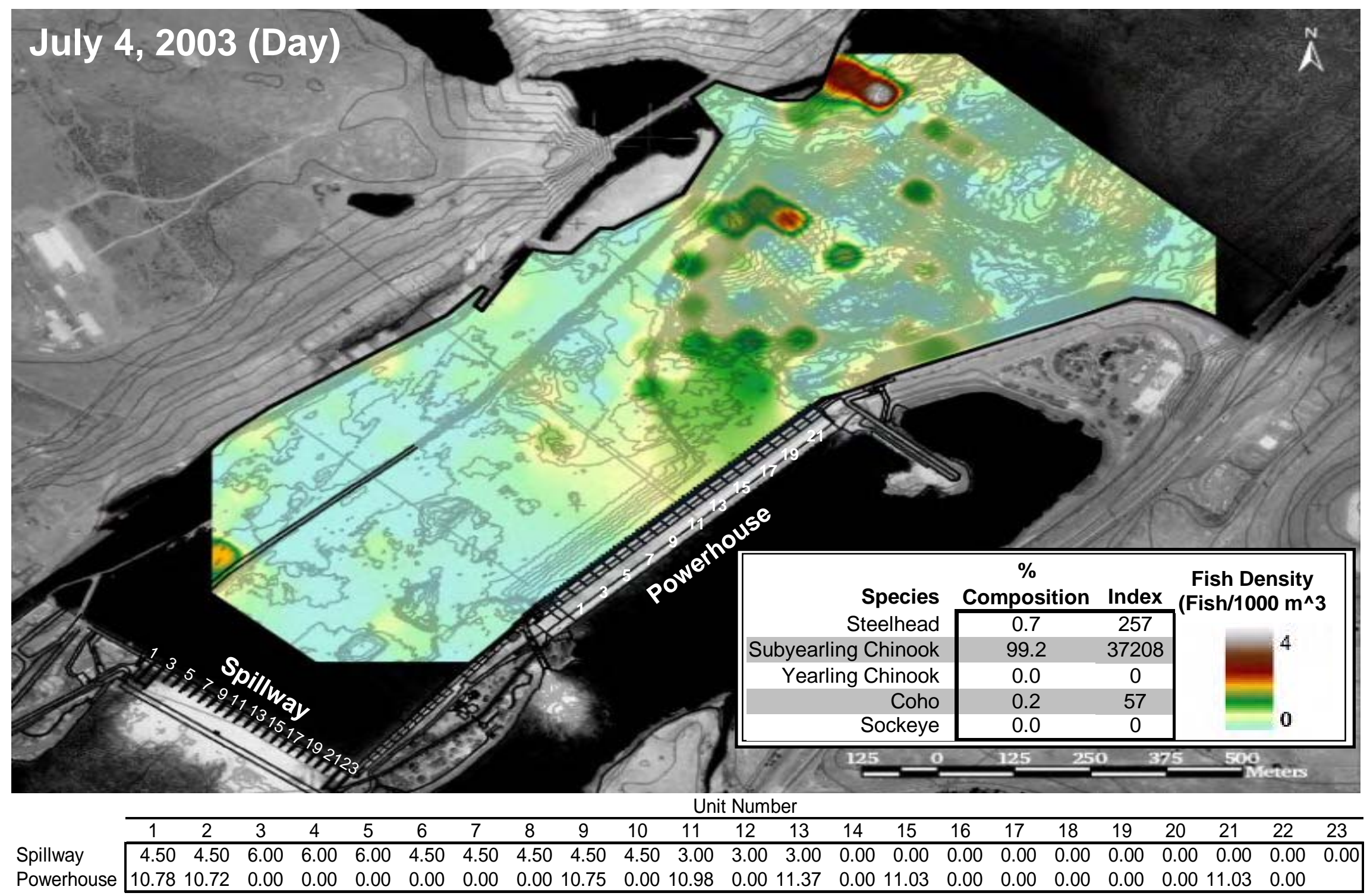

Figure D.17. Small fish density in the forebay of The Dalles Dam. Small fish in the spring were those with a target strength $<-45 \mathrm{~dB}$ re//1 $\mu \mathrm{Pa}$. The table shows mean unit discharge (kcfs) through each unit of the powerhouse and the spillway during the period of fish data collection for that day. The legend table displays the percent species composition of juvenile salmon passing John Day Dam for the same day. Median travel time to The Dalles Dam from John Day Dam of summer radio-telemetry tracked fish was $16 \mathrm{hrs}$ from previous years (Holmberg et al. 1996). 


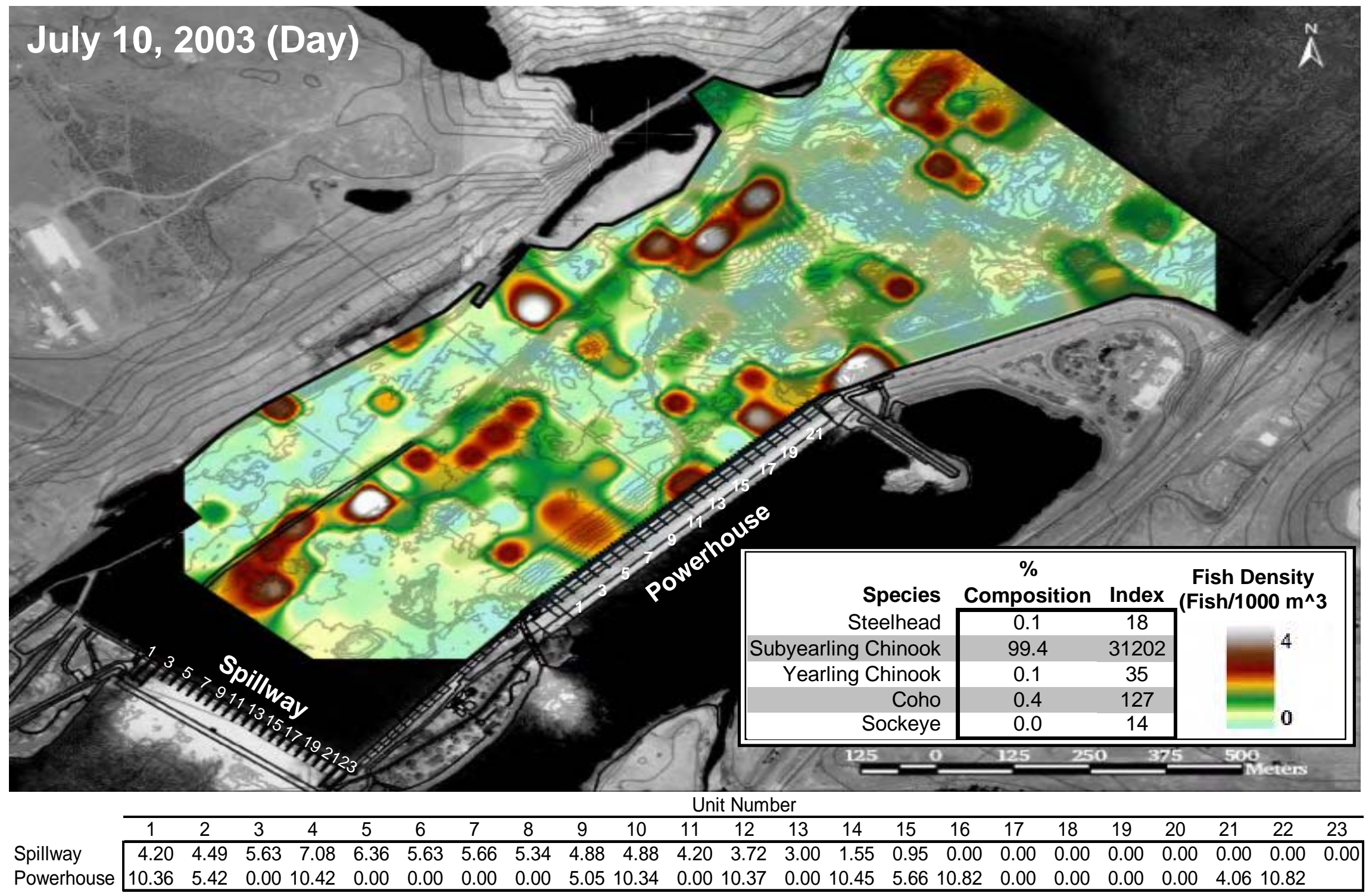

Figure D.18. Small fish density in the forebay of The Dalles Dam. Small fish in the spring were those with a target strength $<-45 \mathrm{~dB}$ re//1 $\mu \mathrm{Pa}$. The

$\underset{\sim}{i}$ table shows mean unit discharge (kcfs) through each unit of the powerhouse and the spillway during the period of fish data collection for that day.

○ The legend table displays the percent species composition of juvenile salmon passing John Day Dam for the same day. Median travel time to The Dalles Dam from John Day Dam of summer radio-telemetry tracked fish was $16 \mathrm{hrs}$ from previous years (Holmberg et al. 1996). 


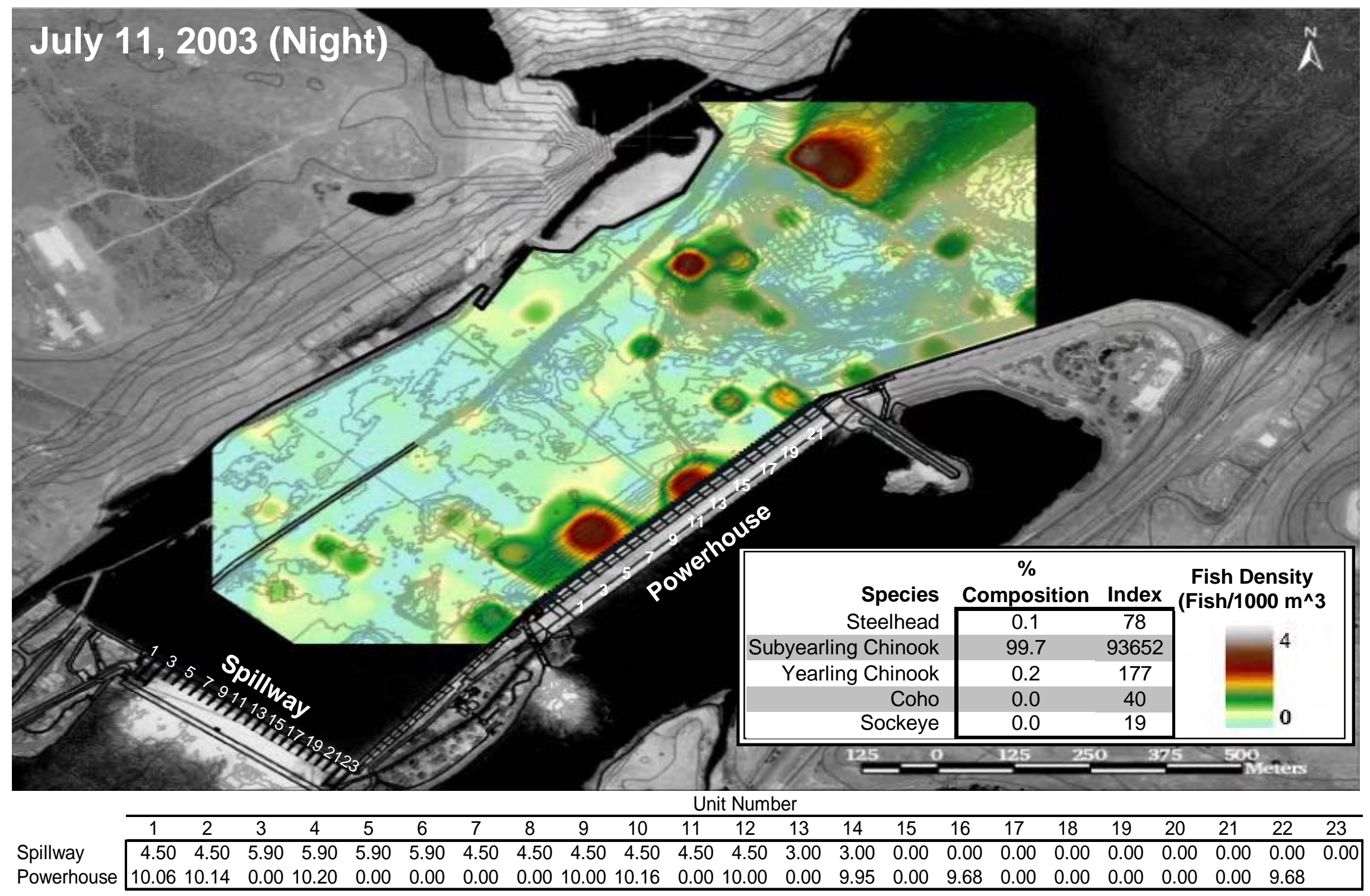

Figure D.19. Small fish density in the forebay of The Dalles Dam. Small fish in the spring were those with a target strength $<-45 \mathrm{~dB}$ re//1 $\mu \mathrm{Pa}$. The

table shows mean unit discharge (kcfs) through each unit of the powerhouse and the spillway during the period of fish data collection for that day. The legend table displays the percent species composition of juvenile salmon passing John Day Dam for the same day. Median travel time to The Dalles Dam from John Day Dam of summer radio-telemetry tracked fish was 16 hrs from previous years (Holmberg et al. 1996). 


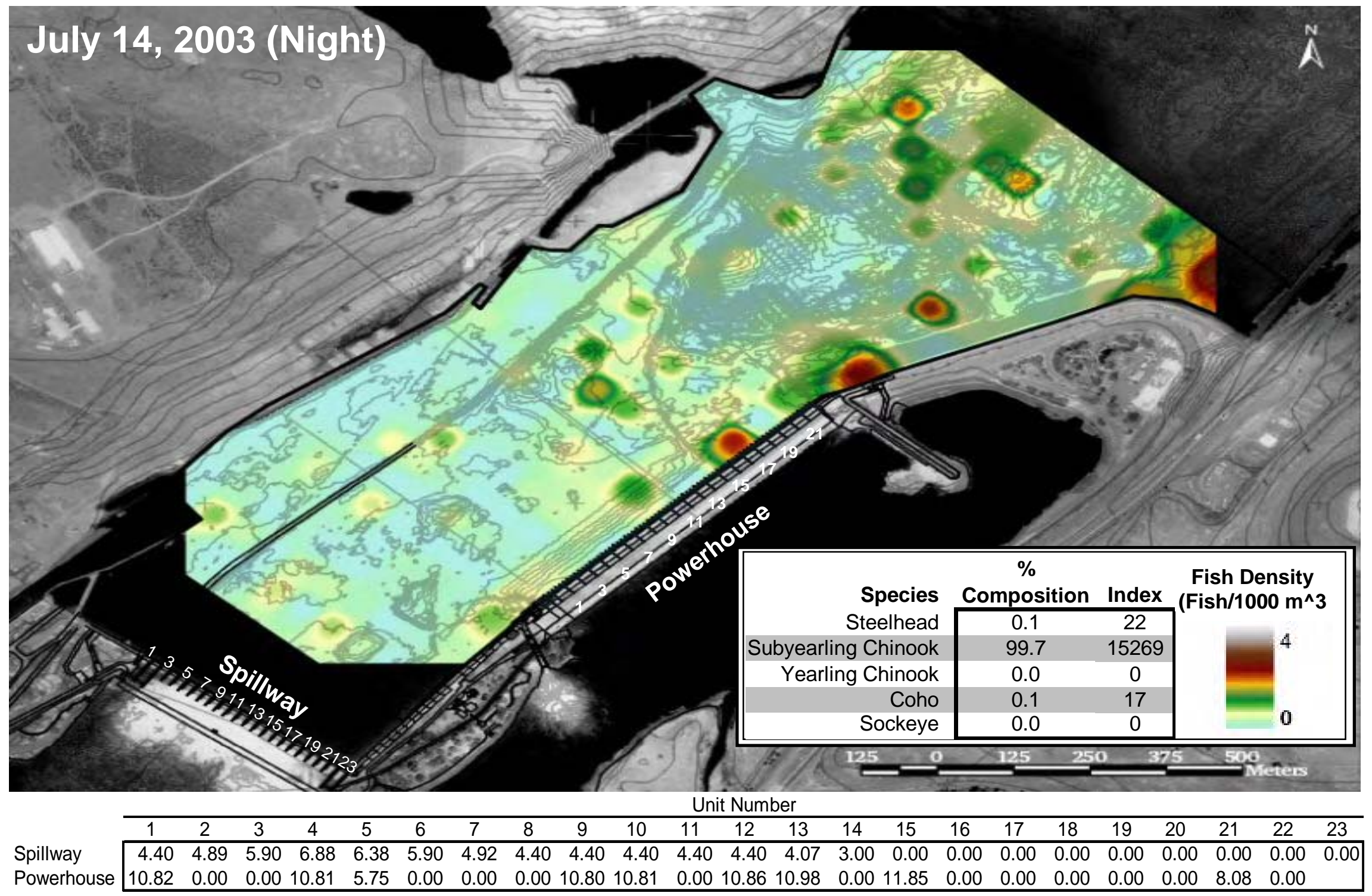

Figure D.20. Small fish density in the forebay of The Dalles Dam. Small fish in the spring were those with a target strength $<-45 \mathrm{~dB}$ re//1 $\mu \mathrm{Pa}$. The

$\underset{\sim}{\sim}$ table shows mean unit discharge (kcfs) through each unit of the powerhouse and the spillway during the period of fish data collection for that day.

$\sim$ The legend table displays the percent species composition of juvenile salmon passing John Day Dam for the same day. Median travel time to The Dalles Dam from John Day Dam of summer radio-telemetry tracked fish was $16 \mathrm{hrs}$ from previous years (Holmberg et al. 1996). 


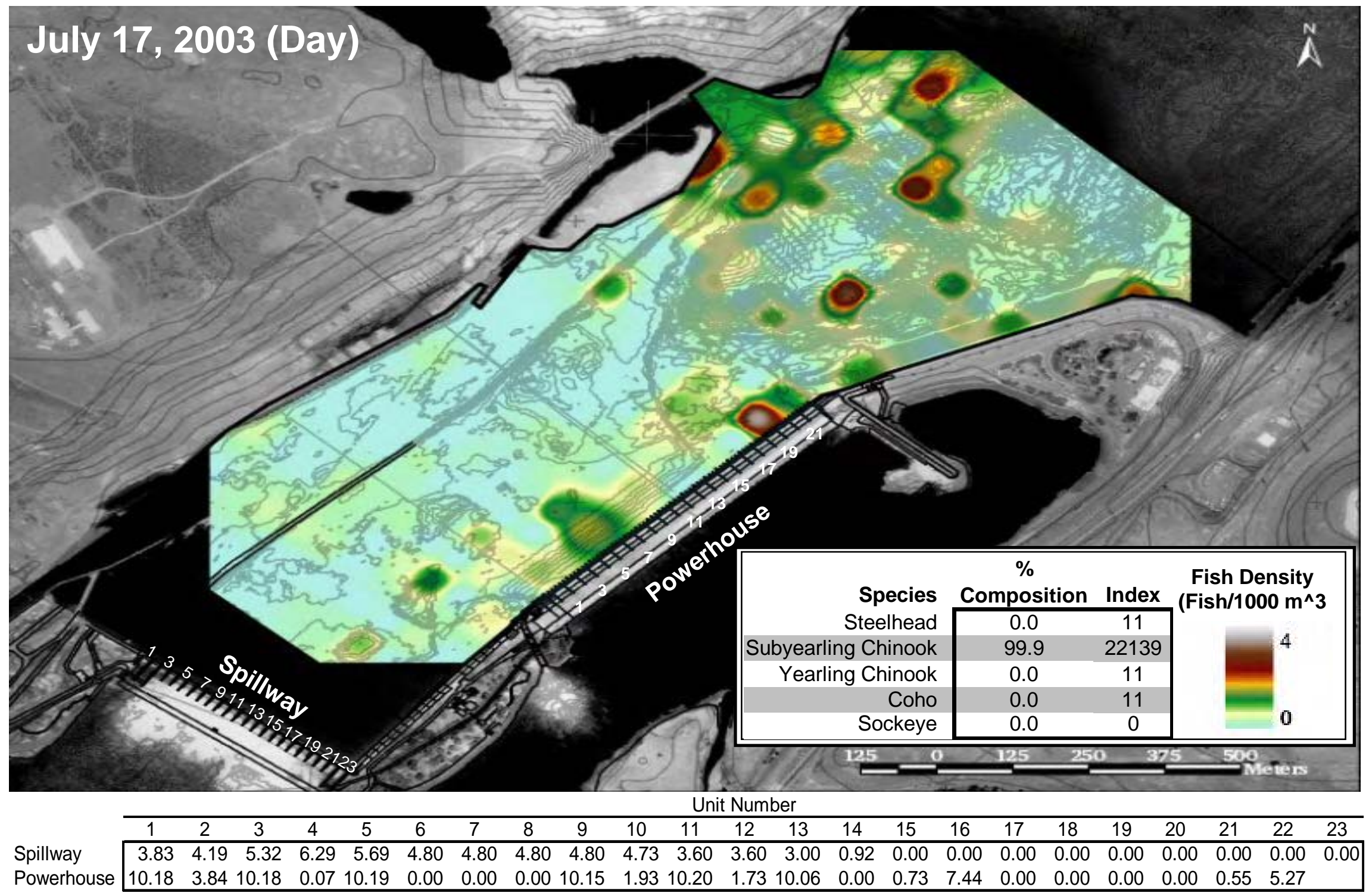

Figure D.21. Small fish density in the forebay of The Dalles Dam. Small fish in the spring were those with a target strength $<-45 \mathrm{~dB}$ re//1 $\mu \mathrm{Pa}$. The

$\underset{\sim}{i}$ table shows mean unit discharge (kcfs) through each unit of the powerhouse and the spillway during the period of fish data collection for that day.

$\underset{\omega}{N}$ The legend table displays the percent species composition of juvenile salmon passing John Day Dam for the same day. Median travel time to The Dalles Dam from John Day Dam of summer radio-telemetry tracked fish was $16 \mathrm{hrs}$ from previous years (Holmberg et al. 1996). 


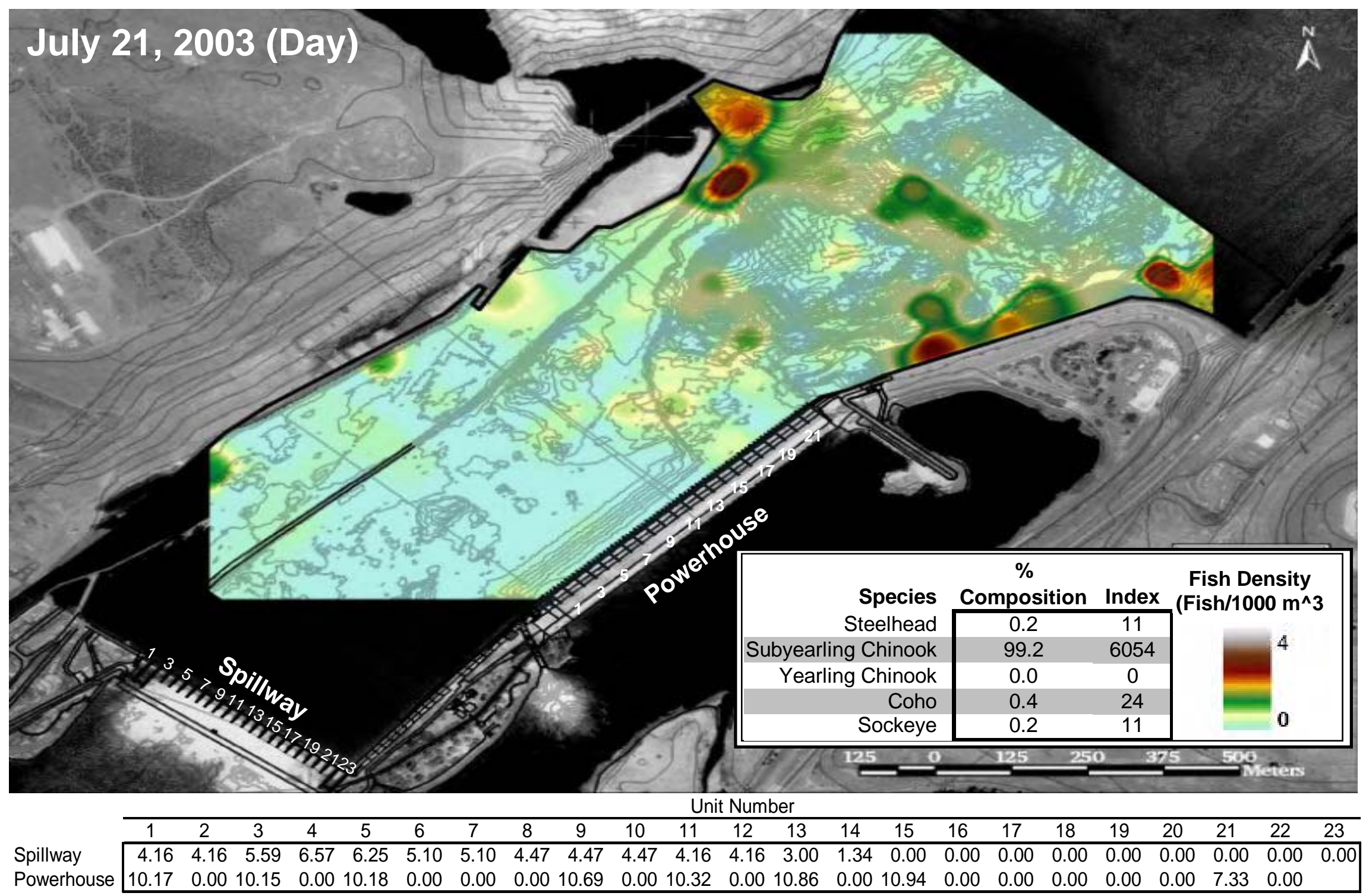

Figure D.22. Small fish density in the forebay of The Dalles Dam. Small fish in the spring were those with a target strength $<-45 \mathrm{~dB}$ re//1 $\mu \mathrm{Pa}$. The

$\underset{\sim}{i}$ table shows mean unit discharge (kcfs) through each unit of the powerhouse and the spillway during the period of fish data collection for that day.

$\triangle$ The legend table displays the percent species composition of juvenile salmon passing John Day Dam for the same day. Median travel time to The Dalles Dam from John Day Dam of summer radio-telemetry tracked fish was $16 \mathrm{hrs}$ from previous years (Holmberg et al. 1996). 


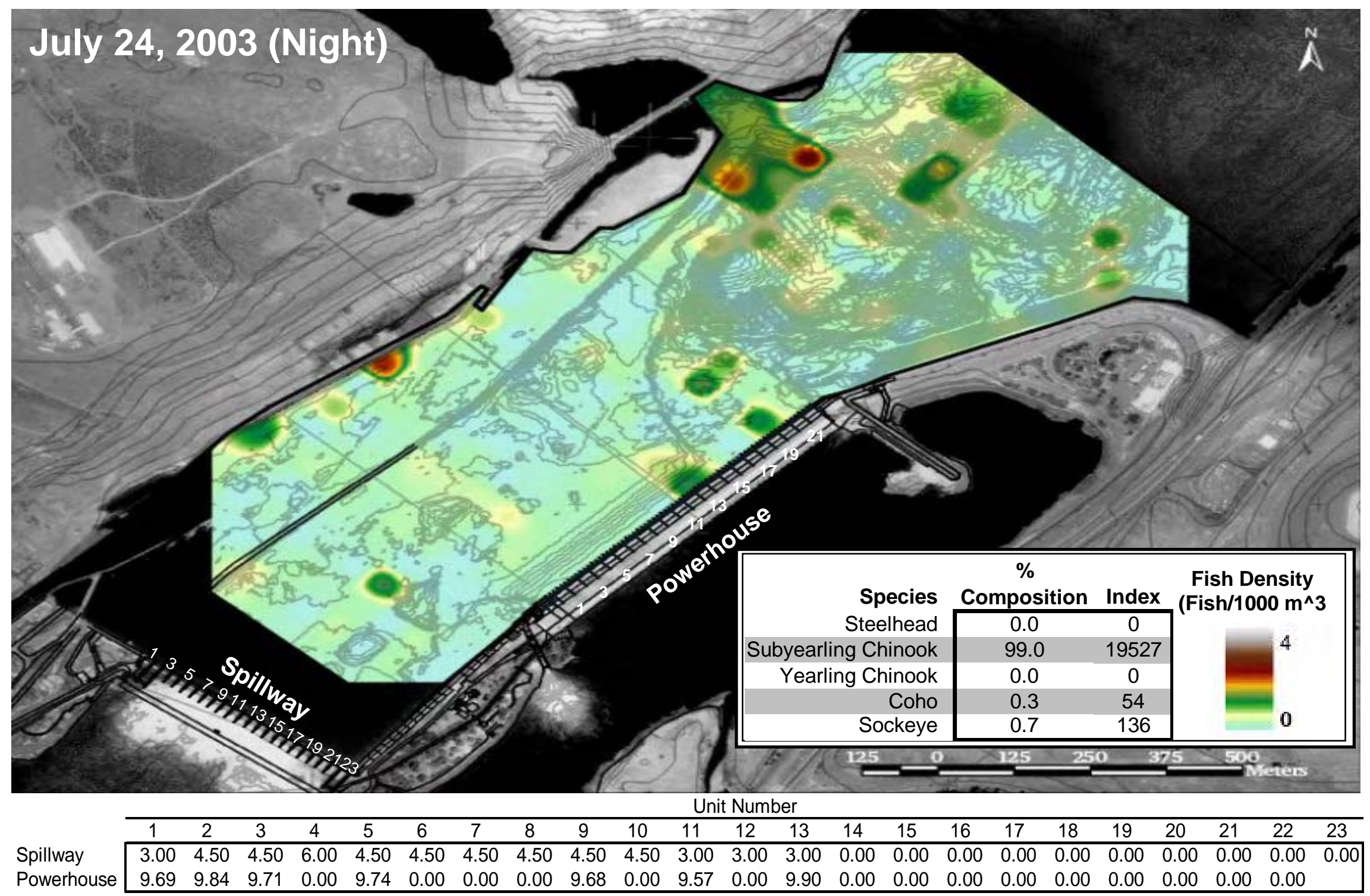

Figure D.23. Small fish density in the forebay of The Dalles Dam. Small fish in the spring were those with a target strength $<-45 \mathrm{~dB}$ re//1 $\mu \mathrm{Pa}$. The

$\underset{\sim}{i}$ table shows mean unit discharge (kcfs) through each unit of the powerhouse and the spillway during the period of fish data collection for that day.

$\mathcal{G}$ The legend table displays the percent species composition of juvenile salmon passing John Day Dam for the same day. Median travel time to The Dalles Dam from John Day Dam of summer radio-telemetry tracked fish was $16 \mathrm{hrs}$ from previous years (Holmberg et al. 1996). 
N 


\section{Appendix E}

Larger-than-Smolt-Sized Fish Distribution as Determined by Mobile Hydroacoustic Sampling for Each Sample Day in the Forebay of The Dalles Dam, Spring and Summer 2003 


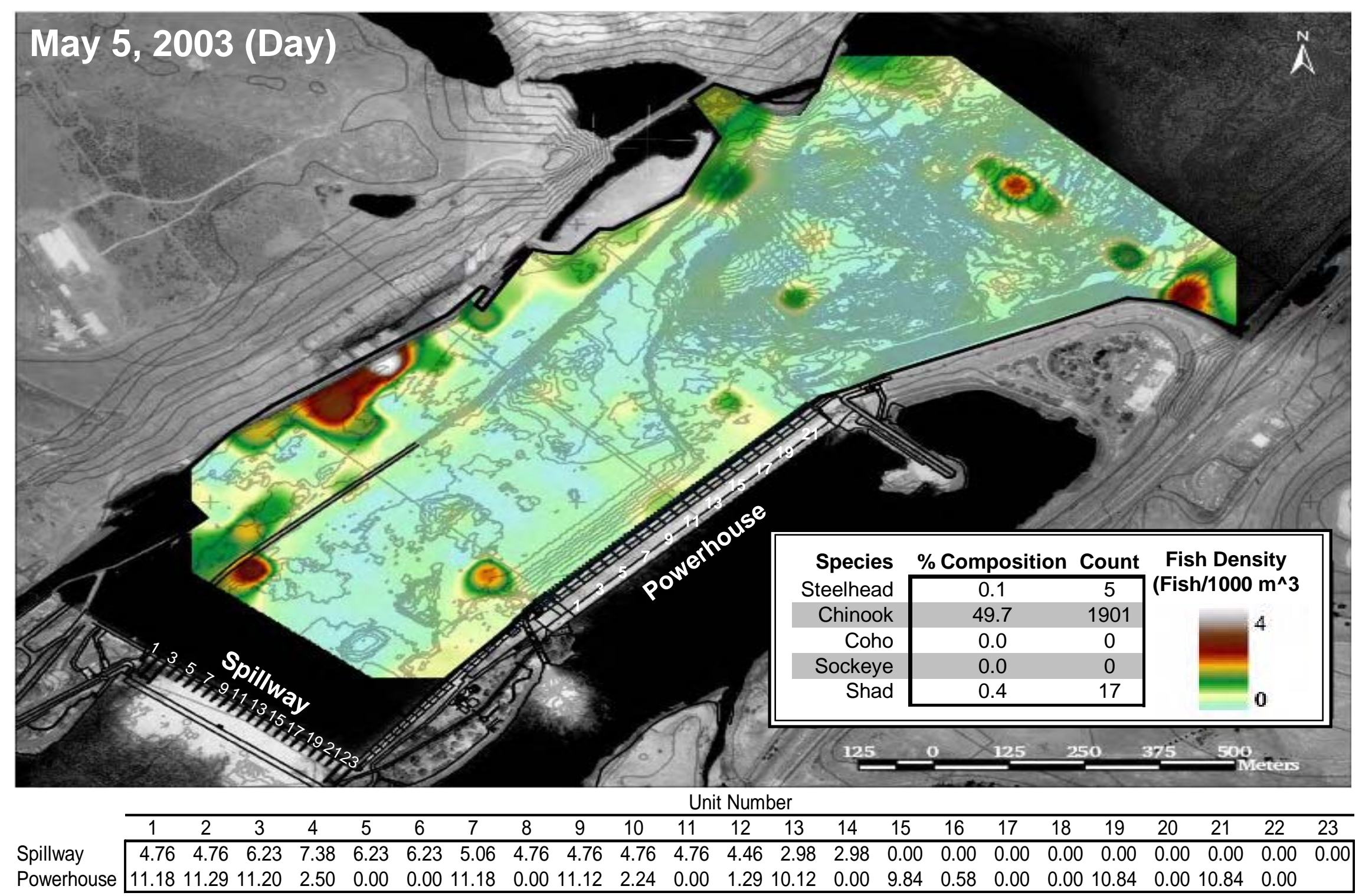

Figure E.1. Larger than smolt-sized fish density in the forebay of The Dalles Dam. Large fish in the spring were those with a target strength >-34 $\mathrm{dB}$ re//1 $\mu \mathrm{Pa}$. The table shows mean unit discharge (kcfs) through each unit of the powerhouse and the spillway during the period of fish data $\underset{\omega}{\omega}$ follection for that day. The legen for the same day. 


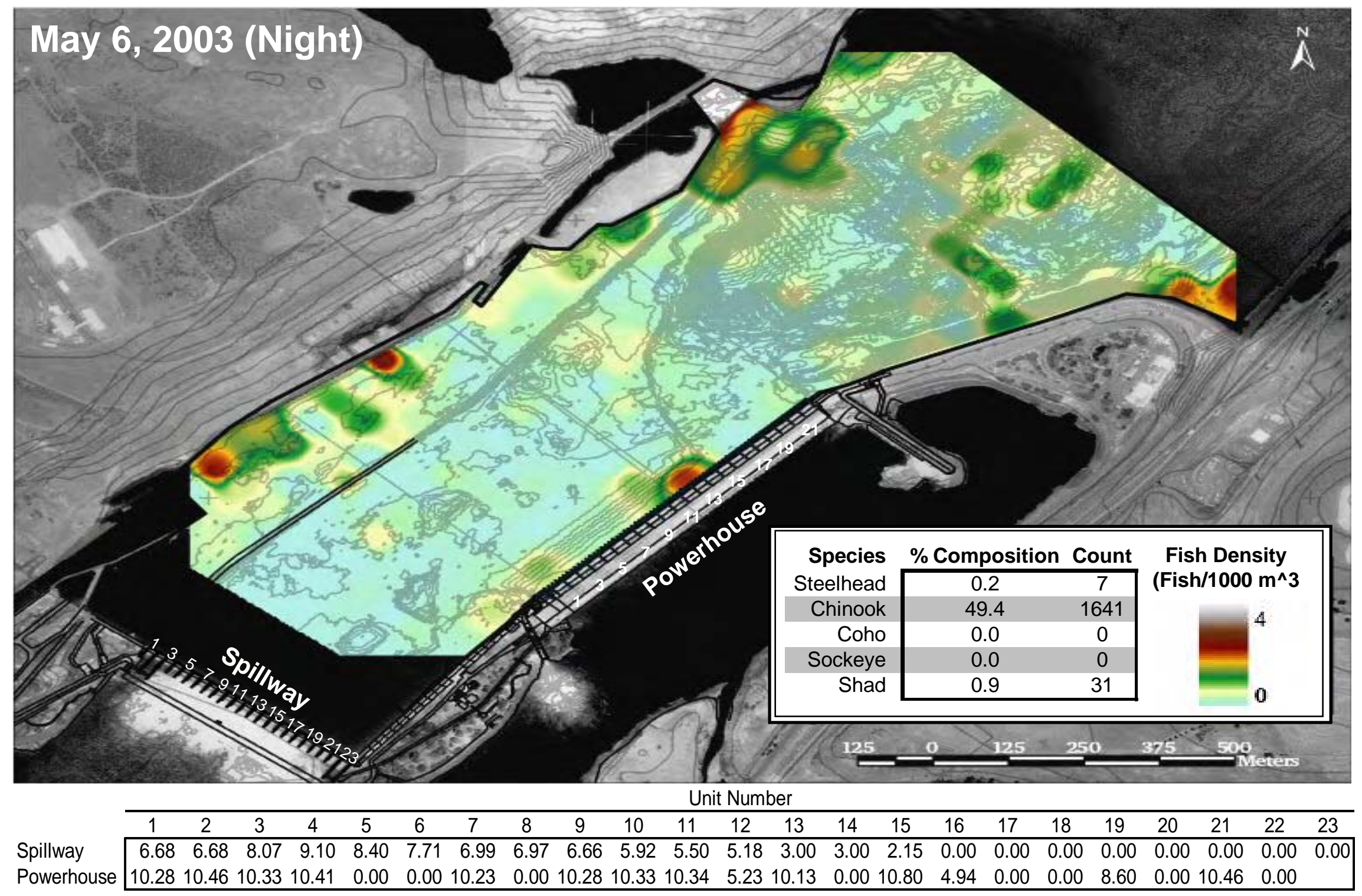

Powerhouse $\begin{array}{lllllllllllllllllllllll}10.28 & 10.46 & 10.33 & 10.41 & 0.00 & 0.00 & 10.23 & 0.00 & 10.28 & 10.33 & 10.34 & 5.23 & 10.13 & 0.00 & 10.80 & 4.94 & 0.00 & 0.00 & 8.60 & 0.00 & 10.46 & 0.00\end{array}$

Figure E.2. Larger than smolt-sized fish density in the forebay of The Dalles Dam. Large fish in the spring were those with a target strength >-34 $\mathrm{dB}$ re//1 $\mu \mathrm{Pa}$. The table shows mean unit discharge $(\mathrm{kcfs})$ through each unit of the powerhouse and the spillway during the period of fish data $\underset{\triangleright}{\square} \quad$ fish ladders for the same day. 


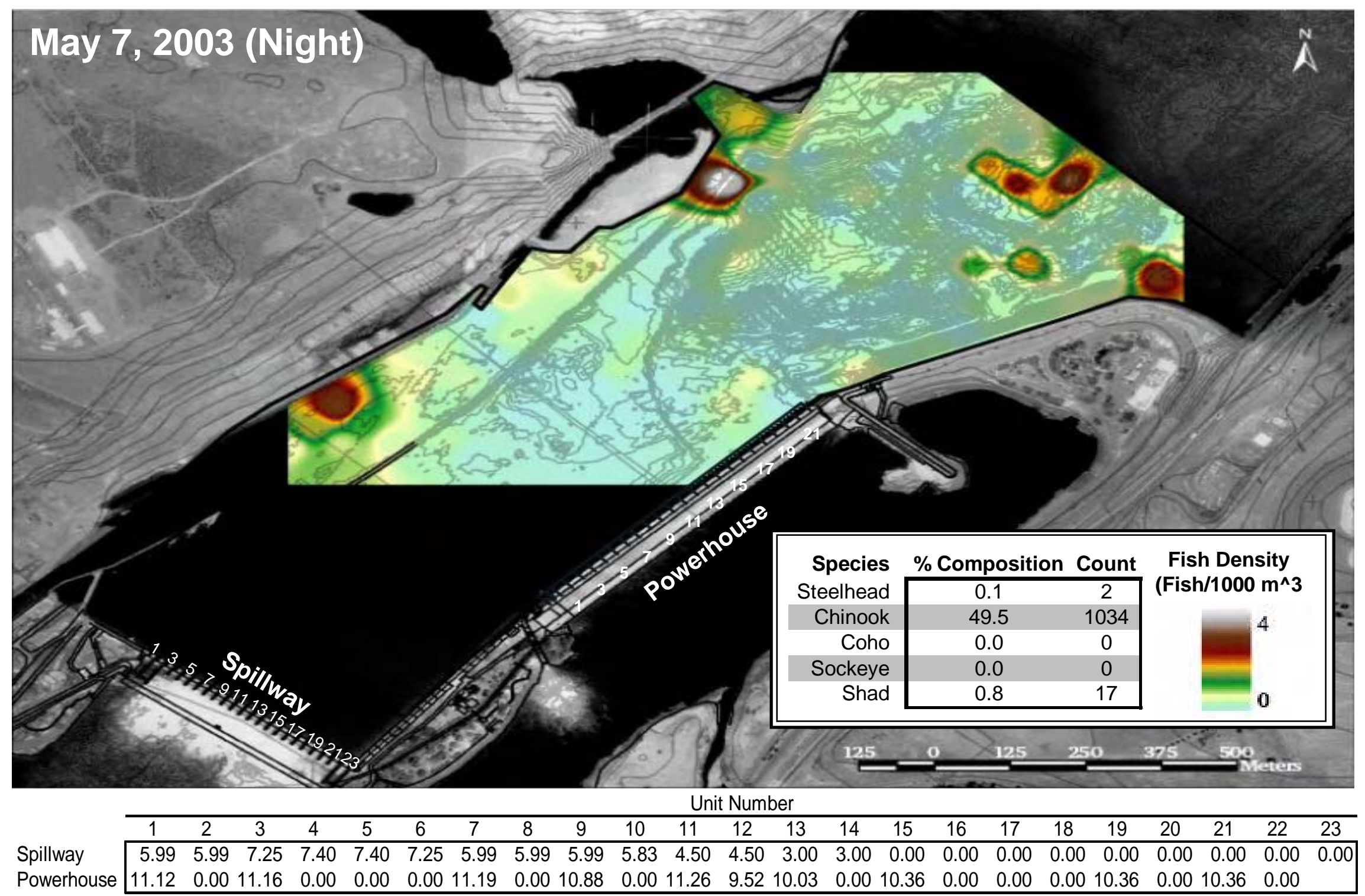

Figure E.3. Larger than smolt-sized fish density in the forebay of The Dalles Dam. Large fish in the spring were those with a target strength >-34 $\mathrm{dB}$ re//1 $\mu \mathrm{Pa}$. The table shows mean unit discharge (kcfs) through each unit of the powerhouse and the spillway during the period of fish data or collection for that day. The legen 


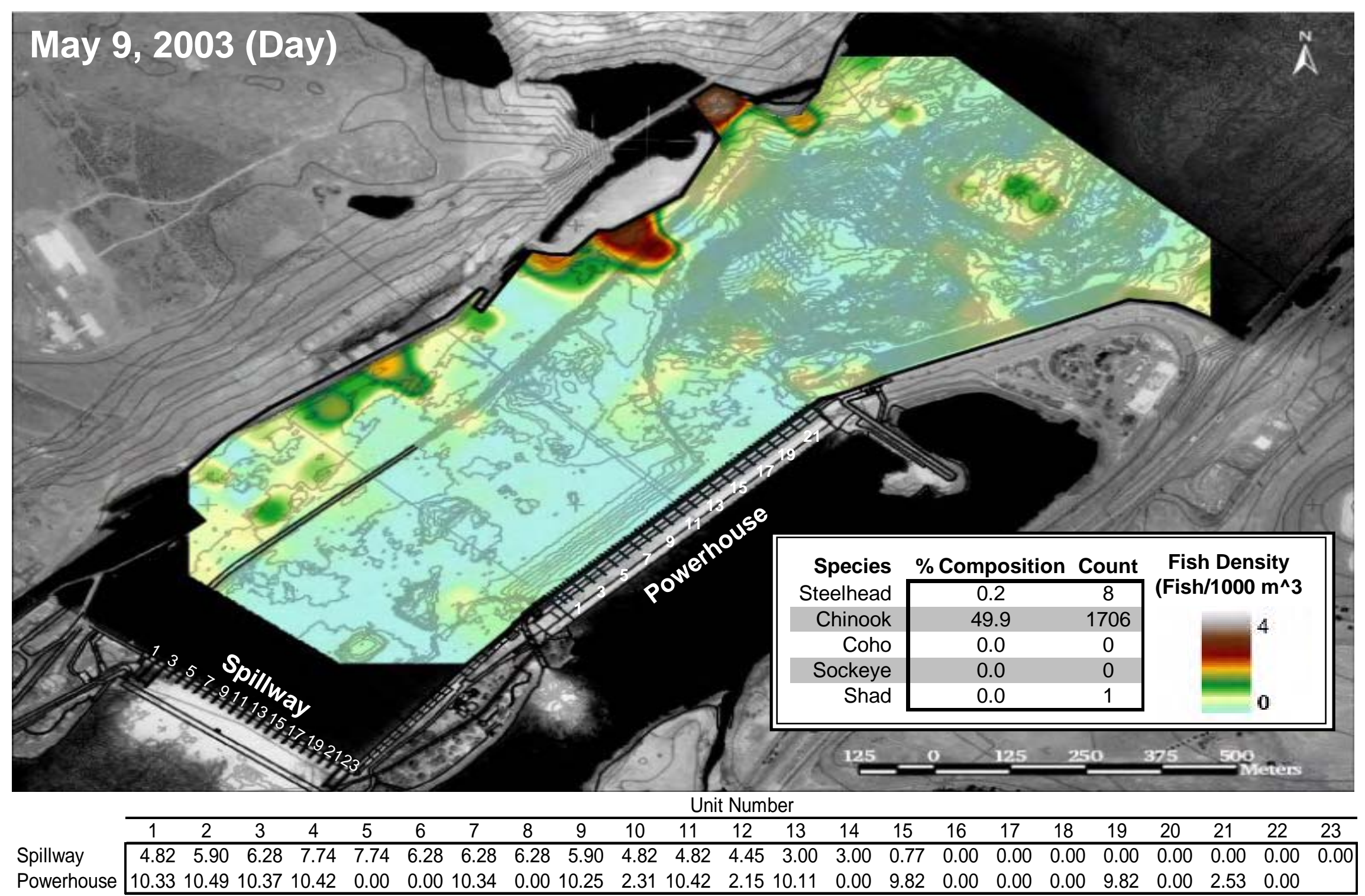

Figure E.4. Larger than smolt-sized fish density in the forebay of The Dalles Dam. Large fish in the spring were those with a target strength >-34 $\mathrm{dB}$ re//1 $\mu \mathrm{Pa}$. The table shows mean unit discharge (kcfs) through each unit of the powerhouse and the spillway during the period of fish data $\underset{\sigma}{m}$ follection for that day. The legen for the same day. 


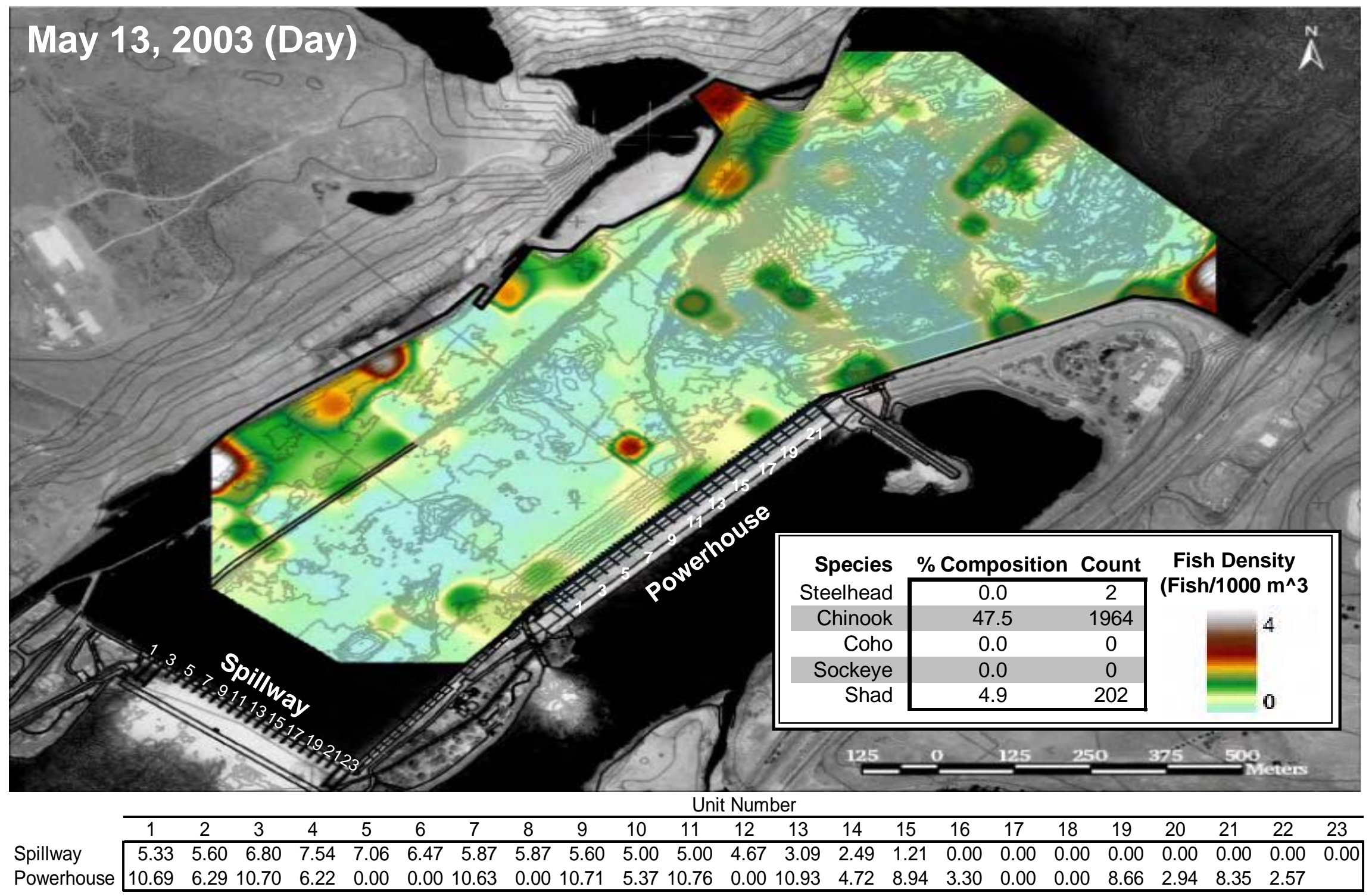

Figure E.5. Larger than smolt-sized fish density in the forebay of The Dalles Dam. Large fish in the spring were those with a target strength >-34 $\mathrm{dB}$ re//1 $\mu \mathrm{Pa}$. The table shows mean unit discharge $(\mathrm{kcfs})$ through each unit of the powerhouse and the spillway during the period of fish data $\underset{7}{ } \quad$ collection for that day. The legen ladders for the same day. 


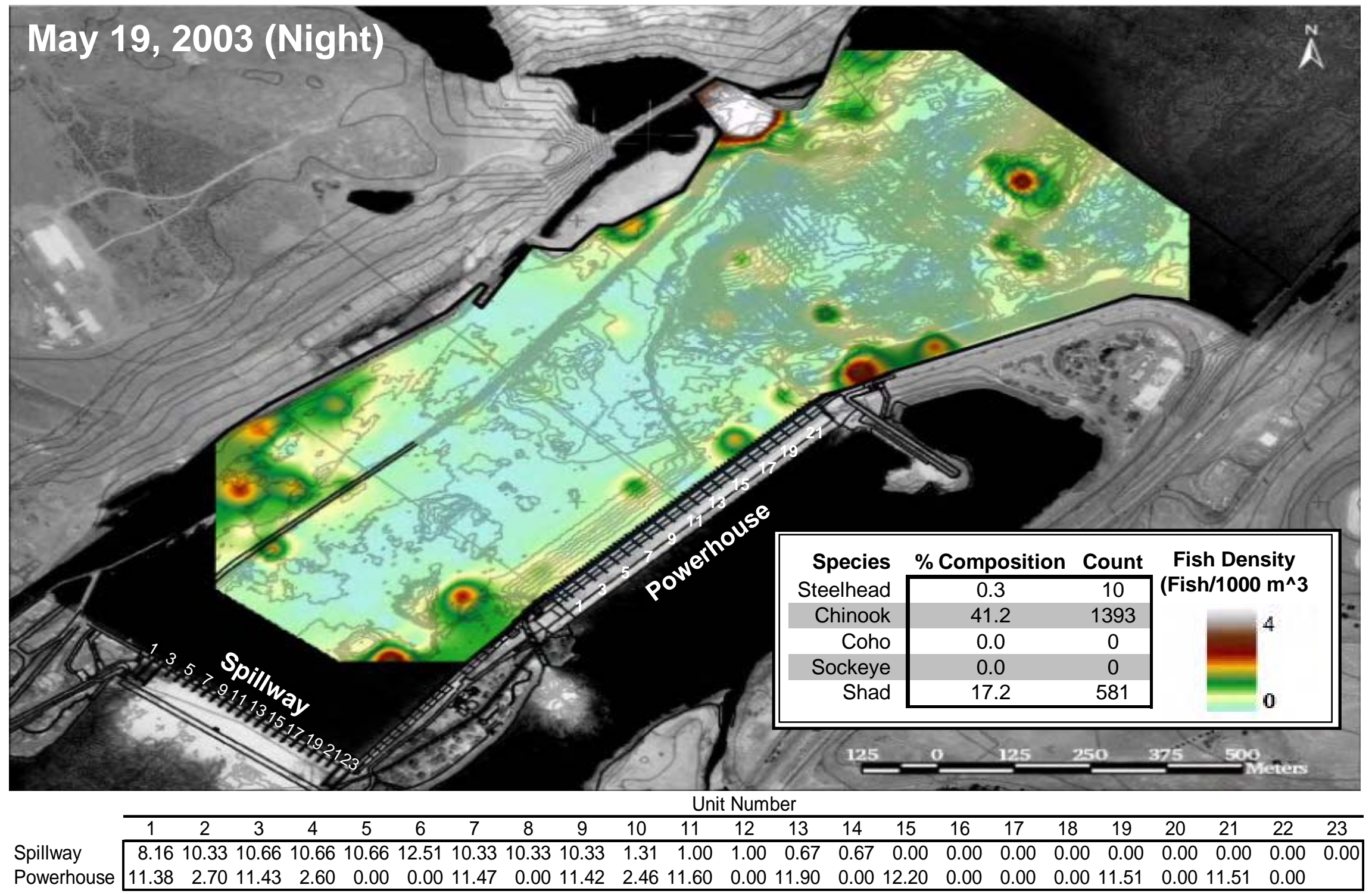

Figure E.6. Larger than smolt-sized fish density in the forebay of The Dalles Dam. Large fish in the spring were those with a target strength >-34 $\mathrm{dB}$ re//1 $\mu \mathrm{Pa}$. The table shows mean unit discharge ( $\mathrm{kcfs}$ ) through each unit of the powerhouse and the spillway during the period of fish data $\underset{\infty}{\infty}$ collection for that day. The legen ladders for the same day. 


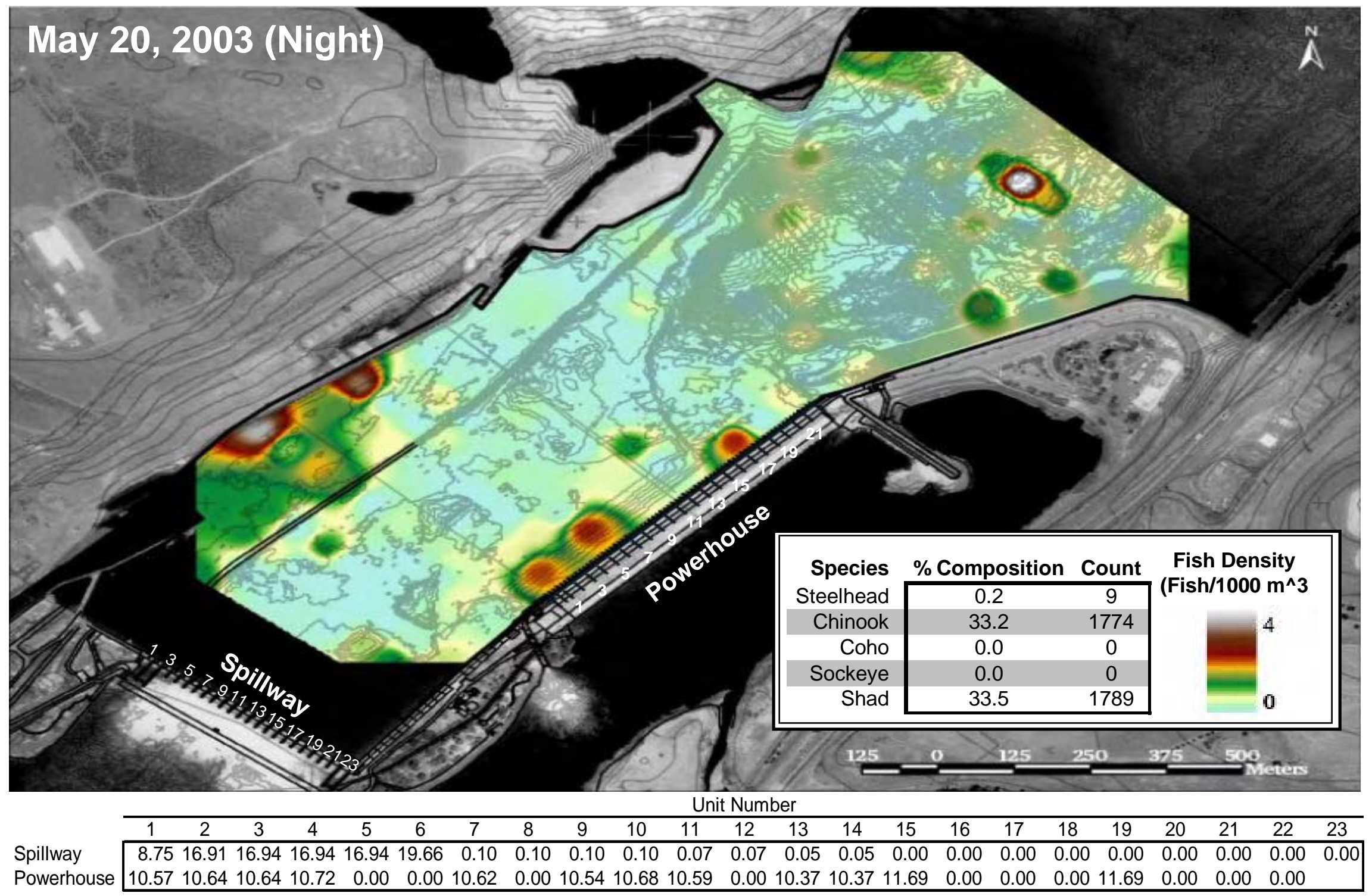

Figure E.7. Larger than smolt-sized fish density in the forebay of The Dalles Dam. Large fish in the spring were those with a target strength >-34 $\mathrm{dB}$ re//1 $\mu \mathrm{Pa}$. The table shows mean unit discharge $(\mathrm{kcfs})$ through each unit of the powerhouse and the spillway during the period of fish data 0 collection for that day. The legen 


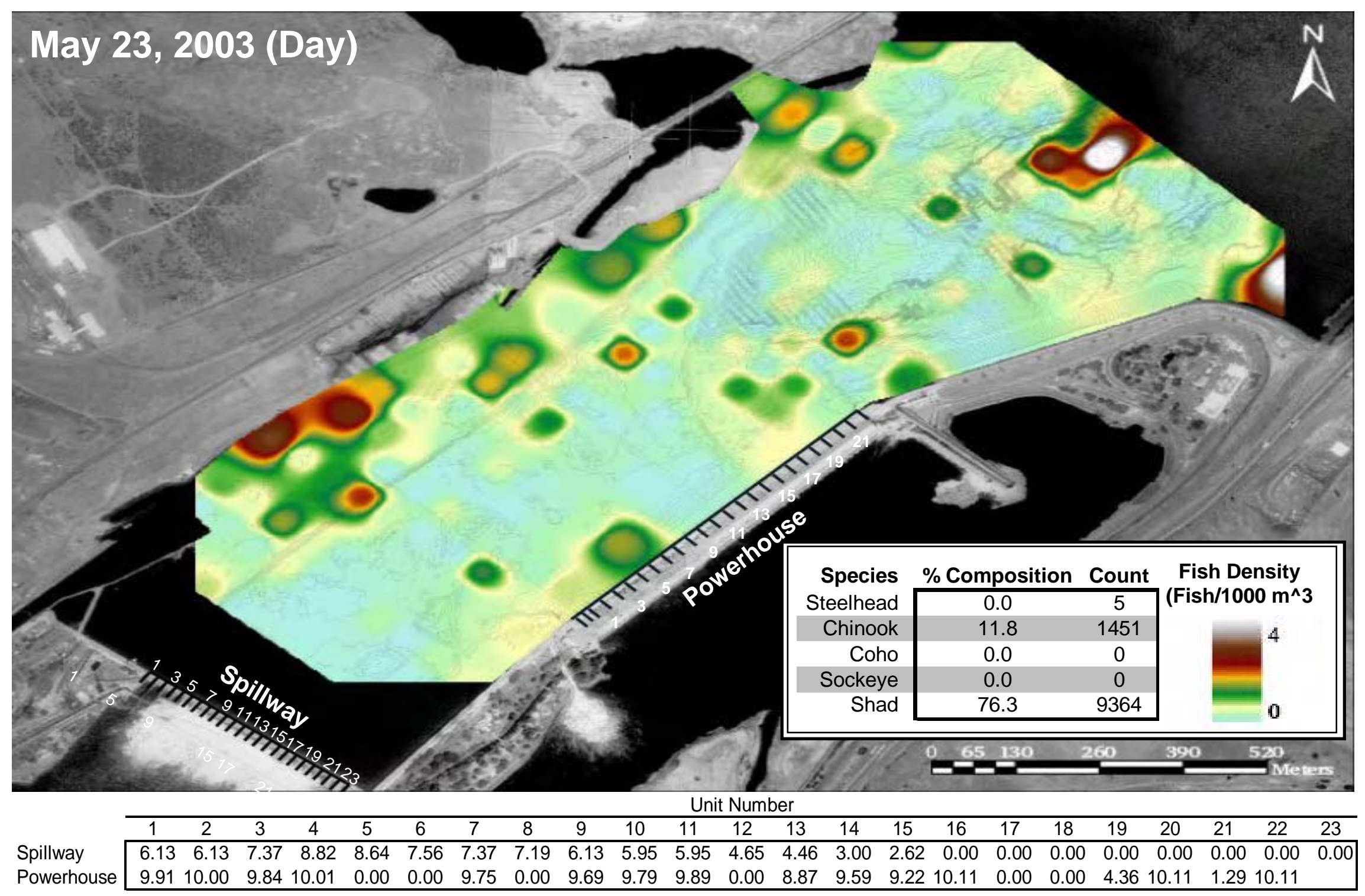

Figure E.8. Larger than smolt-sized fish density in the forebay of The Dalles Dam. Large fish in the spring were those with a target strength >-34 $\mathrm{dB}$ re//1 $\mu \mathrm{Pa}$. The table shows mean unit discharge ( $\mathrm{kcfs}$ ) through each unit of the powerhouse and the spillway during the period of fish data $m$ collection for that day. The legend table displays the percent species composition and number of upstream-migrating fish passing The Dalles Dam $\dot{\circ}$ fish ladders for the same day. 


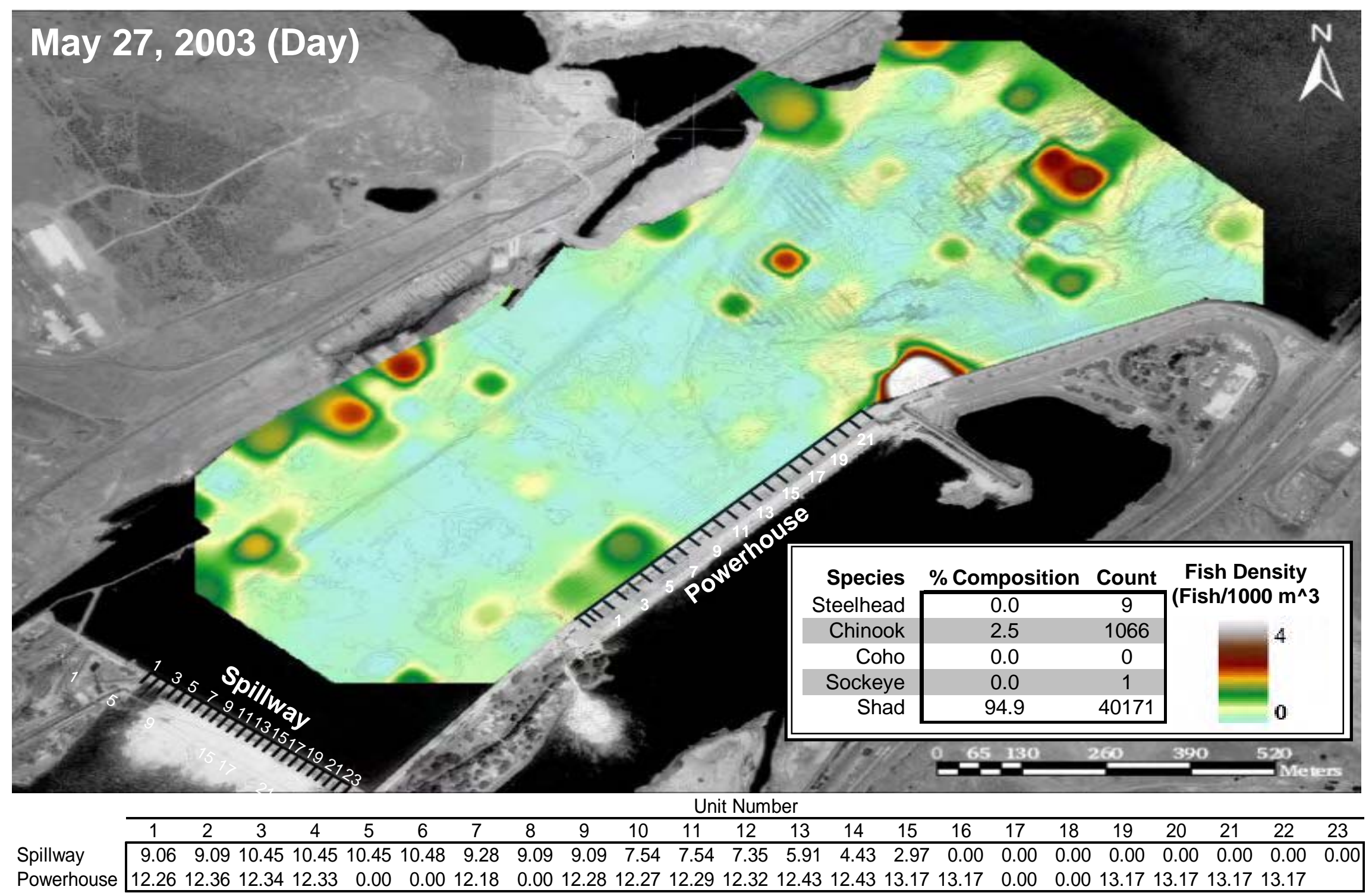

Figure E.9. Larger than smolt-sized fish density in the forebay of The Dalles Dam. Large fish in the spring were those with a target strength >-34 $\mathrm{dB}$ re//1 $\mu \mathrm{Pa}$. The table shows mean unit discharge (kcfs) through each unit of the powerhouse and the spillway during the period of fish data $m$ collection for that day. The legend table displays the percent species composition and number of upstream-migrating fish passing The Dalles Dam $\mapsto \quad$ fish ladders for the same day. 


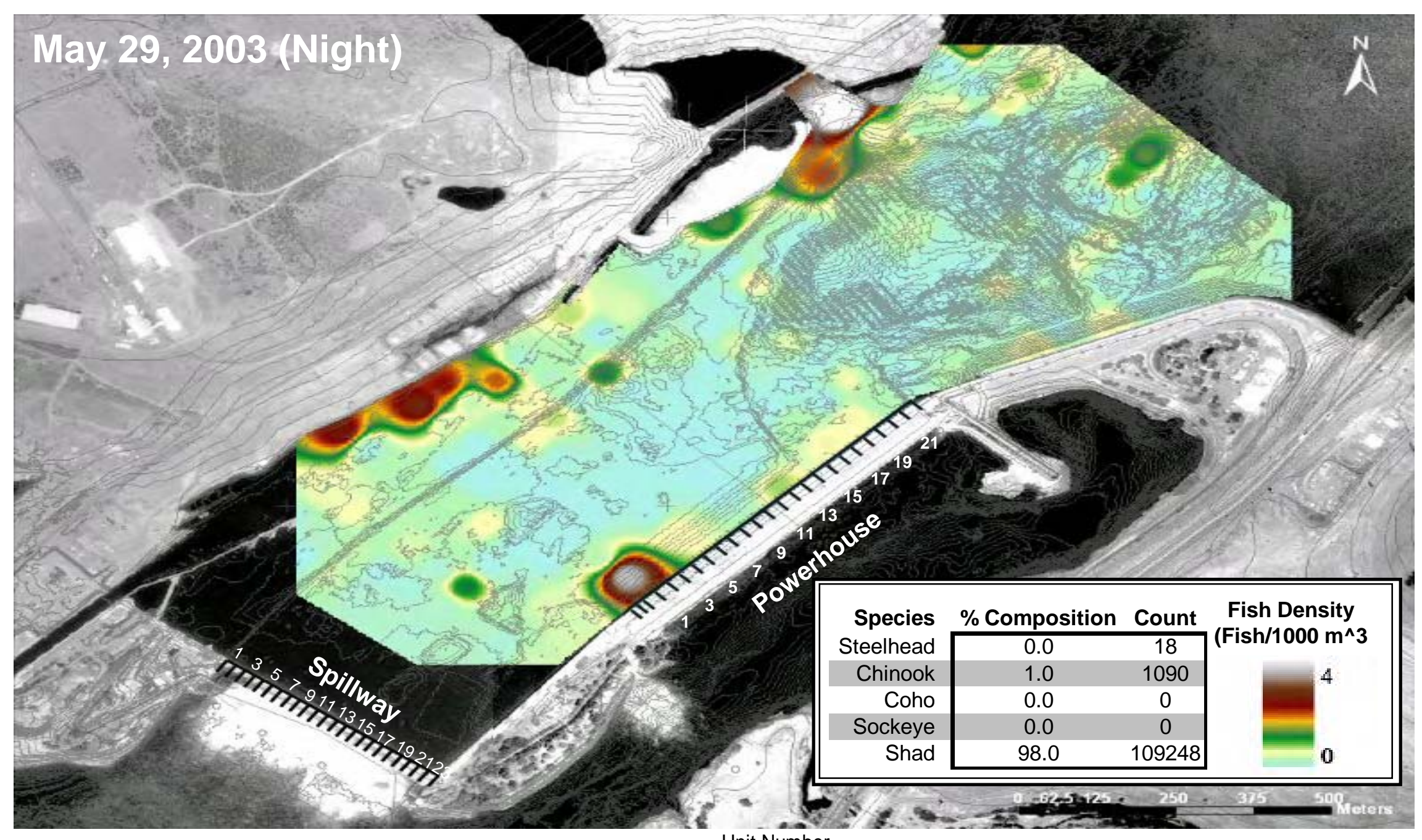

Unit Number

\begin{tabular}{l|ccccccccccccccccccccccc} 
& 1 & 2 & 3 & 4 & 5 & 6 & 7 & 8 & 9 & 10 & 11 & 12 & 13 & 14 & 15 & 16 & 17 & 18 & 19 & 20 & 21 & 22 & 23 \\
\cline { 2 - 7 } & 8.90 & 8.99 & 8.99 & 9.08 & 9.08 & 9.08 & 8.99 & 11.70 & 14.19 & 14.19 & 7.57 & 7.48 & 7.39 & 5.91 & 0.19 & 0.00 & 0.00 & 0.00 & 0.00 & 0.00 & 0.00 & 0.00 & 0.00 \\
\hline
\end{tabular}

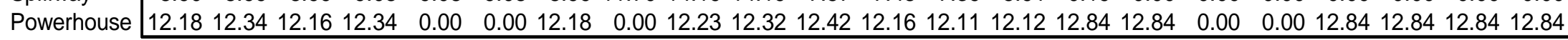

Figure E.10. Larger than smolt-sized fish density in the forebay of The Dalles Dam. Large fish in the spring were those with a target strength >-34 $\mathrm{dB}$ re//1 $\mu \mathrm{Pa}$. The table shows mean unit discharge (kcfs) through each unit of the powerhouse and the spillway during the period of fish data m collection for that day. The legend table displays the percent species composition and number of upstream-migrating fish passing The Dalles Dam $\stackrel{\sim}{\sim}$ fish ladders for the same day. 


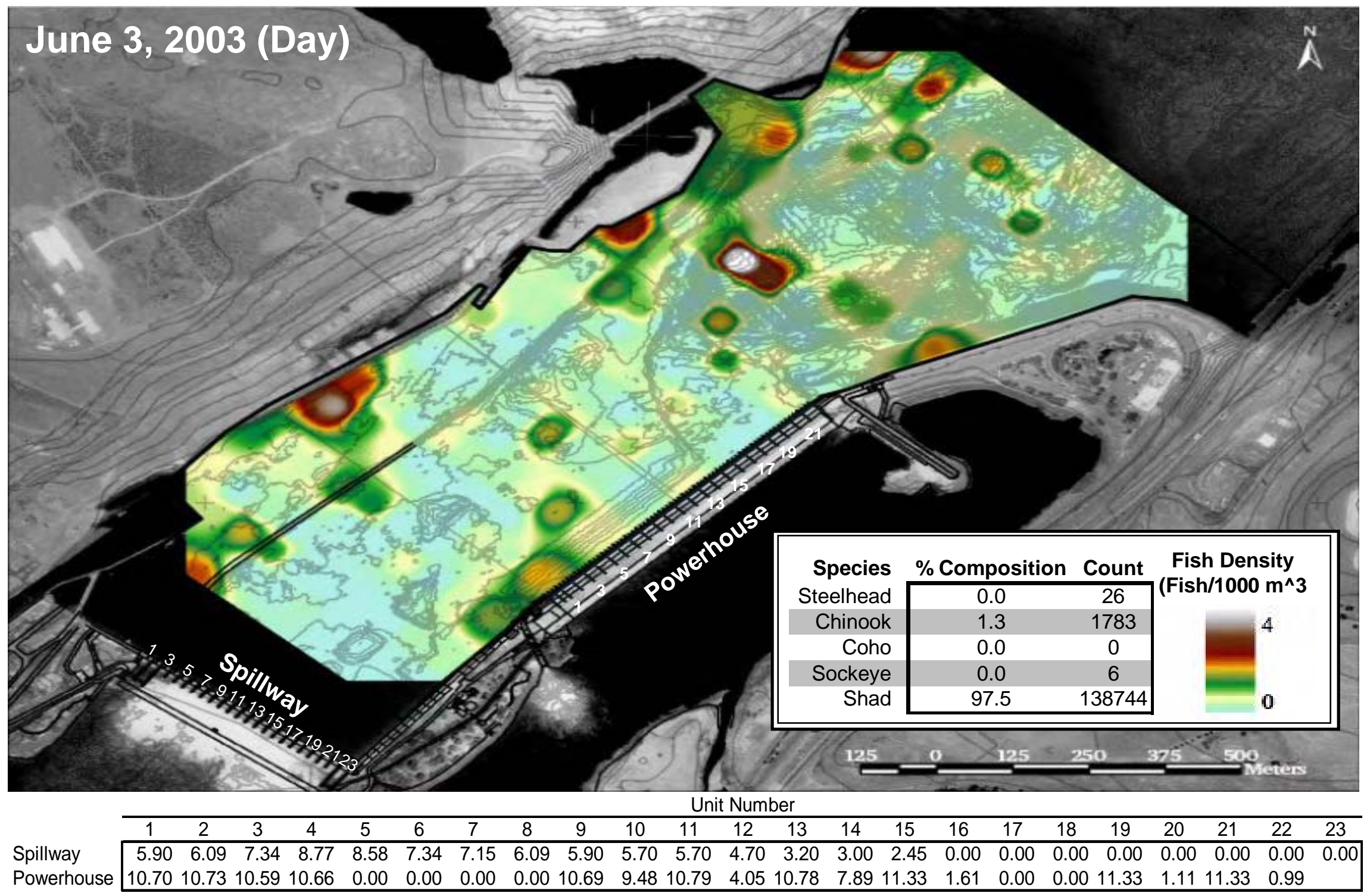

Figure E.11. Larger than smolt-sized fish density in the forebay of The Dalles Dam. Large fish in the spring were those with a target strength >-34 $\mathrm{dB}$ re//1 $\mu \mathrm{Pa}$. The table shows mean unit discharge (kcfs) through each unit of the powerhouse and the spillway during the period of fish data $m$ collection for that day. The legend table displays the percent species composition and number of upstream-migrating fish passing The Dalles Dam $\dot{\omega} \quad$ fish ladders for the same day. 


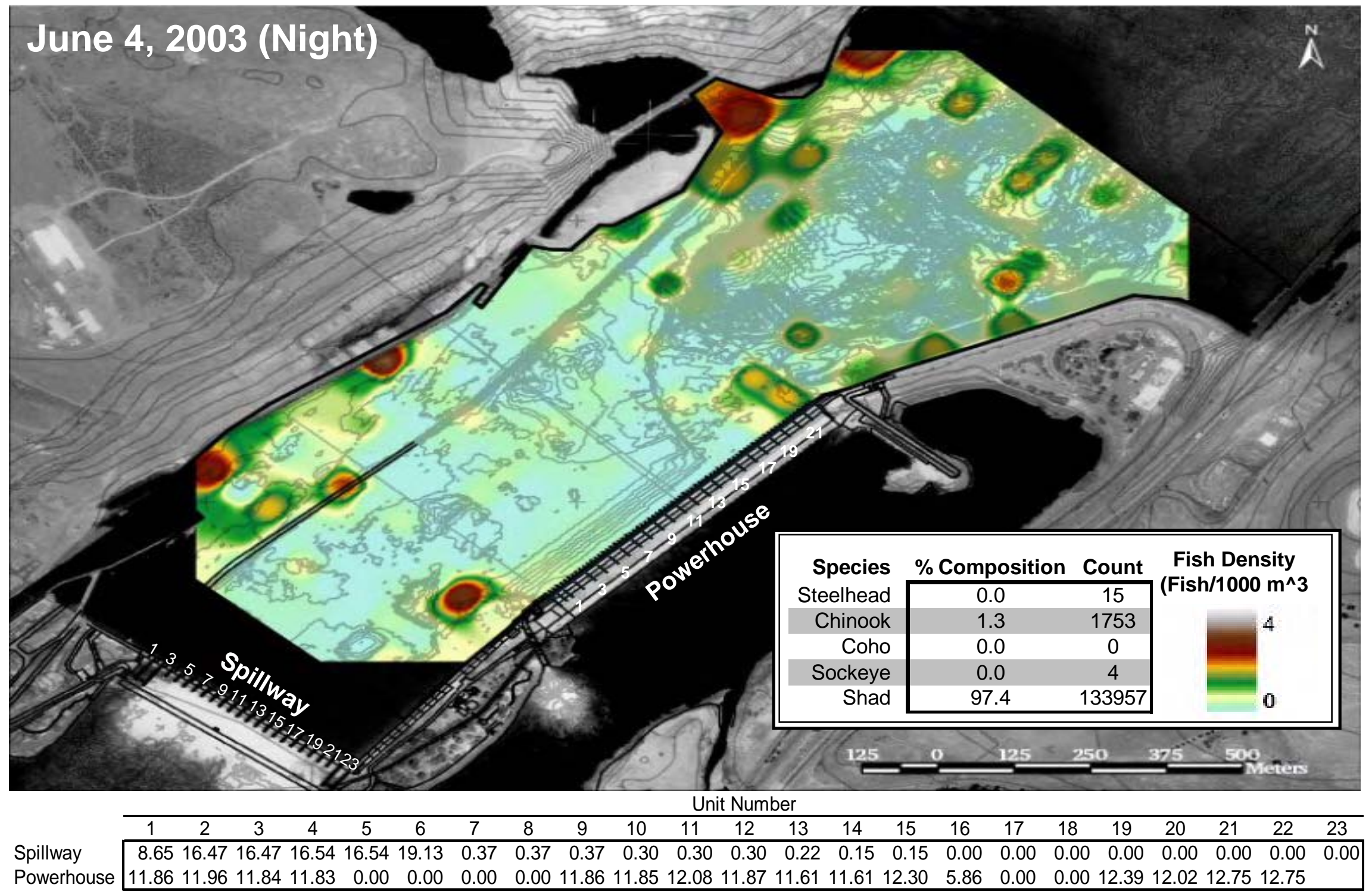

Figure E.12. Larger than smolt-sized fish density in the forebay of The Dalles Dam. Large fish in the spring were those with a target strength >-34 $\mathrm{dB}$ re//1 $\mu \mathrm{Pa}$. The table shows mean unit discharge (kcfs) through each unit of the powerhouse and the spillway during the period of fish data m collection for that day. The legend table displays the percent species composition and number of upstream-migrating fish passing The Dalles Dam

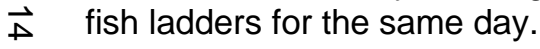




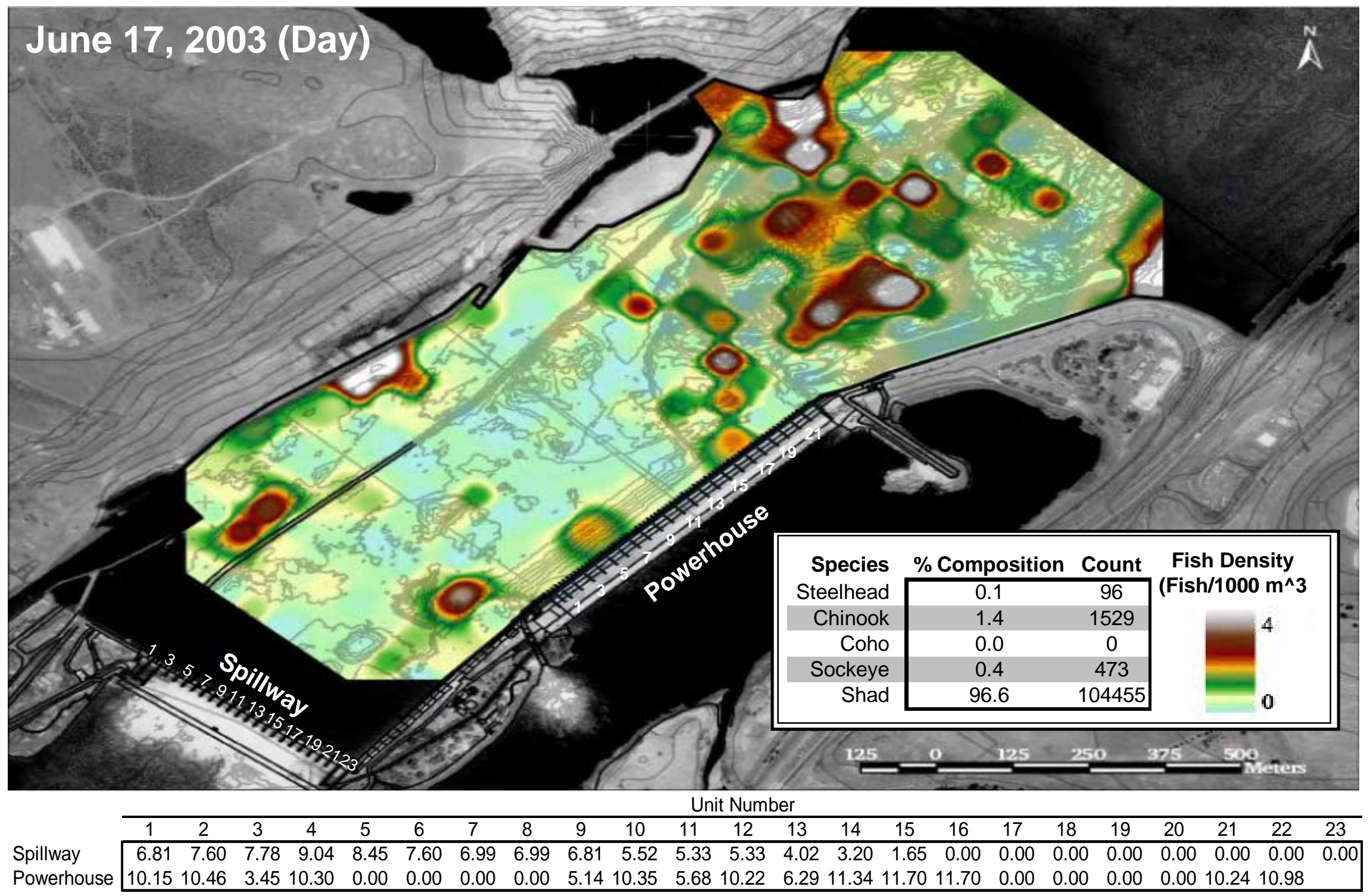

Figure E.13. Larger than smolt-sized fish density in the forebay of The Dalles Dam. Large fish in the spring were those with a target strength >-34

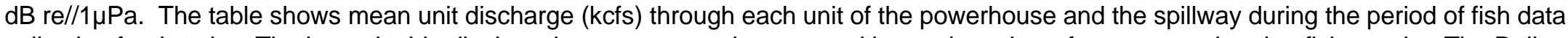
$m$ collection for that day. The legend table displays the percent species composition and number of upstream-migrating fish passing The Dalles Dam $\dot{v} \quad$ fish ladders for the same day. 


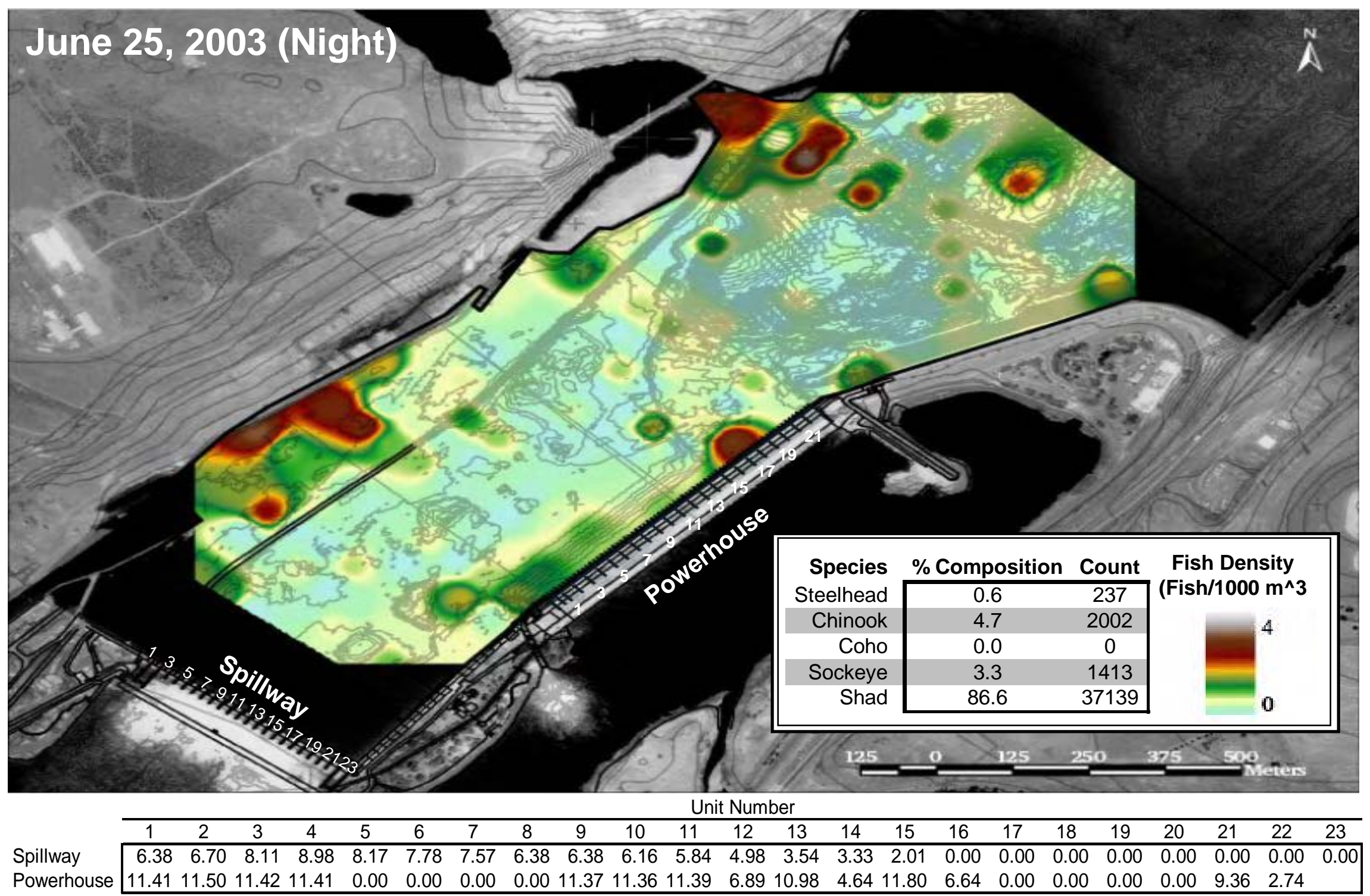

Figure E.14. Larger than smolt-sized fish density in the forebay of The Dalles Dam. Large fish in the spring were those with a target strength >-34 $\mathrm{dB}$ re//1 $\mu \mathrm{Pa}$. The table shows mean unit discharge (kcfs) through each unit of the powerhouse and the spillway during the period of fish data $m$ collection for that day. The legend table displays the percent species composition and number of upstream-migrating fish passing The Dalles Dam $\dot{\sigma} \quad$ fish ladders for the same day. 


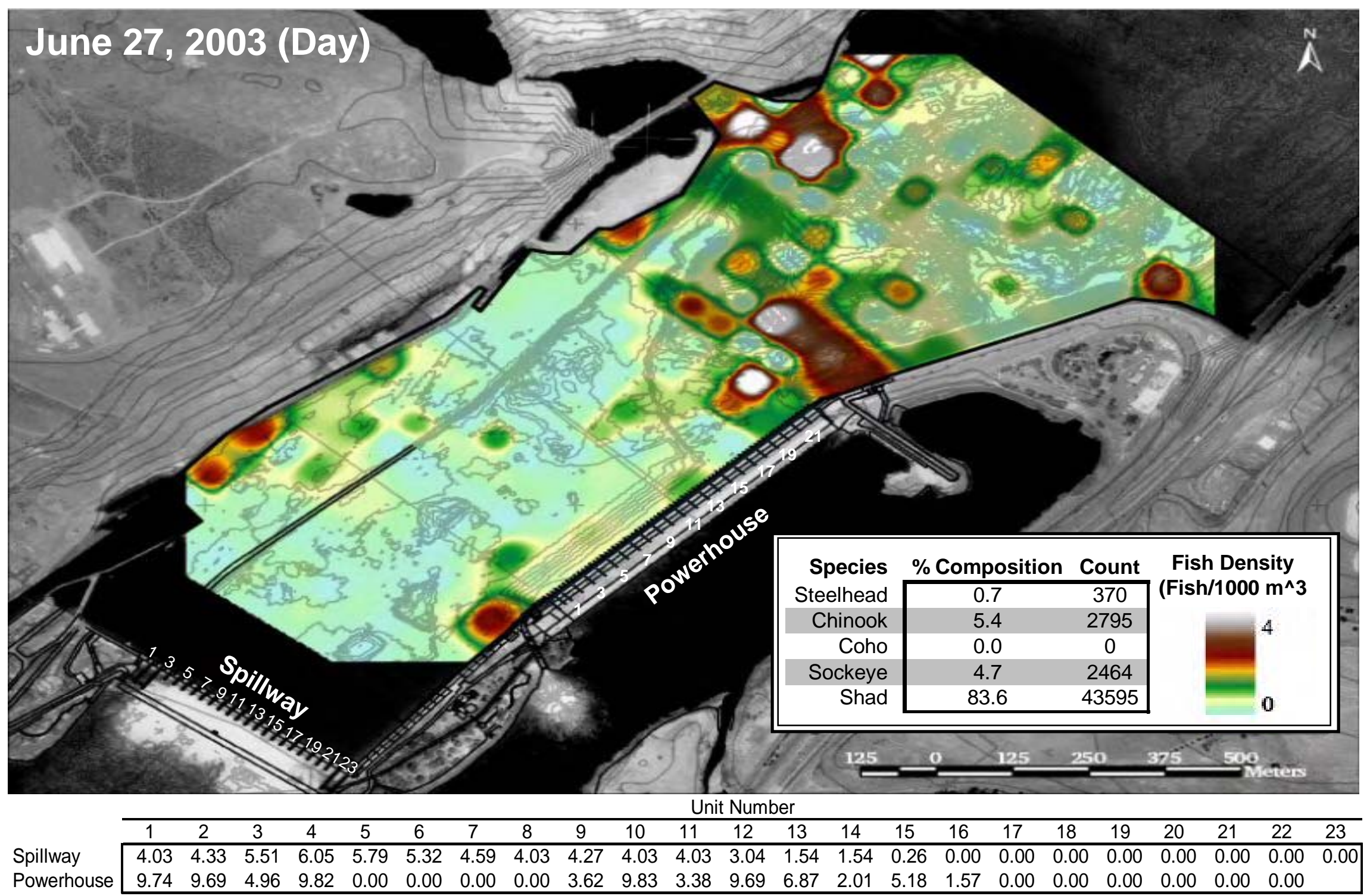

Figure E.15. Larger than smolt-sized fish density in the forebay of The Dalles Dam. Large fish in the spring were those with a target strength >-34 $\mathrm{dB}$ re//1 $\mu \mathrm{Pa}$. The table shows mean unit discharge (kcfs) through each unit of the powerhouse and the spillway during the period of fish data $\mathrm{m}$ collection for that day. The legend table displays the percent species composition and number of upstream-migrating fish passing The Dalles Dam $\stackrel{v}{ } \quad$ fish ladders for the same day. 


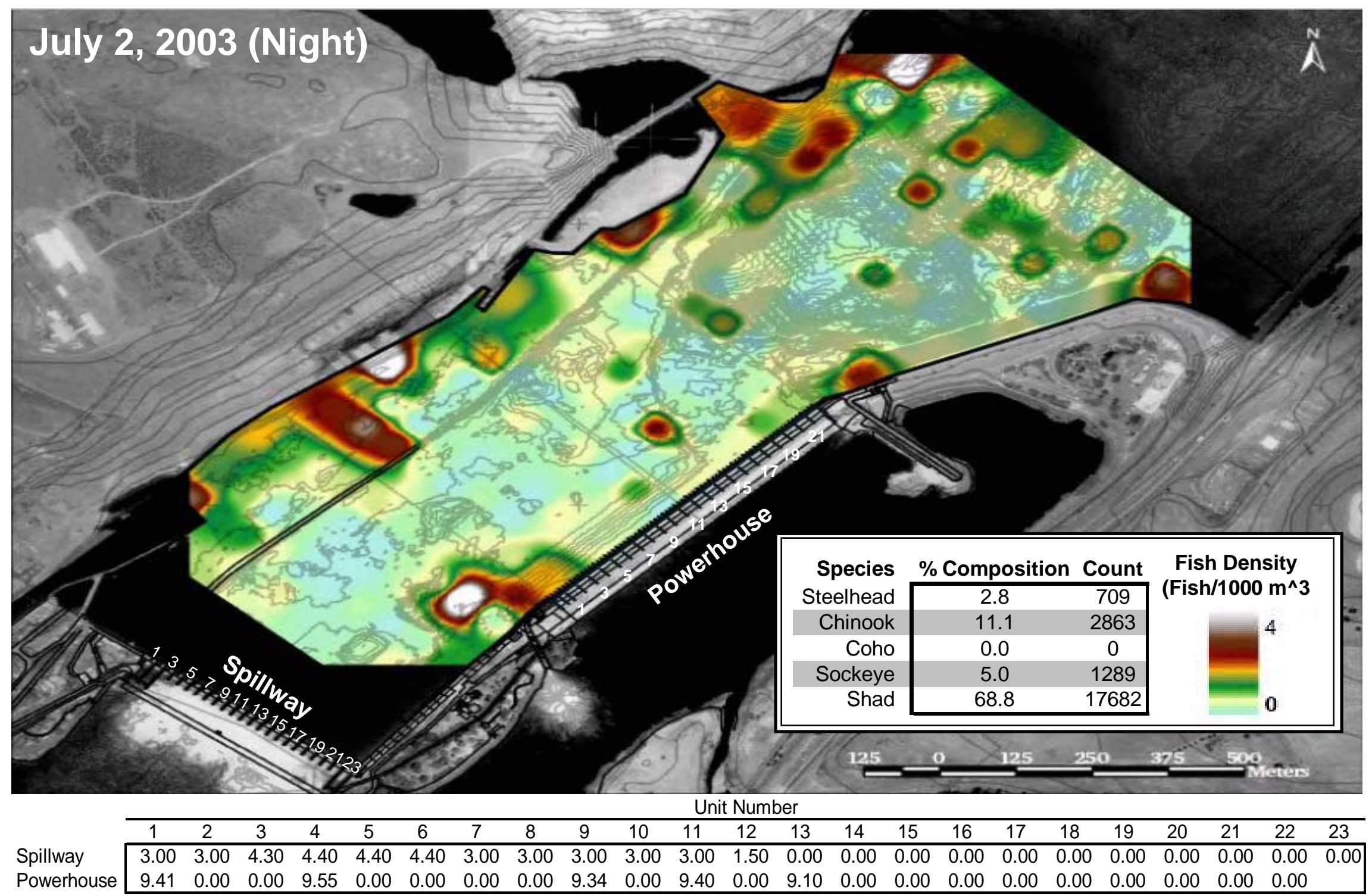

Figure E.16. Larger than smolt-sized fish density in the forebay of The Dalles Dam. Large fish in the spring were those with a target strength >-34 $\mathrm{dB}$ re//1 $\mu \mathrm{Pa}$. The table shows mean unit discharge ( $\mathrm{kcfs}$ ) through each unit of the powerhouse and the spillway during the period of fish data $m$ collection for that day. The legend table displays the percent species composition and number of upstream-migrating fish passing The Dalles Dam $\stackrel{\infty}{\infty}$ fish ladders for the same day. 


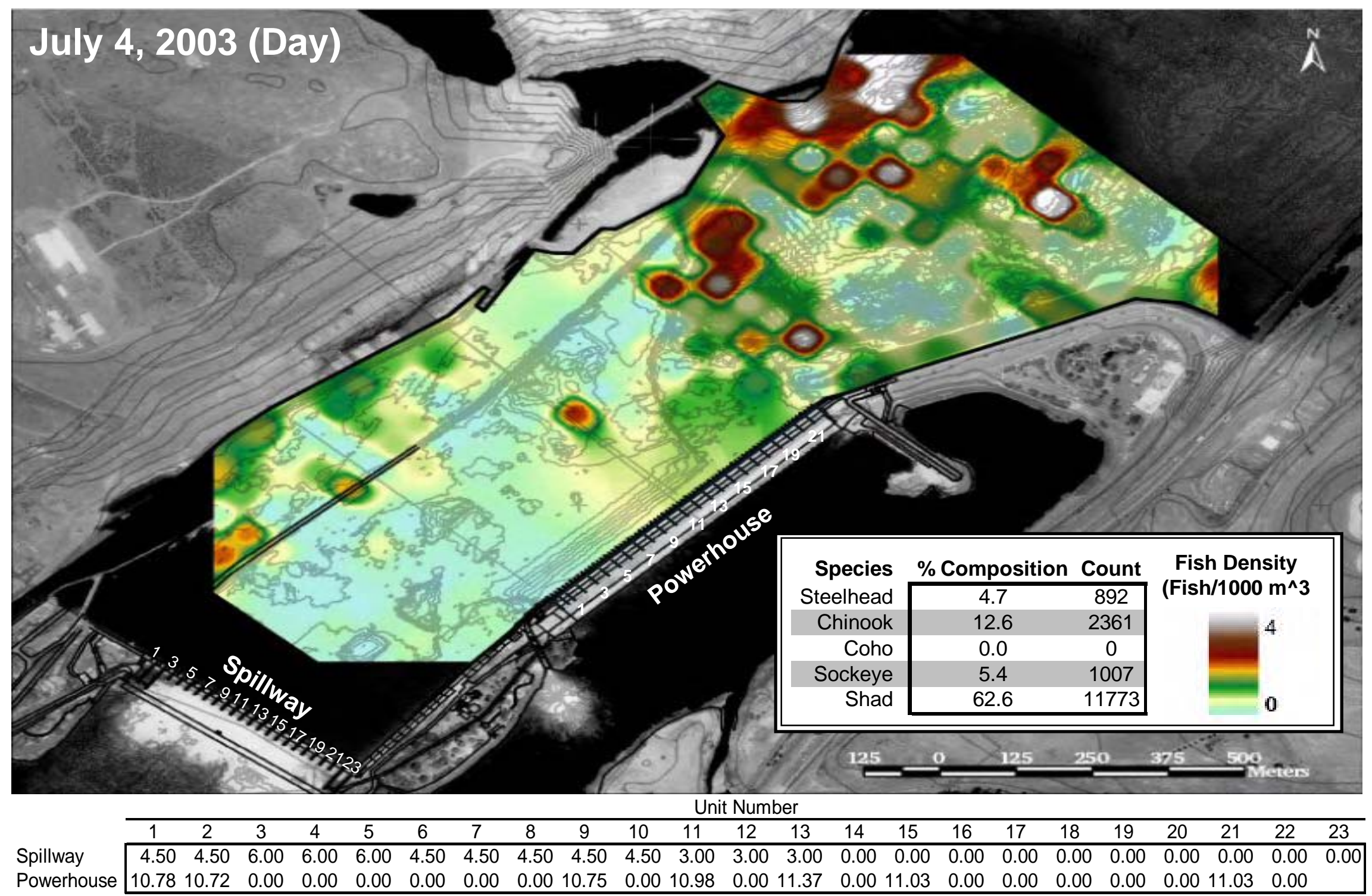

Figure E.17. Larger than smolt-sized fish density in the forebay of The Dalles Dam. Large fish in the spring were those with a target strength >-34 $\mathrm{dB}$ re//1 $\mu \mathrm{Pa}$. The table shows mean unit discharge (kcfs) through each unit of the powerhouse and the spillway during the period of fish data $m$ collection for that day. The legend table displays the percent species composition and number of upstream-migrating fish passing The Dalles Dam $\vec{\bullet} \quad$ fish ladders for the same day. 


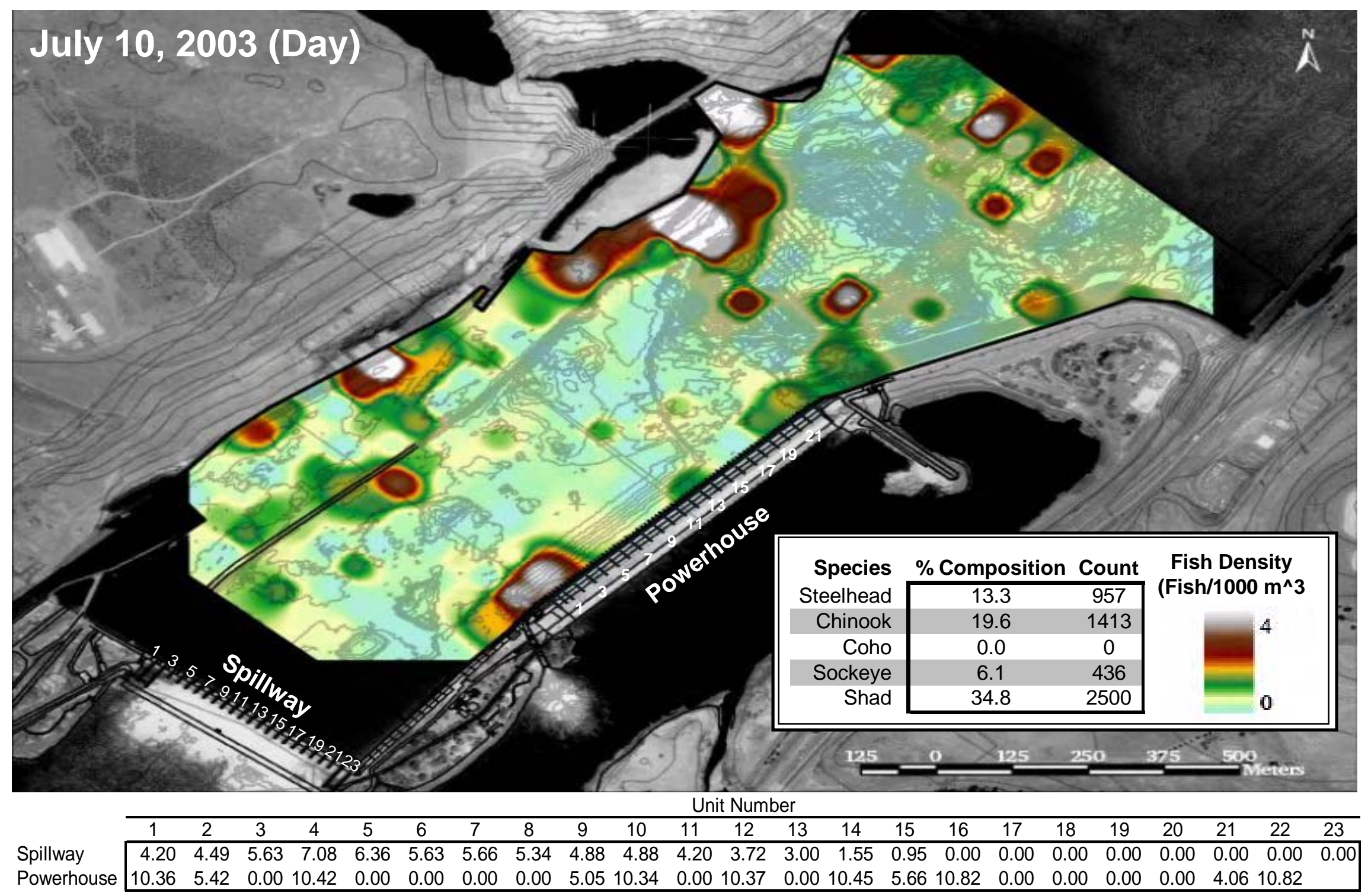

Figure E.18. Larger than smolt-sized fish density in the forebay of The Dalles Dam. Large fish in the spring were those with a target strength >-34

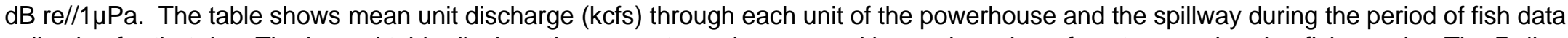
$m$ collection for that day. The legend table displays the percent species composition and number of upstream-migrating fish passing The Dalles Dam స fish ladders for the same day. 


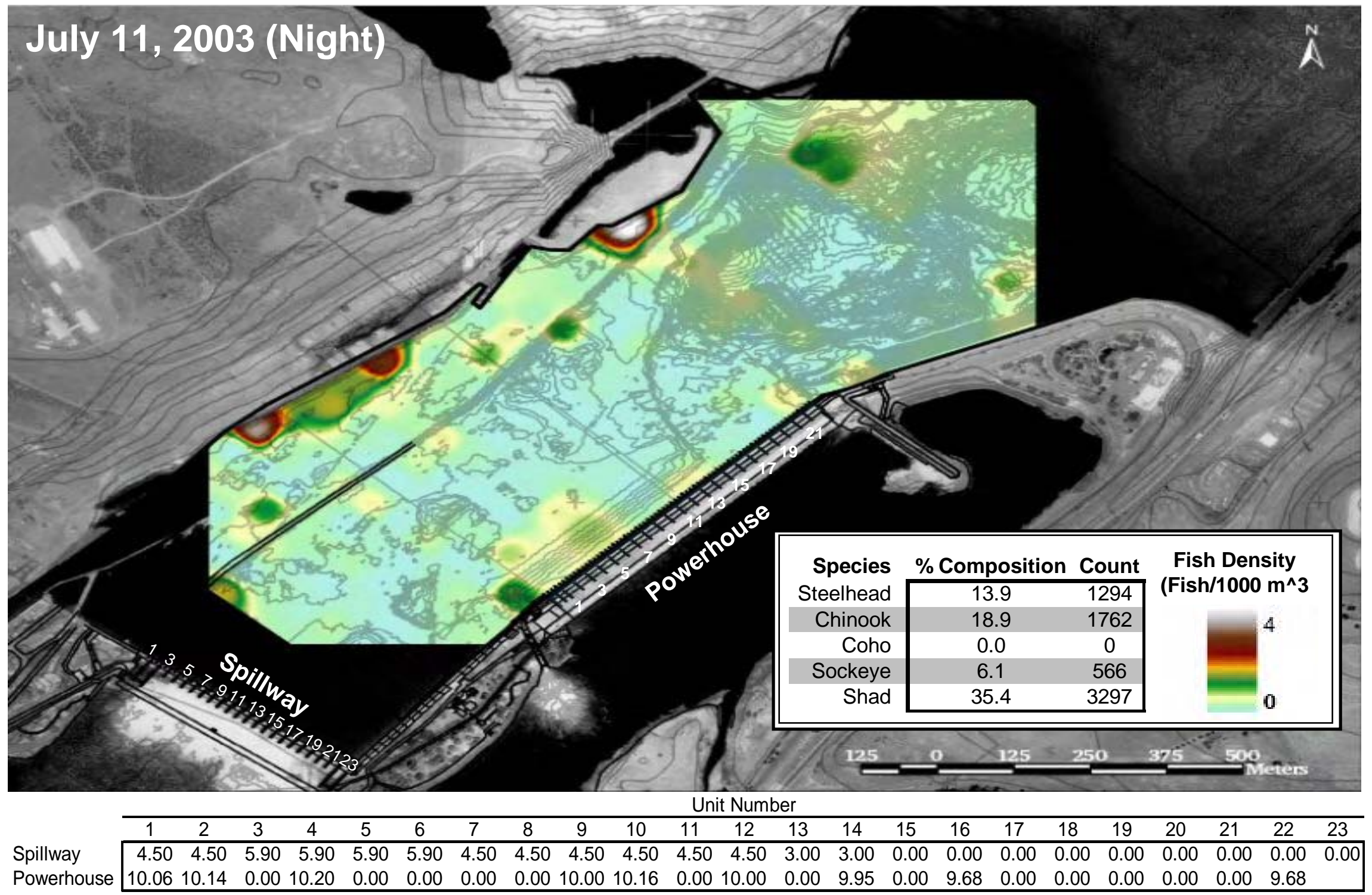

Figure E.19. Larger than smolt-sized fish density in the forebay of The Dalles Dam. Large fish in the spring were those with a target strength >-34 $\mathrm{dB}$ re//1 $\mu \mathrm{Pa}$. The table shows mean unit discharge ( $\mathrm{kcfs}$ ) through each unit of the powerhouse and the spillway during the period of fish data $m$ collection for that day. The legend table displays the percent species composition and number of upstream-migrating fish passing The Dalles Dam $\stackrel{\sim}{\sim}$ fish ladders for the same day. 


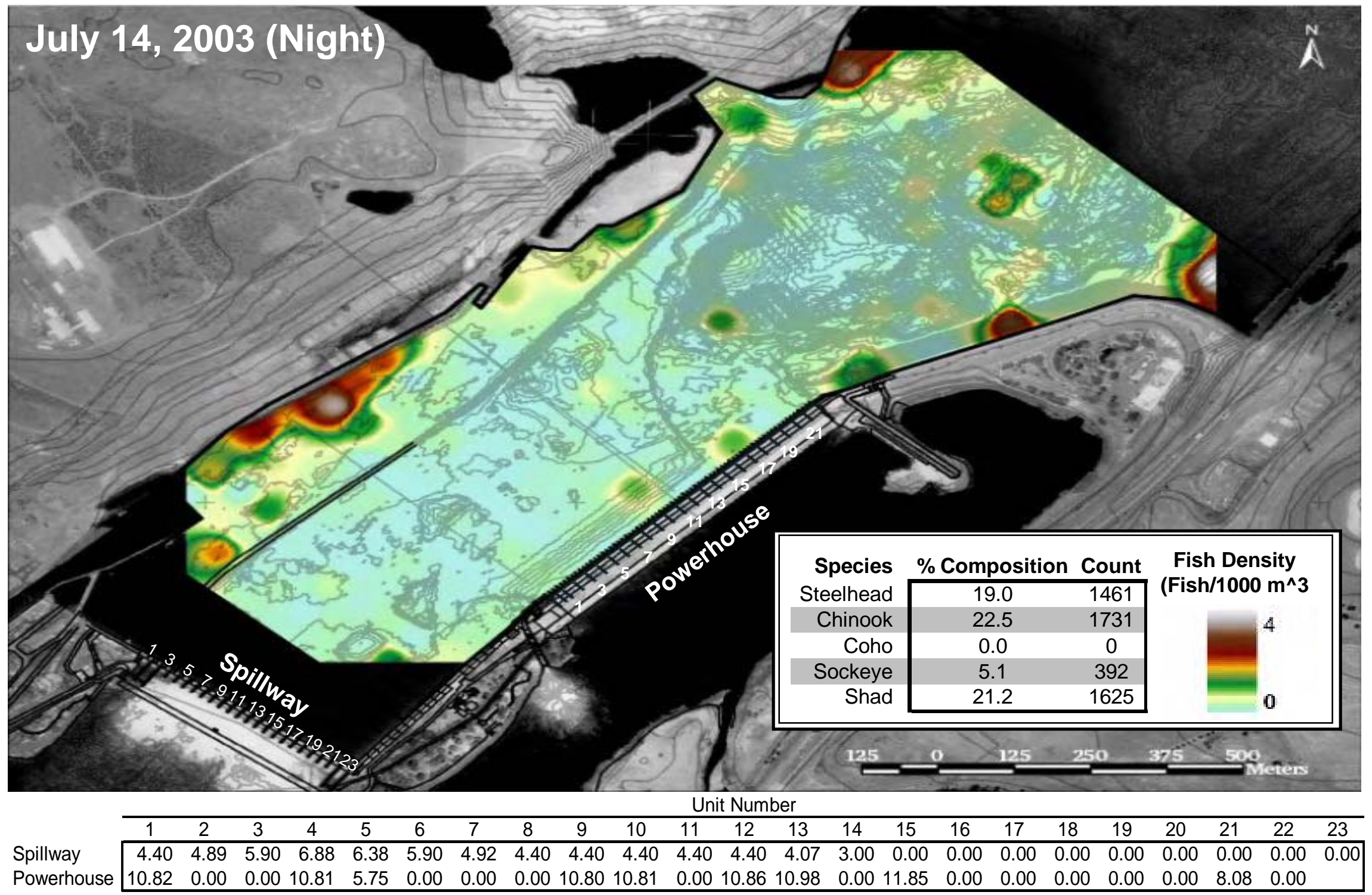

Figure E.20. Larger than smolt-sized fish density in the forebay of The Dalles Dam. Large fish in the spring were those with a target strength >-34 $\mathrm{dB}$ re//1 $\mu \mathrm{Pa}$. The table shows mean unit discharge (kcfs) through each unit of the powerhouse and the spillway during the period of fish data $m$ collection for that day. The legend table displays the percent species composition and number of upstream-migrating fish passing The Dalles Dam N fish ladders for the same day. 


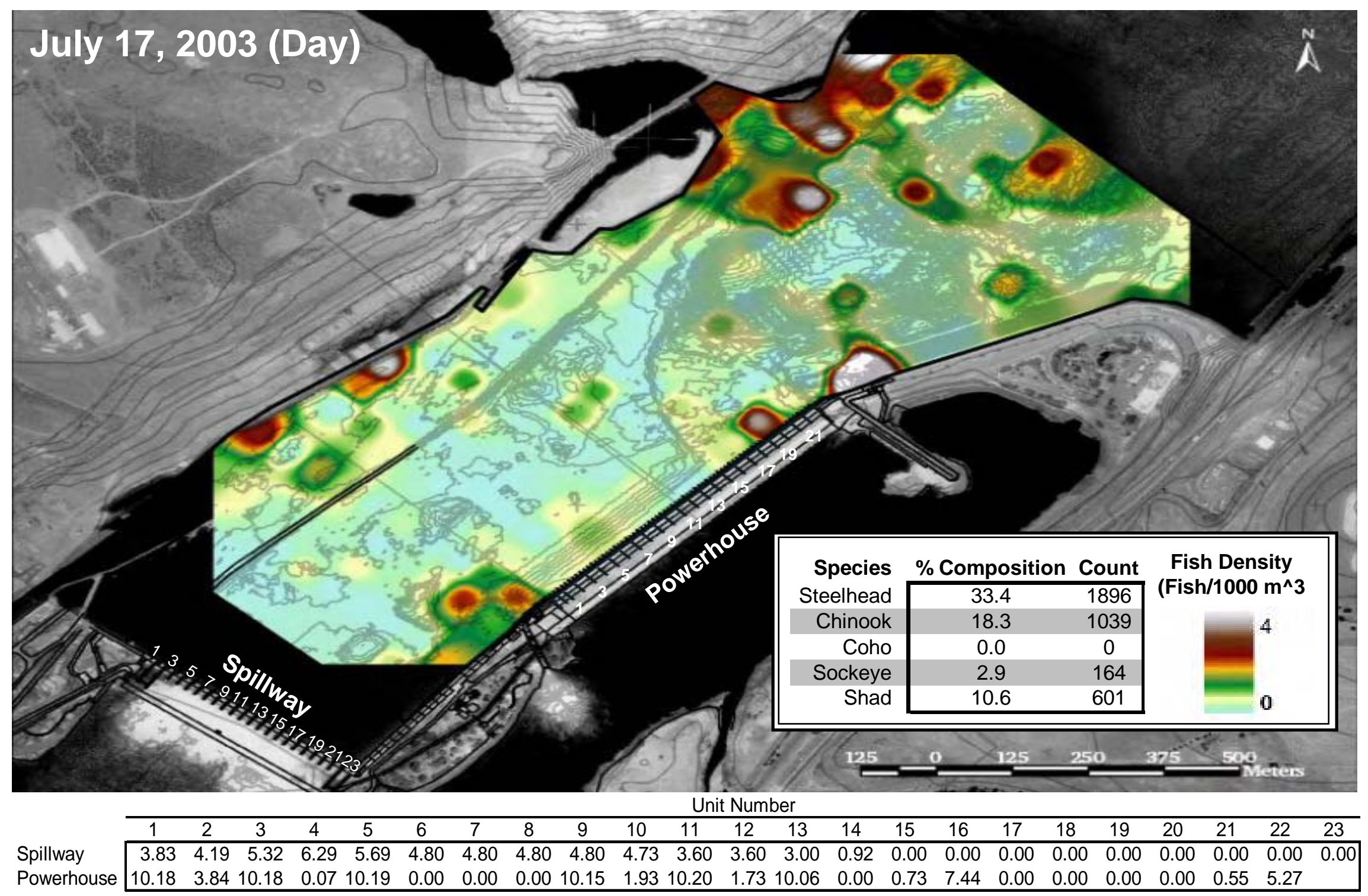

Figure E.21. Larger than smolt-sized fish density in the forebay of The Dalles Dam. Large fish in the spring were those with a target strength >-34 $\mathrm{dB}$ re//1 $\mu \mathrm{Pa}$. The table shows mean unit discharge (kcfs) through each unit of the powerhouse and the spillway during the period of fish data $m$ collection for that day. The legend table displays the percent species composition and number of upstream-migrating fish passing The Dalles Dam $\underset{\omega}{\omega}$ fish ladders for the same day. 


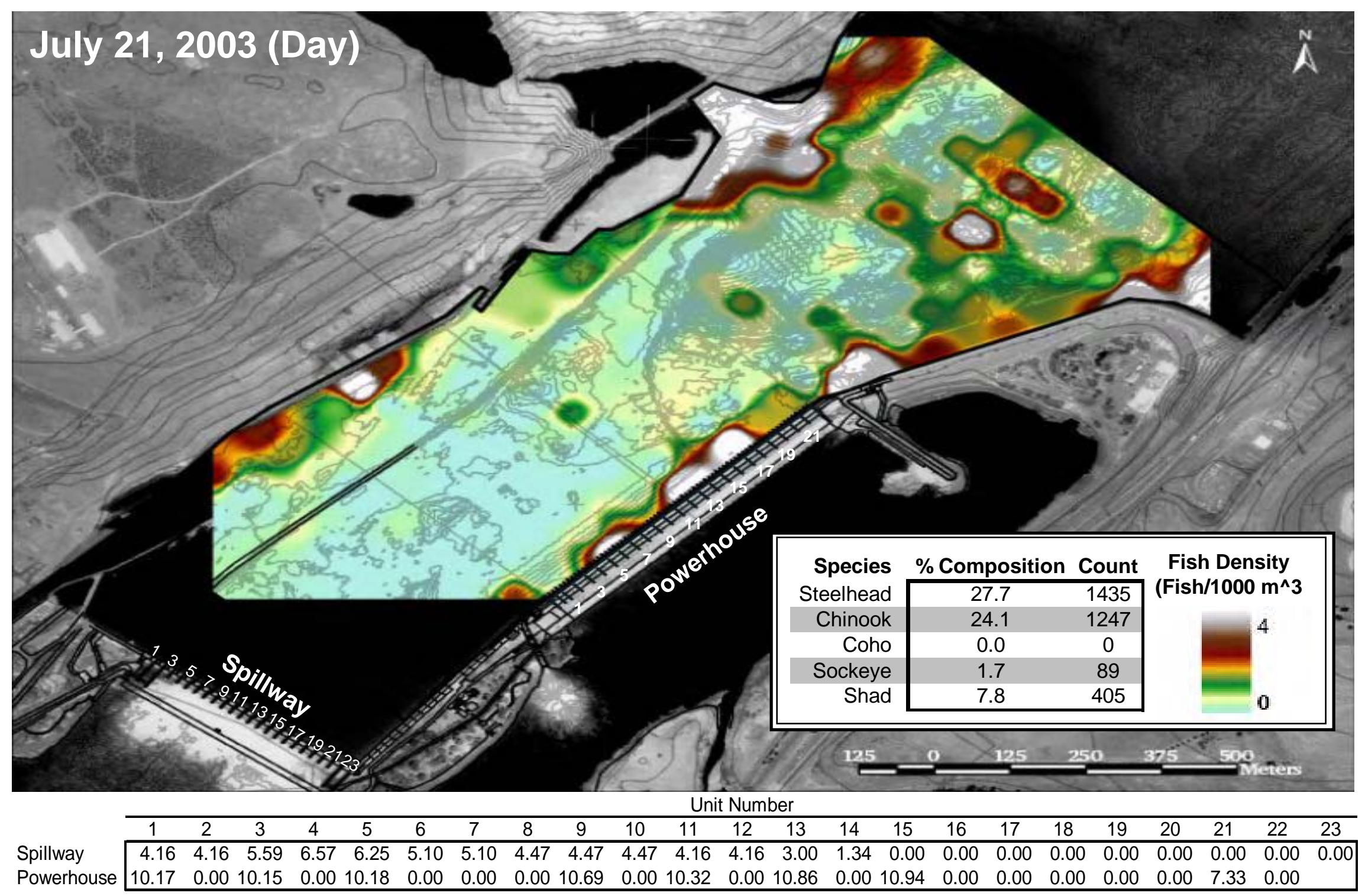

Figure E.22. Larger than smolt-sized fish density in the forebay of The Dalles Dam. Large fish in the spring were those with a target strength >-34 $\mathrm{dB}$ re//1 $\mu \mathrm{Pa}$. The table shows mean unit discharge (kcfs) through each unit of the powerhouse and the spillway during the period of fish data $m$ collection for that day. The legend table displays the percent species composition and number of upstream-migrating fish passing The Dalles Dam i fish ladders for the same day. 


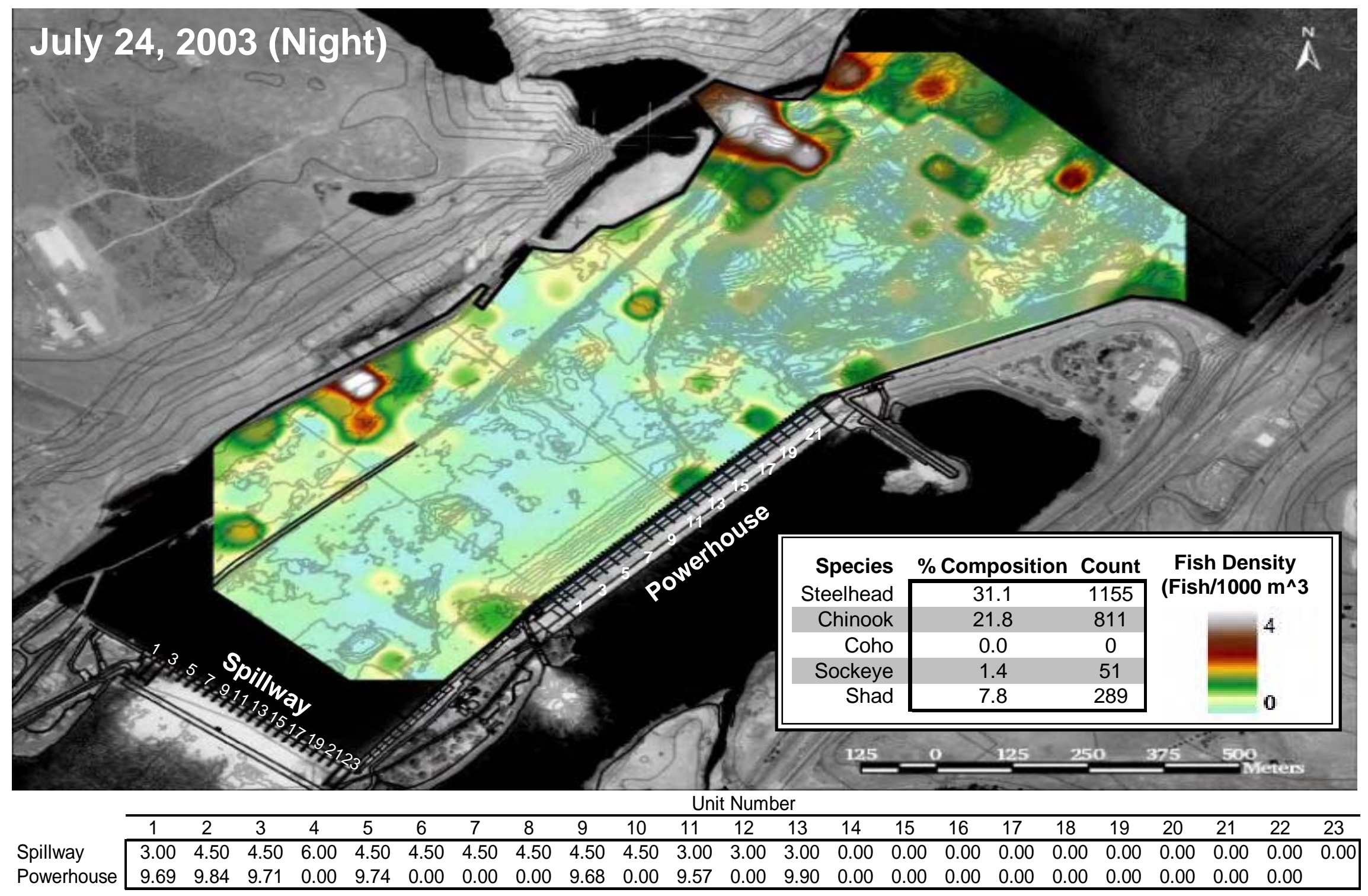

Figure E.23. Larger than smolt-sized fish density in the forebay of The Dalles Dam. Large fish in the spring were those with a target strength >-34 $\mathrm{dB}$ re $/ / 1 \mu \mathrm{Pa}$. The table shows mean unit discharge $(\mathrm{kcfs})$ through each unit of the powerhouse and the spillway during the period of fish data $m$ collection for that day. The legend table displays the percent species composition and number of upstream-migrating fish passing The Dalles Dam ज. fish ladders for the same day. 
Appendix F

The Difference in Distribution between Large and Small Fish and between Spring and Summer Smolt-Sized Fish as Determined by Mobile Hydroacoustic Sampling in the Forebay of The Dalles Dam, 2003 
F.2 

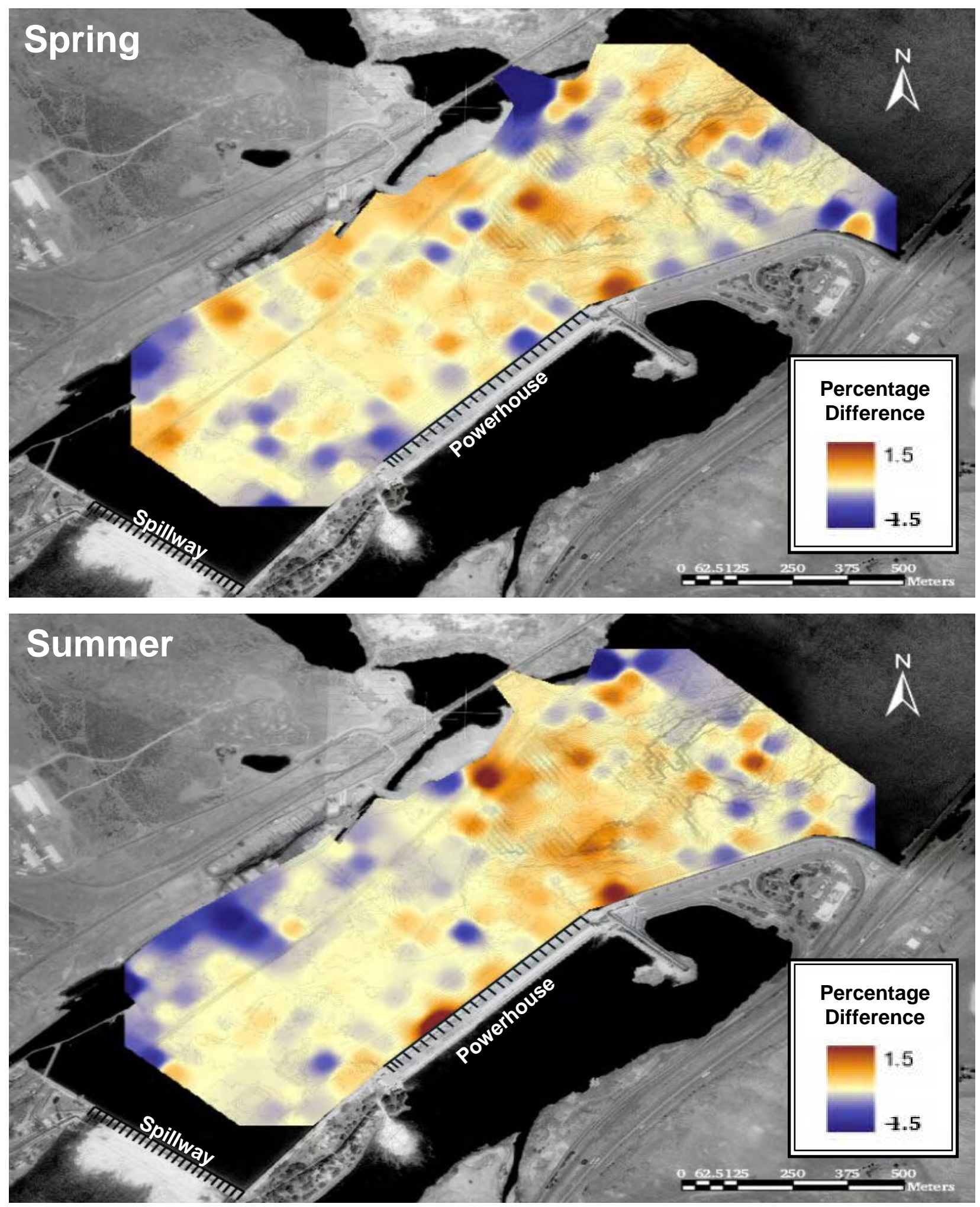

Figure F.1. The above figures display the percentage difference in the day and night distribution of larger than smolt-sized fish (>-34 dB re//1 $\mu \mathrm{Pa})$ for the springtime and summertime samples. Orange areas are those with greater daytime densities of large fish, whereas blue areas had a greater percentage of nighttime fish. 

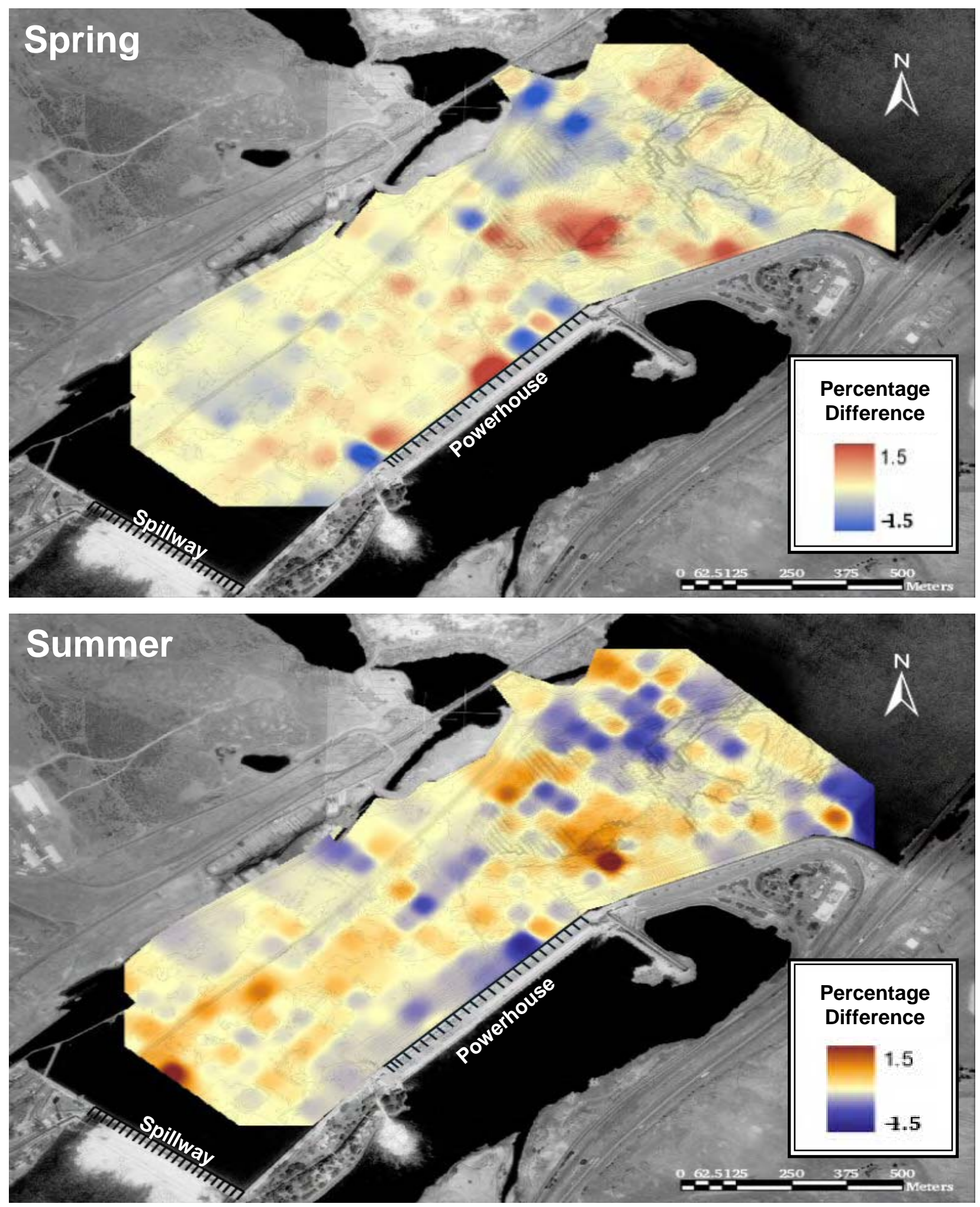

Figure F.2. The above figures display the percentage difference in the day and night distribution of

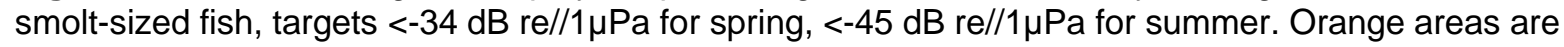
those with greater daytime densities of smolt-sized fish, whereas blue areas had a greater percentage of nighttime fish. 

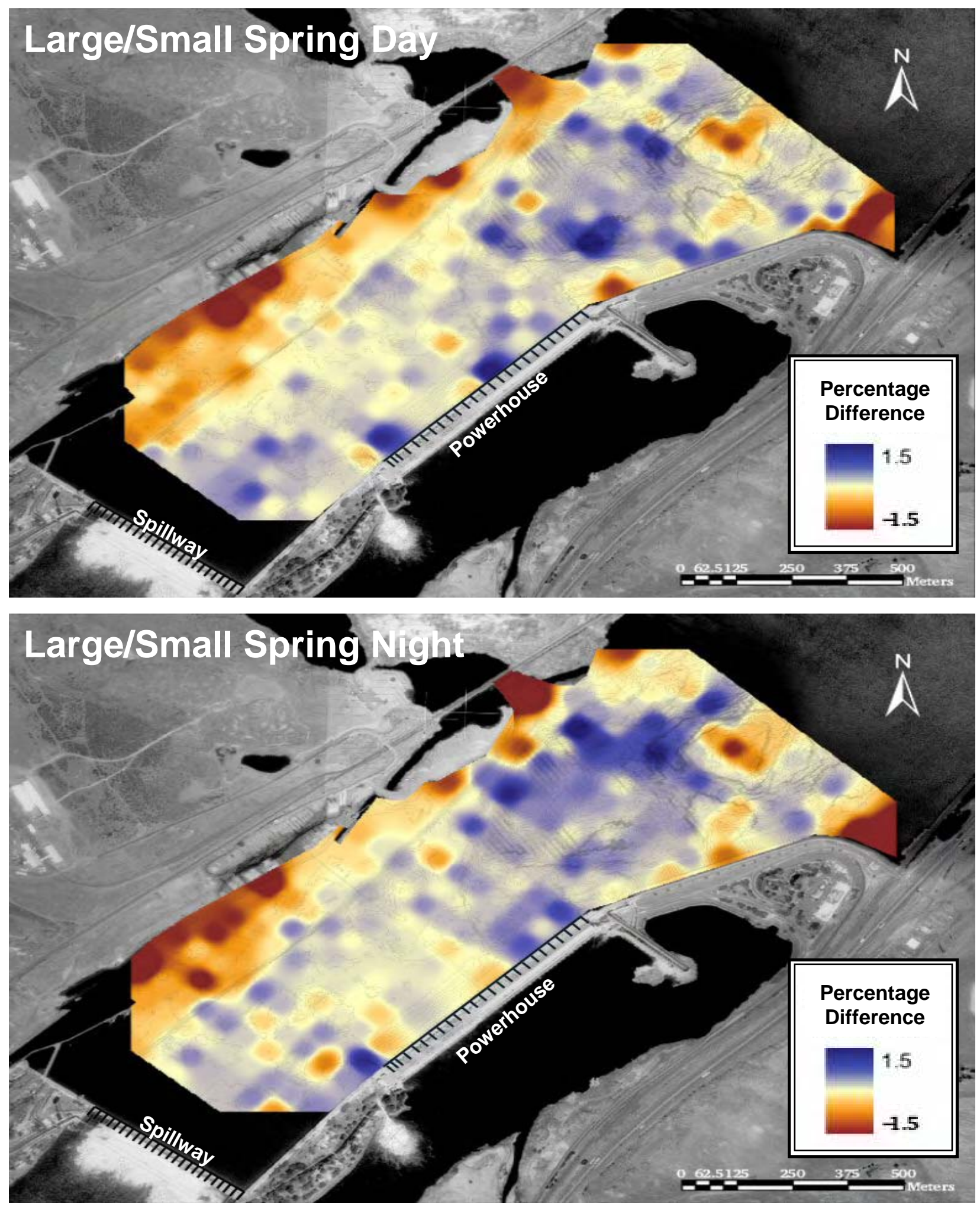

Figure F.3. The above figures display the percentage difference between the larger than smolt-sized fish and smaller than smolt-sized fish for spring day and night samples. Orange areas are those with greater densities of larger than smolt-sized fish, whereas blue areas had a greater percentage of smoltsized fish. 

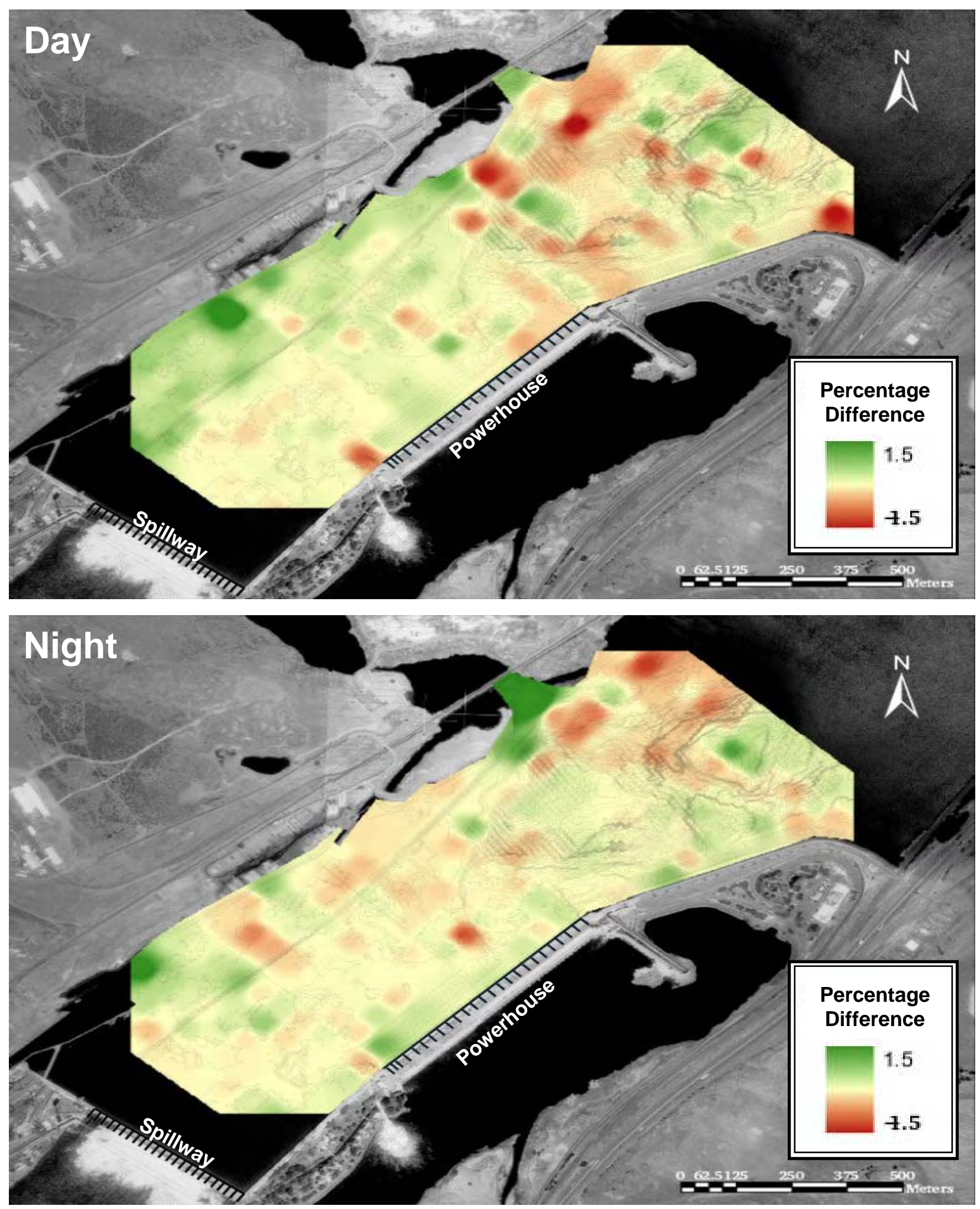

Figure F.4. The above figures display the percentage difference between the spring and summer distribution of fish that were larger than smolt-sized for day and night samples. Green areas are those with greater densities of larger fish in the spring, whereas orange areas had a greater percentage of large fish in the summer. 

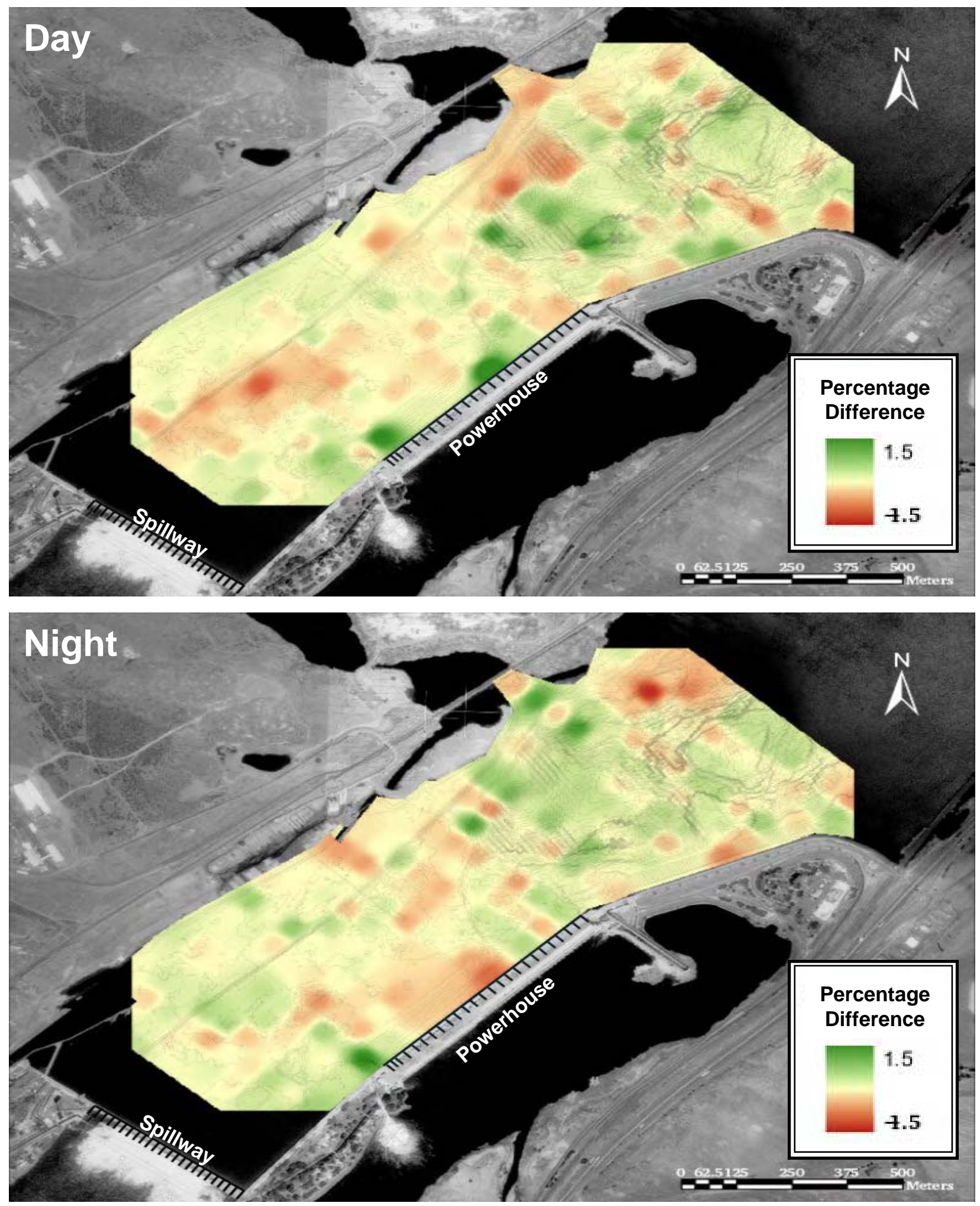

Figure F.5. The above figures display the percentage difference between the spring and summer distribution of fish that were smolt-sized for day and night samples. Green areas are those with greater densities of smolt-sized fish in the spring, whereas orange areas had a greater percentage of large fish in the summer. 
F.8 
Appendix G

\section{Vertical Distribution of Smolt-Sized Fish as Determined by Mobile Hydroacoustic Sampling in the Forebay of The Dalles Dam, 2003}


G.2 

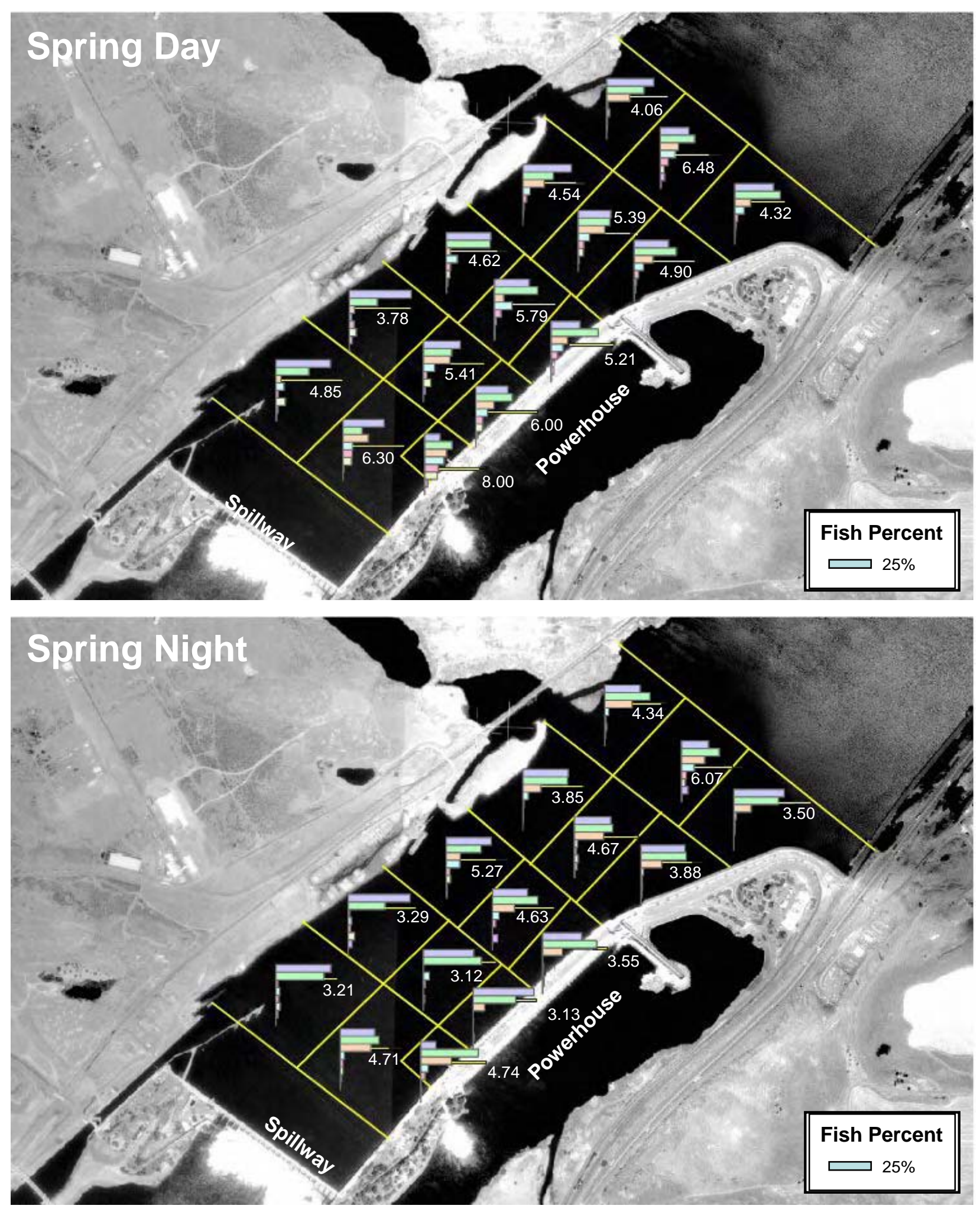

Figure G.1. The above figures display the vertical distribution of smolt-sized fish by the areas delineated with yellow lines. The vertical distribution data is displayed in 1.7-m bins progressing from the water surface to $17 \mathrm{~m}$ deep, and taken from mobile transect data. The number next to the vertical distribution graph was the depth $(\mathrm{m})$ that $80 \%$ of smolt-sized fish were above for each delineated area. Graphs were the combined totals for the spring day and night samples. 

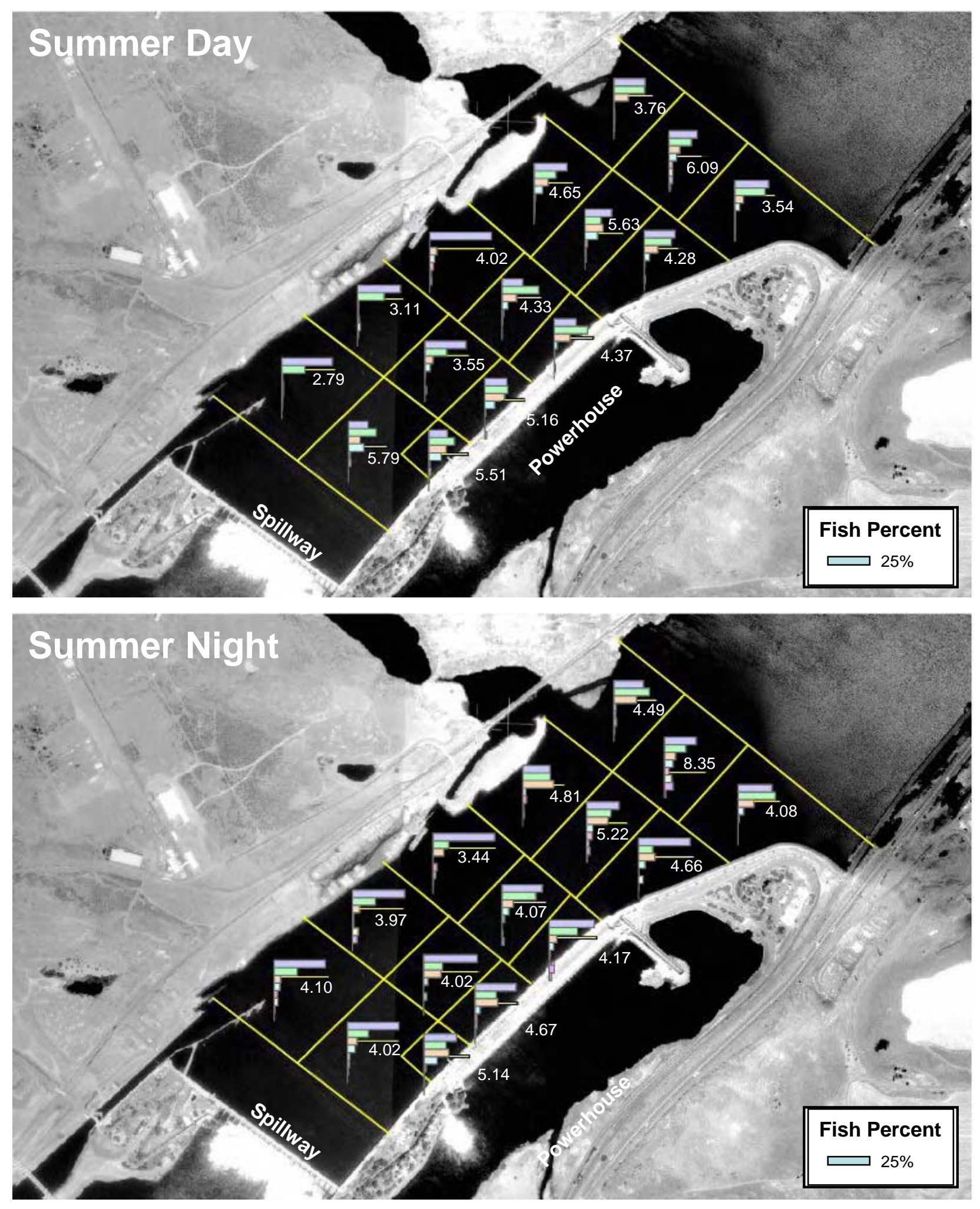

Figure G.2. The above figures display the vertical distribution of smolt-sized fish by the areas delineated with yellow lines. The vertical distribution data is displayed in ten $1.7 \mathrm{~m}$ bins progressing from the water surface to $17 \mathrm{~m}$ deep, and taken from mobile transect data. The number next to the vertical distribution graph was the depth $(\mathrm{m})$ that $80 \%$ of smolt-sized fish were above for each delineated area. Graphs were the combined totals for the summer day and night samples. 

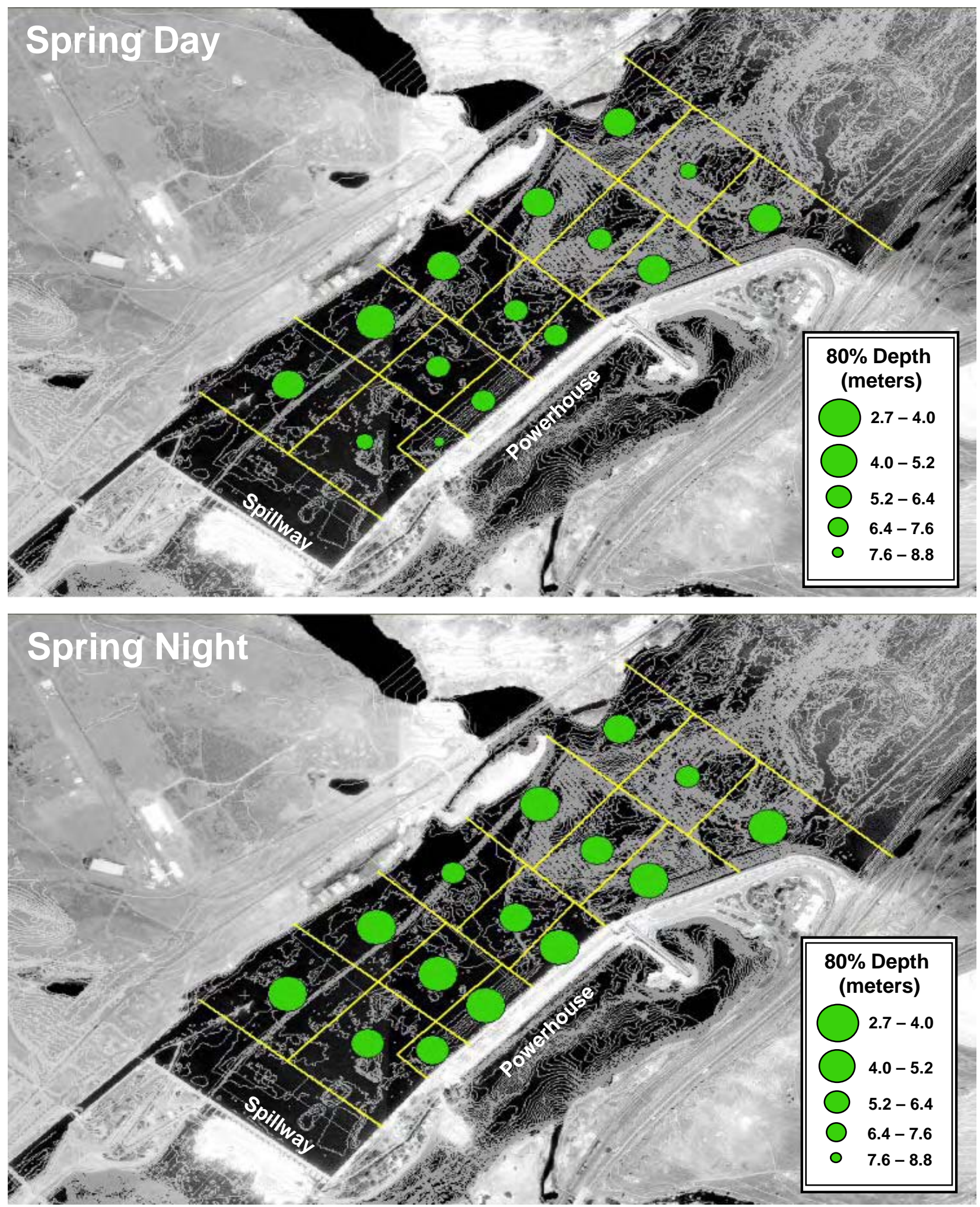

Figure G.3. The above figures display the vertical distribution of smolt-sized fish by the areas delineated with yellow lines. The size of the circle is a function of the depth $(\mathrm{m})$ that $80 \%$ of smolt-sized fish were above for each delineated area. Larger circles denote a shallower distribution and smaller circles denote a deeper distribution for springtime mobile samples. 

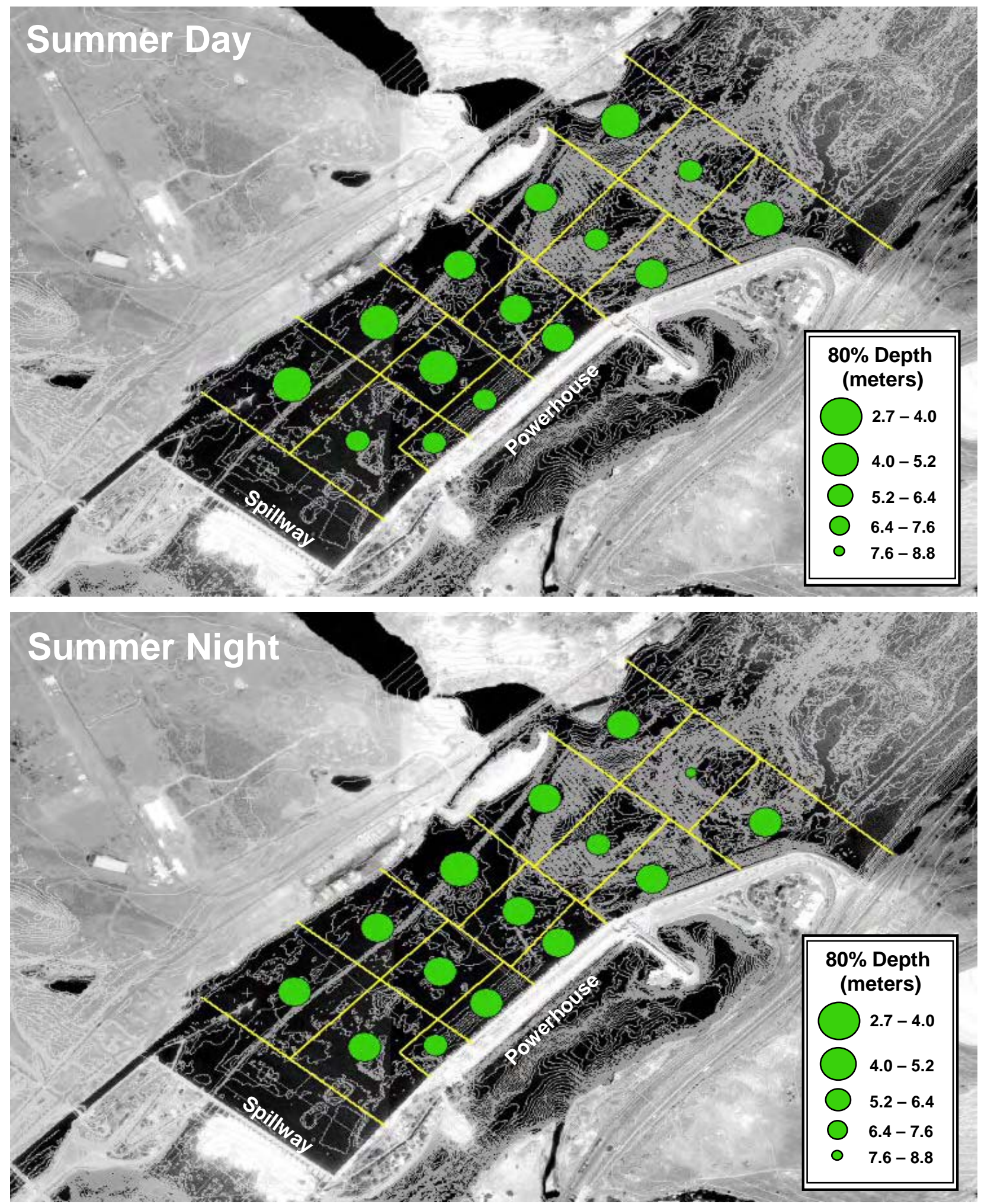

Figure G.4. The above figures display the vertical distribution of smolt-sized fish by the areas delineated with yellow lines. The size of the circle is a function of the depth $(\mathrm{m})$ that $80 \%$ of smolt-sized fish were above for each delineated area. Larger circles denote a shallower distribution and smaller circles denote a deeper distribution for summertime mobile samples. 


\section{Appendix $\mathrm{H}$}

\section{Movement of Smolt-Sized Fish at Fixed \\ Points in the Forebay of The Dalles Dam, 2003}




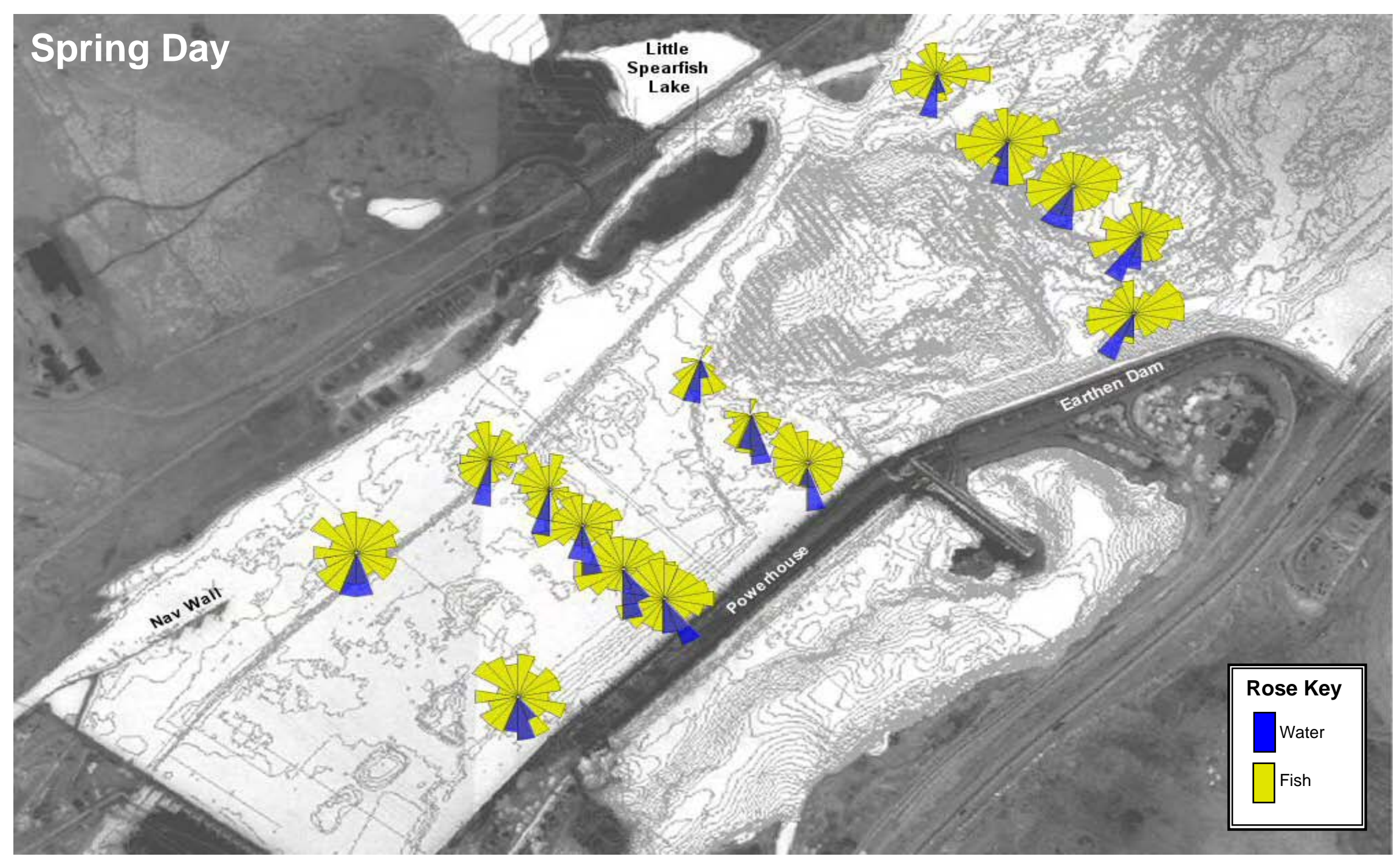

Figure H.1. The above figure displays the relative movement of fish and flow past fixed points in The Dalles Dam forebay for all spring daytime samples. Rose plots display the relative percentage of smolt-sized fish movement in 20 -degree yellow slices, where slice length is a function of percentage. The relative percentage of water direction in the upper $10 \mathrm{~m}$ of the water column is shown in 20 -degree blue slices. 


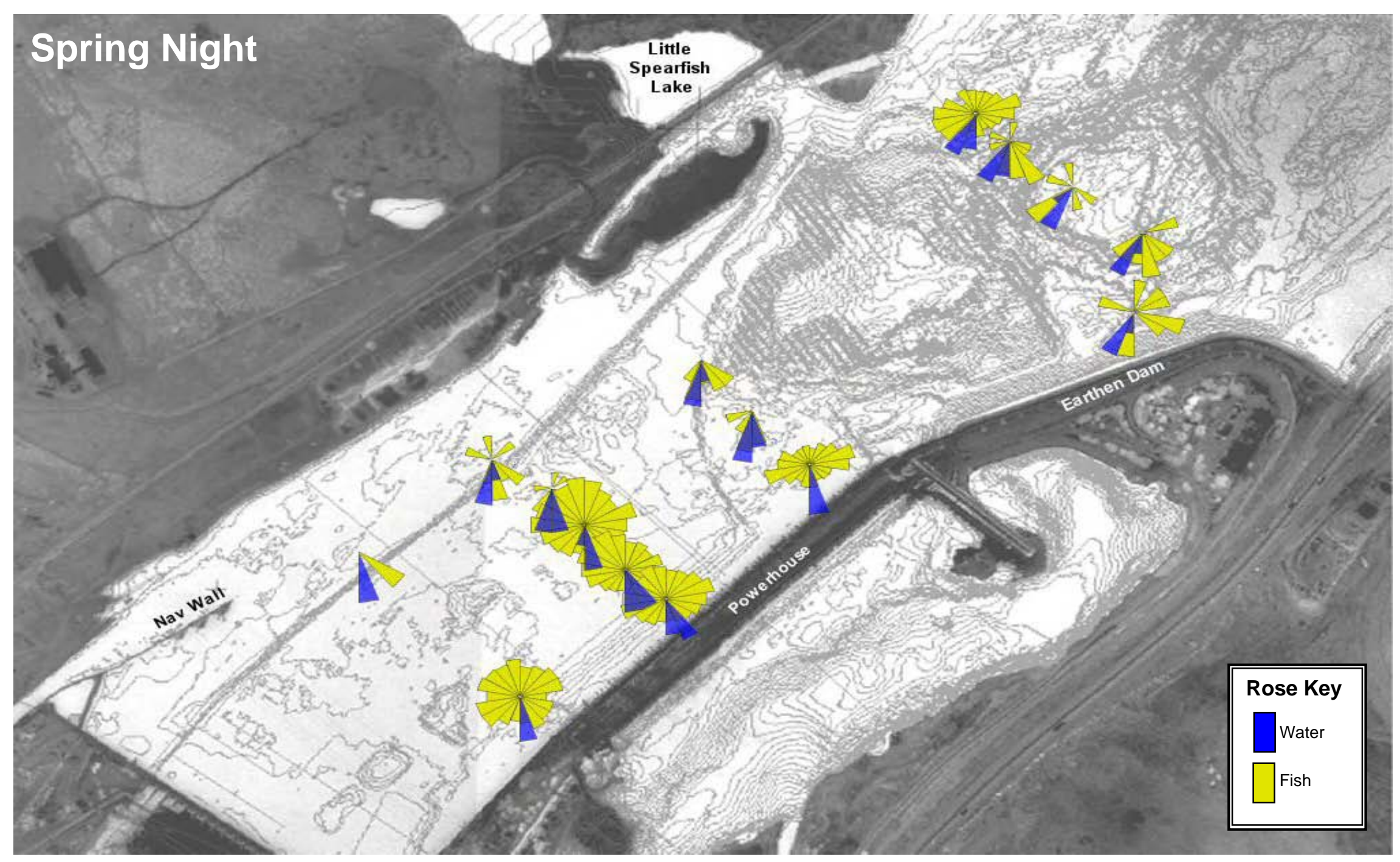

Figure H.2. The above figure displays the relative movement of fish and flow past fixed points in The Dalles Dam forebay for all spring nighttime samples. Rose plots display the relative percentage of smolt-sized fish movement in 20-degree yellow slices, where slice length is a function of percentage. The relative percentage of water direction in the upper $10 \mathrm{~m}$ of the water column is shown in 20 -degree blue slices. 


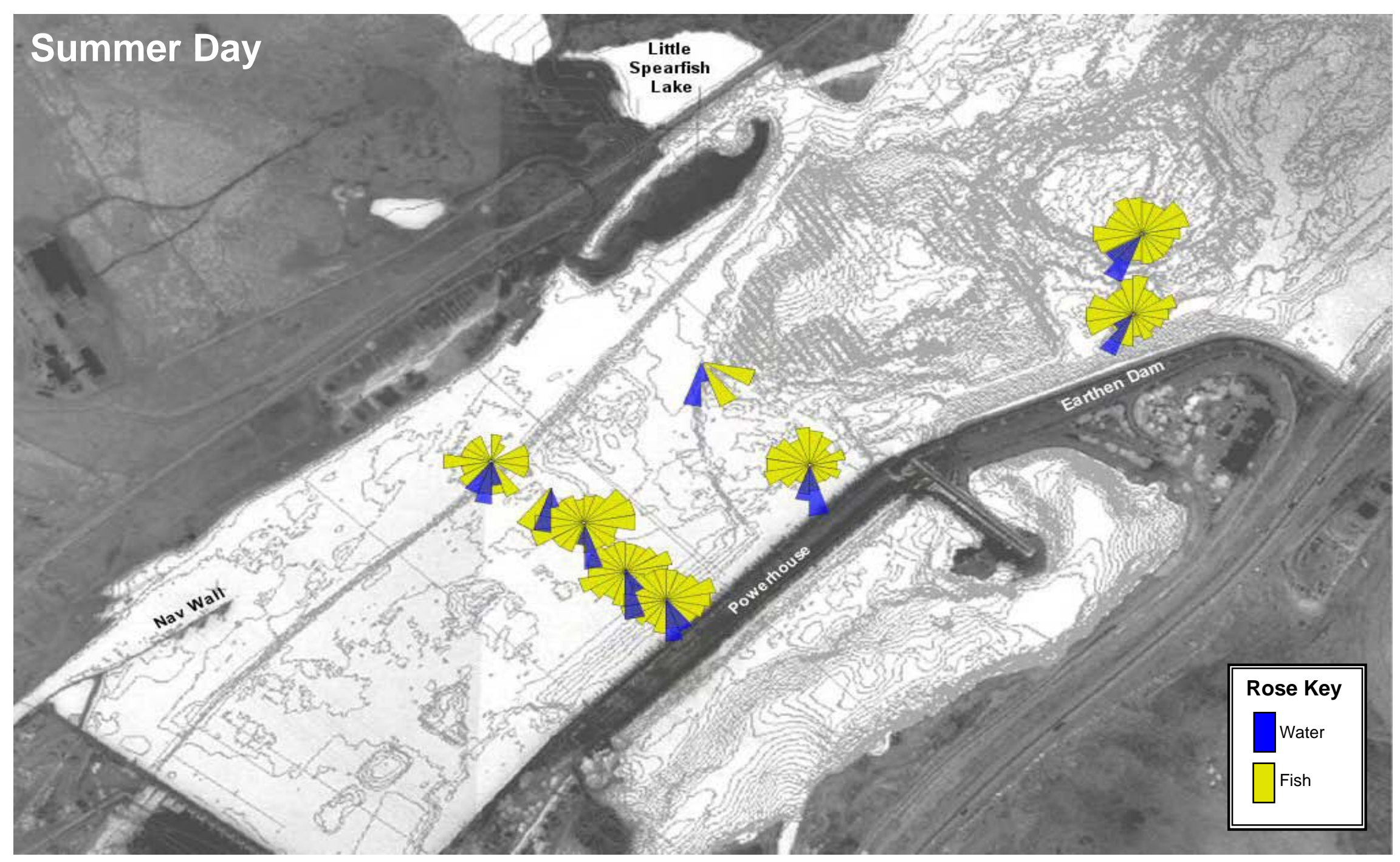

Figure H.3. The above figure displays the relative movement of fish and flow past fixed points in The Dalles Dam forebay for all summer daytime samples. Rose plots display the relative percentage of smolt-sized fish movement in 20 -degree yellow slices, where slice length is a function of percentage. The relative percentage of water direction in the upper $10 \mathrm{~m}$ of the water column is shown in 20 -degree blue slices. 


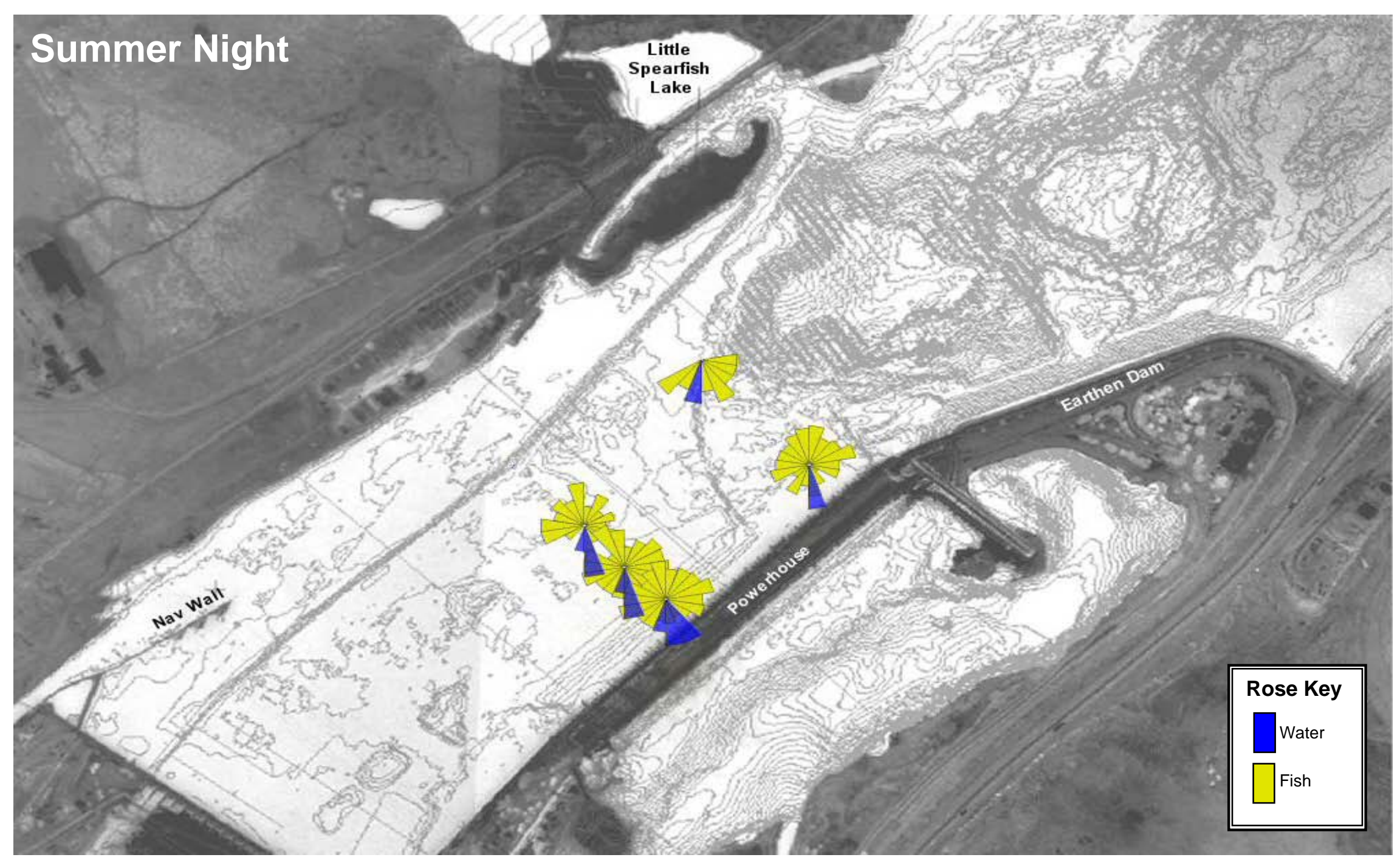

Figure H.4. The above figure displays the relative movement of fish and flow past fixed points in The Dalles Dam forebay for all summer nighttime samples. Rose plots display the relative percentage of smolt-sized fish movement in 20-degree yellow slices, where slice length is a function of percentage. The relative percentage of water direction in the upper $10 \mathrm{~m}$ of the water column is shown in 20-degree blue slices. 


\section{Appendix I}

The Flux of Smolt-Sized Fish at Fixed Points in the Forebay of The Dalles Dam, 2003 

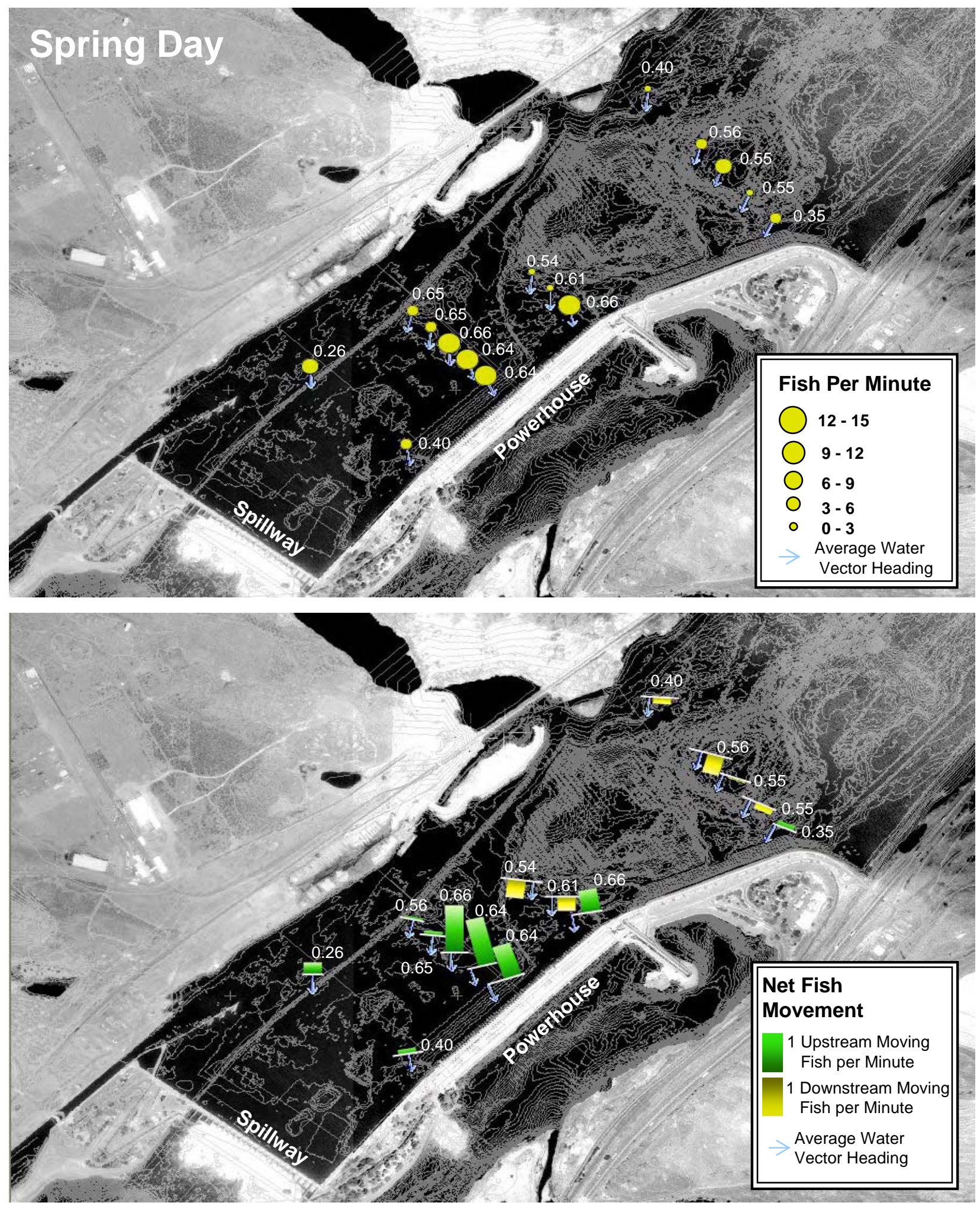

Figure I.1. The figures from top to bottom show the total smolt-sized fish count per minute as a function of circle size, and the net fish movement in relation to the direction of the mean water velocity (blue arrow). Mean water velocity magnitude data (m/s) for the upper $6 \mathrm{~m}$ are displayed next to each point. Data was combined for all spring day samples. Asterisks denote points without fish data. 

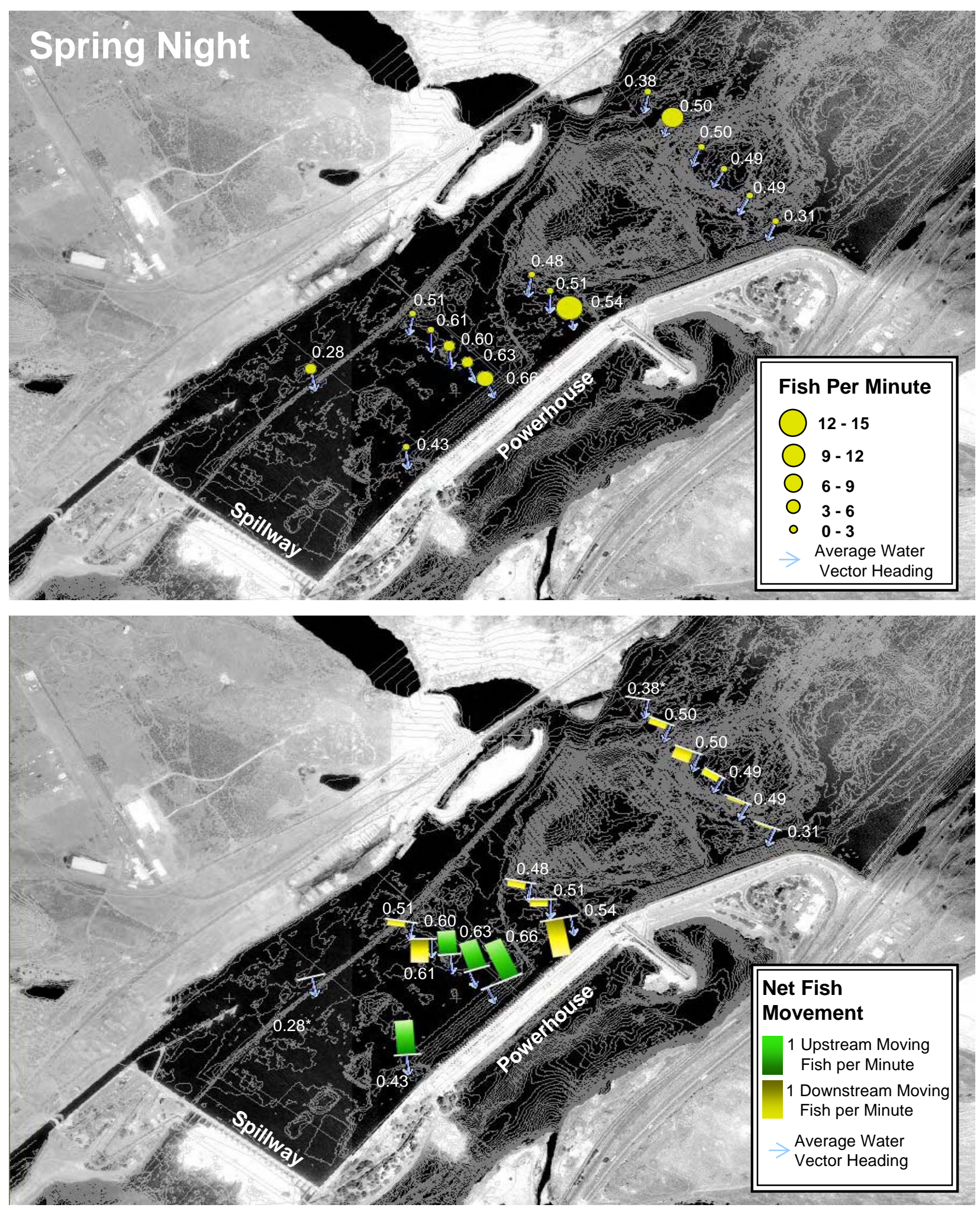

Figure I.2. The figures from top to bottom show the total smolt-sized fish count per minute as a function of circle size, and the net fish movement in relation to the direction of the mean water velocity (blue arrow). Mean water velocity magnitude data (m/s) for the upper $6 \mathrm{~m}$ are displayed next to each point. Data was combined for all spring night samples. Asterisks denote points without fish data. 

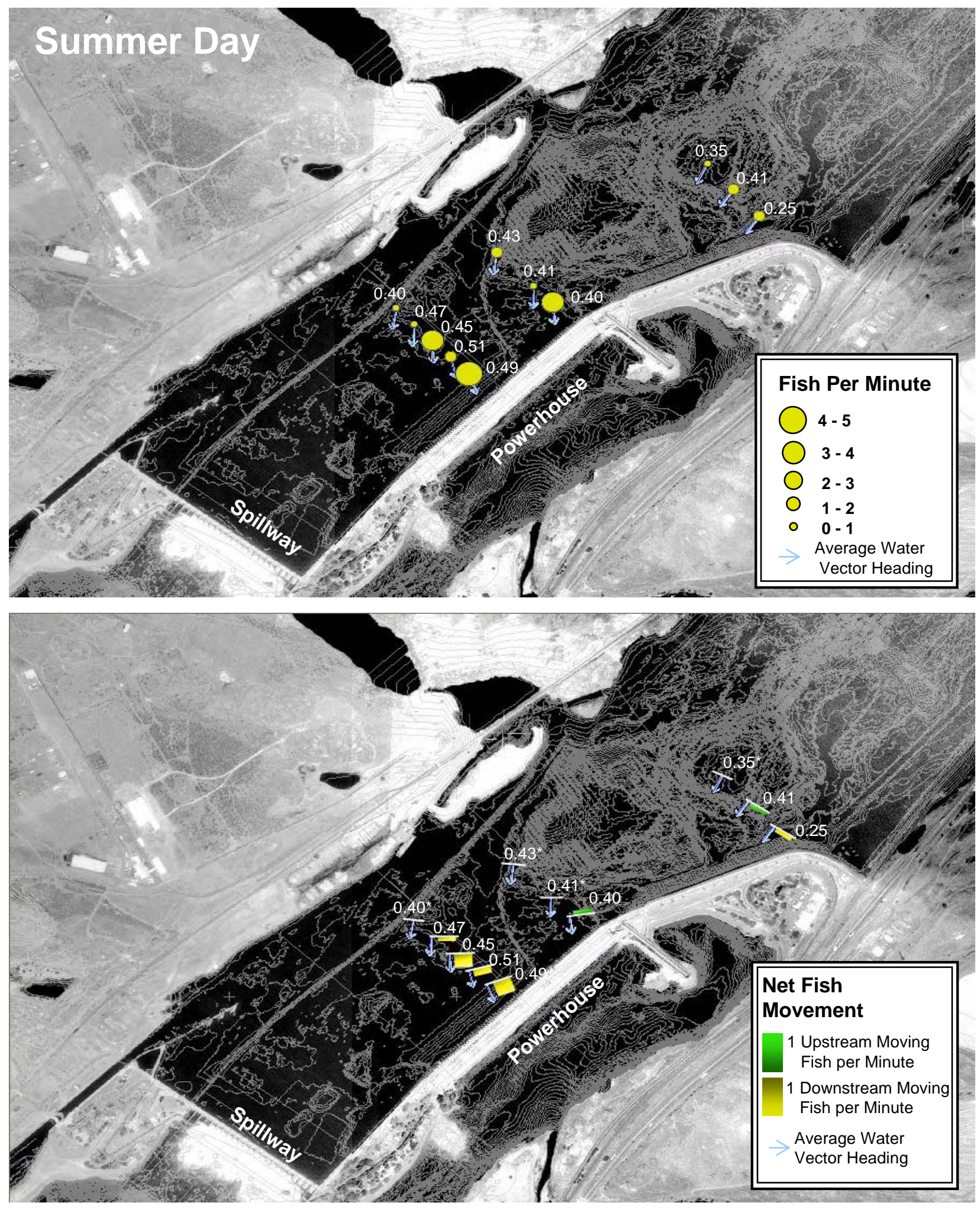

Figure I.3. The figures from top to bottom show the total smolt-sized fish count per minute as a function of circle size, and the net fish movement in relation to the direction of the mean water velocity (blue arrow). Mean water velocity magnitude data (m/s) for the upper $6 \mathrm{~m}$ are displayed next to each point. Data was combined for all summer day samples. Asterisks denote points without fish data. 

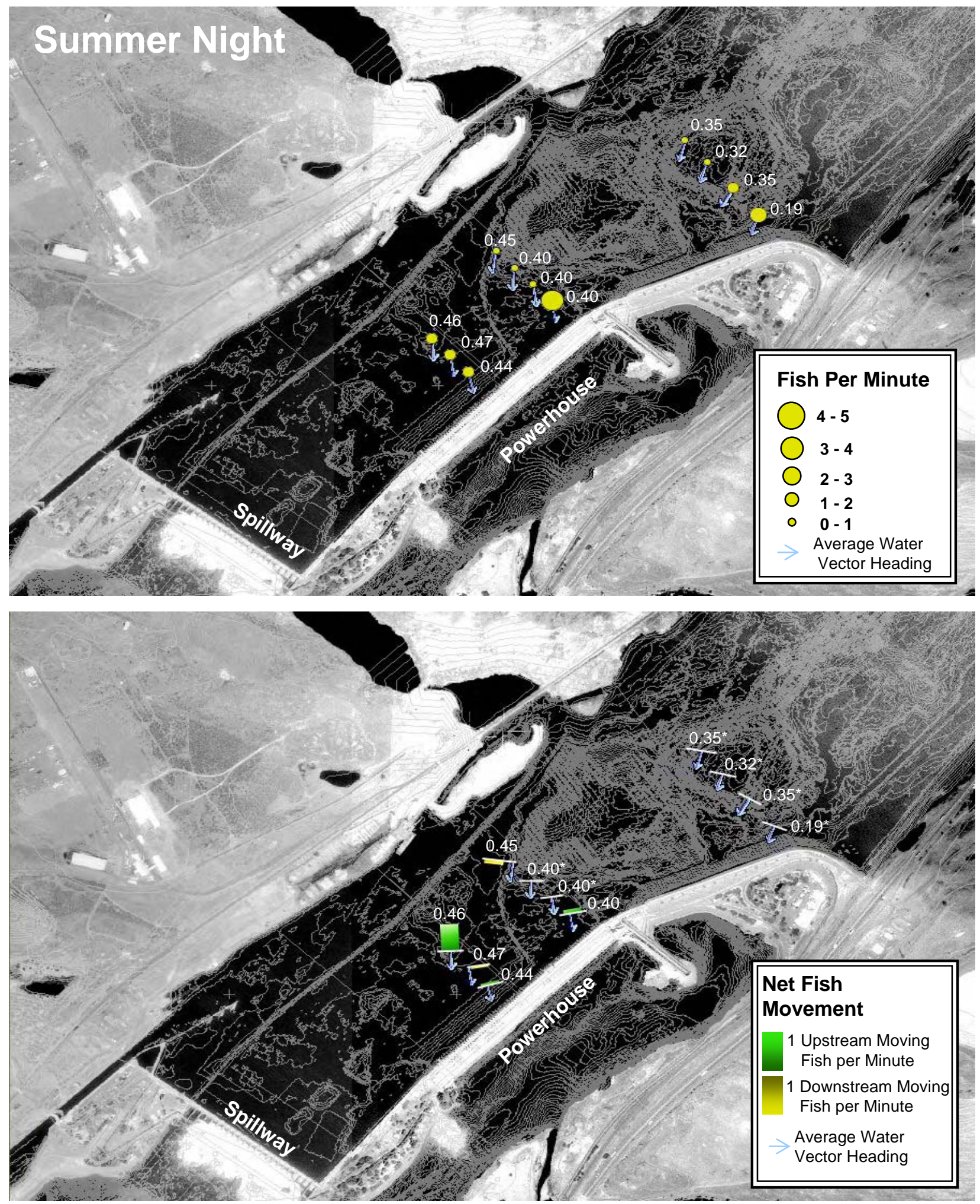

Figure I.4. The figures from top to bottom show the total smolt-sized fish count per minute as a function of circle size, and the net fish movement in relation to the direction of the mean water velocity (blue arrow). Mean water velocity magnitude data (m/s) for the upper $6 \mathrm{~m}$ are displayed next to each point. Data was combined for all summer night samples. Asterisks denote points without fish data. 

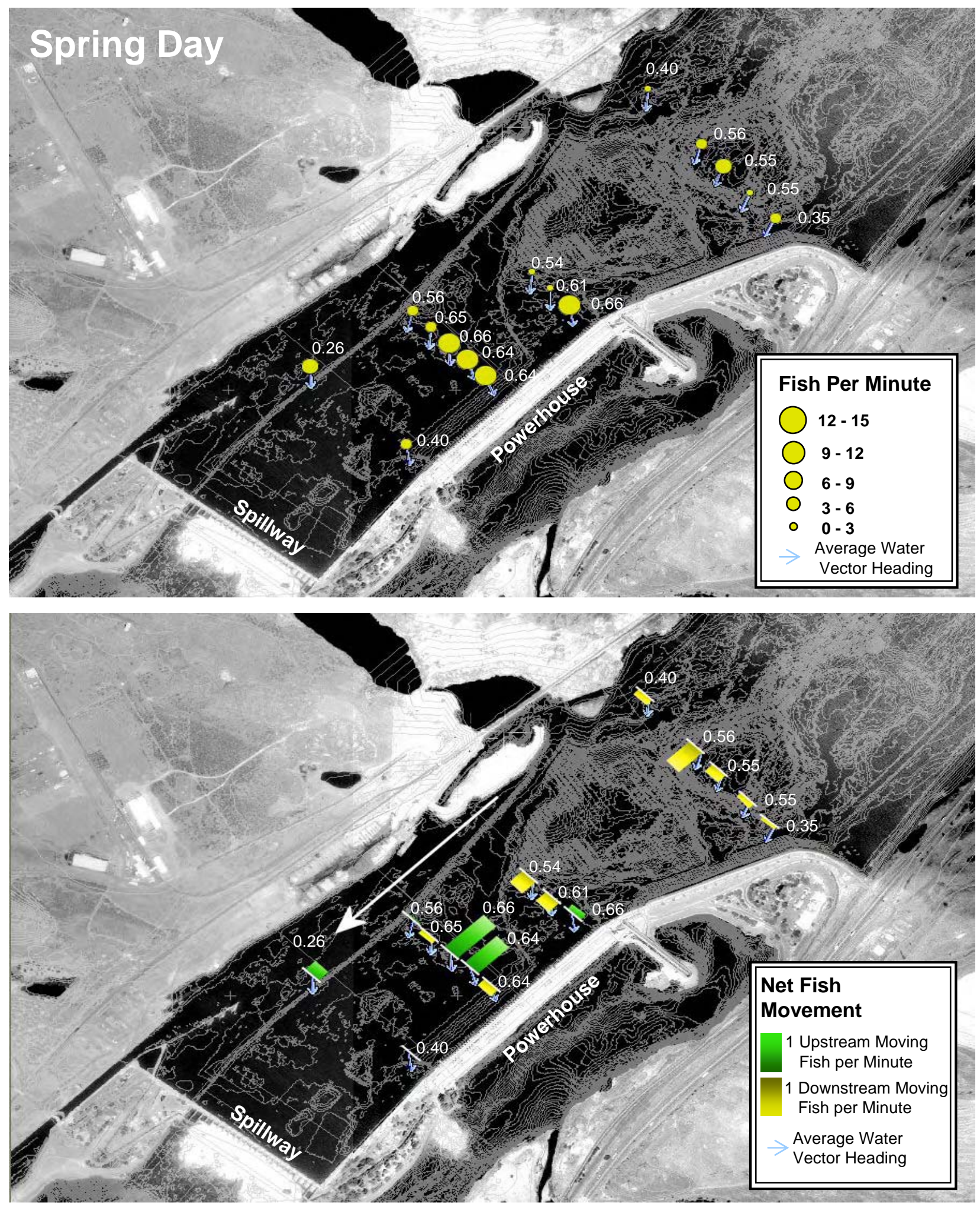

Figure I.5. The figures from top to bottom show the total smolt-sized fish count per minute as a function of circle size, and the net fish movement in relation to the direction of the river channel (white arrow). Mean water velocity magnitude data $(\mathrm{m} / \mathrm{s})$ for the upper $6 \mathrm{~m}$ are displayed next to each point, as well as the flow vector. Data was combined for all spring day samples. Asterisks denote points without fish data. 

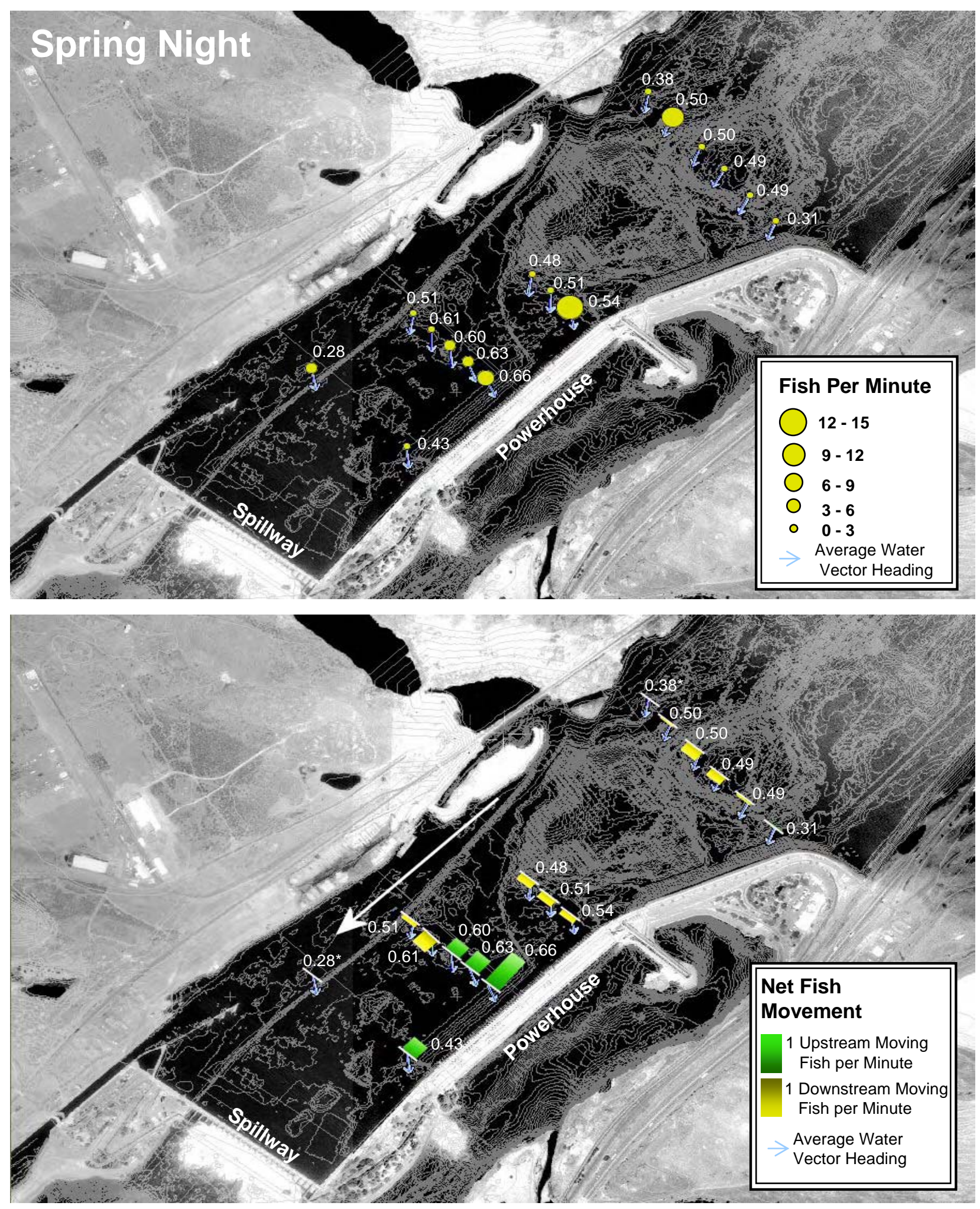

Figure I.6. The figures from top to bottom show the total smolt-sized fish count per minute as a function of circle size, and the net fish movement in relation to the direction of the river channel (white arrow). Mean water velocity magnitude data $(\mathrm{m} / \mathrm{s})$ for the upper $6 \mathrm{~m}$ are displayed next to each point, as well as the flow vector. Data was combined for all spring night samples. Asterisks denote points without fish data. 

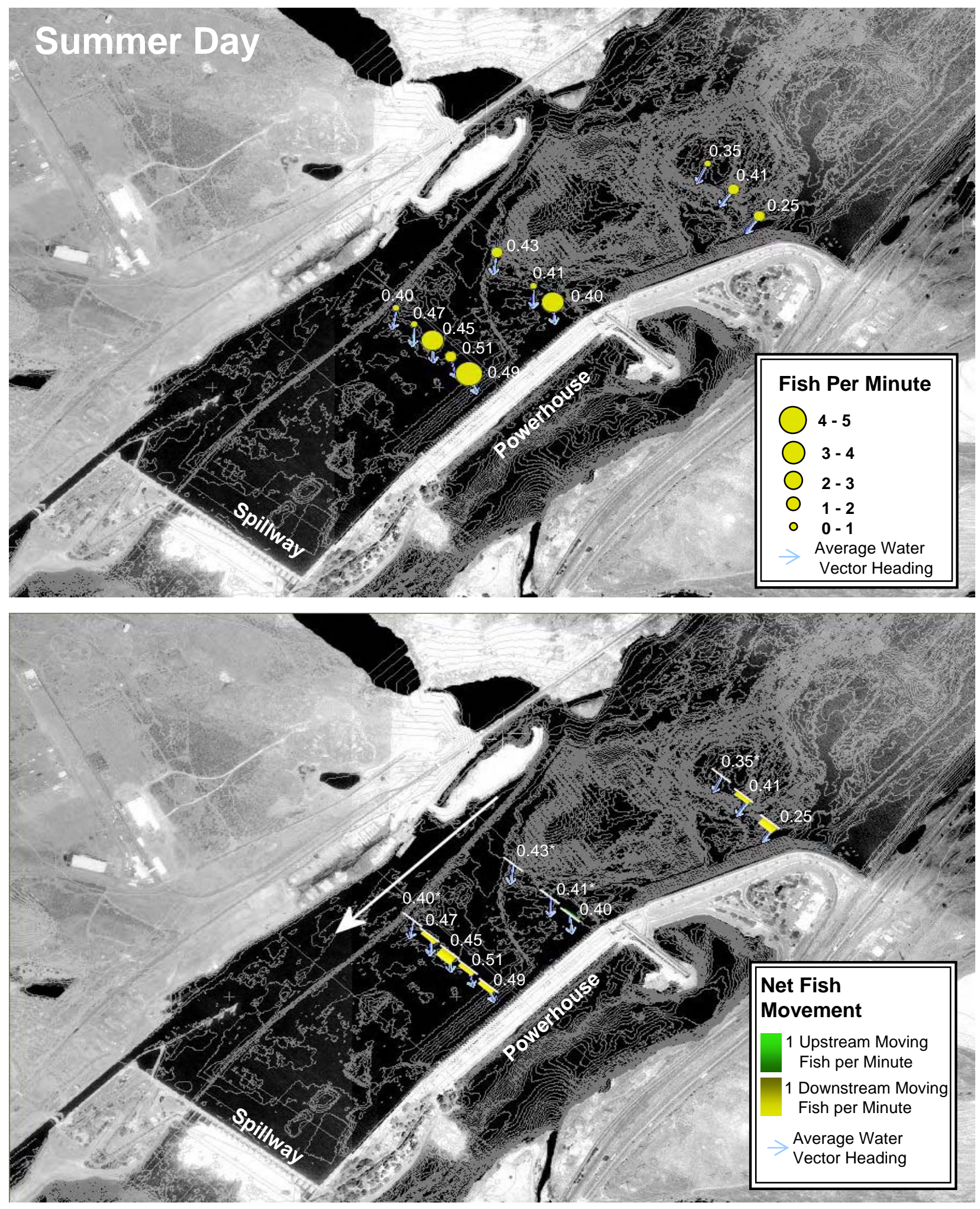

Figure I.7. The figures from top to bottom show the total smolt-sized fish count per minute as a function of circle size, and the net fish movement in relation to the direction of the river channel (white arrow). Mean water velocity magnitude data $(\mathrm{m} / \mathrm{s})$ for the upper $6 \mathrm{~m}$ are displayed next to each point, as well as the flow vector. Data was combined for all summer day samples. Asterisks denote points without fish data. 

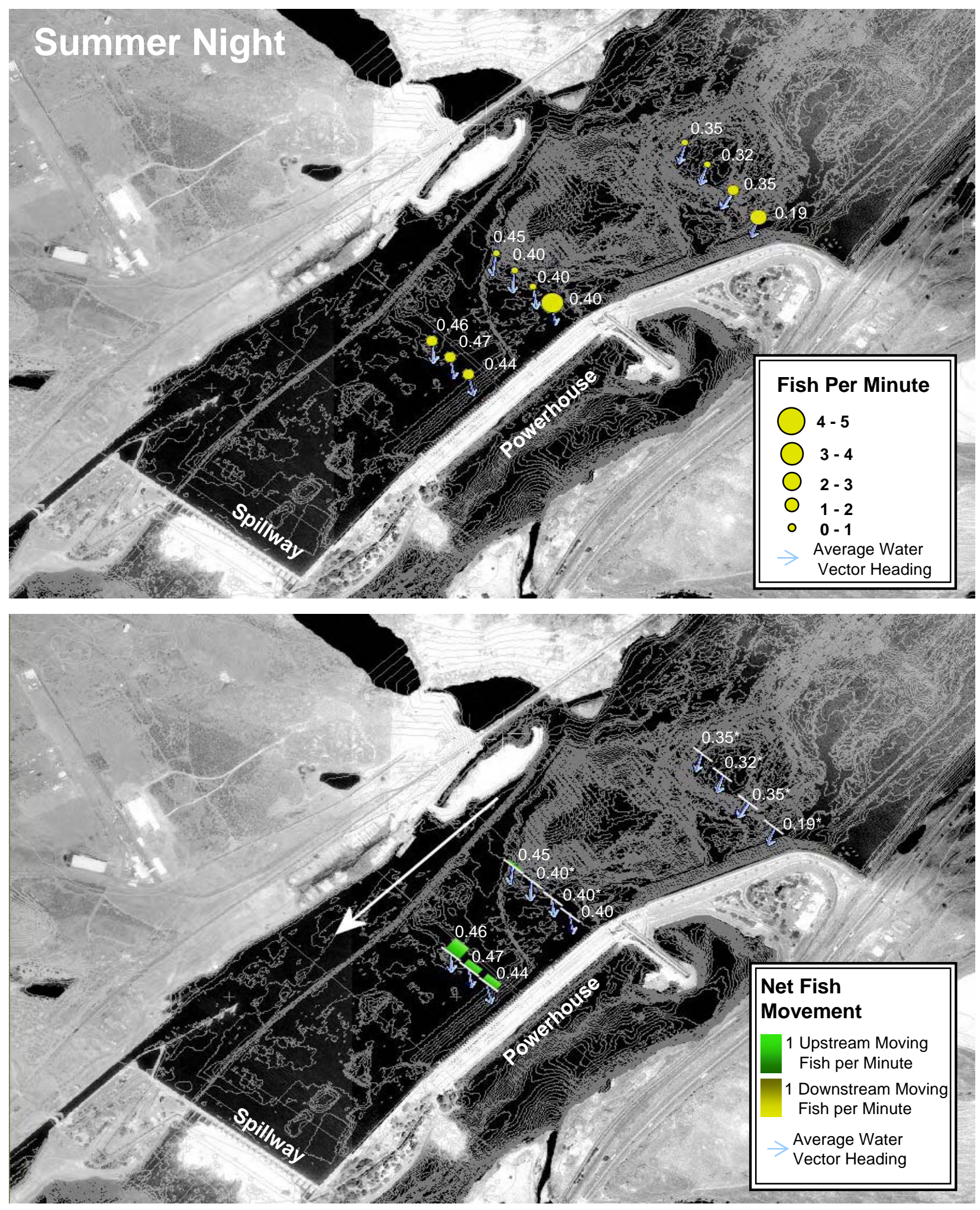

Figure I.8. The figures from top to bottom show the total smolt-sized fish count per minute as a function of circle size, and the net fish movement in relation to the direction of the river channel (white arrow). Mean water velocity magnitude data $(\mathrm{m} / \mathrm{s})$ for the upper $6 \mathrm{~m}$ are displayed next to each point, as well as the flow vector. Data was combined for all summer night samples. Asterisks denote points without fish data. 